\title{
Estimation of Fracture Porosity in an Unsaturated Fractured Welded Tuff Using Gas Tracer Testing
}

\author{
Barry Mark Freifeld \\ (Ph.D. Thesis) \\ Department of Civil and Environmental Engineering \\ University of California, Berkeley \\ and \\ Earth Sciences Division \\ Ernest Orlando Lawrence Berkeley National Laboratory \\ University of California \\ Berkeley, California 94720
}

December 2001

Financial support for this work was provided by the Director, Office of Civilian Radioactive Waste Management, U.S. Department of Energy, under Contract No. DEAC03-76SF00098. 



\begin{abstract}
Estimation of Fracture Porosity in an Unsaturated Fractured Welded Tuff Using Gas Tracer Testing

by

Barry Mark Freifeld

Doctor of Philosophy in Engineering - Civil and Environmental Engineering Professor Nicholas Sitar, Chair
\end{abstract}

Kinematic fracture porosity is an important hydrologic transport parameter for predicting the potential of rapid contaminant migration through fractured rock. The transport velocity of a solute moving within a fracture network is inversely related to the fracture porosity. Since fracture porosity is often one or two orders of magnitude smaller than matrix porosity, and fracture permeability is often orders of magnitude greater than matrix permeability, solutes may travel significantly faster in the fracture network than in the surrounding matrix. This dissertation introduces a new methodology for conducting gas tracer tests using a field portable mass spectrometer along with analytical tools for estimating fracture porosity using the measured tracer concentration breakthrough curves.

Field experiments were conducted at Yucca Mountain, Nevada, consisting of airpermeability transient testing and gas-tracer-transport tests. The experiments were conducted from boreholes drilled within an underground tunnel as part of an investigation of rock mass hydrological behavior. Air-permeability pressure transients, recorded during constant mass flux injections, have been analyzed using a numerical inversion procedure 
to identify fracture permeability and porosity. Dipole gas tracer tests have also been conducted from the same boreholes used for air-permeability testing. Mass breakthrough data has been analyzed using a random walk particle-tracking model, with a dispersivity that is a function of the advective velocity. The estimated fracture porosity using the tracer test and air-injection test data ranges from .001 to .015. These values are an order of magnitude greater than the values estimated by others using hydraulically estimated fracture apertures. The estimates of porosity made using air-permeability test data are shown to be highly sensitive to formation heterogeneity. Uncertainty analyses performed on the gas tracer test results show high confidence in the parameter estimates made. 


\section{Table of Contents}

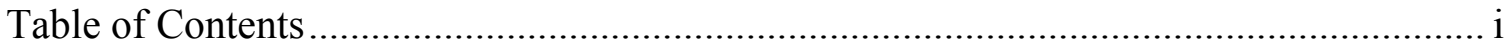

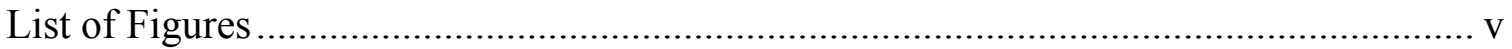

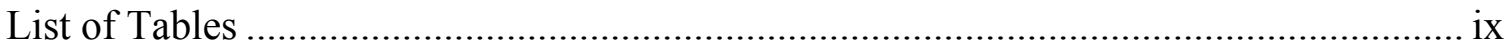

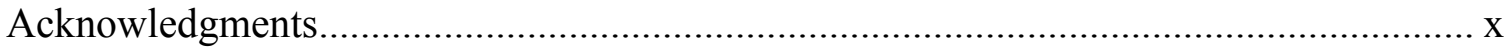

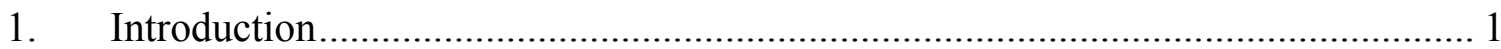

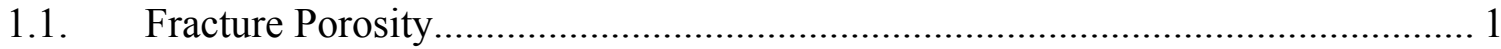

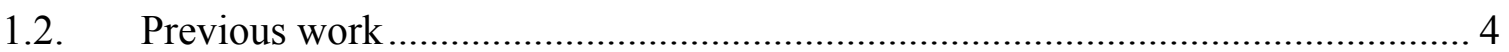

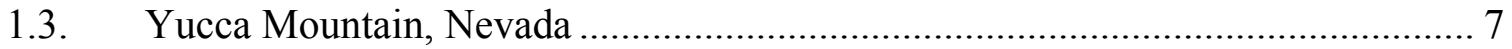

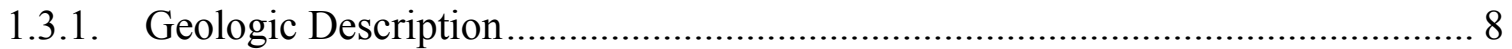

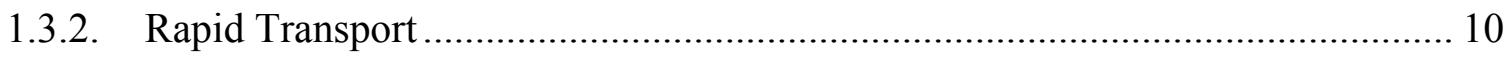

1.3.3. Thermally Mobilized Pore Water .................................................................... 11

2. Field Testing at Yucca Mountain................................................................ 12

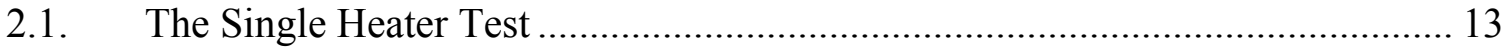

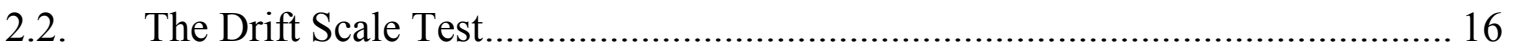

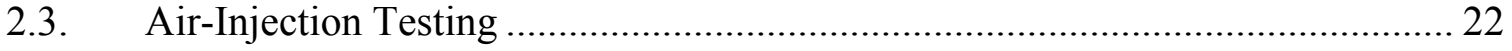

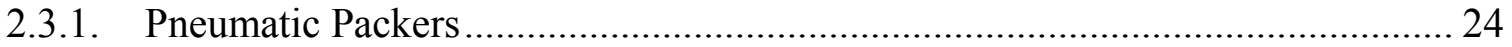

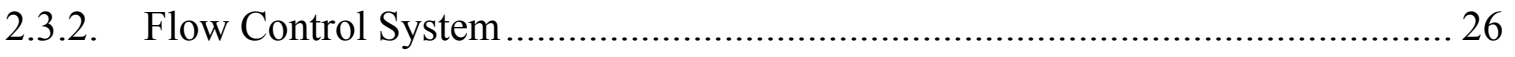

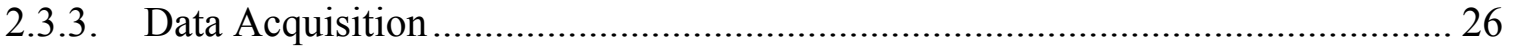

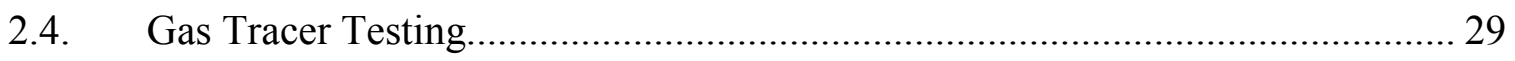

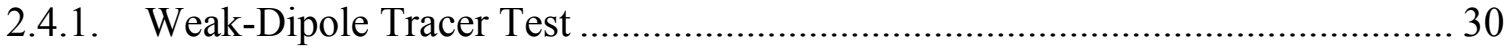




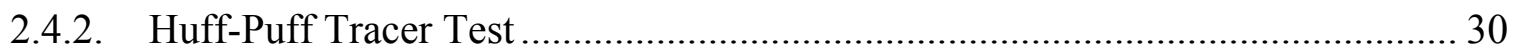

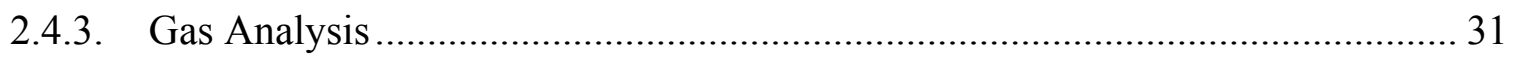

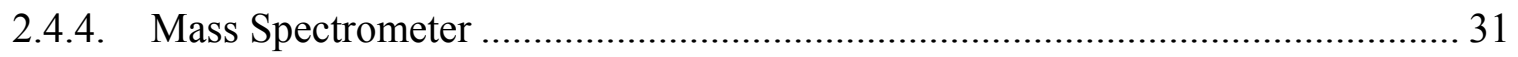

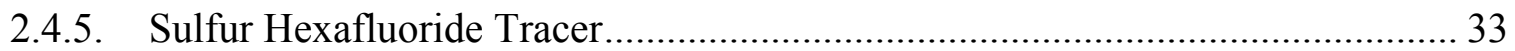

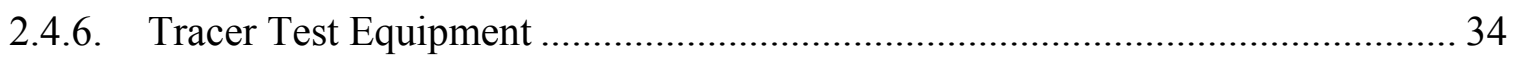

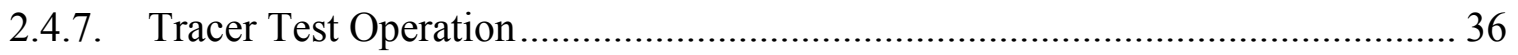

3. Steady State Air-Permeability Data Analysis ........................................................ 40

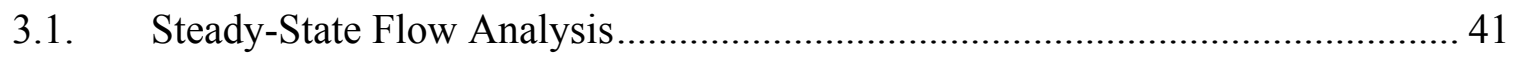

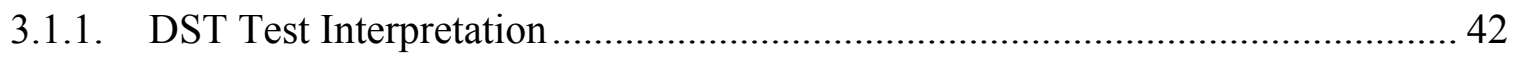

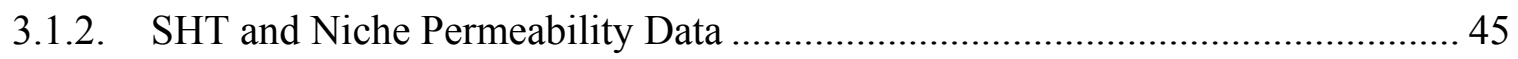

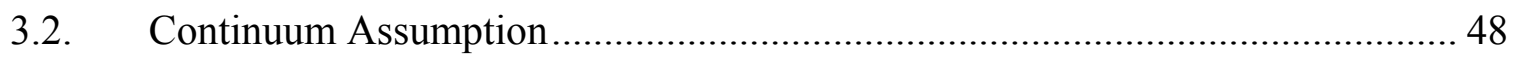

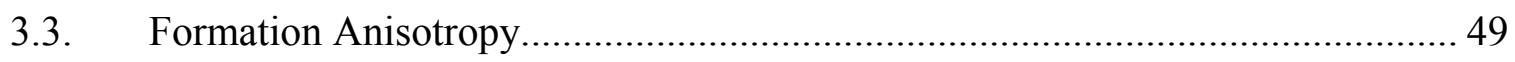

4. Transient Air-Permeability Data Analysis........................................................ 51

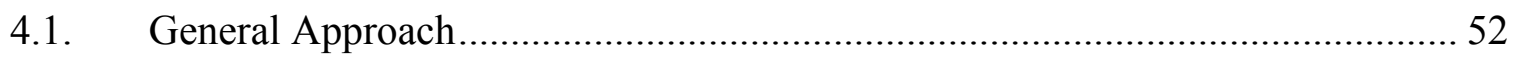

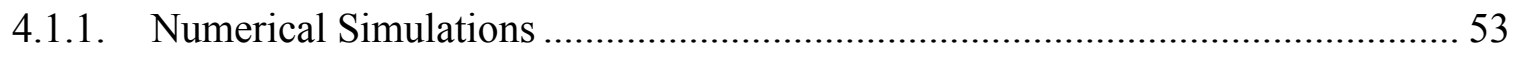

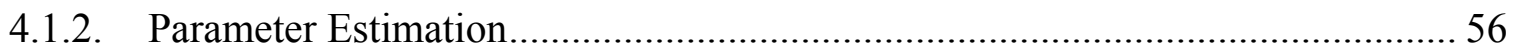

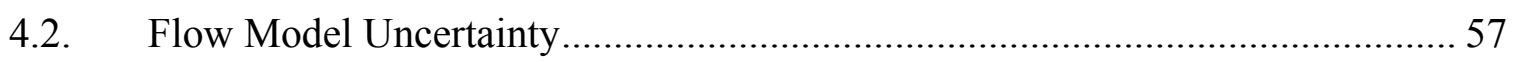

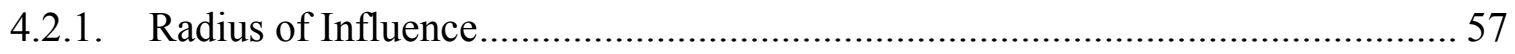

4.2.2. Pore Size Distribution Index Estimation of Gas Relative Permeability .............. 62

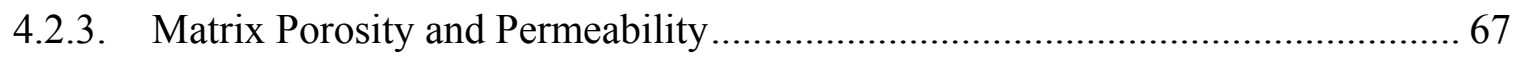

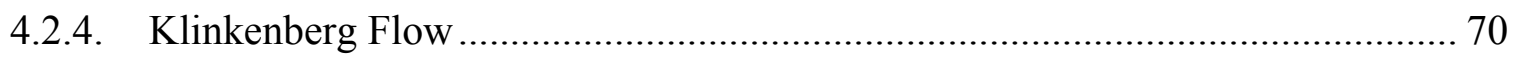

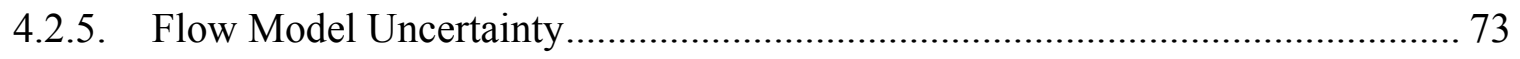

4.3. Fracture Porosity Estimates from Air-Permeability Tests................................... 74 


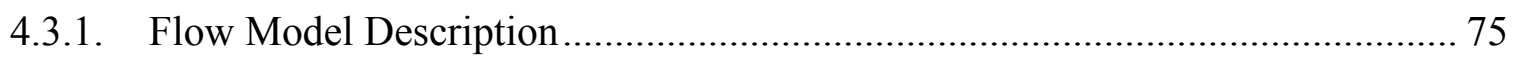

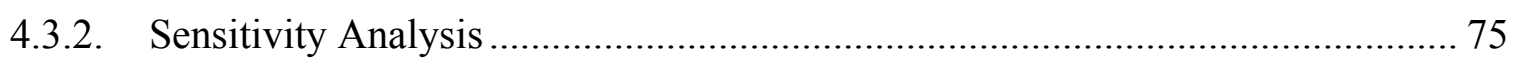

4.3.3. Analysis of Borehole 58-3 and 74-2 Test Data .............................................. 76

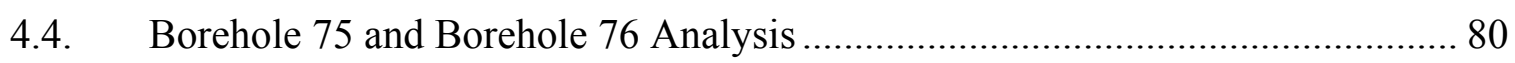

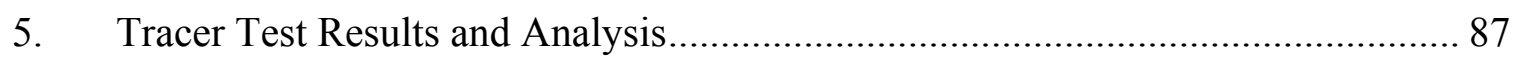

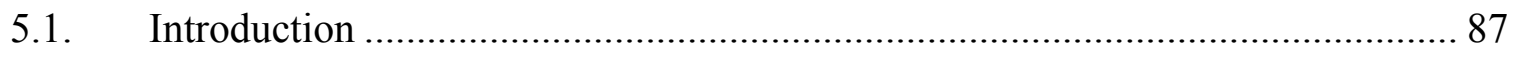

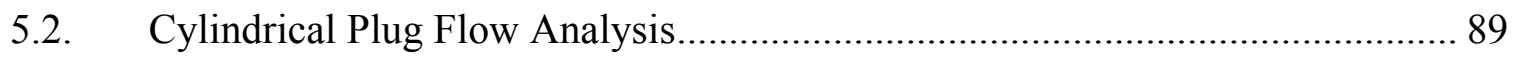

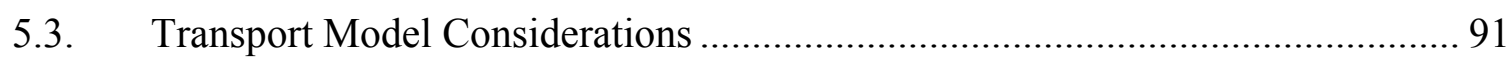

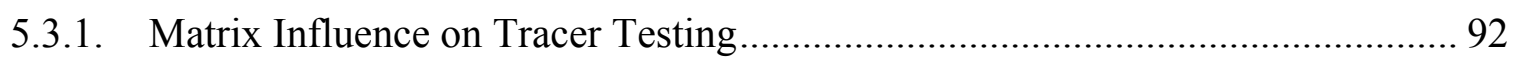

5.3.2. Prior Work on Fractured Rock Tracer Transport .............................................. 93

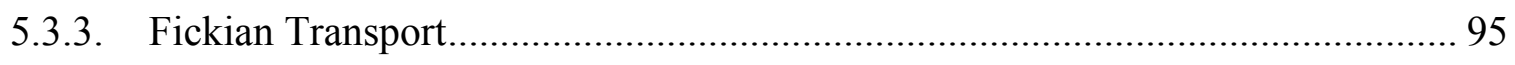

5.4. Random-Walk Particle Method ........................................................................ 96

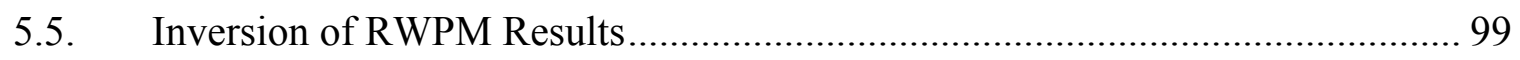

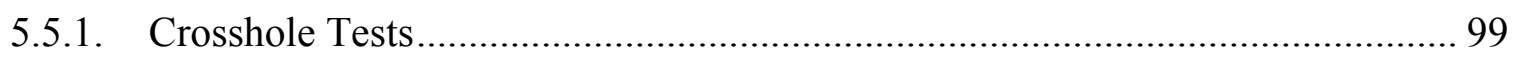

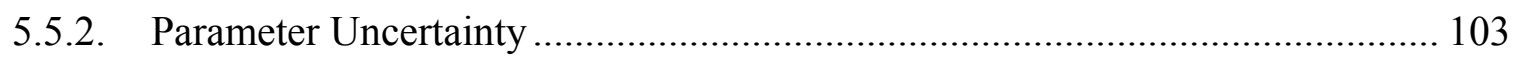

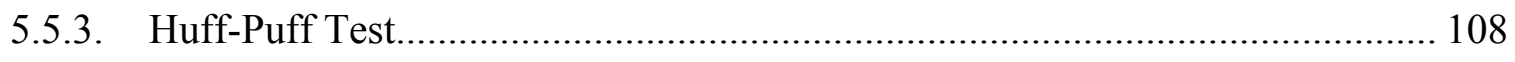

6. Discussion and Conclusions .......................................................................... 112

6.1. Comparison between Air-Injection and Tracer Results ................................... 112

6.2. Field Testing Lessons Learned ................................................................. 115

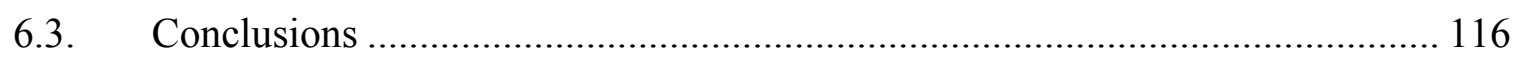

6.4. Recommendations for Future Work ……………....................................... 118

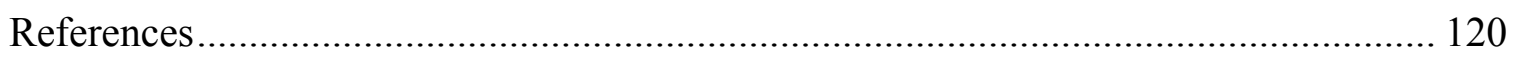

Appendix A: Air-injection Test Data.................................................................... 128 
Appendix B: Standard Operating Procedure for Conducting Air-Permeability Tests.... 153

Appendix C: Standard Operating Procedure for Conducting Gas Tracer Tests ............ 176

Appendix D: Standard Operating Procedure for Calibrating a Mass Spectrometer Using

Standard Reference Tedlar Bags......................................................................... 185 


\section{List of Figures}

Figure 1.1 Location of the Nevada Test Site relative to the state of Nevada, and a schematic layout of the Exploratory Studies Facility pointing out the location of the

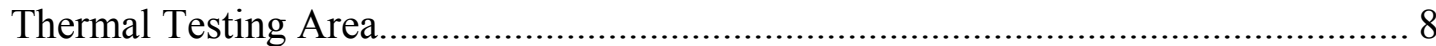

Figure 2.1 Layout of the thermal testing alcove, Alcove \#5 ......................................... 14

Figure 2.2 Borehole layout for the Single Heater Test................................................. 15

Figure 2.3 Photograph of the Drift Scale Test 5-meter-diameter Heated Drift. The heater canisters with power cables are shown as well as ongoing construction of a thermal isolation bulkhead.

Figure 2.4 Borehole layout for the Drift Scale Test, located in Alcove \#5 of the ESF. The air-permeability and gas tracer tests are conducted from the hydrological boreholes.

Figure 2.5 X-Z Co-ordinate layout of hydrology boreholes in the DST. The boreholes numbers increase from top to bottom................................................................... 20

Figure 2.6 Air-permeability trends over time in the DST. Reduced air-permeability indicates the fracture liquid saturation has increased............................................... 22

Figure 2.7 A typical constant mass flux air-permeability test. .......................................... 23

Figure 2.8 Pneumatic packers prior to installation in a borehole. Note the Teflon end pieces, which serve as housings for temperature and relative humidity sensors. ….. 25

Figure 2.9 Schematic layout for air-permeability testing equipment for the DST.

Figure 2.10 Drift Scale Test equipment located at the collars of Boreholes 57-61. The Injection Zone Selection Manifold is at the center top of the photo. The open electronic enclosure shows pressure transducers and packer inflation gages for one borehole

Figure 2.11 Calibration of the Balzer's Mass Spectrometer with $\mathrm{SF}_{6}$ standard Tedlar reference bags.

Figure 2.12 Schematic layout of gas tracer test equipment for measurement of tracer gas concentration 
Figure 2.13 Gas tracer test equipment as installed in the DST. The mass spectrometer is the white instrument located beneath the blue refrigerated air dehumidifier. 35

Figure 2.14 Mass breakthrough curve and cumulative mass recovery for Borehole 76-2 30:1 gas tracer test. 38

Figure 2.15 Mass breakthrough curve and cumulative mass recovery for Borehole 76-2 10:1 gas tracer test.

Figure 2.16 Mass breakthrough curve and cumulative mass recovery for Borehole 76-4 10:1 gas tracer test.

Figure 2.17 Mass breakthrough curve and cumulative mass recovery for Huff Puff gas tracer test.

Figure 3.1 Experimental variogram with raw data for DST permeability data.

Figure 3.2 Permeability cumulative probability distribution with lognormal fit. 45

Figure 4.1 Conceptual schematic of double porosity model used for air-permeability simulation.

Figure 4.2 Numerical inversions as a function of a variable distance to a constant pressure radial boundary using porosity and permeability as fitting parameters. The arrow points to the simulation used to generate synthetic data.

Figure 4.3 Simulated air-injection pressure recovery data showing the influence the assumed outer boundary radius has on the estimates for porosity and permeability. 61

Figure 4.4 Moisture retention curve for Topopah Spring tuff. Data was acquired from a borehole located approximately 400 meters from the DST in the same lithostratigraphic unit.

Figure 4.5 Relative permeability curves for Topopah Spring tuff based on moisture retention curve data and pore distribution theory.

Figure 4.6 Fracture porosity estimates using a fracture only model (no matrix permeability). Synthetic data was generated using a model with finite matrix permeability $\left(10^{-22} \mathrm{~m}^{2}\right.$ to $\left.10^{-20} \mathrm{~m}^{2}\right)$ and the outer boundary set to 50 meters.

Figure 4.7 Fracture porosity estimates using a fracture only model (no matrix permeability). Synthetic data was generated using a model with finite matrix permeability $\left(10^{-22} \mathrm{~m}^{2}\right.$ to $\left.10^{-20} \mathrm{~m}^{2}\right)$ and the outer boundary set to 10 meters.

Figure 4.8 Modeled air pressure recovery transients showing the influence of fracture porosity with a fixed matrix permeability of $10^{-19} \mathrm{~m}^{2}$. 
Figure 4.9 Modeled air pressure recovery transients showing the influence of fracture porosity with a fixed matrix permeability of $10^{-20} \mathrm{~m}^{2}$.

Figure 4.10 Modeled air pressure recovery transients showing the influence of fracture porosity with a fixed matrix permeability of $10^{-24} \mathrm{~m}^{2}$ (essentially no matrix).......... 72

Figure 4.11 Air pressure transient for Borehole 58-3 constant mass flux air injection test. 78

Figure 4.12 Air pressure transient for Borehole 74-2 constant mass flux air injection test.

Figure 4.13 Finite radius radial flow model analysis of 58-3 pressure recovery data..... 79

Figure 4.14 Finite radius radial flow model analysis of 74-2 pressure recovery data..... 80

Figure 4.15 Air pressure transients for Borehole 75 air-injection tests. ........................ 82

Figure 4.16 Air pressure transients for Borehole 76 air-injection tests........................ 83

Figure 4.17 Best fit porosity and permeability as a function of distance to an outer boundary radius for Borehole $75-2$ air-injection test. ......................................... 85

Figure 4.18 Best fit porosity and permeability as a function of distance to an outer boundary radius for Borehole 75-4 air-injection test. 85

Figure 4.19 Radial model simulation of Borehole 75-2 and Borehole 75-4 air-injection test. 86

Figure 5.1 Plug flow advective model used to estimate fracture porosity....................... 91

Figure 5.2 Borehole 76-2 10:1 dipole tracer test RWPM least-squares best fit. .......... 101

Figure 5.3 Borehole 76-2 30:1 dipole tracer test RWPM least-squares best fit. .......... 101

Figure 5.4 Borehole 76-4 10:1 dipole tracer test RWPM least-squares best fit. ........... 102

Figure 5.5 Least-square fitting of RWPM simulation to gas tracer data. ...................... 103

Figure 5.6 Graphical representation of the estimation covariance matrix shown as an elliptical confidence region for the Borehole 76-4 gas tracer test. The prime indicates conditional standard deviation. 106

Figure 5.7 Graphical representation of the estimation covariance matrix shown as an elliptical confidence region for the Borehole 76-2 10:1 gas tracer test. The marginal and conditional standard deviations are approximately the same. 107 
Figure 5.8 Graphical representation of the estimation covariance matrix shown as an elliptical confidence region for the Borehole 76-2 30:1 gas tracer test. The prime indicates conditional standard deviation. ......................................................... 108

Figure 5.9 Huff-puff tracer test RWPM least-squares best fit................................ 111

Figure 5.10 Objective function for huff-puff tracer test inverted in $\left(\phi, \mathrm{D}_{\text {mol }}\right)$ space. ..... 111

Figure 6.1 Relationship established between permeability and porosity for Topopah Spring tuff using air-injection test transient analysis......................................... 114 


\section{List of Tables}

Table 2.1. Tracer Testing Locations and Parameters........................................................ 37

Table 3.1. Permeability Values Calculated for Drift Scale Test Boreholes...................... 43

Table 3.2. Straddle Packer Air-Injection Tests in Single Heater Test, Borehole 6 ......... 47

Table 3.3. Mean and Variance of Log-Air-Permeability Values for Topopah Spring Middle Nonlithophysal Tuff..................................................................................... 47

Table 4.1. Geometry of Fracture-Matrix Gridblocks Used for Air-K Simulations ......... 54

Table 4.2. Steady-state Pressure Responses as a Function of Distance to an Air-Injection

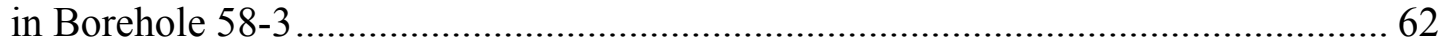

Table 4.3. Steady-state Pressure Responses as a Function of Distance to an Air-Injection

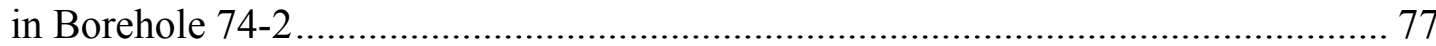

Table 4.4. Fracture Porosity Estimates for Radial Flow Models ..................................... 78

Table 4.5. Parameter Estimates and Sensitivities for Borehole 75 and 76 Air-Injection Tests

Table 5.1. Plug-Flow Tracer Analysis of Crosshole Tracer Data..................................... 91

Table 5.2. RWPM Tracer-Test Best-Fit Results....................................................... 100

Table 5.3. Parameter Uncertainty Analysis Based on A Posteriori Error Variance ...... 105

Table 6.1. Porosity Estimates Using Both Air-Permeability and Gas Tracer Testing Analysis 


\section{Acknowledgments}

I would like to express my gratitude to my adviser and dissertation committee chair, Nicholas Sitar. It is through his patience and guidance that I have completed the doctoral program at Berkeley. I would like to thank Yoram Rubin and Kent Udell for their time and efforts in reviewing my dissertation.

I must also thank my many colleagues at Lawrence Berkeley National Laboratory for providing me opportunities to learn and work in the field of subsurface hydrology. Kenzi Karasaki is foremost responsible for bringing me to Berkeley Lab and exposing me to the joys and frustrations of field work. Yvonne Tsang accompanied me for many weeks of work at Yucca Mountain and was a major force in making the thermal testing program a success. George Moridis provided me the impetus to complete my dissertation. Stefan Finsterle performed a critical review of this work. I thank Curt Oldenburg and Rick Ahlers for their advice and discussion on my research work, as well as assistance in conducting numerical simulations. Douglas Sullivan helped to establish the field methodology used for the gas tracer tests. Numerous collaborators from Lawrence Livermore, Sandia, and Los Alamos National Laboratories, as well as TRW Environmental Safety Systems, Inc. should be credited with making the thermal test program an exciting place to carry out research while working towards solving this nations high-level nuclear waste storage problem. 
Finally, I must express my deepest love for my wife, Patty, and son Graham. Both have provided the support needed for me to complete my dissertation.

Financial support for this work was provided by the Director, Office of Civilian Radioactive Waste Management, U. S. Department of Energy, through Memorandum Purchase Order EA9013MC5X between TRW Environmental Safety Systems, Inc. and the Ernest Orlando Lawrence Berkeley National Laboratory, under Contract No. DEAC03-76SF00098. Educational support was provided by Ernest Orlando Lawrence Berkeley National Laboratory. 


\section{Introduction}

\subsection{Fracture Porosity}

Fracture porosity is an important parameter used in modeling of transport processes in rock formations. Fracture porosity plays a critical role in determining transport velocities in problems that range from contaminant migration and radioactive waste isolation to aquifer resource evaluation in fractured media. The determination of fracture porosity for rock formations can be extremely challenging. Fracture porosity may vary by several orders of magnitude within the same lithostratigraphic unit and may exhibit little or no spatial correlation. This is the case with the Topopah Spring tuff located at Yucca Mountain, Nevada, which was investigated as part of this research. Yucca Mountain is the potential location for a high-level radioactive waste geological repository, and as such, the accurate understanding of flow and transport through the mountain is critically important. The research presented in this dissertation uses a new methodology for determining fracture porosity in an unsaturated fractured welded tuff, using gas-tracertesting techniques. In addition, methods of using air permeability transient data to evaluate formation porosity are explored, and the differences in results between the tracer transport and air-permeability tests are evaluated.

The term porosity describes the volume of voids contained within the total volume of a bulk medium. The bulk volume contains both the volume of solids and the volume of the voids that are typically filled with liquids and/or gases. Intrinsic in the notion of porosity 
is that, like any local property that may vary spatially, the value is averaged over a specified domain.

The porosity of importance for determining advective transport velocities within a geologic media is referred to as the kinematic porosity. The kinematic porosity consists of the volume of voids that are connected together to form a connected network of open channels available for flow. The determination of the kinematic porosity is complicated by the large difference in times scales that may occur when comparing transport through different domains within a geologic medium. These different domains arise from lithologic and structural variations in the formation.

In a rock formation such as the Topopah Spring tuff, which consists of both a matrix with small-scale interconnected pores and larger features such as fractures and lithophysal cavities, the low-permeability rock matrix behaves very differently than the higherpermeability interconnected fractures. The phenomena, which is often referred to as dual porosity, is common to fractured rocks. The rock matrix may have a very low permeability, orders of magnitude below the bulk permeability exhibited by the fracture network, and still have a high porosity. A transient inflow into the formation, such as an episodic infiltration event, may be transported rapidly through the high-permeability fracture network, with little movement into the low permeability matrix. Conversely, a very slow diffusively dominated process may be controlled by the matrix porosity, while the low porosity, high permeability fractures are relatively inconsequential to the process. Neretnieks [1980] observed that contaminant transport in a fractured medium undergoes 
three distinct stages as the time scale for transport increases: the first stage is fracture dominated transport, the second stage is dual-porosity transport, and the third and final stage is total porosity transport.

At Yucca Mountain, Nevada, fracture porosity is an important parameter used in transport process models that are employed to predict the release and transport of radioactive waste from engineered containment systems into the surrounding lithologic units and into the biosphere. The fracture and matrix system associated with the Topopah Spring tuff, the potential repository host rock, can be modeled as two distinct continuua [Tsang, 1998], generally referred to as a dual continuum model (DKM). This is in contrast to the simpler effective continuum model, which treats both the fractures and matrix as a single continuum. In DKM models of Yucca Mountain, a strong component of gravity-driven flow gives rise to high liquid saturations in the fractures after emplacement of the heat-generating radioactive waste. Thus, an accurate assessment of fracture porosity is critical in determining the expected rate of liquid migration, since transport velocity is inversely proportional to formation porosity.

In this dissertation, two methodologies are employed for determining fracture porosity (1) constant mass flux air-injection test transient analysis and (2) gas tracer transport tests. The results show large uncertainties in the fracture porosity estimates using airinjection test data, owing to numerous assumptions inherent in the applied flow model. In contrast, the computed uncertainty measure of the estimated porosity value determined using gas tracer tests reveals high confidence in the parameter estimates. Hence, the 
results show that it is important to perform transport tests in addition to the simpler flow tests.

\subsection{Previous work}

Previous techniques employed to estimate fracture porosity include the use of permeability measurements coupled with flow models, such as the parallel plate approximation [Snow, 1965] or lubrication theory [Zimmerman et al., 1991]. The use of flow models to estimate fracture porosity relies upon a simplification of the NavierStokes equation. Unfortunately, to apply a realistic flow model requires information that is typically not available, such as the mean and standard deviations of the fracture aperture distribution [Keller et al., 1999]. A simple parallel plate approximation is frequently used because of the ease in which analytical solutions can be derived for more geometrically complex problems. The parallel-plate approximation suggests that a fracture can be represented by parallel, uniform, smooth plates with constant aperture and represents a highly idealized model of a real fracture.

Sonnenthal et al. [1997] used a combination of geologic mapping and air-permeability flow measurements to indirectly estimate fracture porosity at Yucca Mountain based on cubic law theory. They developed a site-scale unsaturated zone model of Yucca Mountain and used the results of detailed fracture mappings to obtain mean fracture frequencies for each lithologic layer. The parallel plate approximation was then applied to air-permeability test results, to estimate an average fracture aperture. Sonnenthal et al. [1997] used fracture data that was censured to include only fractures with visible trace 
lengths 1 meter or greater. The formation permeability was obtained from constant mass flux air-injection tests [LeCain, 1997]. The parallel plate approximation for fracture flow leads to the relationship:

$$
k=\bar{f} \frac{b^{3}}{12}
$$

where $\bar{f}$ is the mean fracture frequency taken from the detailed line survey and $k$ is the measured air-permeability. This leaves the fracture aperture, $b$, as the only unknown variable. The fracture porosity is then estimated as $b \times \bar{f}$. The estimate for fracture porosity for the Topopah Spring middle nonlithophysal tuff based on a fracture frequency of $1.88 \mathrm{~m}^{-1}$ and a permeability of $4.3 \times 10^{-13} \mathrm{~m}^{2}$ is 0.00027 [Sonnenthal et al., 1997]. As will be shown later, this value is significantly smaller than the porosity value of 0.002 to 0.004 estimated using gas tracer test analysis.

There are many limitations to the application of the parallel plate approximation to estimate fracture porosity. Silliman [1989] points out that a fracture is not accurately characterized by a parallel plate and that a fracture is better described by a correlated random variable, or as a random variable described through a fractal model. Comparisons between hydraulic and tracer-testing fracture-aperture estimates have been made by Silliman [1989] and Rasmussen [1995]. Silliman investigated differences of fracture aperture estimates based on the measurement method being employed and noted that differences in hydraulic and tracer test aperture estimates are greatest when the variance of the aperture distribution is large. 
Tsang [1992] compares the equivalent aperture estimates from several studies and provides a rationale for the different estimates obtained by the application of hydraulic and tracer test methods. In particular, Tsang [1992] shows that for a heterogeneous random fracture aperture field in two dimensions:

$$
\delta_{m} \geq \delta_{c}
$$

where $\delta_{m}$ is the estimated aperture from the mean residence time of a tracer and $\delta_{c}$, is the cubic law aperture derived from measurements of head loss as a function of volumetric flow.

Laboratory studies have investigated transport of a conservative solute through a single fracture in porous rocks [Haldeman et al., 1991; Moreno et al., 1985], providing some phenomonological understanding of the interrelationship between hydraulic aperture and fracture porosity. However, the methodology to reliably upscale the results of a study within a single fracture to the field scale has yet to be established.

LeCain [2000] conducted tracer measurements at Yucca Mountain, at a location several hundred meters from the location where this current work was conducted. He used a radial convective-dispersive equation (CDE) solution developed by Moench [1995] to analyze his convergent-tracer-test breakthrough curves. Unfortunately, the tracer mass recoveries were very poor, ranging from $10 \%$ to $50 \%$ of the injected tracer mass. The CDE analyses were performed by matching normalized concentration breakthrough curves to the Moench solution, using only the rising portion of the breakthrough curve. This procedure incorrectly scales the concentration to correct for an inadequate 
experimental result. In addition, LeCain's tracer concentration measurements display noise that is up to $35 \%$ of the full tracer breakthrough peak signal. In contrast, the methodology presented as a part of this dissertation gives mass recoveries that approach $100 \%$ and a computed tracer concentration uncertainty of at most $1 \%$ of the maximum tracer concentration value measured.

\subsection{Yucca Mountain, Nevada}

The data that is presented in this dissertation have been collected at Yucca Mountain, Nevada. Yucca Mountain has been chosen as the potential repository site for permanent geologic disposal of U.S. high-level radioactive waste generated by civilian power generating facilities. Yucca Mountain is in Southern Nevada, located within the boundaries of the Nevada Test Site and Nellis Air Force Base, approximately 140 kilometers northwest of Las Vegas, Nevada (Figure 1.1).

The potential repository would be sited 300 to 400 meters below the crest of Yucca Mountain and approximately 200 to 400 meters above the water table. The location is viewed as favorable for long-term storage of waste canisters in the vadose zone because of a thick unsaturated region (600-700 meters) and low infiltration rates (average of 5 $\mathrm{mm} / \mathrm{yr}$ ) [Bodvarsson, 1999]. In addition, Yucca Mountain is located far away from any population centers. 


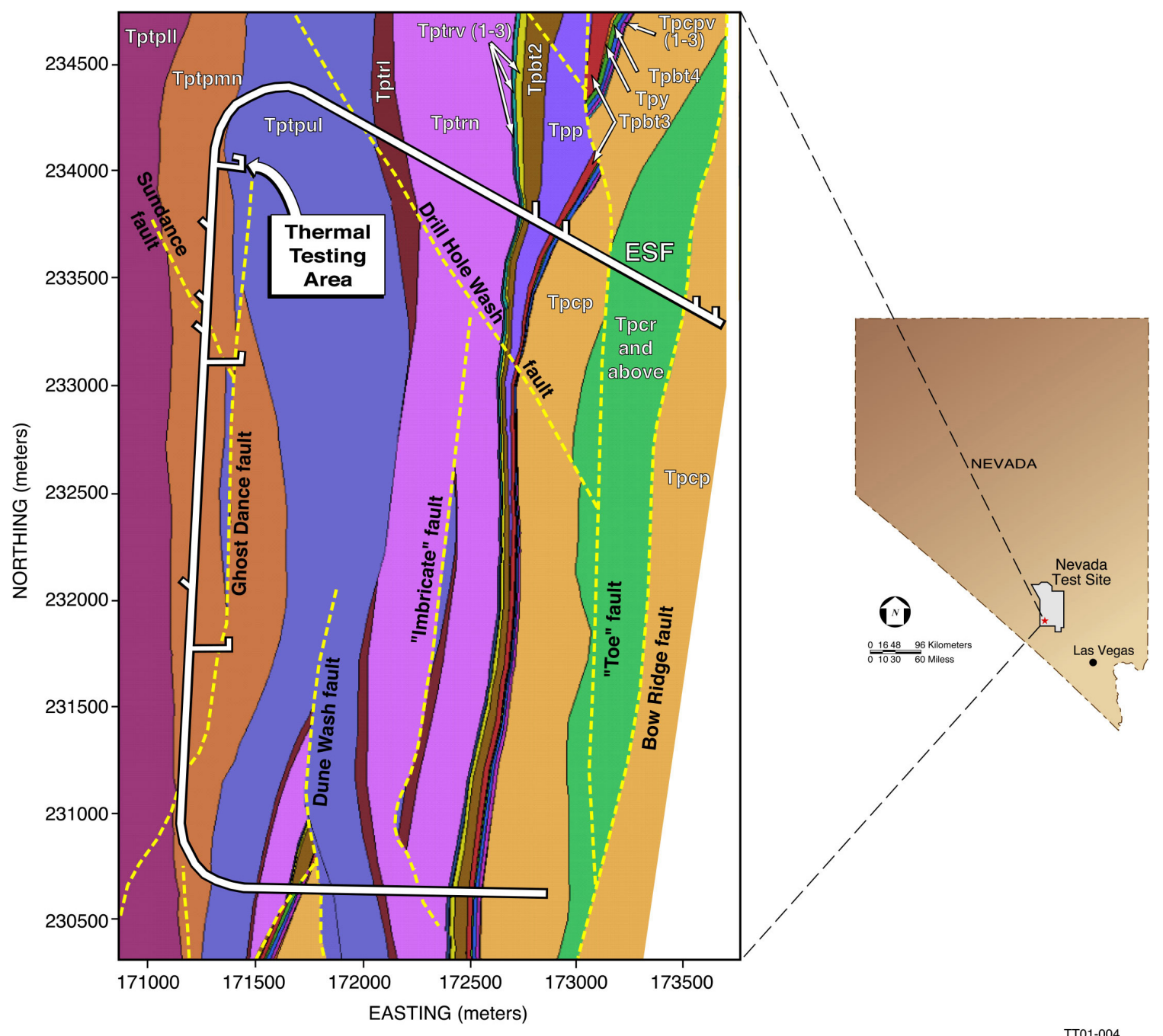

Figure 1.1 Location of the Nevada Test Site relative to the state of Nevada, and a schematic layout of the Exploratory Studies Facility pointing out the location of the Thermal Testing Area.

\subsubsection{Geologic Description}

Yucca Mountain is underlain by a series of ash-fall and ash-flow tuffs that overlie a deep carbonate aquifer. The four major geologic units found in the unsaturated zone in descending order are: (1) the Tiva Canyon Welded unit (12.7 mA), consisting of moderately to densely welded tuffs, (2) the Paintbrush Nonwelded unit (12.7 mA), 
consisting of partially to nonwelded bedded tuffs, (3) the Topopah Spring Welded unit, consisting of moderately to densely welded tuffs down to and including a densely welded basal vitrophyre (12.8 mA), and (4) the Calico Hills Nonwelded unit (12.9 mA), consisting of moderately to nonwelded bedded tuffs.

This work is concerned with the determination of the kinematic fracture porosity of the welded tuff in the Topopah Spring middle nonlithophysal zone of the Topopah Spring unit. This zone is important because the tuff is a part of the host rock for the potential permanent geologic high level nuclear waste repository, and as such it makes up the nearfield environment surrounding the engineered barriers for the waste packages. The Topopah Spring stratigraphic unit consists of several layers of moderately to densely welded zeolitized ash-flow tuffs with numerous lithophysal horizons. The Topopah Spring middle nonlithophysal tuff is densely fractured, with few lithophysal inclusions. The tuff has been further described as containing four subzones [Buesch and Spengler, 1998] with varying amounts of small lithophysae and orthogonal fracture sets (that vary from regular to poorly developed). Significant in the Topopah Spring tuff that is investigated as part of this work are the numerous areas containing small brecciated zones. The brecciated zones vary from centimeter width up to 15 meters and range in shape from simple planar to anastomosing and irregular.

The matrix porosity within the Topopah Spring middle nonlithophysal tuff varies over a narrow range. Based on 244 measurements from surface borings that penetrated the Topopah Spring middle nonlithophysal unit, the porosity has a mean of 0.11 with a 
standard deviation of 0.02 [Flint, 1996]. Measurements of porosity made on 12 sections of core collected in the zone where the current study is located have a mean porosity of 0.11 with a standard deviation of 0.01 [Wang, 1997].

\subsubsection{Rapid Transport}

The finding of several radioactive elements, introduced into the atmosphere during above-ground testing of nuclear weapons, within the repository horizon is evidence for rapid transport through Yucca Mountain. Atmospheric testing occurred primarily between 1952 and 1963 when a nuclear test ban treaty stopped further atmospheric testing. Bomb-pulse levels of radioisotopes have been detected both at the top of the Paintbrush formation as well as within several isolated areas within the Topopah Spring tuff [Rousseau, 1999; Fabryka-Martin et al., 1996]. The presence of elevated ${ }^{36} \mathrm{Cl} / \mathrm{Cl}$ ratios and tritium in concentrations that are unambiguously bomb pulse signatures within the repository horizon is evidence for rapid transport through thick unsaturated zones. A conclusion based on the presence of bomb-pulse ${ }^{36} \mathrm{Cl} / \mathrm{Cl}$, predominantly near faults or areas of increased fracture densities in the Topopah Spring tuff, is that fast flow does occur within Yucca Mountain and that fractures provide the conduits for the rapid transport [Fabryka-Martin et al., 1996]. These observations of fast flow reinforce the importance of estimating fracture porosity and understanding the spatial distribution of porosity at Yucca Mountain. 


\subsubsection{Thermally Mobilized Pore Water}

During the first few centuries after emplacement of radioactive waste, water will be mobilized in large quantities because of the thermal pulse provided by the heatgenerating waste packages. This mobilized water can significantly impact the performance of the nuclear waste repository. Water that contacts the waste packages will cause accelerated corrosion rates. The ability to predict whether thermally mobilized water will drain below the repository, or form a halo above the repository and eventually reflux into the emplacement drifts, relies upon proper understanding of the coupled thermal-hydrology of the near-field environment. The near field is defined as the repository region strongly influenced by the thermal, chemical, and mechanical disturbances produced by the emplaced waste packages. An understanding of fracture porosity as well as fracture permeability is necessary to accurately understand and predict transport in the near field environment. 


\section{Field Testing at Yucca Mountain}

A diverse range of studies has been carried out, both from the surface and underground, to characterize and assess the ability of Yucca Mountain to safely contain high-level nuclear waste for tens of thousands of years. For a brief overview of the Yucca Mountain Project, the USGS has published a circular [Hanks et al., 1999]. For a much more detailed reference on the Yucca Mountain Site, including detailed geologic characterization information, see the Yucca Mountain Site Description [U.S. DOE, 2000].

The research presented in this dissertation for estimating the fracture porosity of the potential repository host rock units has been conducted within the Exploratory Studies Facility (ESF). The ESF is an $8 \mathrm{~km}$ long tunnel, bored within Yucca Mountain using an 8-meter-diameter tunnel boring machine. A map of the ESF in relationship to Yucca Mountain is shown in Figure 1.1. The ESF facilitates direct experimentation on the planned host emplacement units, the Topopah Spring middle nonlithophysal tuff and the Topopah Spring lower lithophysal tuff.

The effort to determine in-situ fracture porosity was conducted as part of a large-scale thermal-testing program designed to investigate coupled thermal-hydrological-chemicalmechanical processes in the potential repository host rock units. Coupled thermal processes, such as moisture induced corrosion, can lead to failure of the waste storage 
canisters and will have a direct impact on the viability of Yucca Mountain to safely contain waste for the tens of thousands of years required. To investigate coupled processes at Yucca Mountain, a thermal testing alcove, Alcove \#5, was mined within the Topopah Spring middle nonlithophysal unit. The location and layout of Alcove \#5, where it comes off the main drift of the ESF at Transit Station (TS) $28+27$ meters, is shown in Figure 2.1. Within Alcove \#5, two thermal tests have been conducted: a small-scale test called the Single Heater Test (SHT) and a full-scale simulated waste emplacement test called the Drift Scale Test (DST).

\subsection{The Single Heater Test}

The SHT, conducted in 1996 and 1997, consisted of a single 5-meter-long $3 \mathrm{~kW}$ tubular heater installed in a $10-\mathrm{cm}$-diameter borehole used to heat a relatively modest volume of rock over a 9-month period [Tsang et al., 1999]. The location of the SHT in Alcove \#5 is shown in Figure 2.1. Air-permeability measurements were performed in 27 boreholes drilled into the SHT area prior to the start of heating. The borehole layout for the SHT is shown in Figure 2.2. Although there was no effort to analyze data collected in the SHT to estimate fracture porosity, high spatial resolution straddle-packer air-injection tests performed in Borehole 6 are included herein because they help characterize the spatialpermeability structure of the Topopah Spring tuff. 


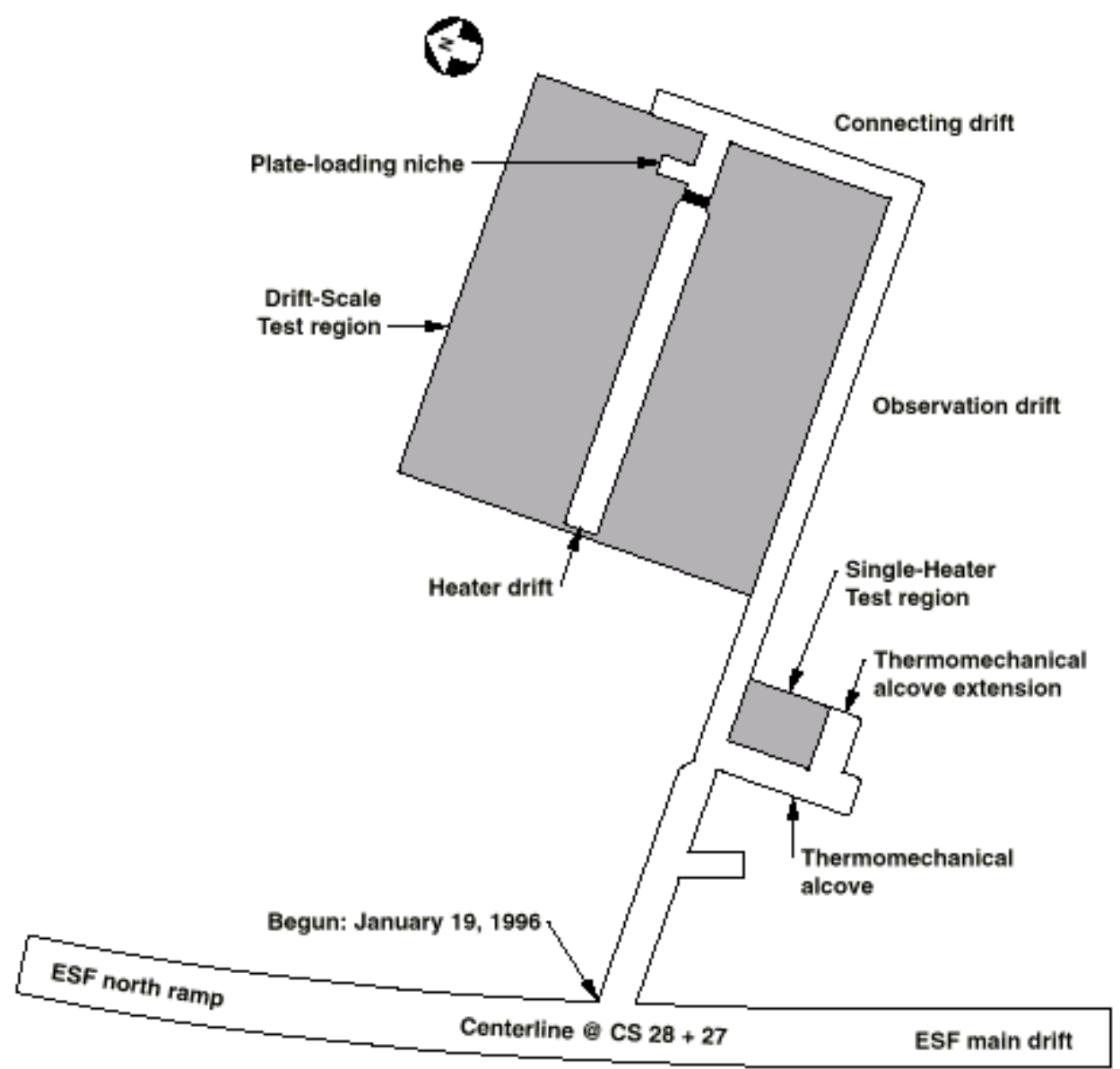

Reference only (scale approximate)

Figure 2.1 Layout of the thermal testing alcove, Alcove \#5.

The SHT served as a pilot test for the development of tools and techniques that were applied to the much larger DST. In particular, the technique of repeatedly performing airinjection measurements as heating progressed in fixed zones isolated with pneumatic packers to delineate changes in fracture liquid saturation was successfully developed in the SHT experiment and repeated for the DST. 


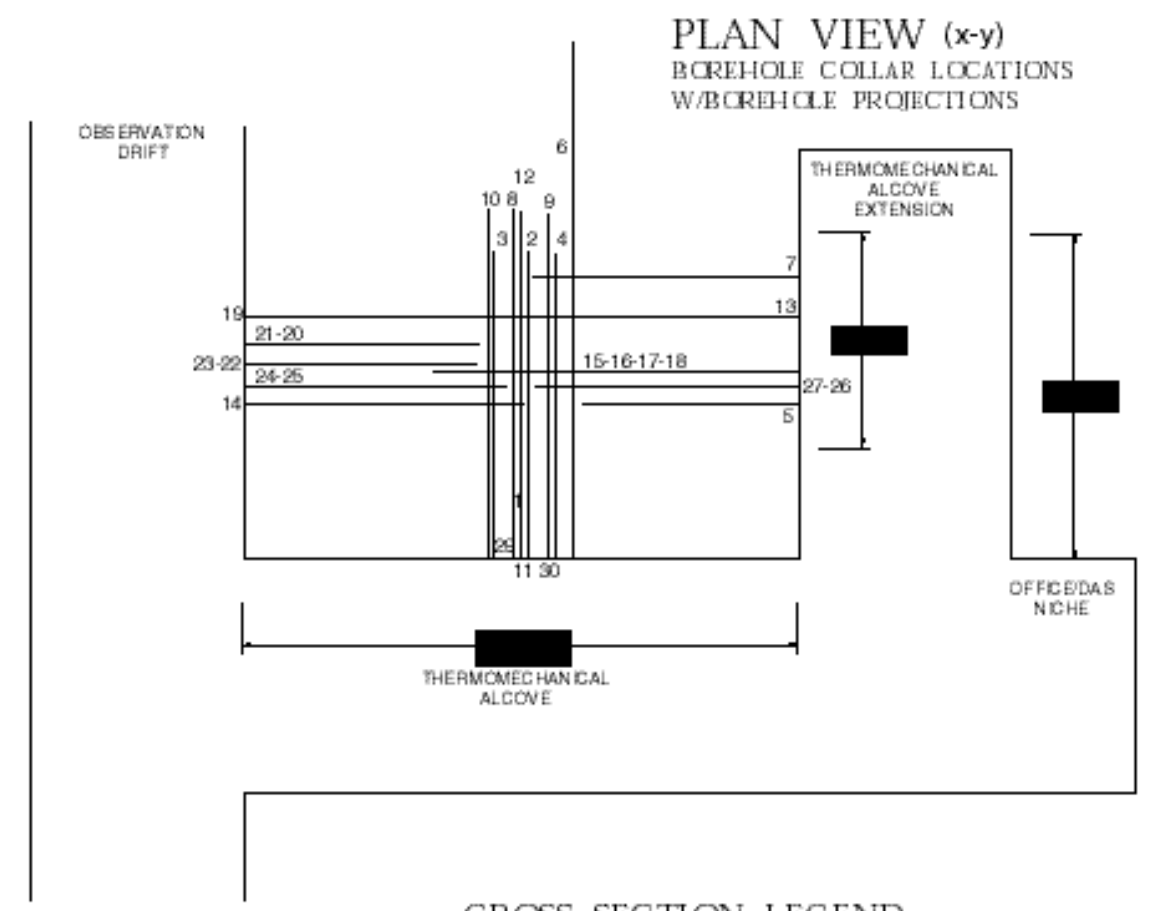

CROSS SECTION LEGEND
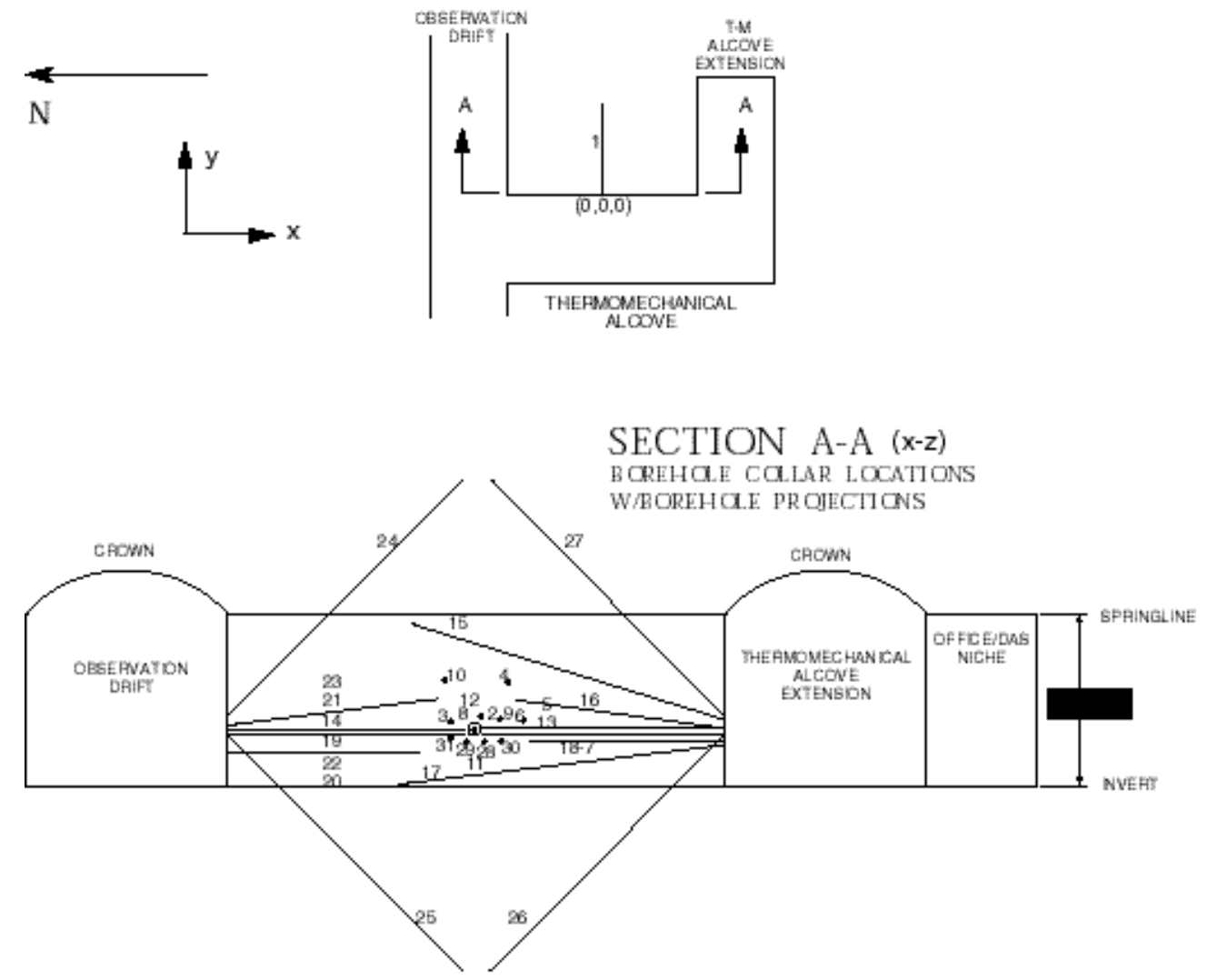

Figure 2.2 Borehole layout for the Single Heater Test. 


\subsection{The Drift Scale Test}

The DST is an 8-year-long test to investigate coupled thermal-hydrological-chemicalmechanical processes associated with the thermal perturbation caused by storing highlevel radioactive waste in the Topopah Spring middle nonlithophysal tuff. The tracer and air-injection test results presented in this dissertation were conducted as part of the baseline characterization of the Topopah Spring tuff rock mass in the DST zone. The tracer tests were to provide fracture porosity values, and the air-injection tests were to provide permeability estimates to use in process models being applied to interpret the data collected in the DST. The DST was designed to operate for four years of heating, followed by a four-year cooling period. The duration of the test was chosen so that approximately $10,000 \mathrm{~m}^{3}$ of rock would be heated above the boiling point of water.

The heart of the DST is a 50-meter-long, 5-meter-diameter drift that contains nine canister heaters, hereafter referred to as the Heated Drift. Along the left and right ribs, 25 $\mathrm{cm}$ below the centerline of the Heater Drift, are installed a total of 50 ten-meter-long, electrical wing heaters. They serve the purpose of raising the temperature of the rock mass more quickly then could be achieved with the floor heaters alone and simulate the thermal effect of having multiple parallel drifts. Figure 2.3 shows a picture of the heated drift along with the canister heaters during the initial construction and emplacement of the heaters. The heaters generate approximately $188 \mathrm{~kW}$, with $52 \mathrm{~kW}$ distributed among the floor heaters and $136 \mathrm{~kW}$ in the wing heaters. A diagram of the heated drift, with 
wing heaters and the surrounding boreholes, is shown in Figure 2.4. Approximately 4,000 sensors have been emplaced to record thermal, mechanical, and hydrological responses of

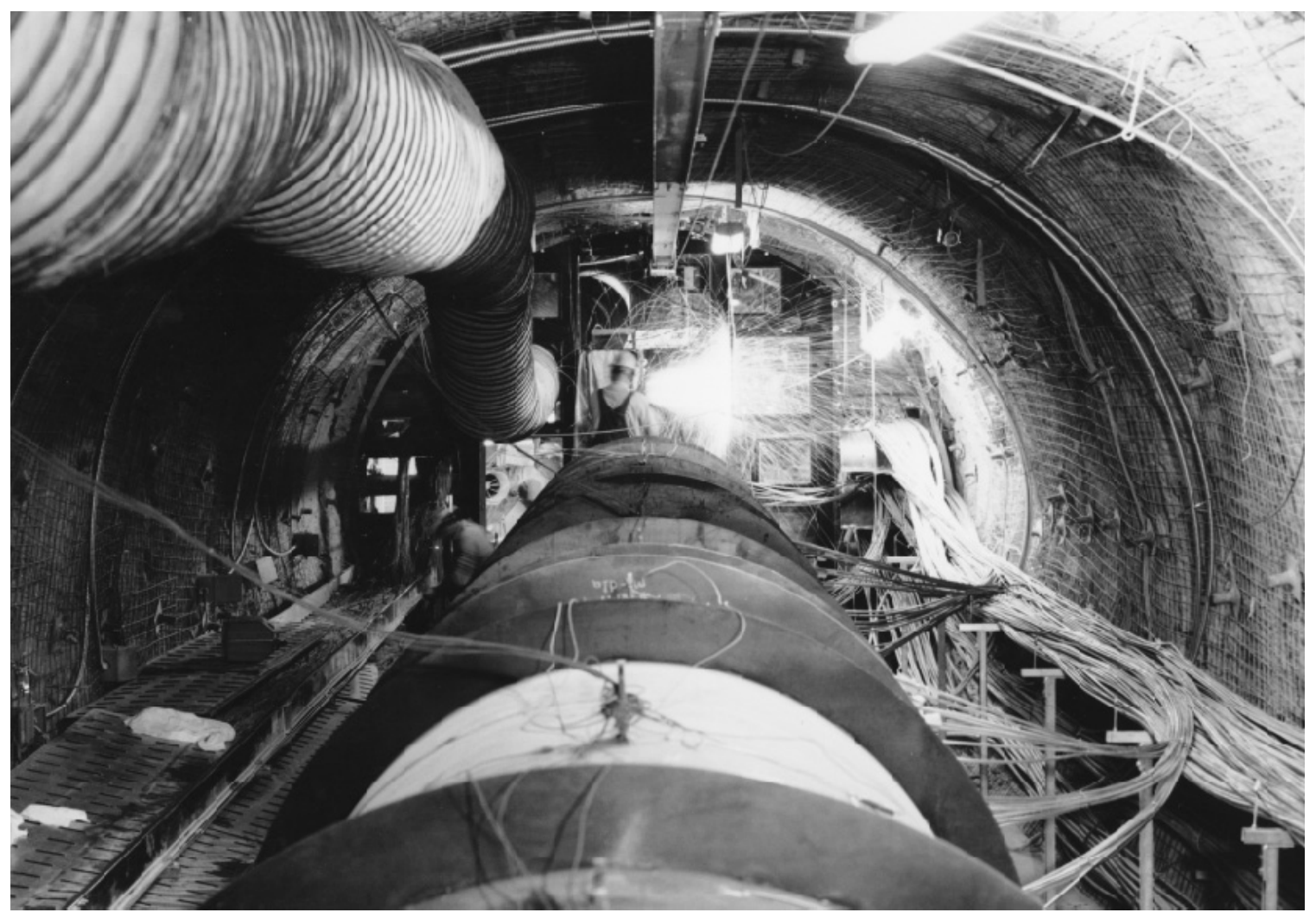

Figure 2.3 Photograph of the Drift Scale Test 5-meter-diameter Heated Drift. The heater canisters with power cables are shown as well as ongoing construction of a thermal isolation bulkhead.

the rock mass both within the heated drift and in the 188 boreholes that surround the drift. Heating of the DST commenced on December 3, 1997, and will be halted on December 3,2001 , followed by a four-year-long period of monitoring the cool down.

To understand the changes that the rock mass undergoes as a result of the heating, a diverse suite of measurements that focus on different processes are conducted. Multiple point borehole extensometer gages are installed within mechanical boreholes. Strain 
gages have been installed to observe changes in a section of cast-in-place concrete liner in the Heated Drift, as well as to observe changes in metal and concrete coupons. A plateloading test looks at changes in the elastic modulus of the rock as a function of temperature. Geophysical techniques including neutron logging, ground penetrating radar, and electrical resistance tomography, are being used to monitor changes in rock saturation. In addition, acoustical emission monitoring is used to detect the locations and relative magnitude of fracture initiation and/or propagation.

As part of the DST hydrological monitoring, 12 hydrology boreholes were drilled (as shown in Figure 2.4). These boreholes serve as the collection points for the airpermeability and tracer data presented in this dissertation. The hydrology boreholes are located in three distinct fans that form planes perpendicular to the main axis of the heater drift. Each borehole in the DST is identified by a unique number, with the hydrology boreholes consisting of Boreholes 57 to 61, Boreholes 74 to 78, and Boreholes 185 and 186 (see Figure 2.5). Each borehole is sectioned into either three or four intervals using pneumatic packers. The borehole numbers increase from top to bottom, with zone numbers increasing from the collar to the deepest portion of the borehole. The isolated zones vary from 5 to 22 meters in length, with an average length of 9 meters. Individual zones are identified by the borehole number, followed by a zone number. For instance, Borehole 75-2 identifies the second zone from the collar in Borehole 75. Boreholes 75 and 76, located in the Borehole 74-78 fan, are the boreholes used for the gas tracer tests as a part of this study. 


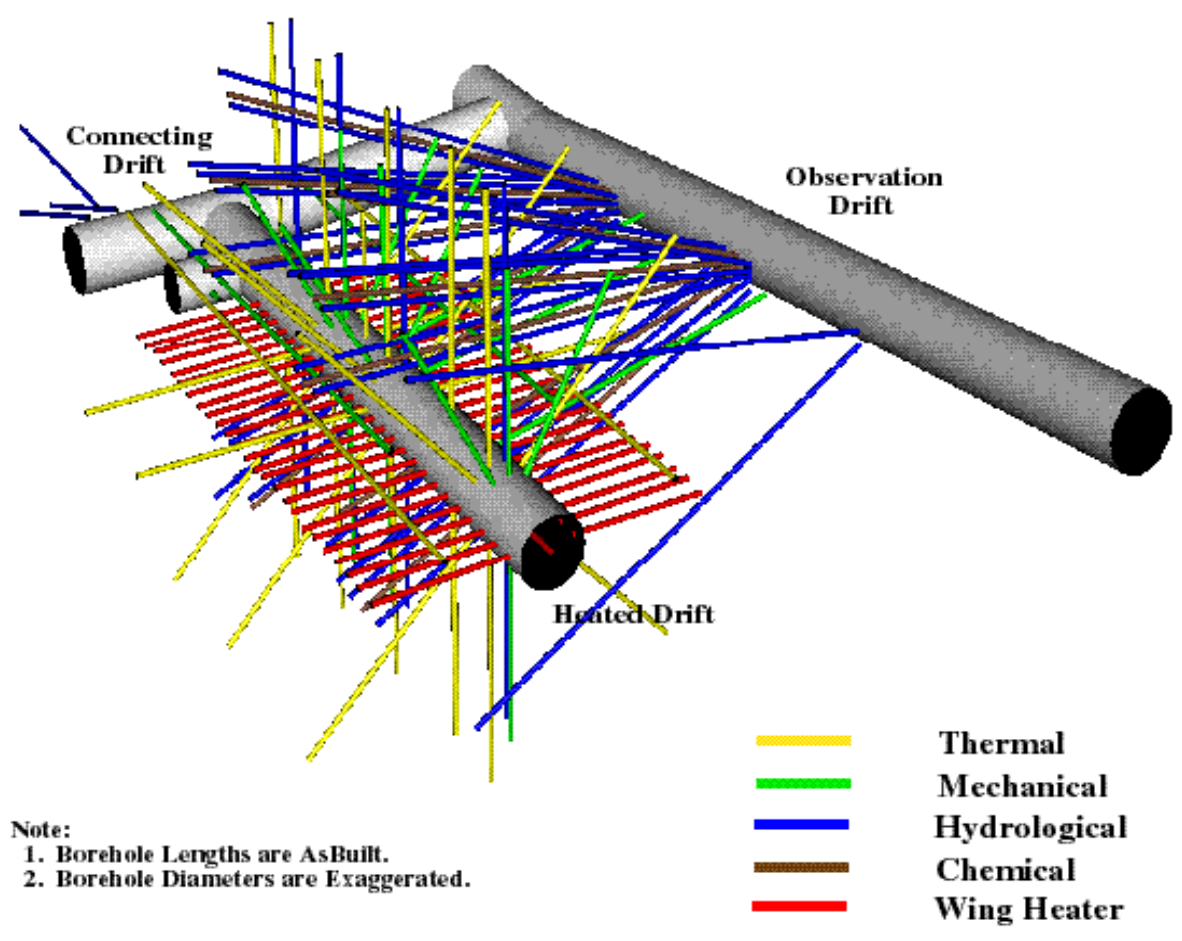

Figure 2.4 Borehole layout for the Drift Scale Test, located in Alcove \#5 of the ESF. The air-permeability and gas tracer tests are conducted from the hydrological boreholes. 

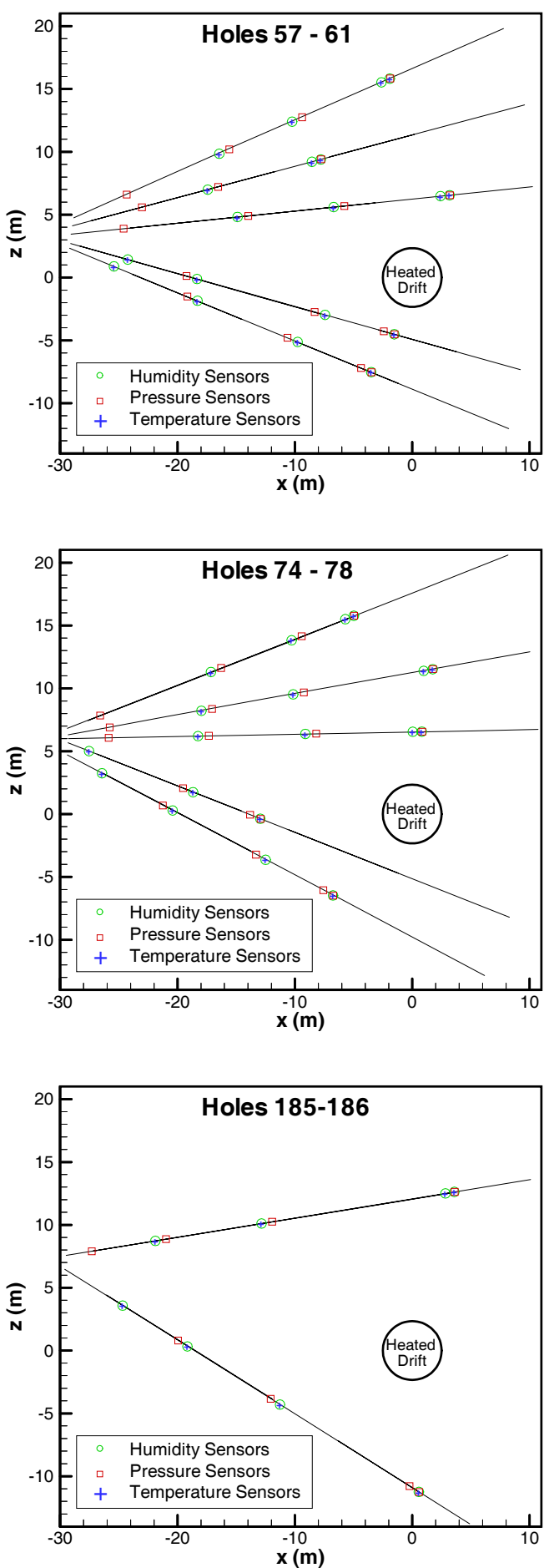

Figure 2.5 X-Z Co-ordinate layout of hydrology boreholes in the DST. The boreholes numbers increase from top to bottom. 
The hydrology boreholes were instrumented to serve multiple purposes. A passive monitoring function consists of measuring temperature, relative humidity, and pressure in 15-minute intervals within each isolated interval throughout the duration of the DST. Temperature sensors and relative humidity sensors were co-located with the packer bodies. Pressure transducers are located near the collars of each borehole, with tubes connecting them to the zone they monitor. Teflon tubes running into each zone also provide the means to obtain liquid and gas samples. These same sampling tubes provide the means for conducting gas tracer tests by providing ports for the injection and withdrawal of gases. On a quarterly basis, the hydrology boreholes are sampled for $\mathrm{CO}_{2}$, with measurements made of total $\mathrm{CO}_{2}$ concentration as well as isotopic composition, to gain an understanding of calcite precipitation and dissolution processes. Any water that accumulated in the zone can also be pumped out, using a peristaltic pump located at the collar of the borehole, to examine aqueous geochemistry.

Air-injection tests are performed quarterly to monitor the redistribution of moisture throughout the duration of the DST. A decrease in gas-phase relative permeability is interpreted as an increased in liquid saturation of the fracture network near the injection location. Figure 2.6 shows some of the trends in air-permeability as a result of the increased saturation above and below the heated drift during the first three years of heating. A review of the changes in gas phase permeability for the 46 isolated intervals in the hydrology boreholes, when supplemented with neutron data, gives a very good picture of the spatial redistribution of moisture in the DST region. While air-injection 
testing is still ongoing as heating continues, the gas tracer testing was conducted only during the baseline data collection, prior to the start of heating.

\section{Boreholes 57-59}

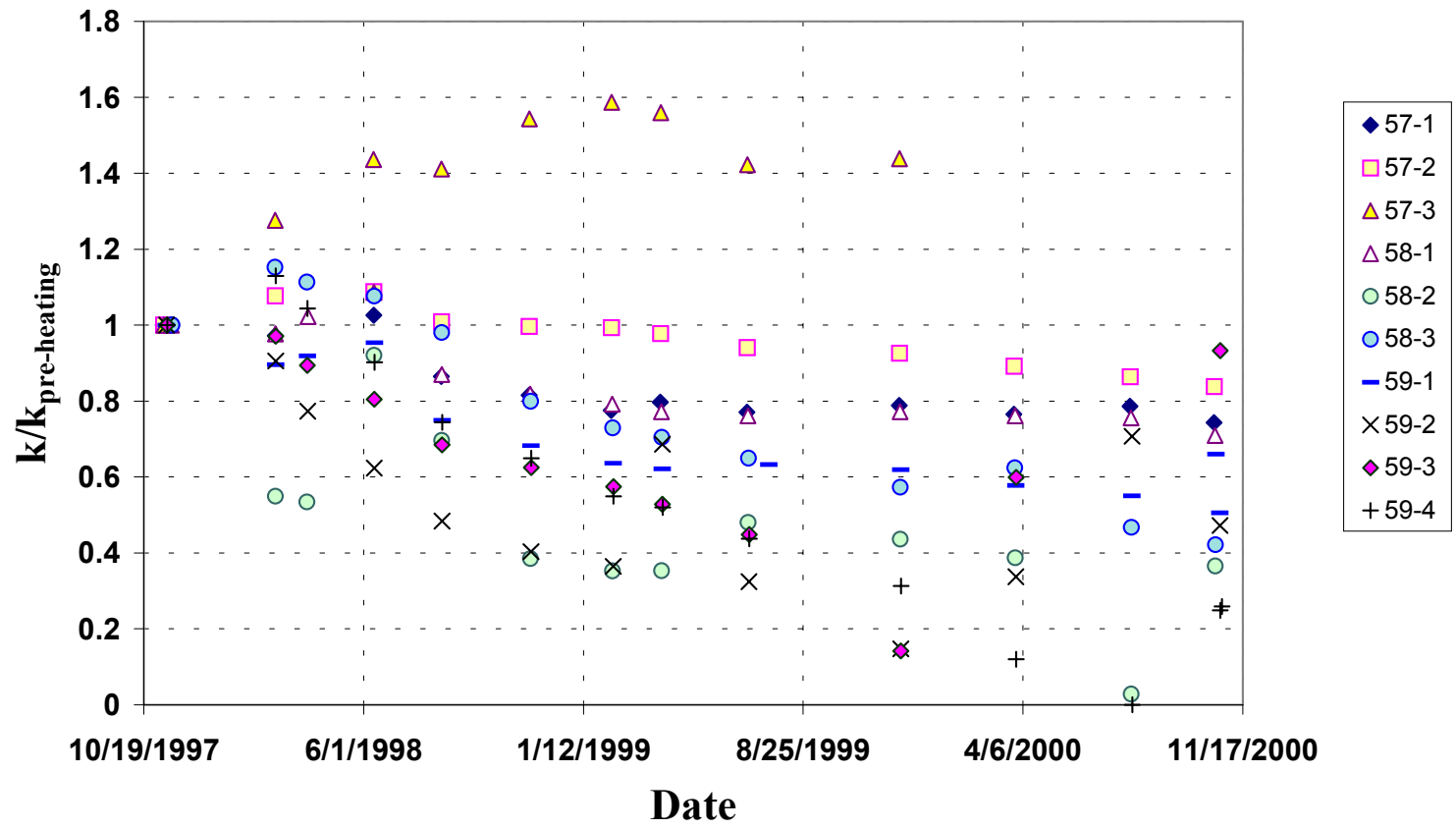

Figure 2.6 Air-permeability trends over time in the DST. Reduced air-permeability indicates the fracture liquid saturation has increased.

\subsection{Air-Injection Testing}

The air-injection tests conducted in the DST hydrology boreholes are considered constant mass-flux tests because the injected gas flow rate is held constant and the borehole pressure is allowed to vary. Pressure in all 46 isolated zones is recorded as a function of time. Air pressure transients recorded for air-injection tests performed as part of the baseline monitoring of the DST are shown in Appendix A, with more detailed graphs included where warranted throughout the main body of this dissertation. The full 
transient test response, including the pressure build-up as well as recovery transients, are evident. Typical air-injection pressure test data from Borehole 57-4 is shown in Figure 2.7. The crosshole data for two of the 45 other monitored intervals are also plotted. The crosshole data are used for delineating the region of influence for an air-injection test. Detailed testing procedures for conducting air-permeability tests in the DST are included as Appendix B.

Air-K Borehole 57-4

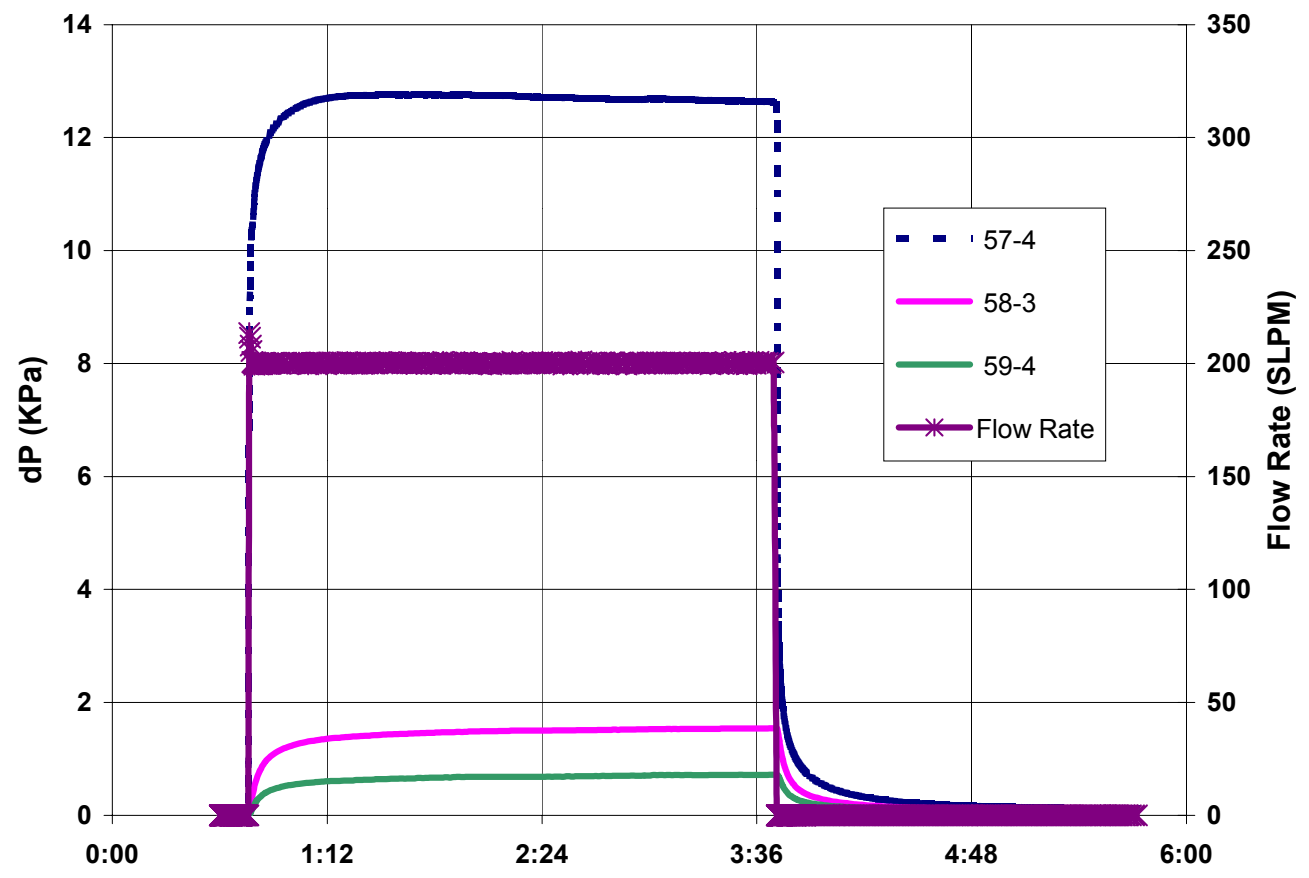

Figure 2.7 A typical constant mass flux air-permeability test.

The pressure change just prior to halting gas injection was used for steady-state analysis to estimate permeability. In this dissertation, only the recovery portion of the air-injection test was used for transient analysis because it was less subject to testing interference than the pressure build-up. The initial pressure build-up data was adversely affected by the 
finite time it took for the injection gas stream to reach the target flowrate (owing to equipment limitations and adjustments made to the initial flowrate to keep the zone pressure within a pre-designated target range). During the pressure recovery portion of an air-injection test, the gas injection was instantaneously halted by the rapid closing of an electronically controlled solenoid valve, providing a very clean transient signal to analyze.

\subsubsection{Pneumatic Packers}

Boreholes were sectioned into multiple zones using pneumatic packers. In the DST area, 46 packers were installed in the 12 hydrology boreholes, creating 46 isolated zones. Figure 2.8 is a photograph of pneumatic packers prior to installation in a borehole. The pneumatic packers use 1.0 meter long stainless steel tubes with an $1 / 8$ " diameter tube welded through the body of the packer to be used for packer inflation. Because the packers will be exposed to temperatures approaching $200^{\circ} \mathrm{C}$ during the heating portion of the DST, the packer gland material was constructed of Viton rubber. The rubber was cured on the packer body and lathe cut to the proper outside diameter. Mold release compound was used in the center portion of the packer to permit rubber inflation. A 10 $\mathrm{cm}$ band of rubber on each end of the packer was vulcanized directly onto the stainless steel tube, with Oetiker-brand compression bands placed around the ends for extra strength. 


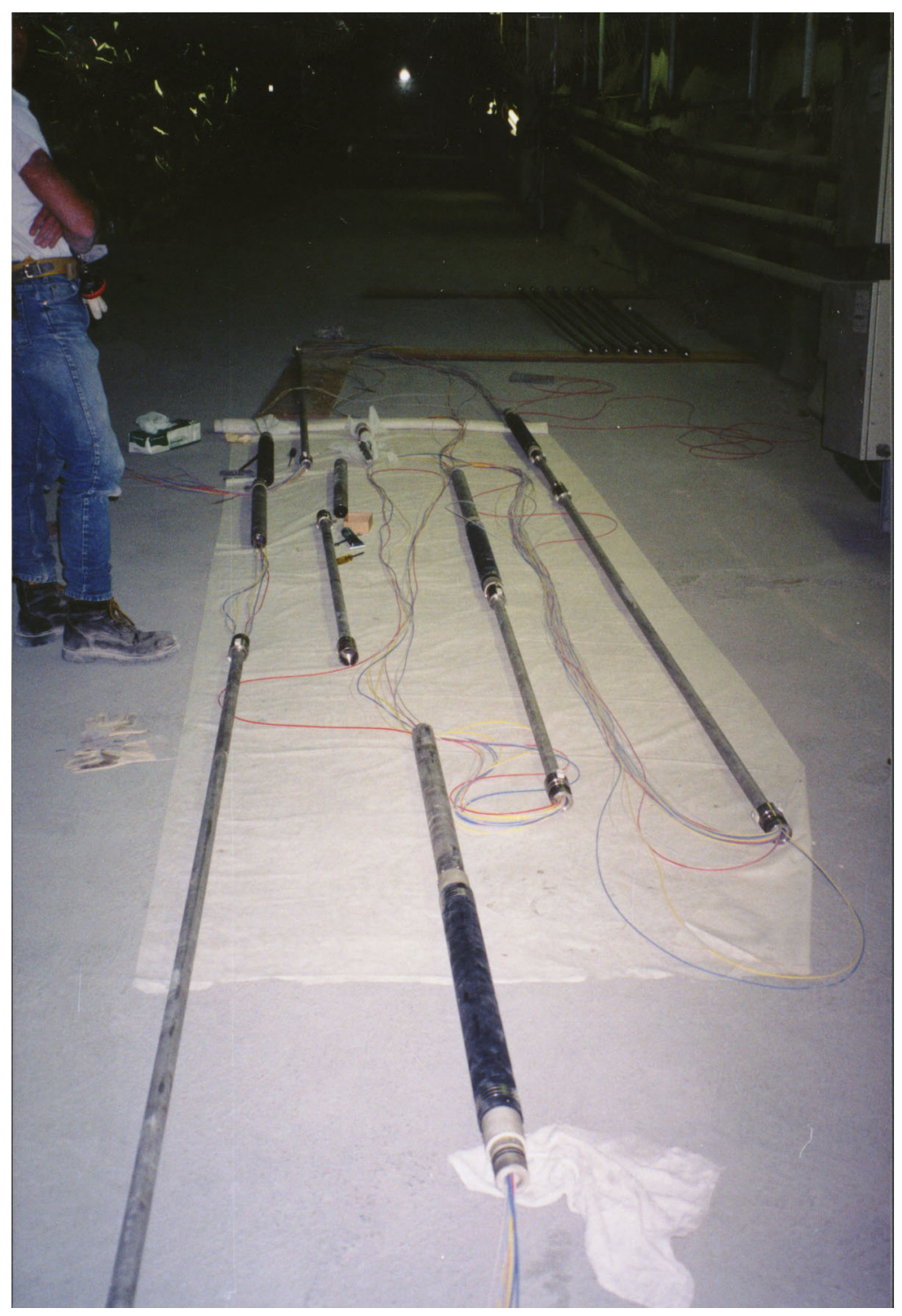

Figure 2.8 Pneumatic packers prior to installation in a borehole. Note the Teflon end pieces, which serve as housings for temperature and relative humidity sensors.

Teflon end pieces were used to connect the main packer body to stainless steel tubes that run between each packer. The stainless steel connecting tubes served as strength members between packers and also to enclose instrument wires and pneumatic lines. Oring seals on each Teflon end piece ensured that there was no communication between isolated intervals. The Teflon end pieces were machined to serve as housings for 
temperature and relative humidity sensors, which were also sealed by O-rings to prevent leakage between zones.

\subsubsection{Flow Control System}

A schematic of the air-permeability testing system equipment is shown in Figure 2.9. As shown, compressed air was filtered, dehumidified, and then passed through a gas massflow controller (MFC), before being injected into an isolated region between pneumatic packers. Since each mass-flow controller had a limited range, a sequence of increasingly larger MFCs yield an operational gas injection range between 0.1 SLPM up to 500 SLPM. For the DST hydrology boreholes, which occur in a cluster of borehole fans collared at the same drift transect, the outlet of the MFCs goes to an array selection manifold. The array selection manifold routs the gas to one of three injection zone selection manifolds. Figure 2.10 is a photo of the equipment located near the collar of one fan of DST hydrology boreholes. At the center top of the photo is the injection zone selection manifold, used to systematically direct the injection gas stream to each zone.

\subsubsection{Data Acquisition}

Pressure data from all 46 borehole intervals were logged to a personal computer via IEEE488.2 controlled measurement instruments. The data acquisition hardware consisted of a Keithley Model 7002 Switch System and a Keithley Model 2001 Digital Multimeter. 
A Hewlett-Packard Model E3631 Programmable Power Supply was used to supply a set Gas Flow Control System Trace Gas
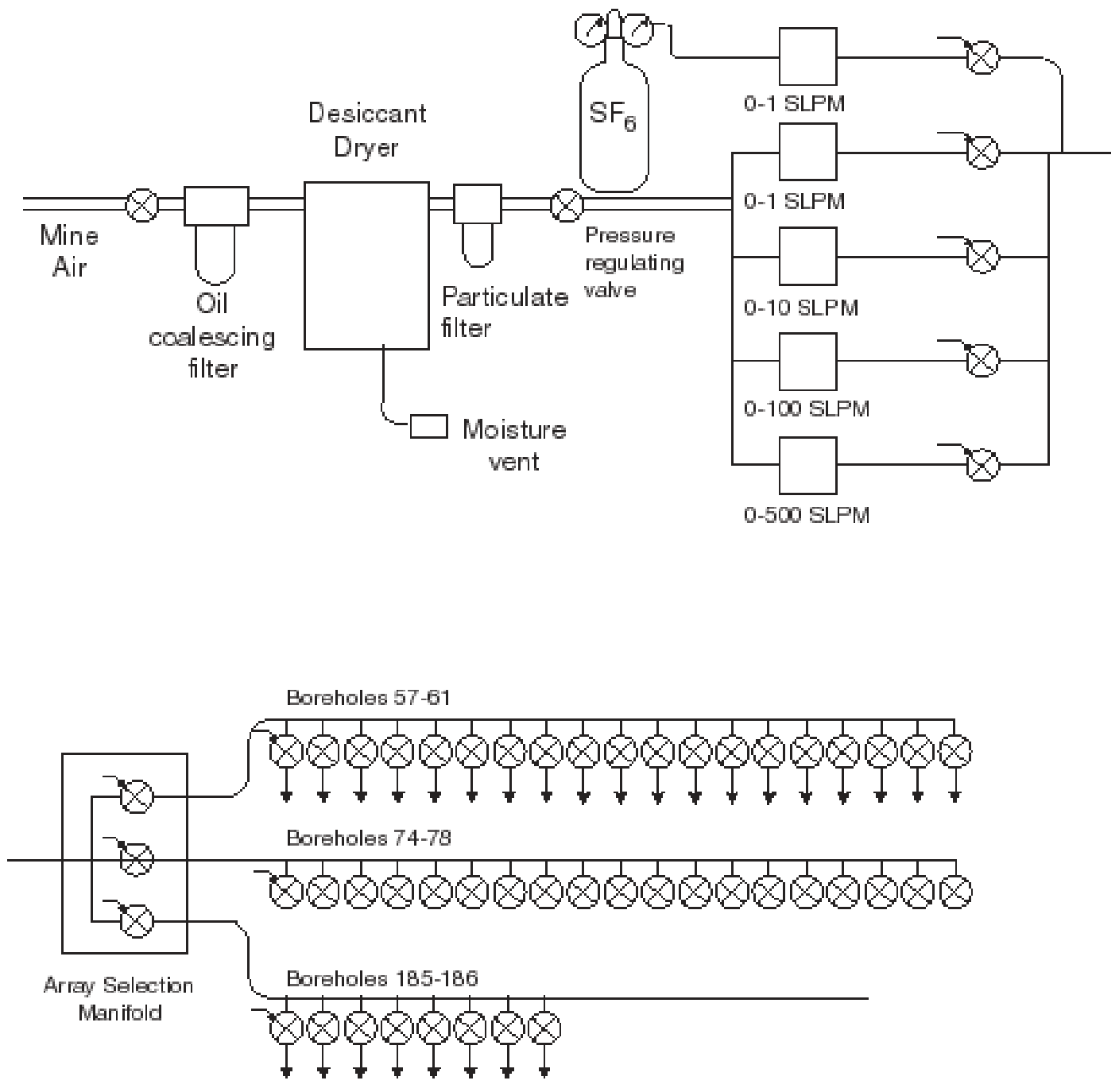

Injection Zone Selection Manifolds

Figure 2.9 Schematic layout for air-permeability testing equipment for the DST. 


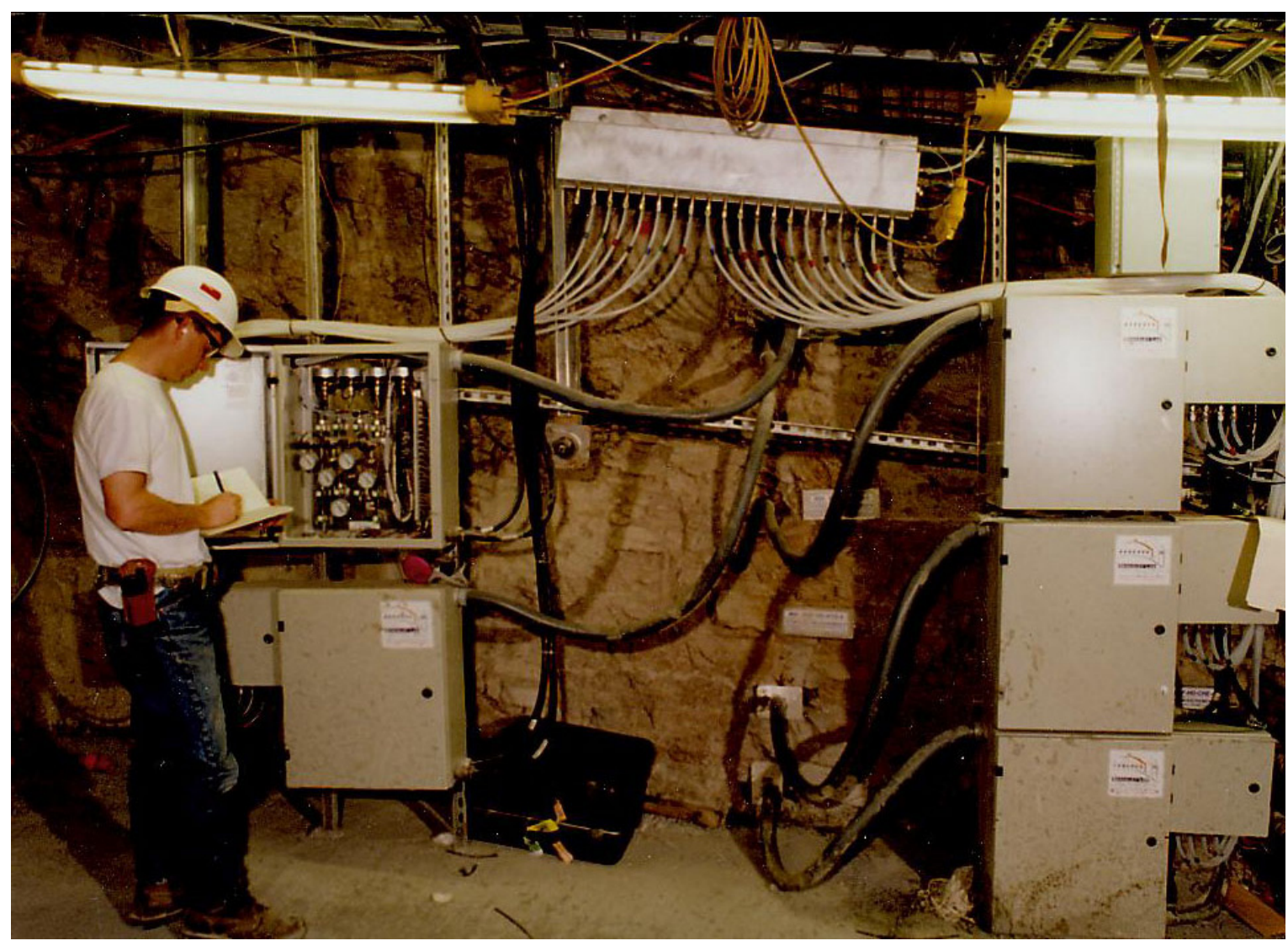

Figure 2.10 Drift Scale Test equipment located at the collars of Boreholes 57-61. The Injection Zone Selection Manifold is at the center top of the photo. The open electronic enclosure shows pressure transducers and packer inflation gages for one borehole.

point voltage to the Sierra Instruments gas MFC. To better capture the rapid time transients associated with the start of the injection and recovery periods, a data logging interval of 5 seconds was used for the first 5 minutes of each testing period. To minimize file size, the data acquisition interval was reduced to one minute after the rapid logging periods concluded.

National Instruments test and measurement software package, Labview, was used to automate the DST air-injection testing. The software code is included as an attachment in 
Appendix B. The computer sequentially opened and closed each of the 46 solenoid valves to permit gas injection into each isolated packer interval. Because air-permeability tests were intended to be repeated throughout the entire 8 year heating and cooling cycle of the DST, it was important to automate the test procedure. Password protected communication software allowed testing to be performed remotely via modem from any location that has telephone communications available.

The software algorithm was written to adjust the flow rate to target a maximum pressure change between 6 and $40 \mathrm{KPa}$ in the injection interval. After the first series of tests was conducted in all zones, a starting flow rate was selected for subsequent tests. The flow rate was adjusted after a minute of injection if the injection zone pressure increase were deemed to be outside of a designated target range. If the pressure in the target interval was too great, the flow rate was reduced, and if the pressure change was too small, the flow rate was increased.

\subsection{Gas Tracer Testing}

Four gas tracer tests were conducted as part of the baseline characterization of the DST rock mass. The primary aim was to determine a fracture porosity for the Topopah Spring tuff that could be incorporated into the DST process models. Two types of gas tracer tests were conducted in the Topopah Spring middle nonlithophysal tuff. The first type of tracer test was an inter-borehole weak-dipole test. The second test was a huff-puff injection/withdrawal from the same location. Analysis of the huff-puff test was to provide information on diffusive gas processes. The collected data have mass balances for each 
test that approach $100 \%$, and the concentration measurements show excellent repeatability.

\subsubsection{Weak-Dipole Tracer Test}

To conduct a dipole tracer test, we introduced tracer gas into one location, isolated using pneumatic packers, and withdrew sample gas from another isolated location. The flow field was monitored using pressure measurements in all locations and by gas flow-rate measurements of the injected and withdrawal gas streams. The tracer gas concentration at the withdrawal borehole was recorded as a function of time. The tracer test was called a weak-dipole test because the tracer injection rate was performed at a much smaller flow rate than the continuous gas withdrawal flow rate. Stable boundary conditions and constant flowrates were maintained to simplify interpretation of the collected data.

\subsubsection{Huff-Puff Tracer Test}

The second type of tracer test conducted was designed to investigate the influence of diffusive processes on gas transport. The test consisted of an injection of gas tracer in an isolated borehole interval for a finite time period, followed by a waiting period in which gas was neither injected or withdrawn. Subsequently, gas was withdrawn from the same interval as it was initially injected. This type of test is referred to as a huff-puff test and has sometimes been used in the petroleum industry to test the effects of fluid injection on reservoir production. The waiting period allows for diffusive processes to occur while no advection occurs. It is typically assumed that this type of test is insensitive to fracture 
porosity and can therefore provide an understanding of the magnitude of purely diffusive processes [Tsang, 1995].

\subsubsection{Gas Analysis}

Because samples can become contaminated and give erroneous results during tracer testing it was critical that tracer samples were properly handled. For gaseous samples, any exchange that occurs between the sample gas and the surrounding air can provide erroneous results, which tend to increase in effect with longer sample holding times. To avoid the problems of collecting and storing gas samples, an in situ measurement technique of analyzing tracer gas in real time using a mass spectrometer was developed, along with quality control procedures to ensure the accuracy of the data. A detailed procedure used for the mass spectrometer analyses of gas tracer samples has been included in Appendix C, and calibration procedures have been included in Appendix D.

\subsubsection{Mass Spectrometer}

A Quadrupole Mass Spectrometer Gas Analyzer was used to perform the quantitative analysis of tracer gas concentration. The Balzer Omnistar Gas Analyzer consists of an ion source chamber that ionizes the gas leaked into a vacuum chamber through a small orifice. The ions are accelerated through a chamber surrounded by four electrodes. A radiofrequency signal is applied 180 degrees out of phase to opposite electrode pairs to accelerate resonant ions through the chamber to strike the ion collector. Non resonant ions strike the electrodes and become neutral particles. The Omnistar Gas Analyzer operates with a mass range from 1 to 200 AMU. The mass spectrometer weighs 
approximately $45 \mathrm{~kg}$ and was set up in the field for real time analysis of the withdrawal gas stream.

The mass spectrometer was calibrated before, during, and after each tracer test by using premixed calibration standards. The reason for the frequent recalibration is the fact that the mass spectrometer signal will tend to drift slowly over time. Tedlar bags were filled with known concentrations of tracer gas using a Stec sgd-710 gas divider. The gas divider is able to precisely mix two gas streams in ratios from 1:1 to 1:10. Zero air, a pure mix of nitrogen and oxygen, was mixed with a stream of tracer gas to create a dilute gas stream. Both the zero air and the tracer gas are available from commercial gas suppliers in standard compressed gas cylinders. A series of Tedlar bags were filled to bracket the anticipated tracer gas concentration prior to the start of the tracer test.

During tracer testing, the gas standard bags were cycled through the mass spectrometer from low concentration to high concentration at a frequency of no less than once per day. Figure 2.11 shows the results of a typical calibration. The ion current measured for the tracer gas was normalized by the ion current for nitrogen to take into account the fluctuation in ion current resulting from variations in pressure within the mass spectrometer vacuum system. Even though the total quantity of gas in the massspectrometer may slowly fluctuate, (causing variations in ion current), the partial pressure of tracer obtained by using normalized ion current readings will remain stable, since the quantity of nitrogen in air does not significantly fluctuate. 
DST Gas Tracer Test

Withdrawal 75-2 Injection 76-2

Calibration

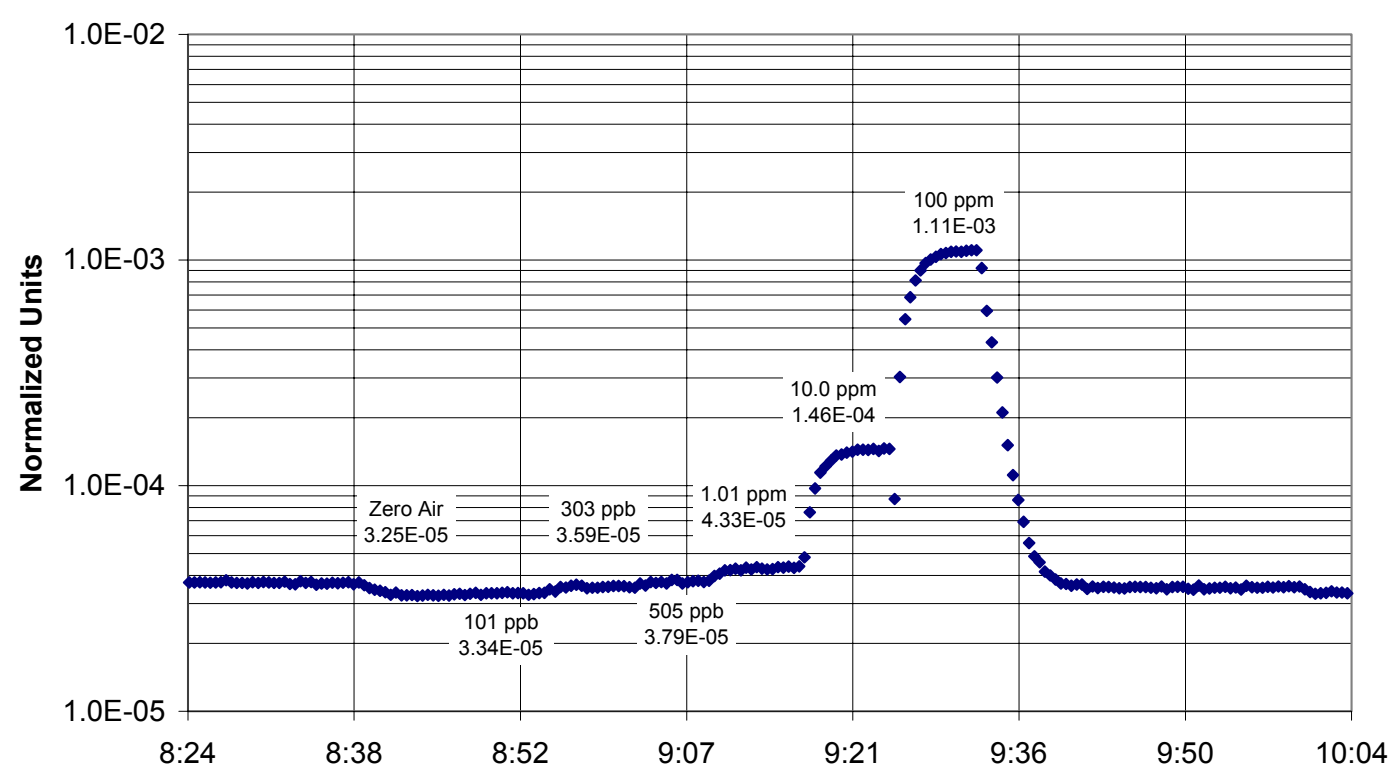

Figure 2.11 Calibration of the Balzer's Mass Spectrometer with $\mathrm{SF}_{6}$ standard Tedlar reference bags.

\subsubsection{Sulfur Hexafluoride Tracer}

Sulfur hexafluoride $\left(\mathrm{SF}_{6}\right)$ was used as a tracer in this study. $\mathrm{SF}_{6}$ is a commonly used industrial gas for insulating electrical equipment, one that has also been widely used as a tracer gas for leak detection and building ventilation studies. The use of $\mathrm{SF}_{6}$ as a tracer for both saturated and unsaturated transport has been investigated by Wilson and Mackay [1993], Glover and Kim [1993], and Adams [1995]. Since $\mathrm{SF}_{6}$ is detectable in the field by mass spectrometry down to $1 \mathrm{ppb}$, the total use of $\mathrm{SF}_{6}$ in the tracer work conducted within this study amounted to only a few standard liters. Using a gas chromatograph equipped with an electron capture detector, $\mathrm{SF}_{6}$ has a detection limit in the sub-ppt range [Mroczek, 1997]. 


\subsubsection{Tracer Test Equipment}

Gas tracer testing was conducted in two of the zones used for conducting the airpermeability tests, using the same pneumatic packers and monitoring electronics. In addition to the air-permeability injection equipment, an extra MFC was added to mix a stream of tracer gas with the regular air-injection stream. A diaphragm pump was used to continuously withdraw gas from the test interval. The output of the diaphragm pump was controlled through another MFC. The necessary hardware to conduct the gas stream analysis using a mass spectrometer is shown schematically in Figure 2.12. Figure 2.13 is a photo of the field equipment as it was installed for the DST in Alcove \#5.

Since the Topopah Spring rock matrix is very nearly saturated, several complications made testing problematic. The sample gas downhole was often warmer than the ambient temperature in the ventilated mine drift. Upon extraction, the temperature of the extracted gas would drop below the water vapor saturation point, and moisture condensed out of the gas stream. To avoid having liquid interfere with the equipment used to regulate the gas flow, a refrigerated gas dryer was used to remove condensable gases from the gas stream. The gas sampling stream introduced to the mass spectrometer was pulled off the main gas stream using a peristaltic pump at approximately 100 SCCM. From this stream, 


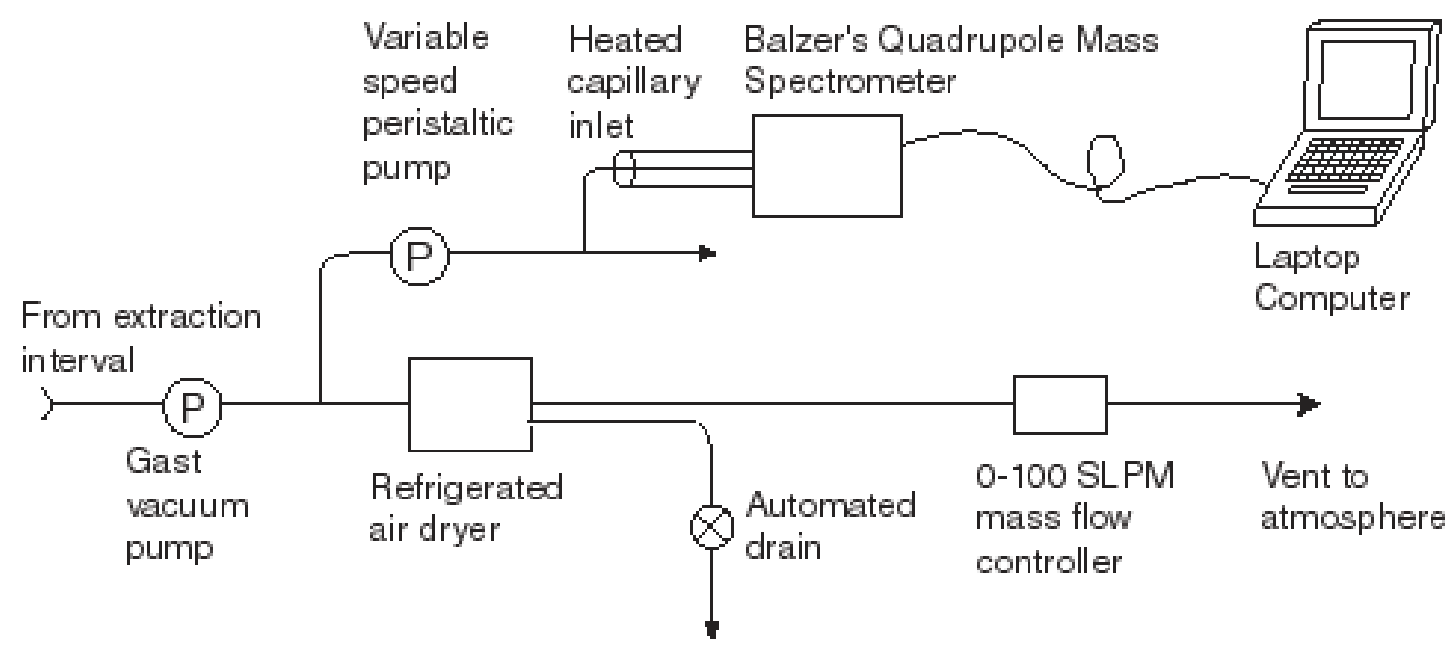

Figure 2.12 Schematic layout of gas tracer test equipment for measurement of tracer gas concentration.

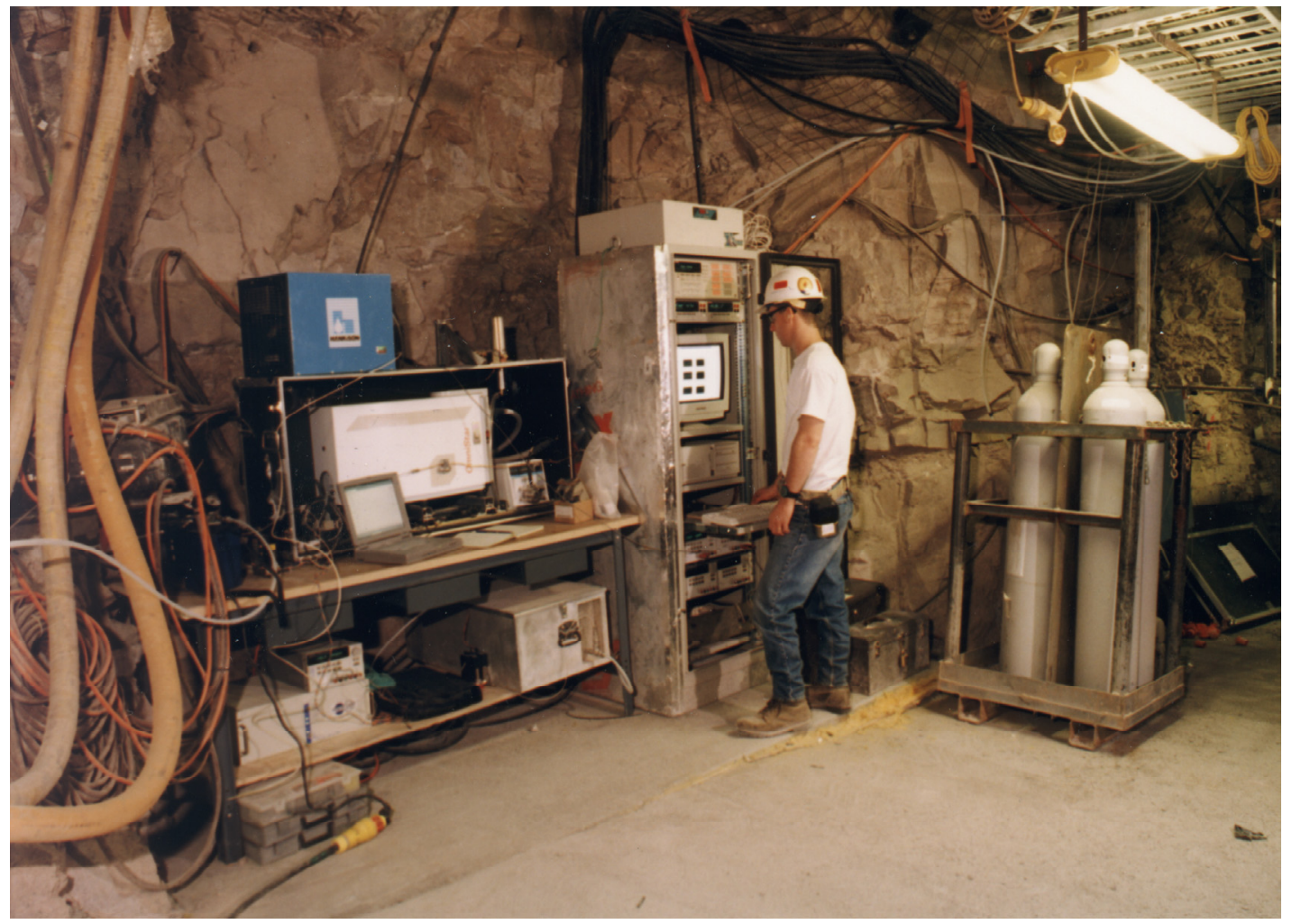

Figure 2.13 Gas tracer test equipment as installed in the DST. The mass spectrometer is the white instrument located beneath the blue refrigerated air dehumidifier. 
a heated capillary tube that leads to a small orifice in the mass spectrometer passes about 0.5 SCCM sample gas, with the remainder of the gas stream being vented to the atmosphere.

\subsubsection{Tracer Test Operation}

Gas tracer tests in the DST area were conducted in Borehole 75 and 76, Zones 2 and 4. The layout of Borehole 75 and 76 are shown in Figure 2.5. Two different strength dipoles were used in Zone 2, 10:1 and 30:1. A 10:1 dipole was used to test Zone 4. The strength of the dipole refers to the ratio of withdrawal gas flux to injected gas flux. In all tests, injections were made in Borehole 76 with withdrawal from Borehole 75. A huff-puff tracer test was conducted in Borehole 76, Zone 2. The flow rates for each test and the borehole geometries are listed in Table 2.1.

For the three crosshole tests, the injection air and withdrawal gas flow rates and zone pressures were monitored prior to the injection of any tracer to ensure that a steady-state flow field was achieved. After a steady-state pressure field was obtained, the air-injection flow rate was reduced to 0.90 of the original value. A make-up gas stream of tracer equal to 0.10 of the original injection air stream was added from a 10,000 PPM cylinder of $\mathrm{SF}_{6}$. The final injection gas stream had a concentration of 1,000 PPM SF 6 . After a certain length of time, the injection of tracer was halted, and the injection air stream was returned to its original flux rate. Throughout the entire duration of the experiment, the withdrawal gas stream was maintained at a steady flux-rate, and $\mathrm{SF}_{6}$ concentration measurements were performed by the mass spectrometer every thirty seconds. Figures $2.14,2.15$, and 
2.16 show the mass breakthrough curves for the three weak-dipole tracer tests, as well as the cumulative mass recovery.

For the huff-puff test, an injection stream of $\mathrm{SF}_{6}$ tracer was injected at a concentration of 100 PPM for twenty minutes. This was followed by a waiting period of thirty minutes prior to starting gas withdrawal. The withdrawal gas' $\mathrm{SF}_{6}$ concentration was recorded every thirty seconds, and the flow rates and pressures were recorded every minute.

Figures 2.17 shows the mass breakthrough curve for the huff-puff tracer test, as well as the cumulative mass recovery.

Table 2.1. Tracer Testing Locations and Parameters

\begin{tabular}{|l|l|l|l|l|l|l|}
\hline $\begin{array}{l}\text { Test } \\
\text { Name }\end{array}$ & $\begin{array}{l}\text { Injection } \\
\text { Location }\end{array}$ & $\begin{array}{l}\text { Withdrawal } \\
\text { Location }\end{array}$ & $\begin{array}{l}\mathbf{Q}_{\text {inject }} \\
\text { (SLPM) }\end{array}$ & $\begin{array}{l}\mathbf{Q}_{\text {withdraw }} \\
\text { (SLPM) }\end{array}$ & $\begin{array}{l}\text { Tracer } \\
\text { Injection } \\
\text { Duration } \\
\text { (min) }\end{array}$ & $\begin{array}{l}\text { Average } \\
\text { Zone } \\
\text { Separation } \\
\text { (m) }\end{array}$ \\
\hline $\begin{array}{l}76-2 \\
10: 1\end{array}$ & $76-2$ & $75-2$ & 3 & 30 & 87 & 2.13 \\
\hline $\begin{array}{l}76-2 \\
30: 1\end{array}$ & $76-2$ & $75-2$ & 2 & 20 & 276 & 6.22 \\
\hline $\begin{array}{l}76-4 \\
10: 1\end{array}$ & $76-4$ & $75-4$ & 1 & 30 & 93 & 2.13 \\
\hline $\begin{array}{l}\text { Huff- } \\
\text { puff }\end{array}$ & $76-2$ & $76-2$ & 10 & 20 & 20 & N/A \\
\hline
\end{tabular}


DST Gas Tracer Test Inject 76-2, Withdrawal 75-2 30:1 Convergent Dipole

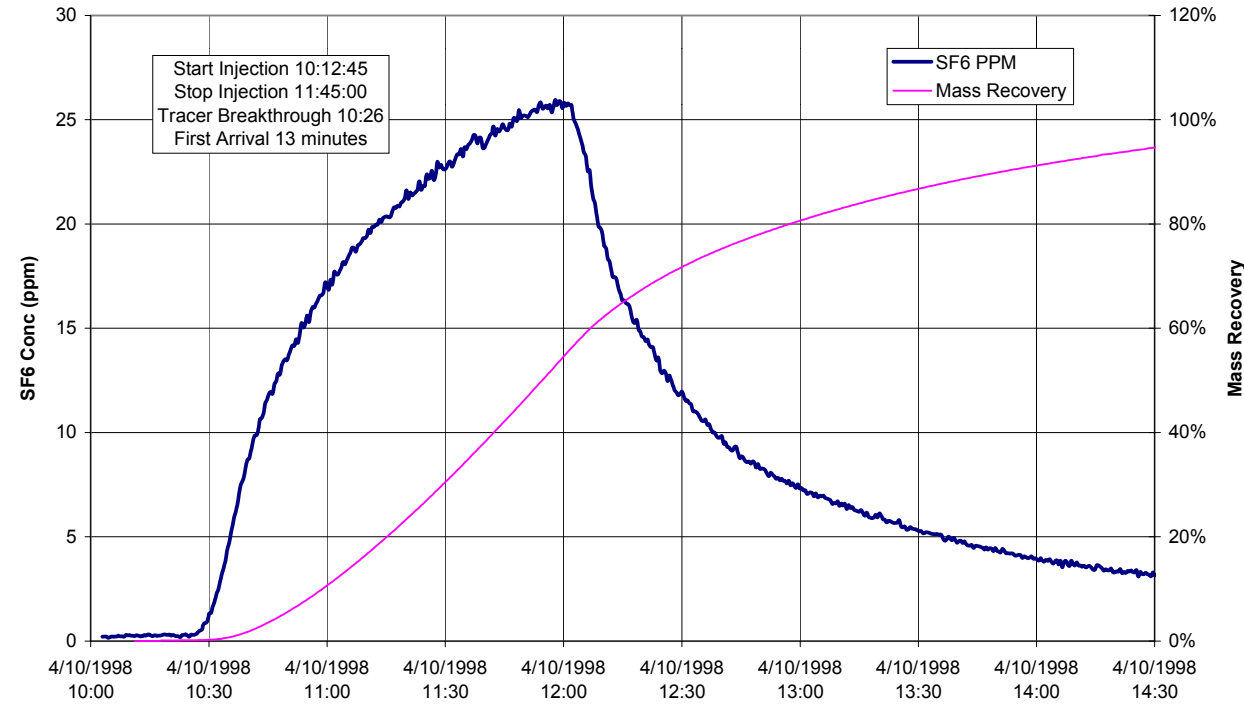

Figure 2.14 Mass breakthrough curve and cumulative mass recovery for Borehole 76-2 30:1 gas tracer test.

DST Gas Tracer Test Withdrawal 75-2, Injection 76-2

10:1 Convergent Dipole

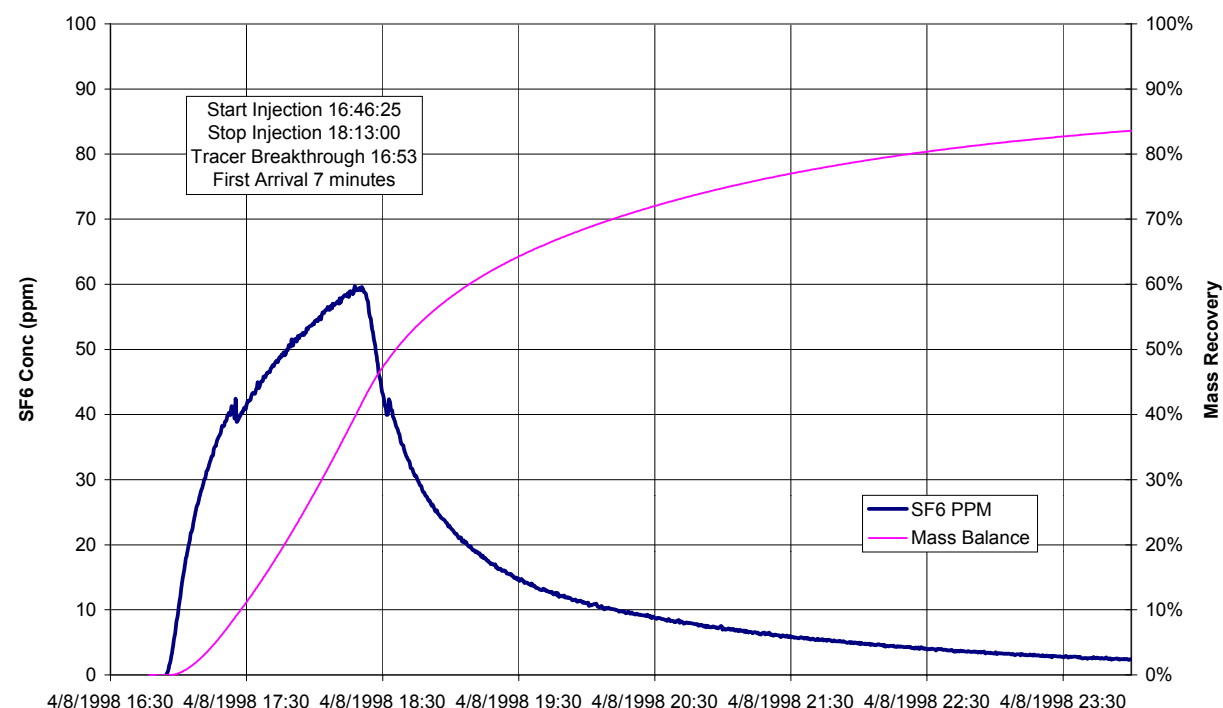

Figure 2.15 Mass breakthrough curve and cumulative mass recovery for Borehole 76-2 10:1 gas tracer test. 


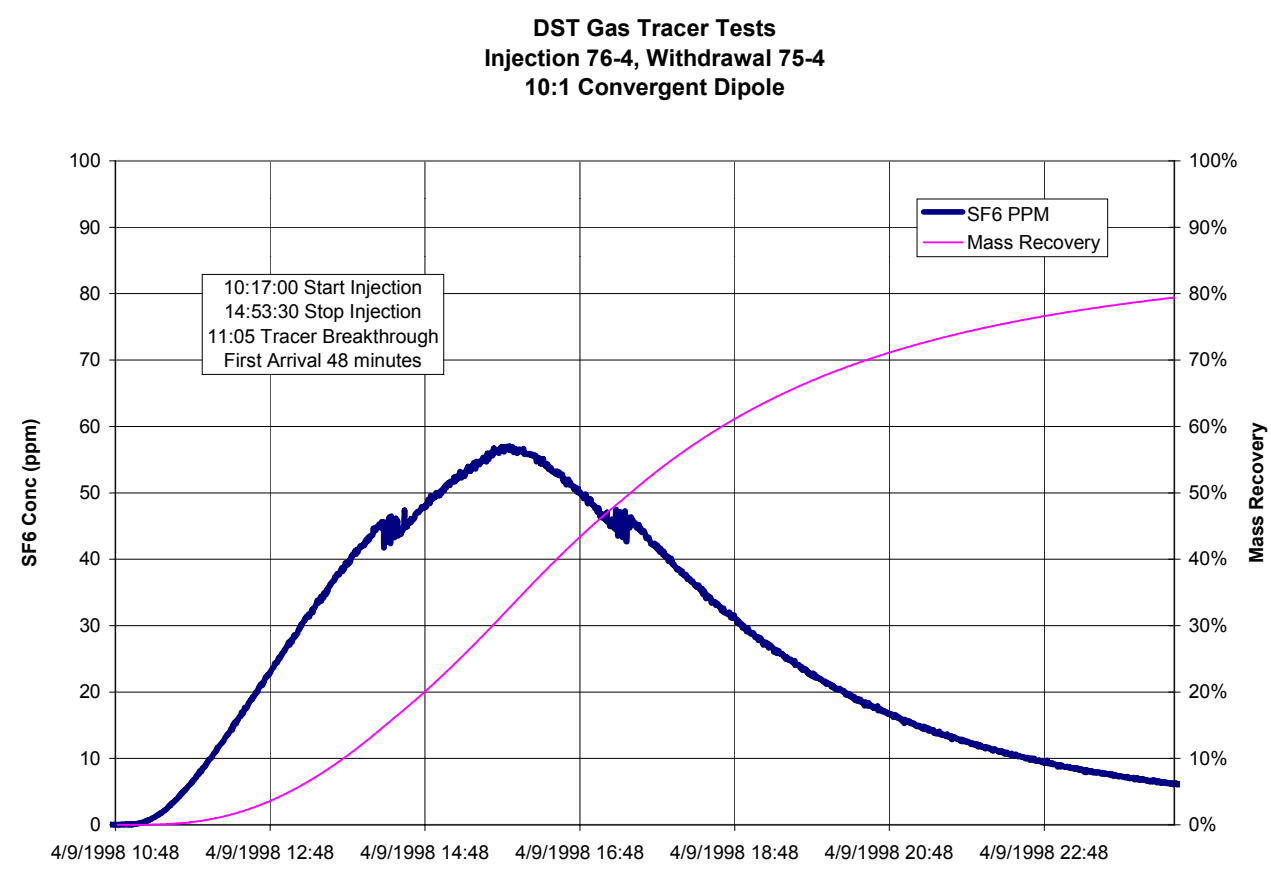

Figure 2.16 Mass breakthrough curve and cumulative mass recovery for Borehole 76-4 10:1 gas tracer test.

Huff-Puff 76-2

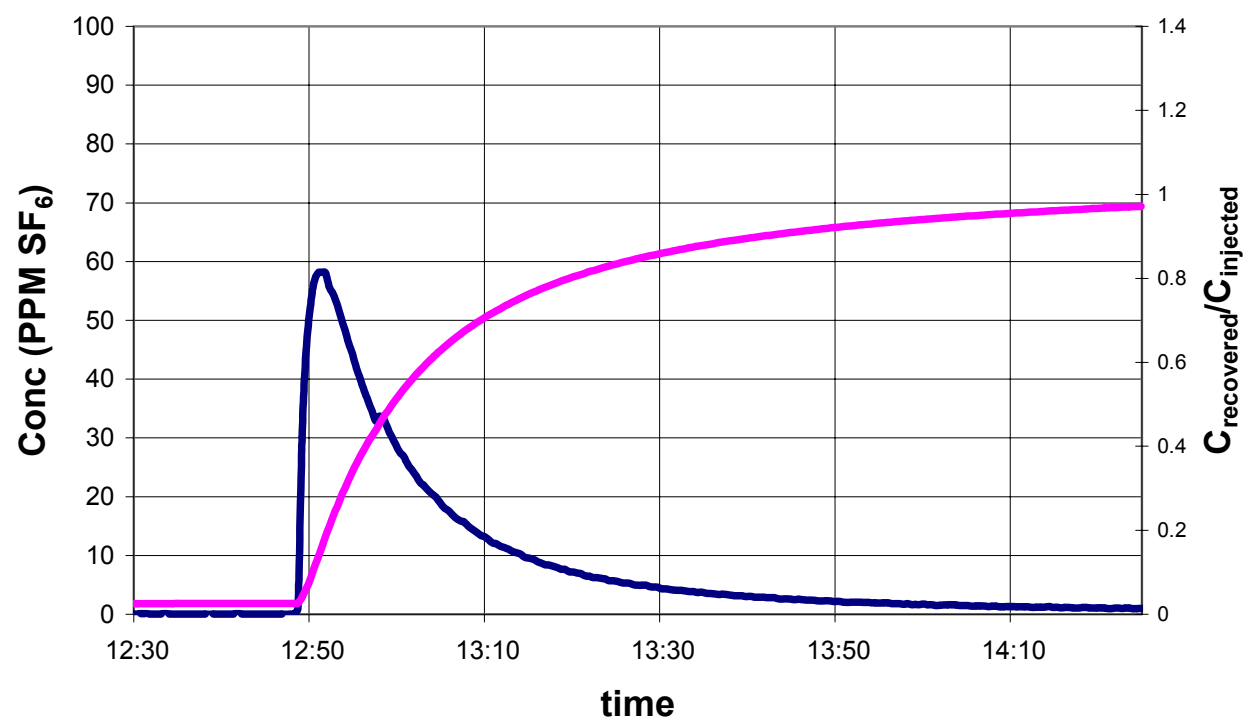

Figure 2.17 Mass breakthrough curve and cumulative mass recovery for Huff Puff gas tracer test. 


\section{Steady State Air-Permeability Data Analysis}

To estimate formation parameters using air-permeability and gas tracer measurements, the data needs to be interpreted using analytical and/or numerical models. These models are simplifications of the actual physical system to make the determination of the parameters of interest tractable. The eventual goal for the parameter set obtained from the DST is to incorporate this information into coupled process models, to predict the behavior of an actual high-level waste repository over many thousands of years. One of the most important assumptions applied to interpret both the air-permeability and the gas tracer data is that the fracture network can be treated as an effective continuum. Herein, the effective continuum assumption is investigated by first looking at the spatial distribution of permeability in the DST, using a steady-state analytical model to estimate the permeability. The DST permeability structure is then be compared with measurements performed on smaller spatial scales, and the variance for the permeability estimates will be compared. Geologic observations of the distribution of fractures and fracture frequencies along with the steady-state permeability measurements are finally used to justify the effective continuum assumption, providing a basis for the application of continuum modeling for analysis of air-injection pressure transients and the tracer concentration data. 


\subsection{Steady-State Flow Analysis}

The first step in evaluating the applicability of the effective continuum assumption is to look at the spatial distribution and spatial correlation structure for DST permeability measurements. The zone lengths for the DST air-permeability measurements vary between 5 meters and 22 meters. The variances for these measurements can be compared with measurements made in the SHT area using intervals with a length of 0.69 meters and by Finsterle et al. [2001] in 0.3-meter interval tests.

Air-permeability values are calculated using the pressure difference between the preinjection pressure measurement, $P_{l}$, and the steady-state pressure response that is recorded, $P_{2}$. To calculate the permeability, $k$, an analytical steady-state elliptical flow field solution derived by Hvorslev [1951] was modified by LeCain [1995] to account for compressible gas effects:

$$
k=\frac{P_{s c} Q_{s c} \mu \ln \left(\frac{L}{r_{w}}\right)}{\pi L\left(P_{2}^{2}-P_{1}^{2}\right)}
$$

where

$P_{s c}=$ pressure at standard conditions, $1.013 \times 10^{5} \mathrm{~Pa}$

$Q_{s c}=$ flowrate at standard conditions, $\mathrm{m}^{3} \mathrm{~s}^{-1}$

$\mu=$ dynamic viscosity of air, $1.81 \times 10^{-5} \mathrm{~Pa}-\mathrm{s}\left(\right.$ at $20^{\circ} \mathrm{C}$ )

$L=$ length of the injection interval, $\mathrm{m}$

$r_{w}=$ radius of borehole, $\mathrm{m}$ 
Equation 3.1 assumes that gas compressibility follows the ideal gas law, where the density of gas, $\rho$, can be written as

$$
\rho=\frac{P}{R T}
$$

where $\mathrm{R}$ is the individual gas constant and $\mathrm{T}$ is temperature in degrees Kelvin. Other solutions for steady-state analysis of air-permeability tests, such as solutions presented by Kearl et al. [1990] and Rasmussen et al. [1990], yield similar results. Differences in the assumed flow geometry are responsible for small variations in estimated permeability values using the various analytical solutions. Since these solutions are all based on pseudo-radial type flow of an ideal compressible gas, they all exhibit the same dependence on $P^{2}$ and a logarithmic dependence on a spatial scale associated with the test geometry.

\subsubsection{DST Test Interpretation}

Air-permeability values were computed using Equation 3.1 from steady-state measurements performed in the 46 isolated DST intervals. The basic assumptions in Equation 3.1 are that the formation is homogeneous, isotropic, and infinite in extent. Table 3.1 shows the computed permeability values. The geometric mean of the computed permeability is $1.26 \times 10^{-13} \mathrm{~m}^{2}$, with the median value being $1.64 \times 10^{-13} \mathrm{~m}^{2}$. The standard deviation of the log permeability value was 0.59 . The minimum estimated permeability is $1.58 \times 10^{-15} \mathrm{~m}^{2}$ while the maximum value is $9.69 \times 10^{-13} \mathrm{~m}^{2}$. In 
Table 3.1. Permeability Values Calculated for Drift Scale Test Boreholes

\begin{tabular}{|c|c|c|c|c|}
\hline Zone ID & $L(m)$ & $\begin{array}{c}\mathbf{Q}_{\mathrm{sc}} \\
(\mathrm{SLPM})\end{array}$ & $\Delta \mathrm{P}(\mathrm{KPa})$ & $k\left(m^{2}\right)$ \\
\hline $57-1$ & 8.84 & 20 & 4.58 & $1.46 \mathrm{E}-13$ \\
\hline $57-2$ & 6.10 & 100 & 18.50 & $2.26 \mathrm{E}-13$ \\
\hline $57-3$ & 7.62 & 2 & 39.90 & $1.58 \mathrm{E}-15$ \\
\hline $57-4$ & 10.55 & 200 & 12.60 & $4.37 \mathrm{E}-13$ \\
\hline $58-1$ & 6.10 & 20 & 5.12 & $1.74 \mathrm{E}-13$ \\
\hline $58-2$ & 8.54 & 20 & 3.18 & $2.15 \mathrm{E}-13$ \\
\hline $58-3$ & 17.98 & 171 & 3.74 & $8.45 \mathrm{E}-13$ \\
\hline $59-1$ & 10.06 & 20 & 4.25 & $1.45 \mathrm{E}-13$ \\
\hline $59-2$ & 7.62 & 100 & 8.95 & $4.04 \mathrm{E}-13$ \\
\hline $59-3$ & 8.54 & 100 & 10.80 & $3.11 \mathrm{E}-13$ \\
\hline $59-4$ & 7.19 & 200 & 7.80 & $9.69 \mathrm{E}-13$ \\
\hline $60-1$ & 5.49 & 100 & 21.20 & $2.13 \mathrm{E}-13$ \\
\hline $60-2$ & 10.67 & 100 & 5.80 & $4.98 \mathrm{E}-13$ \\
\hline $60-3$ & 5.49 & 2 & 7.20 & $1.35 \mathrm{E}-14$ \\
\hline $60-4$ & 11.19 & 20 & 45.50 & $9.85 \mathrm{E}-15$ \\
\hline $61-1$ & 7.01 & 100 & 14.60 & $2.61 \mathrm{E}-13$ \\
\hline $61-2$ & 8.54 & 100 & 3.85 & $8.99 \mathrm{E}-13$ \\
\hline $61-3$ & 6.10 & 20 & 16.30 & $4.68 \mathrm{E}-14$ \\
\hline $61-4$ & 12.63 & 100 & 26.90 & $8.23 \mathrm{E}-14$ \\
\hline 74-1 & 10.37 & 100 & 10.60 & $2.65 \mathrm{E}-13$ \\
\hline 74-2 & 6.71 & 20 & 12.90 & $6.12 \mathrm{E}-14$ \\
\hline 74-3 & 4.27 & 20 & 8.04 & $1.44 \mathrm{E}-13$ \\
\hline 74-4 & 14.09 & 100 & 17.30 & $1.21 \mathrm{E}-13$ \\
\hline $75-1$ & 8.23 & 100 & 11.30 & $2.95 \mathrm{E}-13$ \\
\hline $75-2$ & 7.32 & 100 & 23.70 & $1.46 \mathrm{E}-13$ \\
\hline $75-3$ & 10.67 & 100 & 17.30 & $1.53 \mathrm{E}-13$ \\
\hline $75-4$ & 8.48 & 100 & 4.68 & $7.24 \mathrm{E}-13$ \\
\hline $76-1$ & 7.93 & 100 & 13.10 & $2.64 \mathrm{E}-13$ \\
\hline $76-2$ & 8.54 & 20 & 5.27 & $1.29 \mathrm{E}-13$ \\
\hline $76-3$ & 8.54 & 20 & 9.89 & $6.76 \mathrm{E}-14$ \\
\hline $76-4$ & 10.00 & 20 & 6.82 & $8.62 \mathrm{E}-14$ \\
\hline $77-1$ & 8.84 & 20 & 1.72 & $3.91 \mathrm{E}-13$ \\
\hline $77-2$ & 5.49 & 20 & 33.10 & $2.56 \mathrm{E}-14$ \\
\hline $77-3$ & 22.70 & 100 & 3.83 & $3.94 \mathrm{E}-13$ \\
\hline $78-1$ & 6.10 & 20 & 4.40 & $2.02 \mathrm{E}-13$ \\
\hline $78-2$ & 8.23 & 20 & 14.30 & 4.64E-14 \\
\hline $78-3$ & 5.79 & 20 & 16.00 & $5.49 \mathrm{E}-14$ \\
\hline $78-4$ & 14.49 & 20 & 4.00 & $1.09 \mathrm{E}-13$ \\
\hline $185-1$ & 5.79 & 20 & 2.73 & $3.46 \mathrm{E}-13$ \\
\hline $185-2$ & 8.54 & 100 & 15.60 & $2.07 \mathrm{E}-13$ \\
\hline $185-3$ & 15.24 & 100 & 20.90 & $9.26 \mathrm{E}-14$ \\
\hline $185-4$ & 6.65 & 20 & 4.18 & $2.01 \mathrm{E}-13$ \\
\hline $186-1$ & 5.79 & 20 & 2.47 & $3.80 \mathrm{E}-13$ \\
\hline $186-2$ & 8.54 & 20 & 22.10 & $2.71 \mathrm{E}-14$ \\
\hline $186-3$ & 13.11 & 20 & 51.90 & $7.34 \mathrm{E}-15$ \\
\hline $186-4$ & 5.09 & 2 & 11.40 & $8.68 \mathrm{E}-15$ \\
\hline
\end{tabular}


comparison, laboratory measurements made on 266 intact core samples were determined to have an average matrix permeability value of $1.5 \times 10^{-18} \mathrm{~m}^{2}$.

Raw and experimental variograms for the DST data, as shown in Figure 3.1, do not reveal any spatial dependence for log air-permeability values, based on the values established using the steady-state analysis applied in Section 3.1. Furthermore, the log-permeability values follow a normal distribution, with mean $\log (\mathrm{k})$ value of -12.9 and a variance of 0.35 (Figure 3.2).

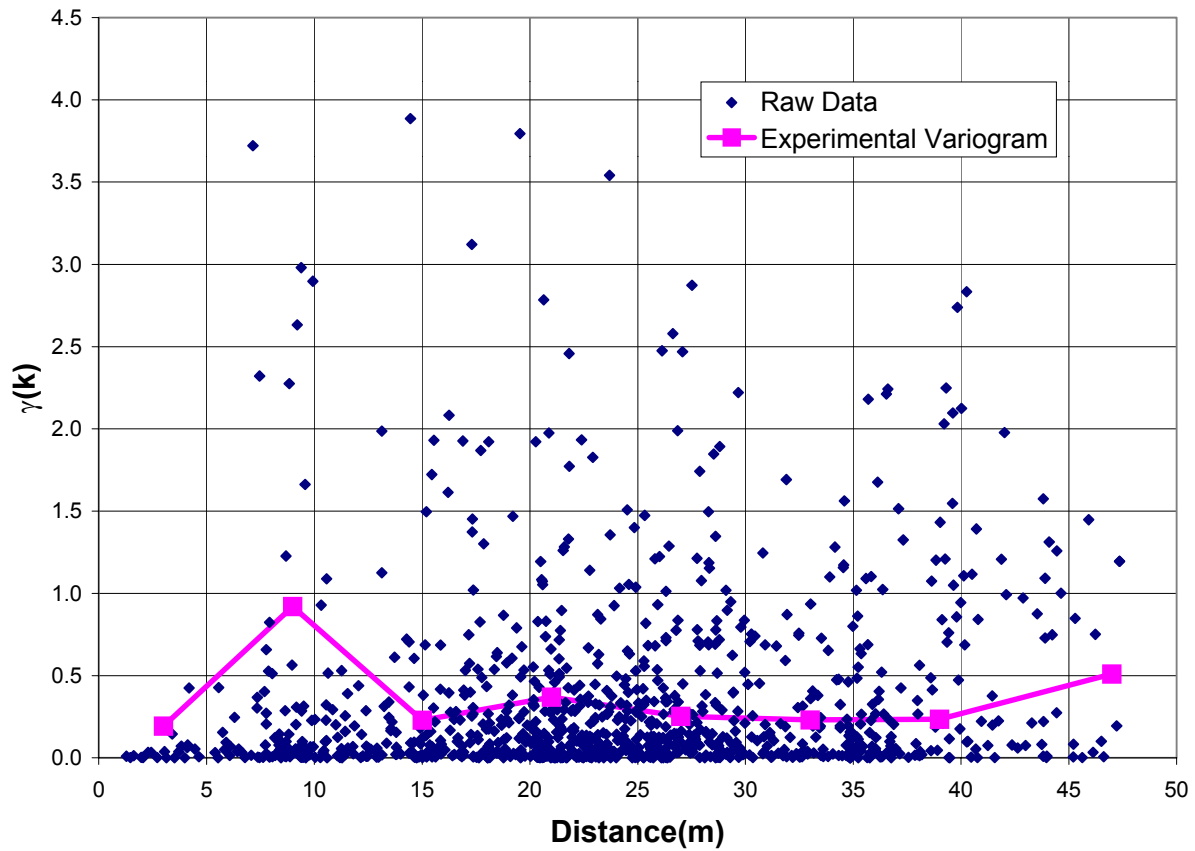

Figure 3.1 Experimental variogram with raw data for DST permeability data. 


\section{Permeability Log(k)}

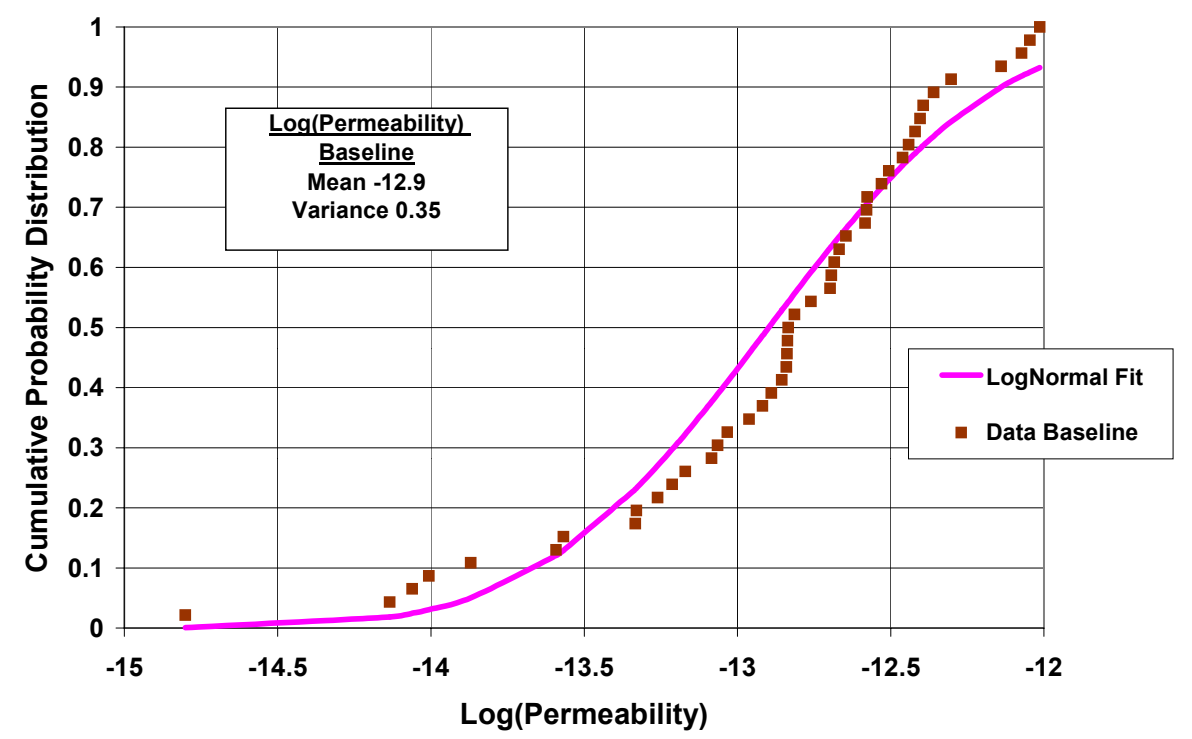

Figure 3.2 Permeability cumulative probability distribution with lognormal fit.

\subsubsection{SHT and Niche Permeability Data}

To facilitate an understanding of the scale-dependencies of air-permeability estimates in the Topopah Spring tuff, DST permeability estimates can be compared with permeability values obtained from 16 short intervals in the SHT area of Alcove \#5, in SHT Borehole 6. The location of the SHT is shown in Figure 2.1. (For more detailed information on the air-permeability measurements conducted in the SHT, see Tsang et al. [1999]). In addition, other researchers performed permeability measurements at the $0.3 \mathrm{~m}$ scale [Finsterle et al., 2001] during experiments called Niche studies, located in small addits drifted off the ESF main tunnel. For the measurements made at small spatial scales, there is an expectation that the measured permeability values will have a larger variance:

reflecting permeabilities that range from the low values on the order of $10^{-18} \mathrm{~m}^{2}$ 
associated with matrix permeability, up to values on the order of $10^{-12} \mathrm{~m}^{2}$ to $10^{-11} \mathrm{~m}^{2}$ that indicate highly brecchiated, intensely fractured zones. This wide variation in permeability values is because at smaller spatial scales, the assumption of a fracture continuum breaks down and the influence of discrete features becomes more important.

A steady-state test was used to determine the air permeability for the entire length of SHT Borehole 6. The 12-meter-long borehole was isolated by a single packer located at the collar of the boring. The resulting computed permeability value is $5.1 \times 10^{-14} \mathrm{~m}^{2}$. Table 3.2 shows permeability values measured using a $0.69 \mathrm{~m}$ long straddle packer injection interval, also in Borehole 6. Permeability values range from below field measurement detectability, $<5 \times 10^{-16} \mathrm{~m}^{2}$, to $6.3 \times 10^{-13} \mathrm{~m}^{2}$, with a mean permeability of $1.25 \times 10^{-14}$ $\mathrm{m}^{2}$. The variance for the 16 SHT log permeability measurements made in Borehole 6 is 0.92. The two intervals tested that exhibited permeabilities below the measuring limit of the equipment used, $5 \times 10^{-16} \mathrm{~m}^{2}$, were assigned that value for the calculation of the variance. For the niche studies conducted at a niche located at TS $31+07$ (280 meters beyond Alcove \#5 location of TS 28+27) the mean air-permeability for 780.3 meter scale measurements is $7.9 \times 10^{-13} \mathrm{~m}^{2}$, with a variance in $\log (\mathrm{k})$ of 0.64 . Table 3.3 shows the data sets available, listed with the mean $\log (\mathrm{k})$ values and variances.

Note that within the 7 meters closest to the collar of Borehole 6 , all permeability values are less than $2.0 \times 10^{-14} \mathrm{~m}^{2}$. Beyond the first 7 meters, all permeability values are above $3.0 \times 10^{-14} \mathrm{~m}^{2}$. While the DST data does not show any spatial correlation at the scale the 
measurements are made, clearly Borehole 6 reveals distinct spatial structure in the permeability field.

Table 3.2. Straddle Packer Air-Injection Tests in Single Heater Test, Borehole 6

\begin{tabular}{|c|c|c|c|}
\hline $\begin{array}{l}\text { Straddle Injection } \\
\text { Location (m) }\end{array}$ & Flowrate (SLPM) & $\mathbf{P}_{2}-\mathbf{P}_{1}(\mathrm{KPa})$ & Permeability $\left(\mathrm{m}^{2}\right)$ \\
\hline $.91-1.60$ & 1.03 & 47.0 & $4.0 \times 10^{-15}$ \\
\hline $1.60-2.29$ & 0.39 & 65.0 & $1.0 \times 10^{-15}$ \\
\hline $2.29-2.98$ & 0.62 & 57.2 & $1.9 \times 10^{-15}$ \\
\hline $2.98-3.67$ & 0.62 & 58.0 & $1.9 \times 10^{-15}$ \\
\hline $3.67-4.36$ & 0.62 & $*$ & $*\left(<5.0 \times 10^{-16}\right)$ \\
\hline $4.36-5.05$ & 2.04 & $*$ & $*\left(<5.0 \times 10^{-16}\right)$ \\
\hline $5.05-5.74$ & 2.01 & 58.0 & $6.1 \times 10^{-15}$ \\
\hline $5.74-6.43$ & 2.01 & 24.5 & $1.7 \times 10^{-14}$ \\
\hline $6.43-7.12$ & 2.01 & 28.0 & $1.4 \times 10^{-14}$ \\
\hline $7.12-7.81$ & 4.00 & 17.2 & $5.0 \times 10^{-14}$ \\
\hline $7.81-8.50$ & 4.02 & 8.0 & $1.1 \times 10^{-13}$ \\
\hline $8.50-9.19$ & 42.00 & 25.0 & $3.4 \times 10^{-13}$ \\
\hline $9.19-9.88$ & 2.00 & 6.2 & $7.3 \times 10^{-14}$ \\
\hline $9.88-10.57$ & 2.00 & 13.0 & $3.4 \times 10^{-14}$ \\
\hline $10.57-11.26$ & 2.03 & 14.0 & $3.1 \times 10^{-14}$ \\
\hline $11.26-12.00$ & 2.00 & 0.75 & $6.2 \times 10^{-13}$ \\
\hline
\end{tabular}

Table 3.3. Mean and Variance of Log-Air-Permeability Values for Topopah Spring Middle Nonlithophysal Tuff

\begin{tabular}{|l|l|l|l|l|}
\hline Location & $\begin{array}{l}\text { Zone Length } \\
(\mathrm{meters})\end{array}$ & Mean Log(k) & Sample Size & Variance \\
\hline DST & $5-22$ & -12.9 & 46 & 0.36 \\
\hline SHT Borehole 6 & 0.69 & -13.9 & 16 & 0.92 \\
\hline Niche 3107 & 0.3 & -12.1 & 78 & 0.64 \\
\hline
\end{tabular}




\subsection{Continuum Assumption}

The variance for the DST permeability estimates is significantly less than the variance for the estimates made on smaller spatial scales. Furthermore, all permeability values in the DST are three orders of magnitude or more greater than the matrix permeability, suggesting significant fracturing of all tested intervals. We can conclude that large fluctuations in permeability for the Topopah Spring tuff, attributable to the presence or absence of discrete features, occur on a smaller spatial scale than the scale of DST measurements. At the scale of the air-permeability measurements made at the DST, the fracture network takes on the behavior of a fracture continuum, enabling the application of continuum-based flow models, that assume a moderate degree of continuity of the fracture network within the region of measurement.

Geologically, the fracture network at the location of the DST consists of a well-developed orthogonal set of planar to slightly planar fractures [Buesch and Spengler, 1998]. Fracture spacing can be as infrequent as one every four meters, but is more typically three to five per meter, for fractures with a trace length greater than one meter. Within brecciated zones no well-established strike or dip directions are observed. These brecciated zones, coupled with the dense fracture network, serve to make the fracture network behave like a continuum at the scale that the air-permeability and tracer tests have been performed on. The tracer test data further supports the general geologic description, because the tracer breakthrough curves are smooth, with no indication of the multiple peak response that occurs when there are only a limited number of flow channels [Moreno and Tsang, 1991]. 
Assessing the veracity of a continuum model description of the Topopah Spring tuff on the scale of a few meters is not a trivial problem. The arguments in support of a continuum description have included the narrow range of permeability values indicative of fracturing in all DST intervals tested, as well as the geological observations on the extensiveness of fracturing and smoothness of tracer breakthrough data. Since there is no definitive litmus test that can applied to verify or disprove the applicability of a continuum description we rely on the observed evidence and must continuously assess acquired data and observations for instances in which the continuum assumption is inappropriate.

\subsection{Formation Anisotropy}

One question that arises in fractured systems is whether there is any anisotropy resulting from fracture orientation, and how the effects of anisotropy influence testing results. Because the hydrology boreholes in the DST are arranged in vertical fans, they are not amenable to a clear analysis of permeability anisotropy. This is caused by the close proximity of observation locations in vertical planes and the distant observation locations in horizontal to subhorizontal directions. The DST measurements are spatially biased, and no general conclusion regarding the applicability of anisotropic formation properties can be made, based on the air-permeability measurements. The lithology of the DST which contains brecciated zones of variable strike and dip directions and well developed sets of orthogonal closely spaced fractures, supports the neglect of anisotropy in analyzing the gas tracer and permeability test results. However, this is not a general 
conclusion, since there are some regions in the Topopah Spring tuff where one fracture orientation is better developed than the other sets, leading to a clearly anisotropic system [Buesch and Spengler, 1998]. 


\section{Transient Air-Permeability Data Analysis}

Air-permeability testing was undertaken at Yucca Mountain to establish the intrinsic permeability and porosity of the formation being characterized. The air-injection testing in the Topopah Spring tuff was specifically aimed at providing estimates for fracture properties. In the Topopah Spring tuff, the bulk of the gas permeability is located in large aperture fractures that have a negligible liquid saturation. In general, for fractured formations with low matrix permeability the parameter estimates determined using airinjection testing are reasonable estimates for fracture properties, assuming the matrix is at a high liquid saturation and the fractures are predominantly gas filled. The validity of these assumptions will be further investigated in this chapter.

Air-permeability tests in porous media, including fractured tuffs, were conducted by numerous other investigators at other sites. Baehr and Hult [1991] and Shan et al. [1992] developed analytic solutions for porous media steady-state air flow toward a well screen and above a water table or confining layer. Massman and Madden [1994] estimated air conductivity and porosity in a soil assuming an infinite homogeneous and isotropic formation. Their analysis used Theis and Hantush solutions modified for compressible gas flow. Edwards and Jones [1994] used a layered model to account for air-permeability responses measured in an oxidized fractured till. Their experiment, conducted in the shallowest few meters of soil, measured pressure responses in a series of wells containing nested piezometer tubes when one of the wells was subjected to gas extraction. 
Kearl et al. [1990] conducted air-permeability measurements in the Bandelier tuff, near Los Alamos, New Mexico, and Rasmussen et al. [1990] similarly looked at relatively unfractured tuffs at the Apache Leap Test Site near Superior, Arizona. The work of Kearl et al. [1990] compared a field-scale steady-state injection and vacuum-extraction testing methodology with laboratory data. Their results showed a higher estimate of intrinsic permeability for air injection, when compared with the vacuum and laboratory methods. The work by Rasmussen et al. [1990] showed that the permeability in air-dried core was higher than field measurements indicated, and attributed the difference to moisture in the tuff when it is in situ.

\subsection{General Approach}

In this study, the air-permeability test transients were analyzed to produce a fracture porosity estimate. The numerical flow and transport simulator TOUGH2 [Pruess et al., 1999] was used, along with the inversion and statistical analysis code iTOUGH2 [Finsterle, 1997a,b]. Prior to the analysis of DST data, an investigation into model uncertainties, including flow-field geometry and the influence of the partially saturated matrix, was conducted. Synthetic numerical modeling tests were used to evaluate the influence of flow-field geometry and fracture-matrix flow on estimated fracture porosity.

Since limited data exist to constrain the behavior of the matrix, subsequent analysis of collected DST data was conducted neglecting matrix effects. The result of this simplifying assumption is that the eventual porosity estimates are considered upper bounding estimates, since any matrix effect will tend to make the fracture porosity appear 
larger. In spite of the large amount of uncertainty, the ability to use air-injection test transients to estimate porosity is considered important. Whereas gas tracer tests will be later shown to generate reliable results, they are time consuming and expensive to conduct, and hence cannot be performed with the same frequency and across as many different spatial scales as air-injection testing.

\subsubsection{Numerical Simulations}

The synthetic simulations described here were performed using a 5-meter-thick radial symmetric grid using the heat and mass flow simulator TOUGH2. A double porosity model with interconnecting fractures and matrix gridblocks was created to represent the fractured tuff formation, following the development of Warren and Root [1963]. The integral finite difference formulation used by TOUGH2 simplifies modeling multiple fracture-matrix interfaces by allowing the specification of interface areas and the nodal distances between gridblocks that represent integrated volumes. By creating a model that represents a fracture-matrix continuum, computational efficiency is achieved, and it is unnecessary to explicitly define each actual matrix block. The matrix is realized by eight "layers" of matrix blocks using the method of multiple interacting continua (MINC) [Pruess and Narasimhan, 1982, 1985]. Fracture spacing is specified, and the relative interfacial areas and nodal distances are automatically computed by the TOUGH2 gridding algorithm.

Figure 4.1 shows a conceptual representation for the radially symmetric model. A simple way of thinking of the matrix is as a series of nested blocks. The interface areas between 
the matrix and fractures are calculated assuming three orthogonal fracture sets with a uniform fracture spacing of 0.30 meters. The outermost matrix block, which has the largest surface area, also has the smallest volume. Matrix gridblocks located closer to the center of the nested matrix elements have larger volumes with smaller surface areas. Table 4.1 shows the relative volume and surface area chosen for the simulation. The reason for using a sequence of matrix gridblocks which have a small volume near the surface and larger volume near the center of a "nested matrix block" is to more accurately model the larger pressure gradients which occur at the fracture-matrix interface. The computation of gas flow between fracture and matrix gridblocks is accomplished by applying the flow equation using the harmonic average of the fracture and matrix permeability.

Table 4.1. Geometry of Fracture-Matrix Gridblocks Used for Air-K Simulations

\begin{tabular}{|l|l|l|}
\hline Matrix Block Location & $\begin{array}{l}\text { Relative } \\
\text { Volume }\end{array}$ & $\begin{array}{l}\text { Relative Outer } \\
\text { Surface Area }\end{array}$ \\
\hline 1 (outermost element) & 0.00021 & 1.0000 \\
\hline 2 & 0.0021 & 0.9999 \\
\hline 3 & 0.021 & 0.9993 \\
\hline 4 & 0.21 & 0.9925 \\
\hline 5 & 0.42 & 0.9238 \\
\hline 6 & 0.42 & 0.9043 \\
\hline 7 (innermost element) & 1.0 & 0.6161 \\
\hline
\end{tabular}


The numerical model has 50 radial gridblocks representing fractures. Connected to the fracture gridblocks are $350(50 \times 7)$ matrix gridblocks. Wellbore storage is included in

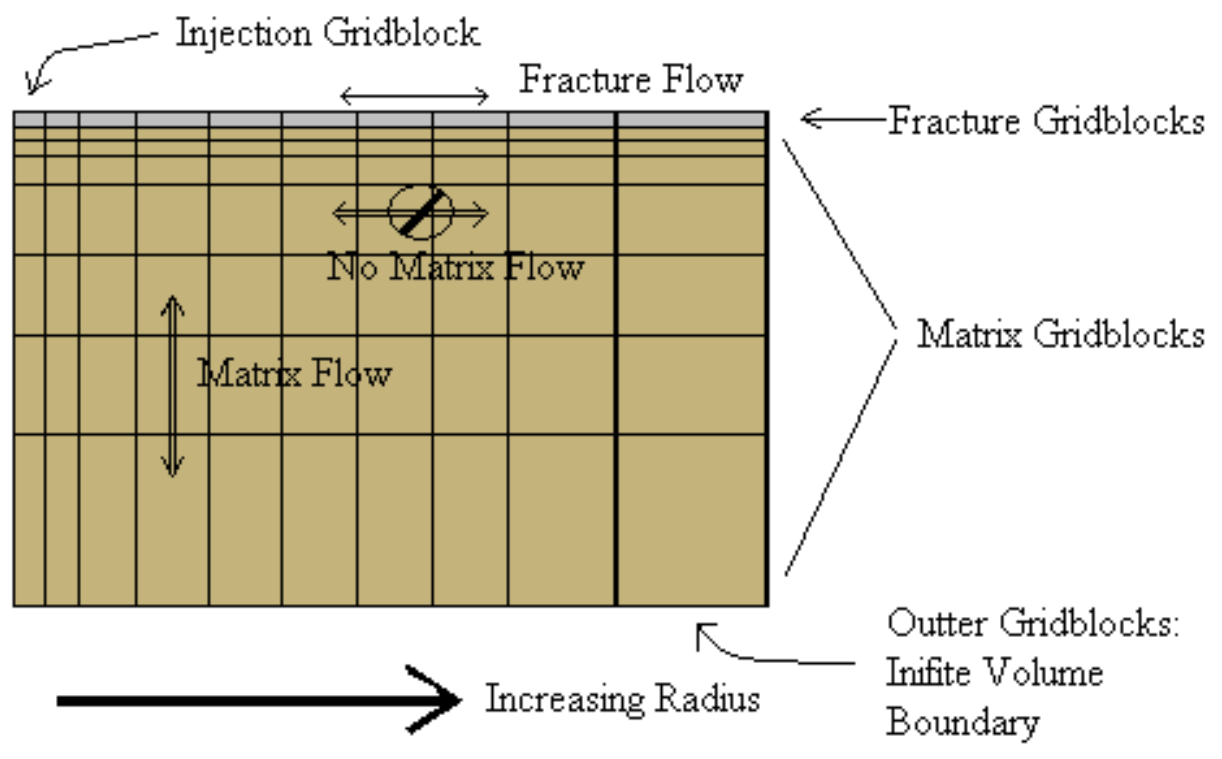

Figure 4.1 Conceptual schematic of double porosity model used for air-permeability simulation.

the model by setting the innermost fracture gridblock volume equal to the actual borehole volume. The outermost gridblock is located at a distance of 100 meters from the injection borehole, with gridblock size increasing logarithmically from inner to outer radius.

Flow can occur between fracture gridblocks and between a fracture gridblock and the matrix gridblock adjacent to it. Within the matrix, flow occurs within the 7 interconnected gridblocks, from outer layer to inner layer. However, the model does not allow for any flow between nested sets of matrix gridblocks, which would correspond to flow between outer layers of two adjacent gridblocks. This formulation implies that the 
significant transport pathways are through fractures and neglects matrix block to matrix block flow. TOUGH2 allows any gridblock to be set as inactive, which will make that gridblock a constant boundary condition for all time (based upon the initial parameters it was assigned). This permits simulations with a variable distance from the injection borehole to the outer constant head boundary without regridding the mesh, simply by setting a gridblock at a specified distance as inactive.

\subsubsection{Parameter Estimation}

The numerical inversion simulator iTOUGH2 is used to estimate fracture porosity and fracture permeability by matching simulation pressure response to either measured or synthetic pressure recovery transient curves. iTOUGH2 estimates elements of a parameter vector, $\mathbf{p}$, based on observations sumarized in vector $\mathbf{z}^{*}$, by minimizing an objective function $\mathrm{S}$, which is a function of the residual vector $\mathbf{r}$. For example, in the inversions presented herein, the elements of $\mathbf{p}$ are the fracture porosity and fracture permeability. Vector $\mathbf{z}$ contains the pressure at discrete points in time, where the measured quantities are indicated by the asterisk, $\mathbf{z}^{*}$, and simulated results are represented by $\mathbf{z}$. The residual vector $\mathbf{r}$ contains the differences between the measured and calculated system response; the latter is a function of parameter vector $\mathbf{p}$. The objective function, $\mathrm{S}$, is a weighted least squares measure of the misfit between the data and the model calculation. Minimization of the objective function, $\mathrm{S}$, is based on local linearization of the model output by calculating partial derivatives of the system response with respect to the parameters. The Levenberg-Marquardt modification of the GaussNewton algorithm is used to iteratively update the parameter vector. Details of the 
inverse modeling theory, as implemented in iTOUGH2, objective functions, minimization algorithms, residual and error analysis, and extensive references are given by Finsterle [1997b].

\subsection{Flow Model Uncertainty}

There are several uncertainties relating to gas flow in Topopah Spring tuff that potentially can have a significant effect on the estimates of transport parameters. Perhaps the most significant uncertainty relates to the geometry of the gas flow paths, which can greatly impact the porosity estimates. To address flow geometry uncertainties the testing radius of influence determined by the location of a constant pressure head outer boundary is investigated. In addition, a calculation of the matrix relative gas permeability and the Klinkenberg flow parameter based on capillary pressure theory is performed to facilitate a review of the potential impacts the matrix can have on parameter estimates. Because there is not sufficient data to fully eliminate these uncertainties, they will persist and reduce the confidence in the parameter estimates that result from analyzing the airinjection test data.

\subsubsection{Radius of Influence}

An outer constant-head boundary condition was considered a "fictitious radius of action" by de Marsily [1986] to solve the problem of "the well on an island." While de Marsily calls "the well on an island" groundwater flow solution, often referred to as Dupuit's or Thiem's formula "quite far from reality," in heterogeneous formations the fictitious radius of action can partially be attributed to the fact that at larger spatial scales, there is a 
greater likelihood of encountering higher permeability features. In a highly fractured rock formation, where fractures occur on many hierarchical scales, very large faults and fractures, although sparse compared to the more numerous smaller fractures, form constant-pressure boundaries.

In this study the outer boundary radius is considered the distance at which the overall formation gas diffusivity is sufficiently great to transport the injected air such that the measured pressure response is less than $1 \%$ of the steady-state pressure buildup in the injection zone. To keep the air-injection test zone within a pre-designated pressure range, zones with high local permeability are tested with a greater flow rate than zones with low local permeability. As a result, the outer-boundary would have a smaller radius for test intervals with a low local permeability and a greater radius for a test interval with a higher local permeability. This is because a low-permeability zone, tested with a small injection flow rate, will (statistically, based on the lack of spatial correlation in the permeability field) be located a short distance to a region of diffusivity sufficient to act as a constant-pressure outer-boundary. In contrast, a high-permeability zone will be further from a region of sufficient diffusivity to act as a constant-pressure outer-boundary for the larger injection flow rate. The dependency of the zone of influence on local permeability is counterintuitive since for a homogeneous medium both the low and high permeability formation would have the same zone of influence if the flow rate is scaled to the permeability. 
To quantify the effects of a variable distance to an outer constant pressure boundary, forward simulations were carried out using TOUGH2 with three different radii to the boundary: 2.0 meters, 10.8 meters, and 93.0 meters. To generate synthetic data the formation was assumed homogeneous with a porosity of 0.005 , and a permeability of $2.32 \times 10^{-13} \mathrm{~m}^{2}$. For all three simulations, inversions were then performed using iTOUGH2 to determine a best-fit permeability and porosity with the distance to the outer-boundary radius varied from 2.0 meters to 93.0 meters (Figure 4.2).

As expected, Figure 4.2 shows that the inversion correctly estimates the forward simulation permeability and porosity used to generate the synthetic data at the correct radii to the outer boundary. Figure 4.2 also shows that there is only a weak coupling between the estimated permeability and the assumed radius. However, the porosity is significantly overestimated when the assumed radius is too small, and underestimated when the assumed radius is too large. An example synthetic case air-transient with the radius to the outer-boundary assumed to be 10.8 meters is shown in Figure 4.3. To illustrate the potential for misestimating the porosity based on the application of an incorrect flow model, an inversion of the forward model assuming 52 meter radius to the outer-boundary is plotted along with the synthetic case. The resulting porosity estimate of 0.0004 is an order of magnitude less than the 0.005 porosity assumed for the synthetic case, yet the model fit is observed to be very good. Figure 4.3 illustrates the importance of using the correct flow model to properly estimate porosity. 

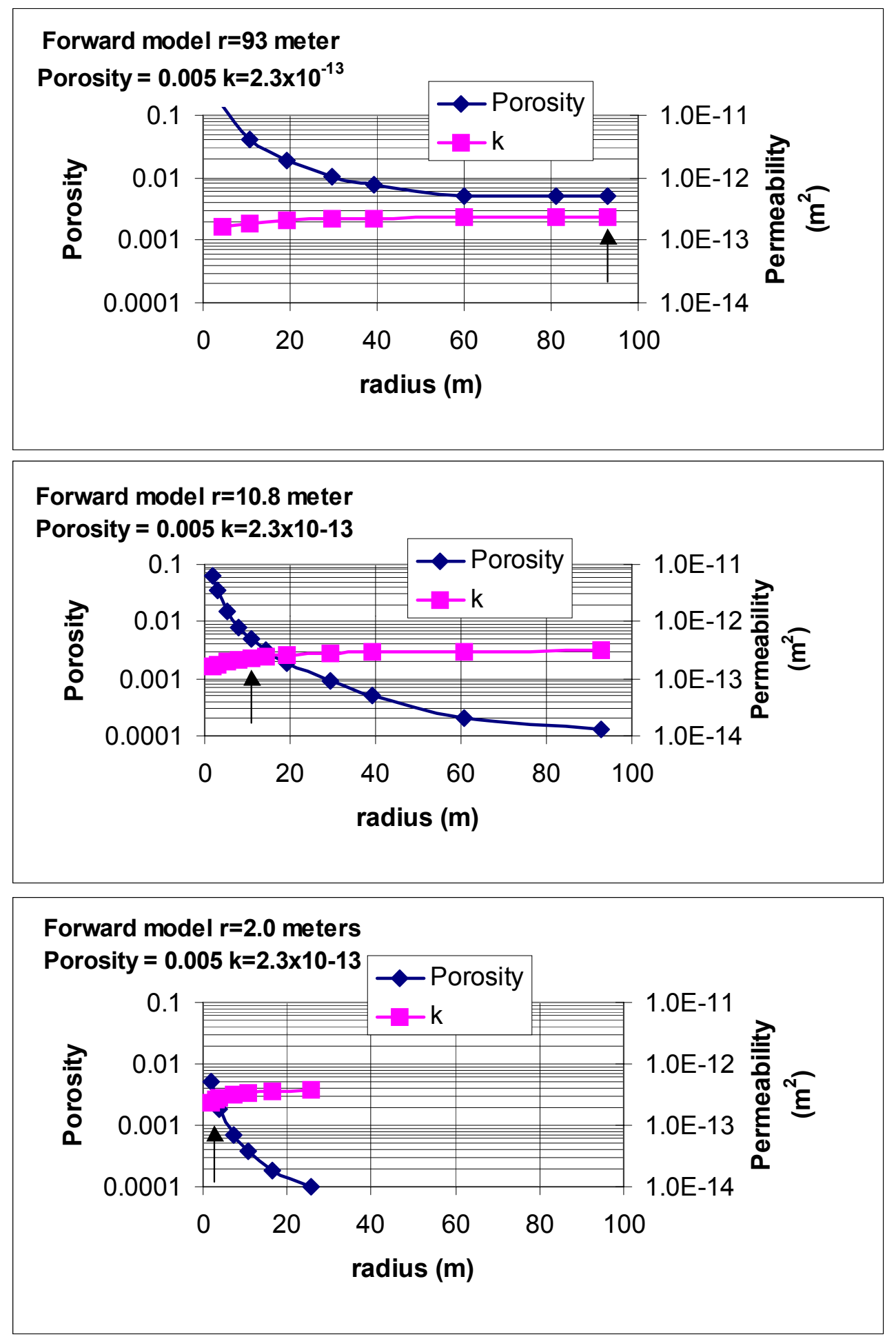

Figure 4.2 Numerical inversions as a function of a variable distance to a constant pressure radial boundary using porosity and permeability as fitting parameters. The arrow points to the simulation used to generate synthetic data. 


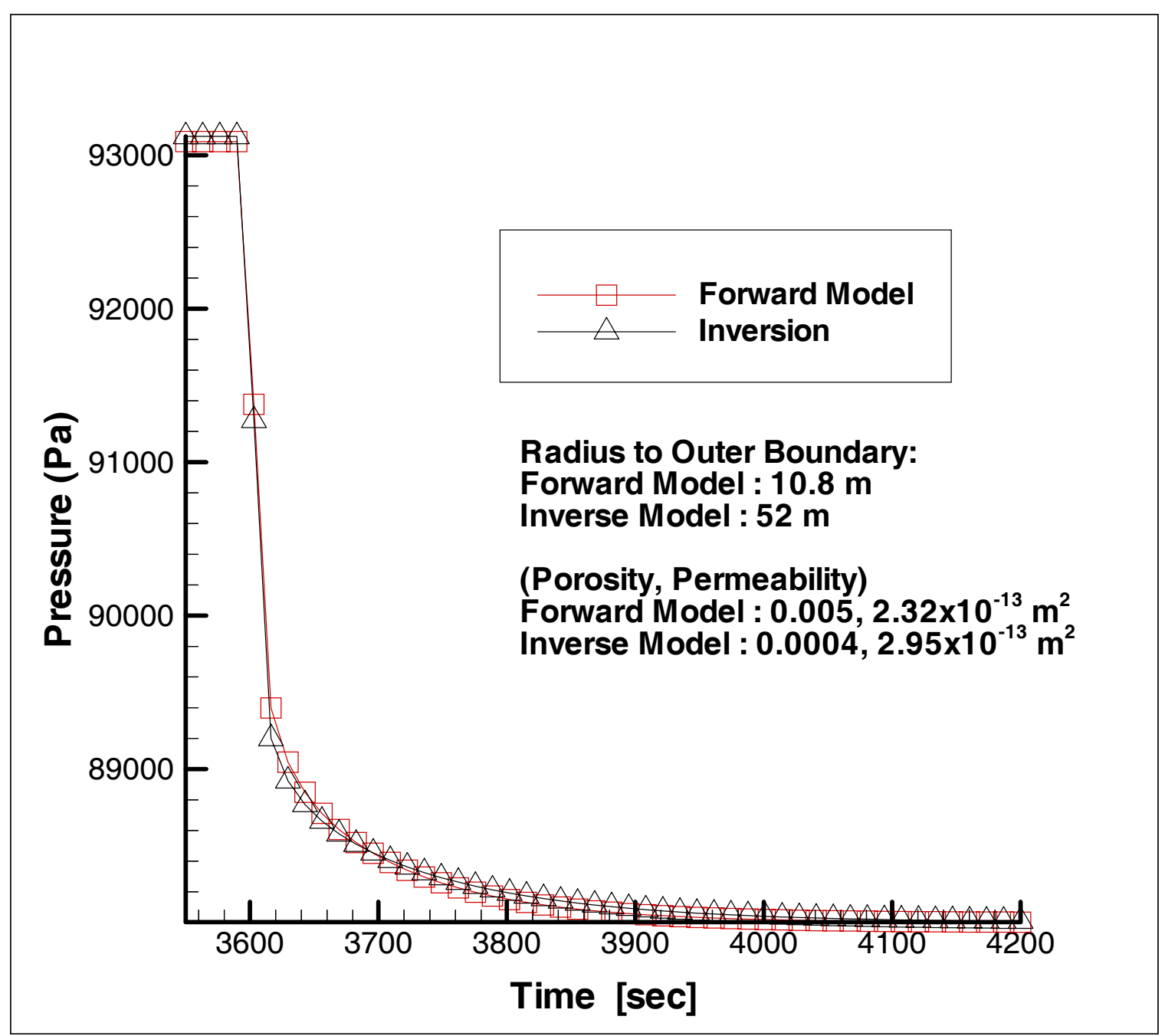

Figure 4.3 Simulated air-injection pressure recovery data showing the influence the assumed outer boundary radius has on the estimates for porosity and permeability.

For air-injection tests, inspection of crosshole pressure response data, collected at varying distances from the injection interval, was used to determine a radius to set as the assumed constant pressure head boundary. Since each air injection was monitored in 45 observation locations of varying radii from the injection borehole, a reasonable 
understanding of the geometry of the flow paths and spatial scale of the air injection zone of influence can be made. As an example, maximum pressure responses to an airinjection test in Borehole 58-3 are listed in Table 4.2. The measurements show that the zones between 15 meters and 18 meters fail to provide a detectable crosshole pressure response ( $1 \%$ of injection pressure), but a measurable response is detected in 59-4, 16 meters from the injection zone. Based on the observations in Borehole 59-4, 61-4 and 603 , an outer-boundary radius of 16 meters is chosen with an uncertainty of \pm 2 meters. It should be noted that there are more zones at greater distances from the injection zone that fail to provide crosshole response; they have been omitted from Table 4.2.

Table 4.2. Steady-state Pressure Responses as a Function of Distance to an Air-Injection in Borehole 58-3

\begin{tabular}{|l|l|l|l|}
\hline $\begin{array}{l}\text { Location } \\
\text { (Borehole-Zone) }\end{array}$ & $\begin{array}{l}\text { Distance from } \\
\text { Injection } \\
(\mathbf{m})\end{array}$ & $\begin{array}{l}\text { Max } \Delta \mathbf{P} \\
(\mathbf{K P a})\end{array}$ & $\begin{array}{l}\text { Response } \\
\left(>\mathbf{1 \%} \mathbf{P}_{\text {inj }}\right)\end{array}$ \\
\hline $58-3$ (Injection) & 0.0 & 3.70 & \\
\hline $57-3$ & 4 & 0.38 & Yes \\
\hline $57-2$ & 4 & 0.07 & Yes \\
\hline $59-2$ & 6 & 0.04 & Yes \\
\hline $58-2$ & 8 & 0.07 & Yes \\
\hline $57-4$ & 9 & 1.29 & Yes \\
\hline $59-3$ & 12 & 0.93 & Yes \\
\hline $60-3$ & 15 & 0.0 & No \\
\hline $59-4$ & 16 & 1.22 & Yes \\
\hline $61-4$ & 18 & 0.02 & No \\
\hline $60-4$ & 21 & 0.0 & No \\
\hline
\end{tabular}

\subsubsection{Pore Size Distribution Index Estimation of Gas Relative Permeability}

Matrix gas permeability influences the air-injection pressure transients and neglecting it would result in an overestimate of the fracture porosity. The matrix relative gas 
permeability is estimated herein and this estimate is used in the next section to investigate model sensitivity towards matrix gas permeability. However, it is important to note that the matrix relative gas permeability is not the only factor influencing fracture-matrix flow. Many of the fractures in the Topopah Spring tuff are coated with various forms of silica (quartz, cristobalite, and amorphous silica) [Sonnenthal et al., 1998], which tend to reduce the fracture-to-matrix permeability when they are deposited on the fracture surfaces. No available measurements suggest the degree to which mineral coatings reduce fracture-matrix flow, so the estimated matrix gas relative permeability should be interpreted as a conservative estimate for predicting fracture-matrix flow interaction.

The Topopah Spring middle nonlithophysal tuff was determined in the laboratory to have an intrinsic permeability of $1.5 \times 10^{-18} \mathrm{~m}^{2}$ [Flint, 1996]. Because the matrix in situ liquid saturation is 0.88 , the effective gas permeability is expected to be considerably less than the intrinsic permeability. No measured relative permeability information exists for this unit. Fredlund et al. [1994] showed that a technique to predict relative gas permeability based on capillary pressure/saturation data can provide useable relative permeability estimates for soils. More recently, Dana and Skoczylas [1999] used the equations of Brooks and Corey to correlate rock pore structure, determined through mercury porosimetry and sorption techniques, with values of gas relative permeability for sandstones.

The capillary pressure-saturation model developed by van Genuchten, [1980] along with a Brooks and Corey relative permeability model are applied to data collected in the 
Topopah Spring tuff to produce an estimate for gas phase relative permeability. The van Genuchten model for describing the capillary-pressure saturation behavior, as opposed to the Brooks and Corey capillary pressure-saturation model, is being used because it better represents the capillary pressure as the formation approaches full saturation and the capillary pressure approaches zero.

Van Genuchten's [1980] model for gas relative permeability $\left(1-k_{r l}\right)$ is reasonable for describing the fracture system behavior, where large fractures would quickly develop a continuous gas phase while the bulk of the fractures stay fully saturated. In contrast, the Brooks and Corey [1964] model is more realistic in representing the expected gradual increase in relative gas permeability as saturation decreases, owing to the relatively uniform size of matrix pores, and hence the Brooks and Corey model as used by Dana and Skoczylas [1999] is used herein.

Following Van Genuchten [1980], the capillary pressure can be represented as a function of the van Genuchten Parameters $P_{a e}$ and $m$ :

$$
P_{c}=-P_{a e}\left(S_{e f f}^{-1 / m}-1\right)^{1-m}
$$

The effective saturation, $S_{e f f}$, is a function of the liquid saturation $S_{l}$ and the residual liquid saturation $S_{l r}$ :

$$
S_{e f f}=\frac{S_{l}-S_{l r}}{1-S_{l r}}
$$

The water retention curve was determined for the Topopah Spring tuff using data acquired from a location approximately 400 meters from the DST [Flint, 1997], in the 
same lithostratigraphic unit. The van Genuchten parameters $m$ and $P_{a e}$ were determined to be 0.75 and $3.57 \times 10^{6} \mathrm{~Pa}$ respectively (Figure 4.4 ). The relative liquid permeability function can be written as

$$
k_{r l}=\sqrt{S_{e f f}}\left\{1-\left(1-S_{e f f}^{1 / m}\right)^{m}\right\}^{2}
$$

The relative gas permeability as a function of the Brooks and Corey pore size distribution parameter $\lambda$ is expressed as:

$$
k_{r g}=\left(1-S_{e f f}\right)^{2}\left(1-S_{e f f}^{(2+\lambda) / \lambda}\right)
$$

Morel-Seytoux et al. [1996] have shown that the Brooks and Corey pore size distribution index $\lambda$ can be related to the van Genucten parameter $m$ by the relation

$$
\lambda=1+\left(\frac{2}{m}\right)
$$

The relative liquid and gas permeabilities, calculated using Equation 4.4 and Equation 4.5 respectively, are shown in Figure 4.5. The relative gas permeability for Topopah Spring tuff based on the Brooks and Corey model at the average saturation of $0.88\left(\mathrm{~S}_{\mathrm{eff}}=0.85\right.$ and $\left.\mathrm{S}_{\mathrm{lr}}=0.2\right)$ and $\lambda=3.7$ is 0.006 . The effective gas phase permeability based on the Brooks and Corey model is therefore $\sim 1 \times 10^{-20} \mathrm{~m}^{2}$. Thus, while the simulations in the next section investigate the effects of matrix gas permeability over a wide range of values, a reasonable estimate for the matrix gas permeability, considering the existence of permeability-reducing fracture coatings, should be a value less than $10^{-20} \mathrm{~m}^{2}$. 


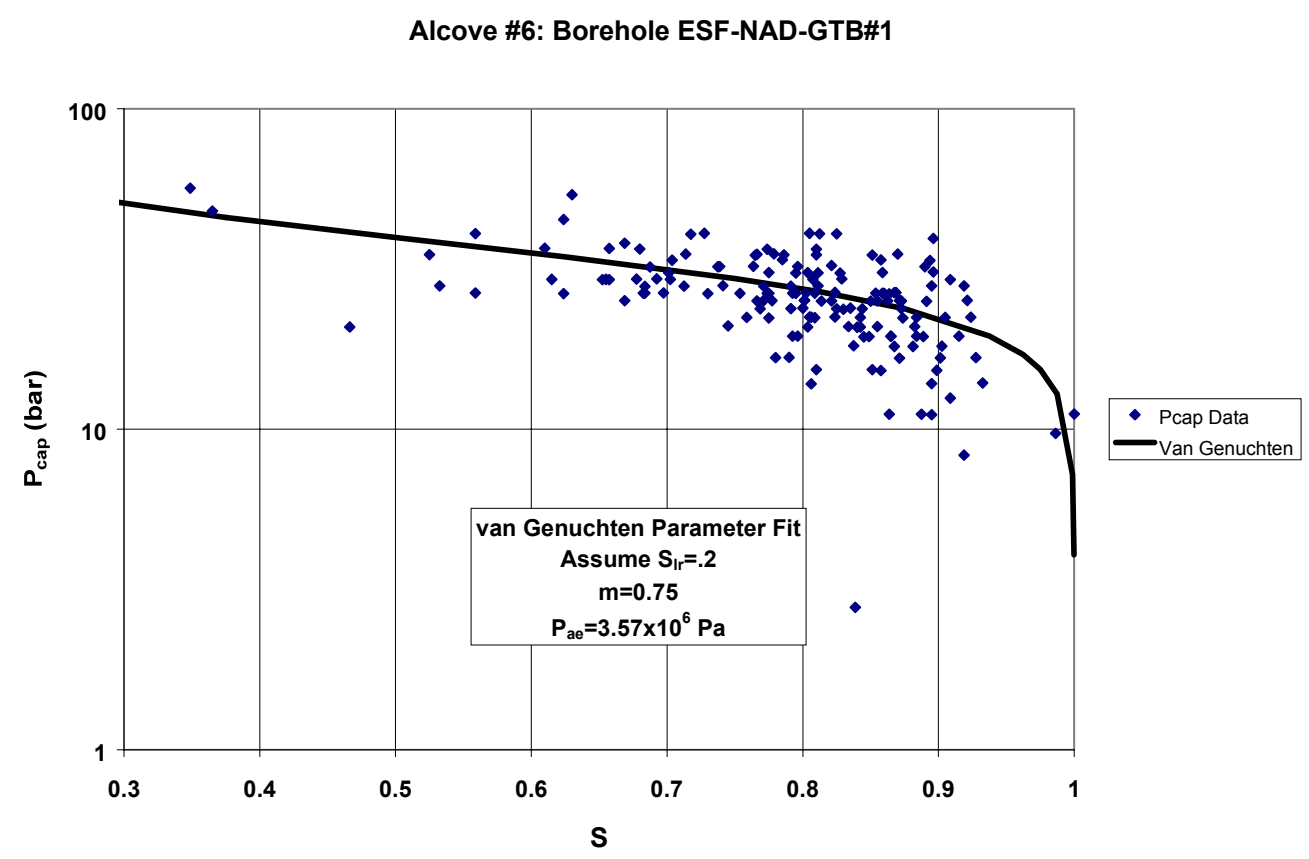

Figure 4.4 Moisture retention curve for Topopah Spring tuff. Data was acquired from a borehole located approximately 400 meters from the DST in the same lithostratigraphic unit.

Relative Permeability for Topopah Spring tuff

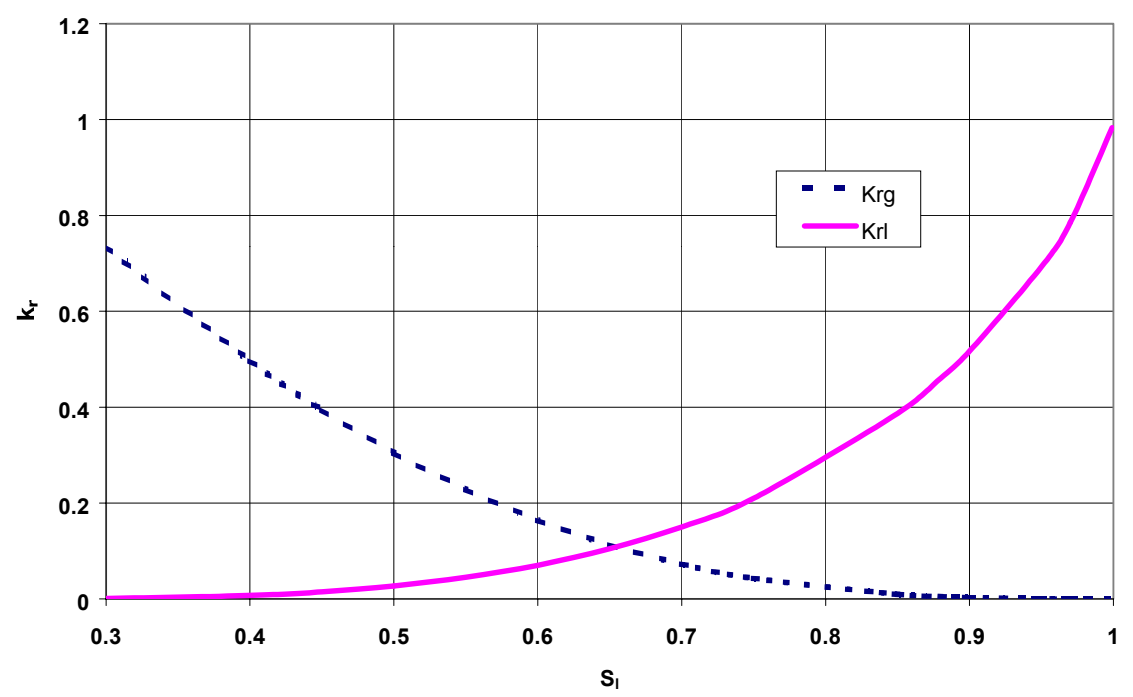

Figure 4.5 Relative permeability curves for Topopah Spring tuff based on moisture retention curve data and pore distribution theory. 


\subsubsection{Matrix Porosity and Permeability}

To quantify the effect of uncertainty in matrix gas relative permeability, forward simulations were conducted with an effective matrix gas permeability ranging from $10^{-20}$ $\mathrm{m}^{2}$ to $10^{-22} \mathrm{~m}^{2}$ and fracture porosity in the range from 0.001 and 0.011 . The forward model synthetic data was then inverted using an iTOUGH2 model that does not incorporate matrix permeability. The difference in the porosity estimate between the inversion solution and the forward simulation is the error introduced by the incorrect model, which neglects the matrix. Figure 4.6 shows the relationship between the forward model and the inversion porosity estimate as a function of matrix permeability when the outer boundary radius is held constant at 50 meters. Figure 4.7 shows the result of the same simulations if the outer boundary is set at 10 meters.

The omission of matrix porosity introduces a systematic error that is essentially independent of fracture porosity. The error decreases as the distance to an outer boundary is reduced, since the shorter the distance to the outer boundary, the less opportunity the injected gas has to flow from the fracture system into the matrix. In the simulation with the 50 meter radius, the average error in the porosity estimate decreases from 0.01 to 0.0006 , as the matrix permeability decreases from $10^{-20}$ to $10^{-22} \mathrm{~m}^{2}$. For the simulation with the boundary at 10 meters the average error in the porosity estimate decreases from 0.002 to 0.0002 as the matrix permeability decreases from $10^{-20}$ to $10^{-22} \mathrm{~m}^{2}$. Hence, the 


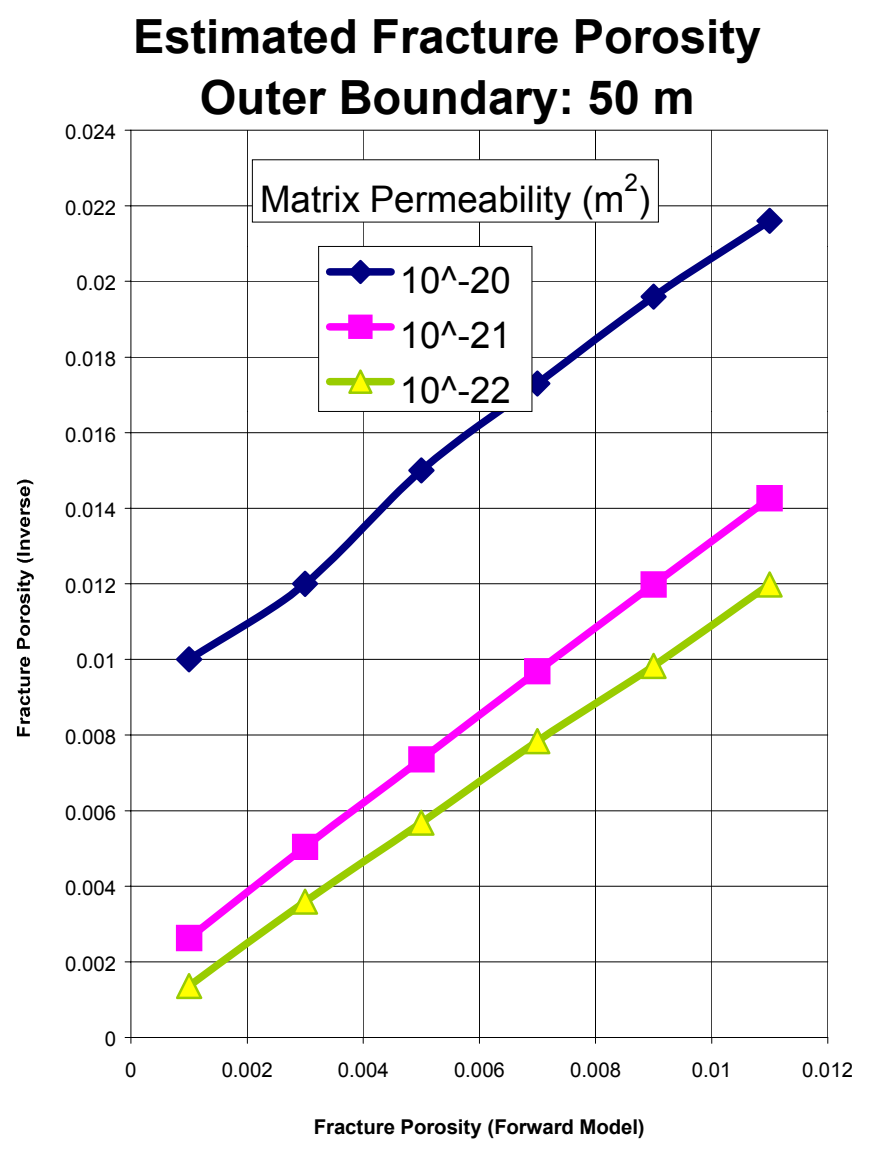

Figure 4.6 Fracture porosity estimates using a fracture only model (no matrix permeability). Synthetic data was generated using a model with finite matrix permeability $\left(10^{-22} \mathrm{~m}^{2}\right.$ to $\left.10^{-20} \mathrm{~m}^{2}\right)$ and the outer boundary set to 50 meters.

larger the flow domain, the greater the impact of the matrix porosity on the transient flow and the porosity estimate.

To assess the influence of matrix permeability on the air-injection pressure recovery transients, three cases were modeled with a variable fracture porosity. The time- 


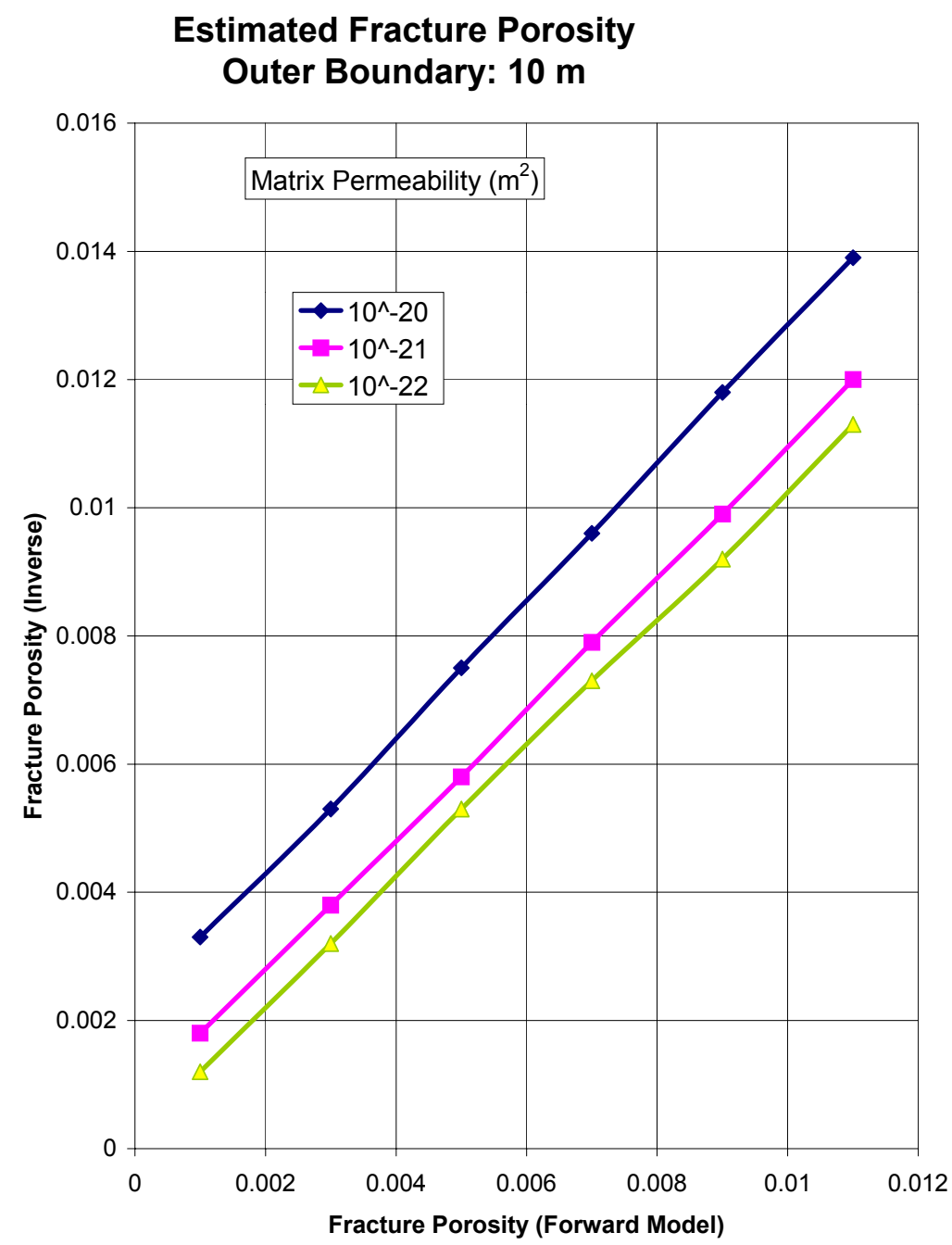

Figure 4.7 Fracture porosity estimates using a fracture only model (no matrix permeability). Synthetic data was generated using a model with finite matrix permeability $\left(10^{-22} \mathrm{~m}^{2}\right.$ to $\left.10^{-20} \mathrm{~m}^{2}\right)$ and the outer boundary set to 10 meters.

dependent pressure responses are plotted in Figures 4.8-4.10. In the first and second case the matrix permeability is set at $10^{-19} \mathrm{~m}^{2}$ and $10^{-20} \mathrm{~m}^{2}$, respectively, and the fracture porosity varies between 0.001 and 0.010 (Figure 4.8 and Figure 4.9). In the third case 
(Figure 4.10) the variation in fracture porosity is the same, but the matrix permeability is set to a very low value of $10^{-24} \mathrm{~m}^{2}$, i.e. essentially zero. The plots show that the greater the matrix permeability, the less sensitive the model results are to the variations in the fracture porosity. Consequently, it is apparent that estimates of fracture porosity based on field measurements are subject to increasing error as a function of increasing matrix gas permeability.

\subsubsection{Klinkenberg Flow}

Klinkenberg theory [Klinkenberg, 1941] predicts that a gas will have a higher permeability than a liquid through small pores based on "slip" conditions at the solid/gas boundary during flow. The resulting expression for gas permeability as a function of the liquid permeability is given as

$$
k_{g}=k_{l}(1+b / p)=k_{l}\left(1+4 C \lambda_{f p} / d\right)
$$

where $b$ is the Klinkenberg slip flow coefficient $(\mathrm{Pa}), p$ is the mean gas pressure, $C$ is a proportionality factor, usually taken as $1, \lambda_{c p}$ is the gas mean free path length, and $d$ is the average pore diameter. The average pore size for the Topopah Spring tuff matrix can be derived from the moisture retention curve data (Figure 4.4) using the capillary pressure equation

$$
d=\frac{2 \sigma_{w a}}{P_{c}}
$$

where $\sigma_{w a}$ is the water-air interfacial surface tension. The moisture retention curve is very flat between 20 to 30 bars, indicating an average pore size of approximately $50 \mathrm{~nm}$. Taking the mean free path for air at STP as roughly $5 \times 10^{-8} \mathrm{~m}$, Klinkenberg theory 
predicts an enhancement of gas permeability by a factor of eight. This enhancement will occur in the matrix and not in the fractures, since the fracture apertures are much larger than the matrix pore diameters.

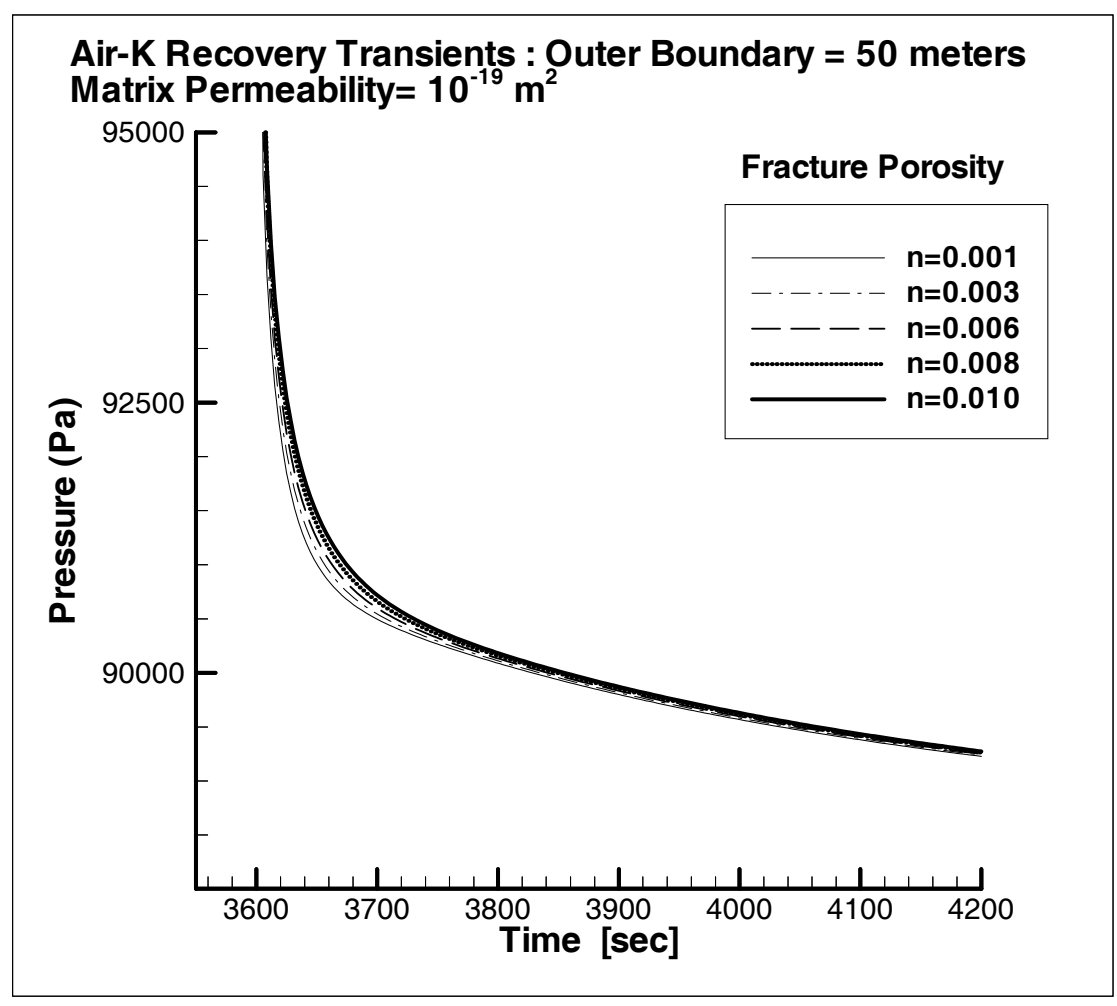

Figure 4.8 Modeled air pressure recovery transients showing the influence of fracture porosity with a fixed matrix permeability of $10^{-19} \mathrm{~m}^{2}$. 


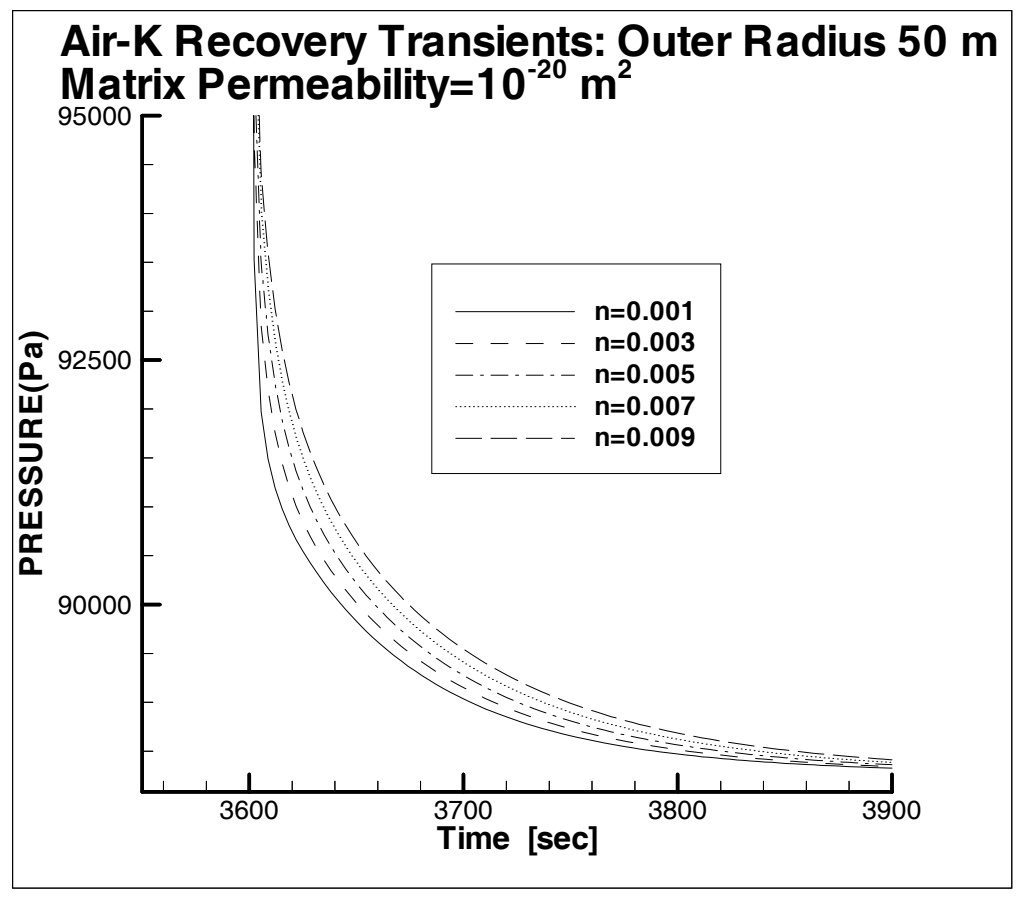

Figure 4.9 Modeled air pressure recovery transients showing the influence of fracture porosity with a fixed matrix permeability of $10^{-20} \mathrm{~m}^{2}$.

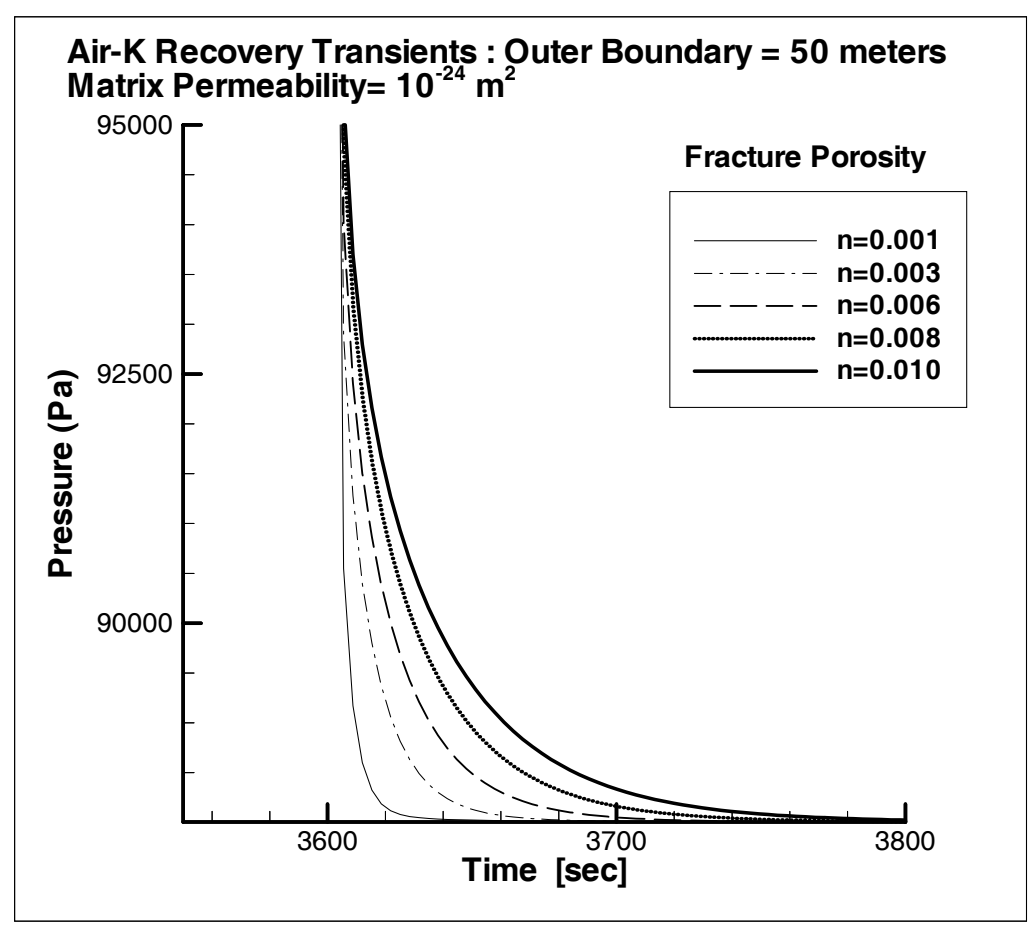

Figure 4.10 Modeled air pressure recovery transients showing the influence of fracture porosity with a fixed matrix permeability of $10^{-24} \mathrm{~m}^{2}$ (essentially no matrix). 


\subsubsection{Flow Model Uncertainty}

In summary, the estimate of fracture porosity derived through the application of a flow model analysis of air-injection data is subject to numerous uncertainties. Uncertainty in the radius of influence can be reduced by looking at the interference test data that is collected. The magnitudes of the interference responses at observation boreholes can provide a useable estimate for the distance to a constant-head outer boundary. Nevertheless, instances of dissimilar crosshole responses at equidistant observation locations highlight the heterogeneous nature of fracture flow and point to the limitations in applying homogeneous models.

The influence of gas flow in the matrix and Klinkenberg slip flow are more problematic to take into account and will create significant uncertainty in the fracture porosity estimate. Moderate matrix permeability and Klinkenberg slip flow in the matrix will both erroneously increase the fracture porosity estimate. On the other hand, mineral coatings on fracture surfaces may serve to reduce the influence of the matrix by limiting permeability into the matrix blocks. Finally, the exact fracture-matrix interaction surface area is unknown and would be difficult to constrain, based on the variability in the fracturing throughout the formation. These limitations point to gaps in available data and can serve as a guide for subsequent studies to reduce the uncertainty in estimates of fracture porosity performed using air-injection testing analysis. 


\subsection{Fracture Porosity Estimates from Air-Permeability Tests}

Two air-permeability tests, Borehole 58-3 and Borehole 74-2, were selected for initial analysis of fracture porosity. They respectively represent locations that exhibit the higher and lower permeability bounds for Topopah Spring tuff as determined through the steady-state air-permeability analysis (Section 3.1). Figures 4.11 and 4.12 show the full pressure transients acquired for the Borehole 58-3 and 74-2 air-permeability tests, along with several of the observation zones that showed significant pressure response. Note that the flow rate for the Borehole 58-3 test is 170 SLPM, while for Borehole 74-2 it is 20 SLPM. The crosshole responses for the Borehole 74-2 injection test have been plotted on a second $\mathrm{Y}$-axis with an expanded scale, because the pressure responses are small compared to the pressure build-up in the injection borehole. The steady-state airpermeability estimate for Borehole $58-3$ is $8.5 \times 10^{-13} \mathrm{~m}^{2}$; for Borehole $74-2$ it is $6.1 \times 10^{-}$ ${ }^{14} \mathrm{~m}^{2}$ (see Table 3.1).

The methodology for determining fracture porosity using air-injection pressure transients used the following steps: (1) a transient flow model incorporating the testing gas injection flowrate and borehole geometry was developed; (2), the measured data was inverted using iTOUGH2, to find the best estimate for both porosity and permeability as a function of distance to an outer-boundary condition; (3) using crosshole pressure data, a reasonable range at which to place the assumed outer-boundary radius was determined, and using that range, a porosity estimate with error bounds based on the uncertainty of the distance to an outer boundary radius was established. Finally (4), a sensitivity 
analysis was performed using iTOUGH2 to determine the significance of the porosity estimate.

\subsubsection{Flow Model Description}

The same basic radial grid was used for iTOUGH2 air-permeability inversions as was used for conducting the synthetic TOUGH2 and iTOUGH 2 simulations discussed in Section 4.2 -with the exception that the matrix was not included in the simulations. The reason for neglecting the matrix is that it would add the following unknown or poorly understood parameters: (1) fracture spacing (which controls relative fracture-matrix interaction area as well as matrix block size), (2) matrix gas permeability, (3) Klinkenberg slip parameter and (4) permeability weighting factors to determine fracturematrix flow. As a result of removing the matrix, the estimate for fracture porosity should be considered an upper bounding estimate. Any matrix effects will erroneously lead to higher estimates of fracture porosity. The thickness of the radial model was varied to match the length of the injection interval zone. Gas injection time in the simulation matched the actual injection period used in the field test, and the gas mass flux was set at the controlled injection rate.

\subsubsection{Sensitivity Analysis}

Sensitivity analyses performed using iTOUGH2, are intended to be used to rank the sensitivity of pressure measurements to model parameters. The sensitivity values are computed by summing the changes in the observation vector $\mathbf{z}$ with respect to the 
variation of the parameter vector $\mathbf{p}$. The sensitivity values presented are weighted by the expected measurement error and scaled by the inverse of the parameter variation [Finsterle, 1997c]. Inversion results as measured in the residual vector, $\mathbf{r}$, will be most sensitive to permeability, which determines the magnitude of the overall pressure change as a result of the air-injection. The porosity, which controls the time transient towards the background pressure, has a smaller influence on the elements of r. Based on a visual inspection of inversion results, a ratio in sensitivity between $\log (\mathrm{k})$ and $\phi$ greater than 100 was interpreted as showing that the inversion was too insensitive to $\phi$ to provide a reasonable parameter estimate. This indicates that the pressure transient exhibits an extremely fast pressure decline, suggesting a very small fracture porosity and/or a close outer-boundary radius.

\subsubsection{Analysis of Borehole 58-3 and 74-2 Test Data}

To apply the radial homogeneous model, the outer boundary radius was estimated by reviewing the 45 crosshole pressure responses and selecting a distance from the injection wellbore at which no discernable pressure response is detected. This radius was used to select an appropriate permeability and porosity value from the series of iTOUGH2 inversions. Figure 4.11 and Figure 4.12 show the crosshole transient pressure data for constant mass flux injection tests in Borehole 58-3 and 74-2, respectively. For the borehole 58-3 injection, the radius to an outer boundary was located at $14 \pm 2$ meters based on the data shown in Table 4.2. Steady-state crosshole observation data for the Borehole 74-2 injection test is shown in Table 4.3. Using this data, the outer-boundary radius was located at $8 \pm 1$ meters from the injection zone. 
The results of the iTOUGH2 inversions performed on the air-permeability test recovery transients, as a function of assumed outer boundary, are shown in Figure 4.13 and Figure 4.14. The porosity estimates are $0.01 \pm 0.003$ and $0.001 \pm 0.0001$ respectively, based on the range of outer boundary radii deemed appropriate. The final parameter estimates are shown in Table 4.4. Sensitivity analysis shows acceptable sensitivity towards porosity as determined by the criterion established, since the sensitivity towards porosity is greater than $1 / 100^{\text {th }}$ the sensitivity towards permeability. Note that the high-permeability zone results in a greater fracture porosity than the low-permeability zone, as would be expected owing to the larger aperture and more densely spaced fractures associated with higher permeability regions.

Table 4.3. Steady-state Pressure Responses as a Function of Distance to an Air-Injection in Borehole 74-2

\begin{tabular}{|l|l|l|l|}
\hline $\begin{array}{l}\text { Location } \\
\text { (Borehole-Zone) }\end{array}$ & $\begin{array}{l}\text { Distance from } \\
\text { Injection } \\
(\mathbf{m})\end{array}$ & $\begin{array}{l}\text { Max } \Delta \mathbf{P} \\
\mathbf{( K p a )}\end{array}$ & $\begin{array}{l}\text { Response } \\
\left(\mathbf{>} \mathbf{1 \%} \mathbf{P}_{\text {inj }}\right)\end{array}$ \\
\hline $74-2$ (Injection) & 0 & 12.85 & \\
\hline $75-2$ & 4 & 0.267 & Yes \\
\hline $76-2$ & 7 & 0.077 & No \\
\hline $74-3$ & 7 & 0.000 & No \\
\hline $74-1$ & 8 & 0.203 & Yes \\
\hline $75-3$ & 9 & 0.034 & No \\
\hline $75-1$ & 10 & 0.000 & No \\
\hline $76-1$ & 11 & 0.089 & No \\
\hline $76-3$ & 11 & 0.000 & No \\
\hline $77-2$ & 13 & 0.030 & No \\
\hline $78-1$ & 15 & 0.000 & No \\
\hline $74-4$ & 16 & 0.000 & No \\
\hline $78-3$ & 18 & 0.000 & No \\
\hline
\end{tabular}


Table 4.4. Fracture Porosity Estimates for Radial Flow Models

\begin{tabular}{|l|l|l|l|l|}
\hline Location & \multicolumn{2}{|c|}{ Parameter Estimate } & \multicolumn{2}{c|}{ Sensitivity } \\
\hline & $\phi$ & $\mathrm{k}\left(\mathrm{m}^{2}\right)$ & $\phi$ & $\log (\mathrm{k})\left(\mathrm{m}^{2}\right)$ \\
\hline $58-3$ & $0.01 \pm 0.003$ & $5.7 \times 10^{-13}$ & 321 & 2291 \\
\hline $74-2$ & $0.001 \pm 0.0001$ & $4.0 \times 10^{-14}$ & 9974 & 26575 \\
\hline
\end{tabular}

Injection in 58-3 Flow Rate: 170 SLPM

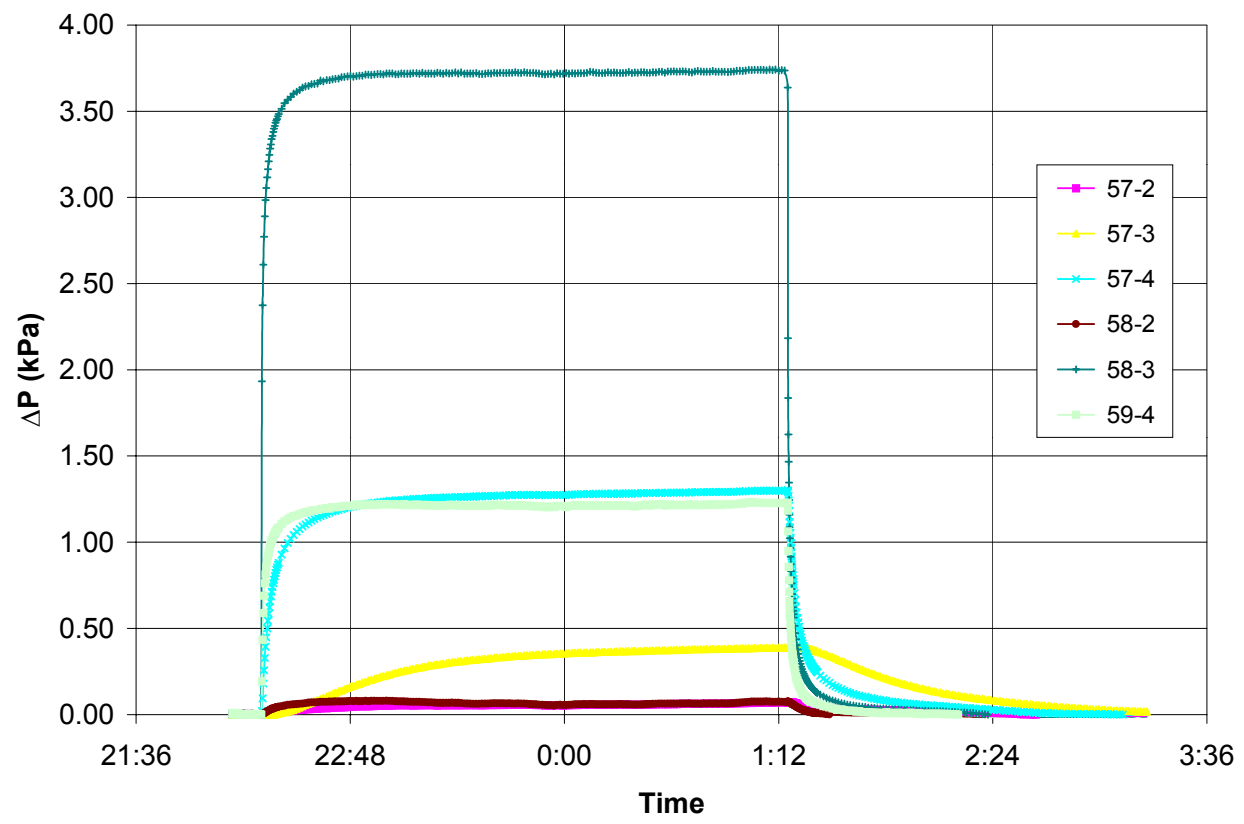

Figure 4.11 Air pressure transient for Borehole 58-3 constant mass flux air injection test. 


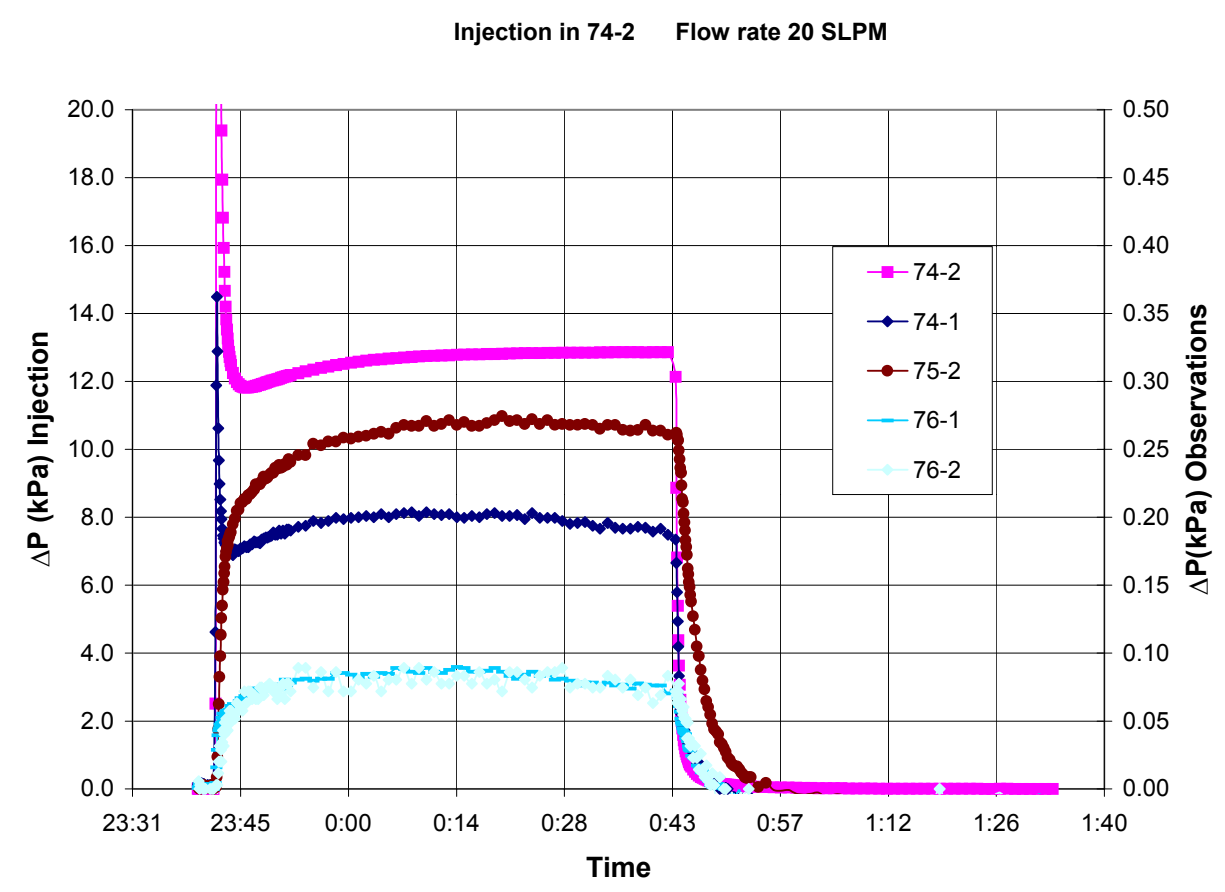

Figure 4.12 Air pressure transient for Borehole 74-2 constant mass flux air injection test.

58-3 Air-K iTOUGH2 inversion

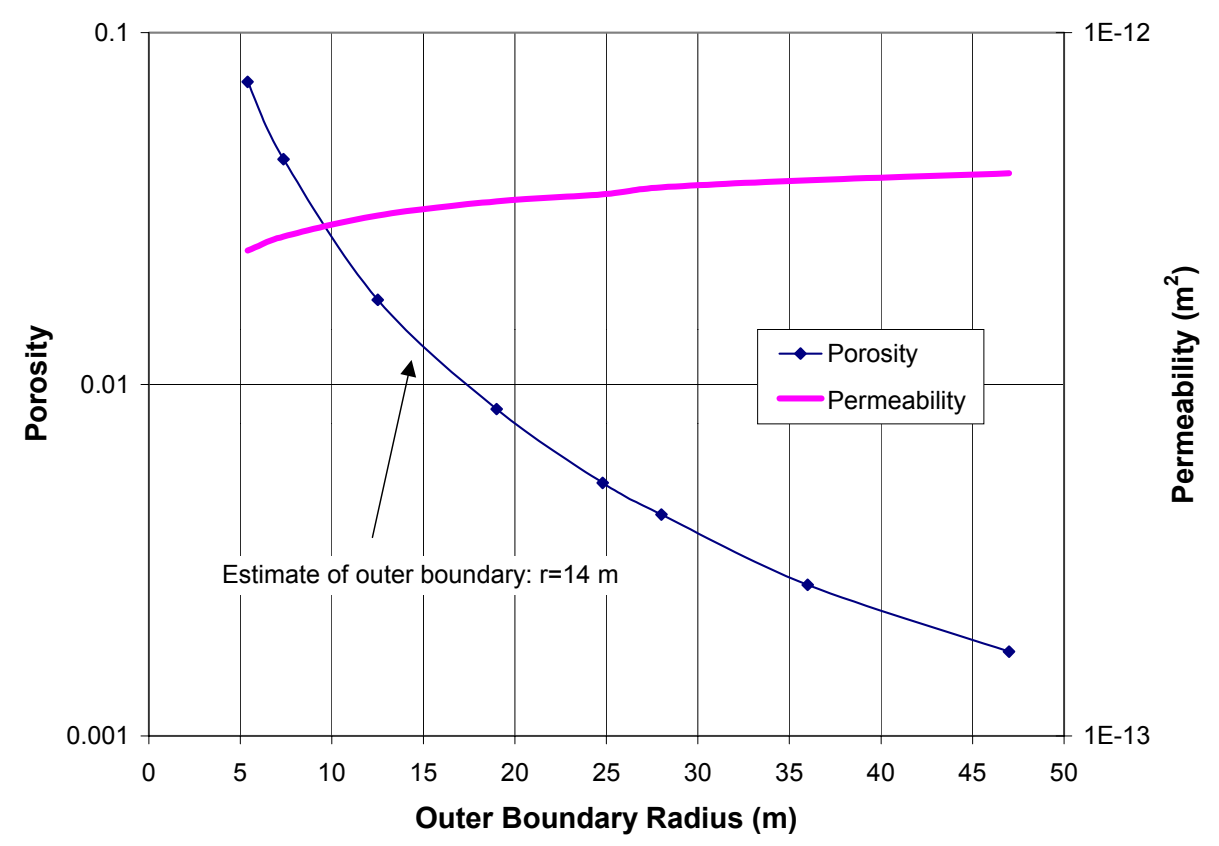

Figure 4.13 Finite radius radial flow model analysis of 58-3 pressure recovery data. 
74-2 Air-K iTOUGH2 inversion

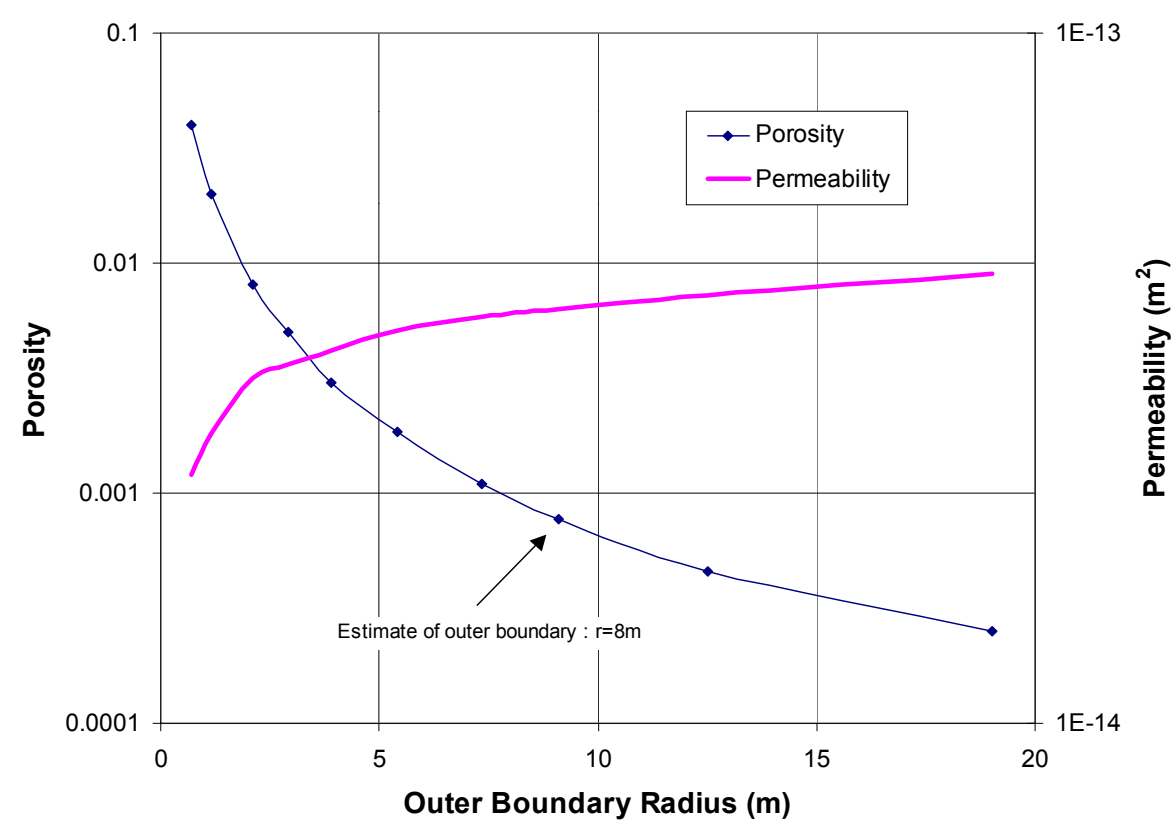

Figure 4.14 Finite radius radial flow model analysis of 74-2 pressure recovery data.

\subsection{Borehole 75 and Borehole 76 Analysis}

To facilitate a comparison of porosity estimates between the air-permeability transient recovery data and the gas tracer porosity estimates, parameter estimates were performed using data from air-permeability tests conducted in Borehole 75-2, 75-4, 76-2, and 76-4. The full air-permeability test pressure transients for Borehole 75 injection tests are shown in Figure 4.15, with Borehole 76 injection tests shown in Figure 4.16. For both Borehole 75 air-permeability tests, measurable pressure responses occurred in the distant boreholes, Borehole 185 and Borehole 186. The permeability values established using steady-state analysis for Borehole 75-2 and 75-4 are $1.5 \times 10^{-13} \mathrm{~m}^{2}$ and $7.2 \times 10^{-13} \mathrm{~m}^{2}$ respectively. Both values are above the mean formation permeability of $1.3 \times 10^{-13} \mathrm{~m}^{2}$. 
The Borehole 76-2 and 76-4 permeability values are at or below the mean formation permeability value, at $1.3 \times 10^{-13} \mathrm{~m}^{2}$ and $8.6 \times 10^{-13} \mathrm{~m}^{2}$ respectively. Table 4.5 shows the best-fit numerical porosity and permeability results as well as the parameter sensitivities obtained from the iTOUGH2 inversion.

Table 4.5. Parameter Estimates and Sensitivities for Borehole 75 and 76 Air-Injection Tests

\begin{tabular}{|l|l|l|l|l|}
\hline Location & \multicolumn{2}{|c|}{ Parameter Estimate } & \multicolumn{2}{c|}{ Sensitivity } \\
\hline & $\phi$ & $\mathrm{k}\left(\mathrm{m}^{2}\right)$ & $\phi$ & $\log (\mathrm{k})\left(\mathrm{m}^{2}\right)$ \\
\hline $75-2$ & $0.0015 \pm 0.0005$ & $1.6 \times 10^{-13}$ & 8,467 & 504,700 \\
\hline $75-4$ & $0.014 \pm 0.005$ & $8.5 \times 10^{-13}$ & 122 & 6,706 \\
\hline $76-2$ & $*$ & $1.2 \times 10^{-13}$ & 6 & 20,685 \\
\hline $76-4$ & $*$ & $3.5 \times 10^{-14}$ & 75 & 37,840 \\
\hline
\end{tabular}

* No porosity estimate given; porosity sensitivity $<1 \%$ sensitivity exhibited towards $\log (\mathrm{k})$. 
Borehole 75-4

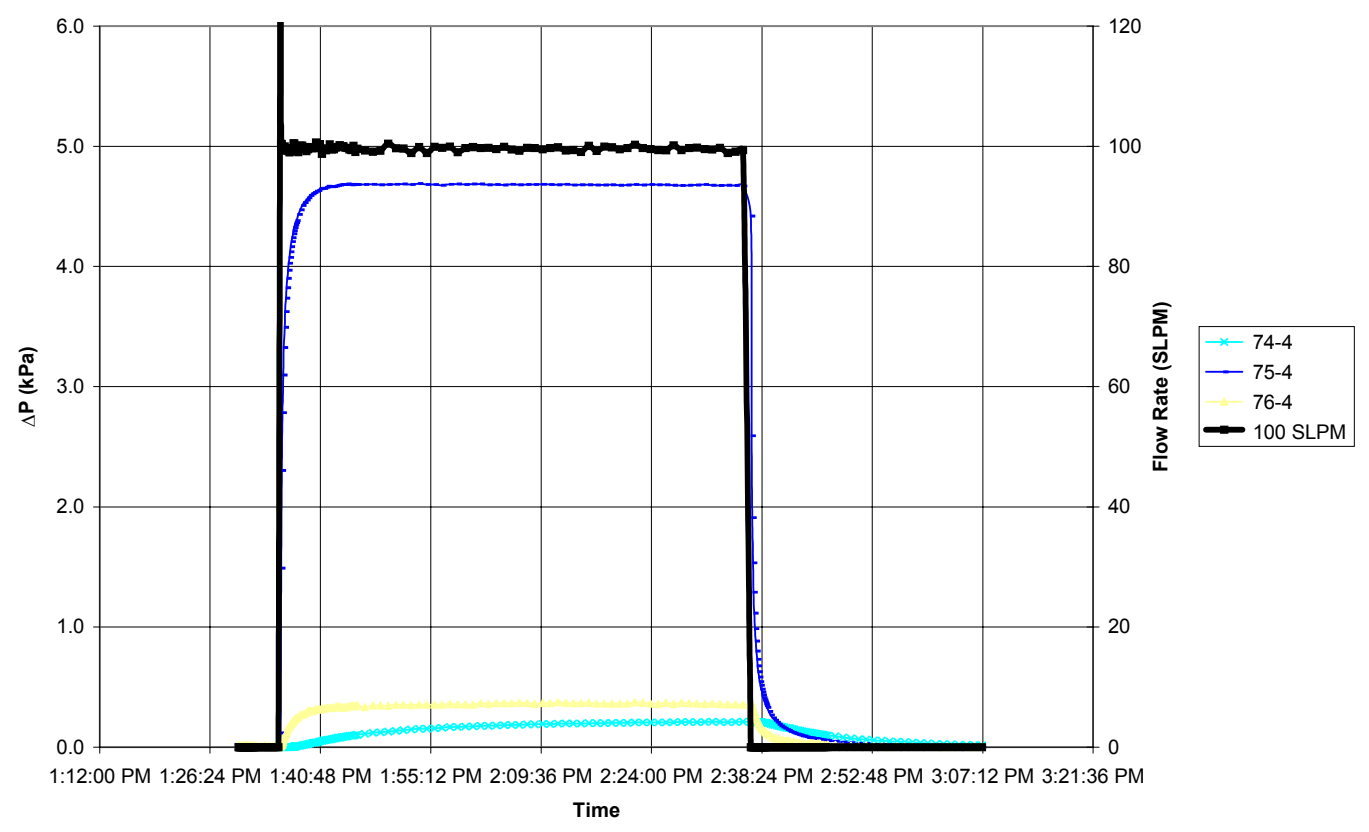

Borehole 75-2

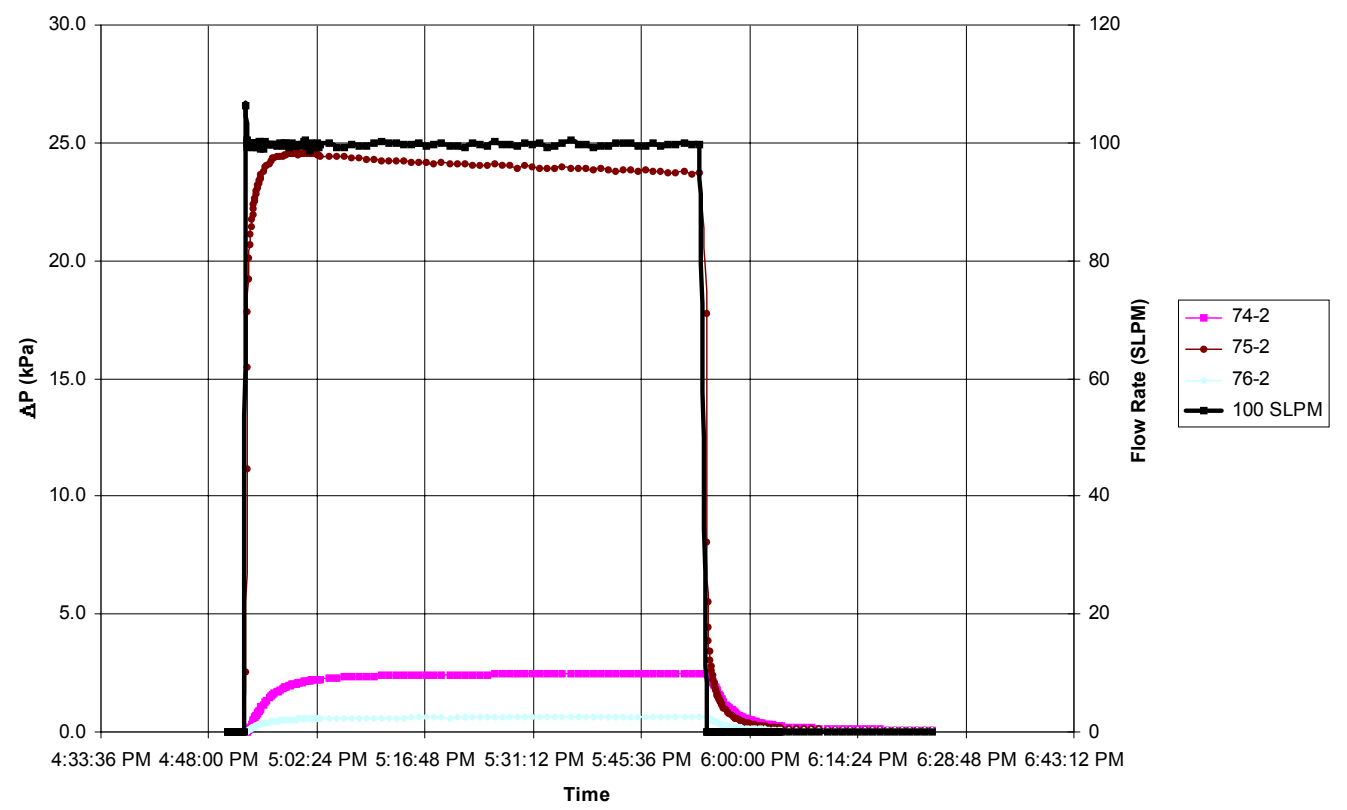

Figure 4.15 Air pressure transients for Borehole 75 air-injection tests. 
Borehole 76-2

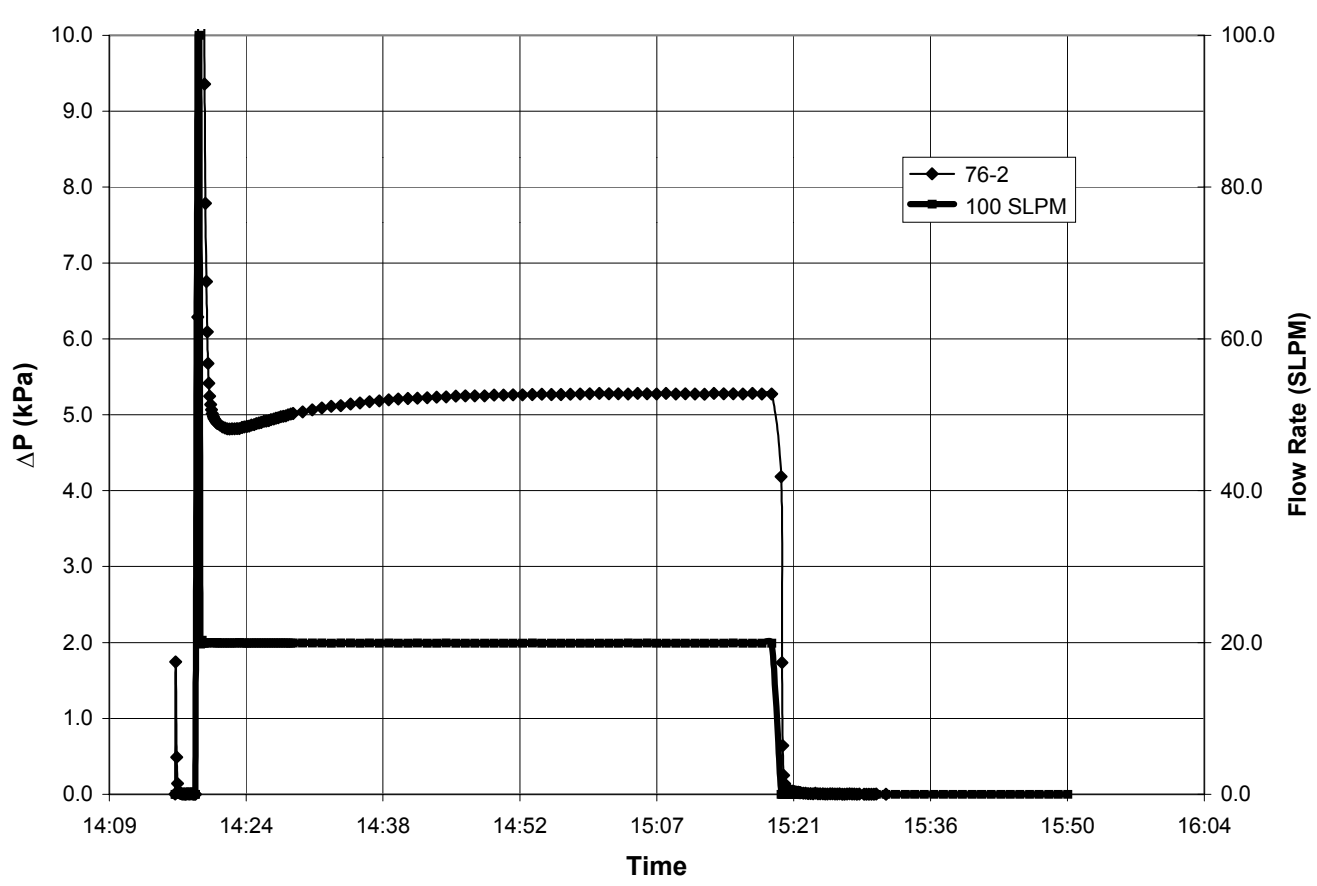

Borehole 76-4

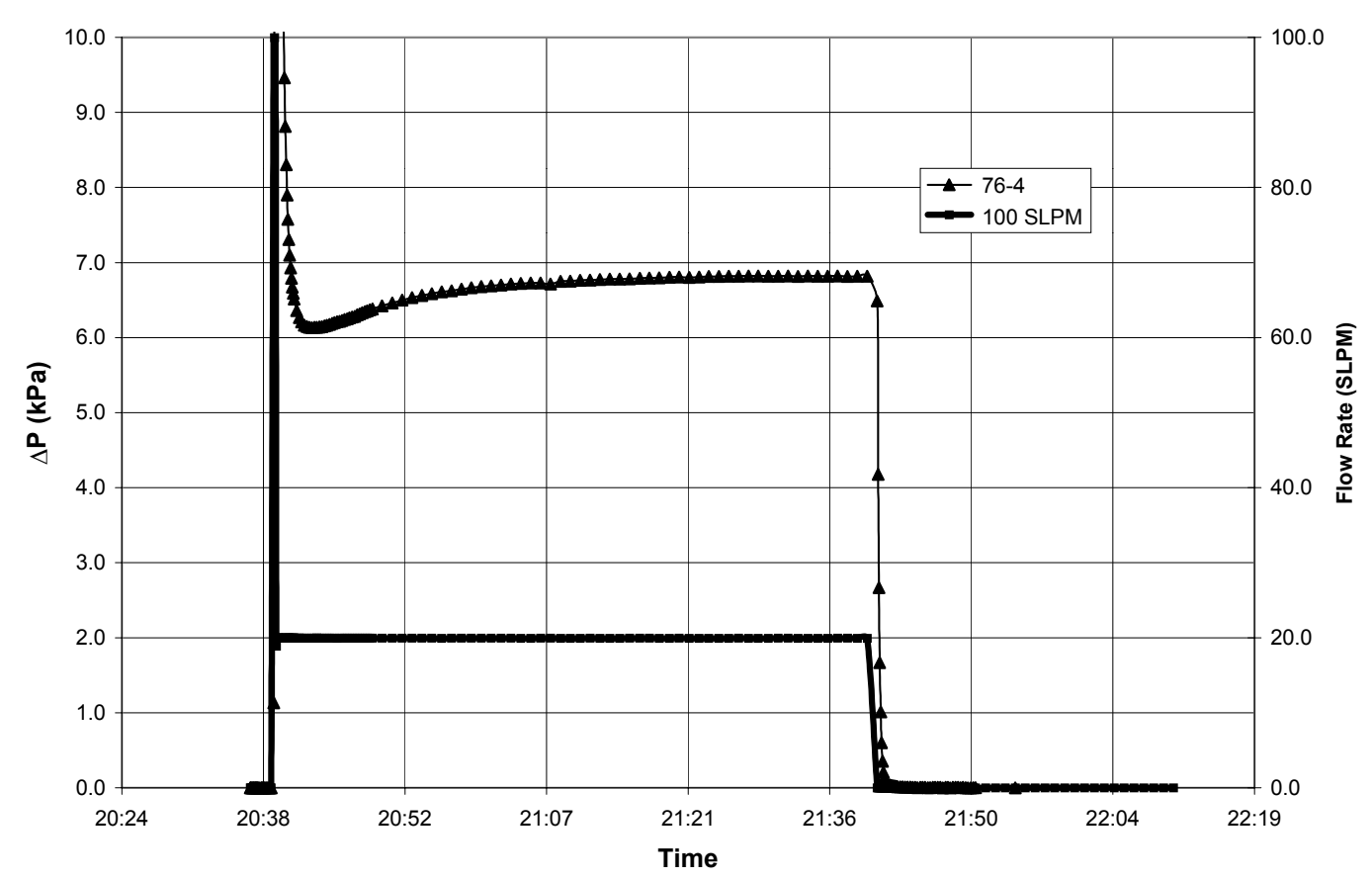

Figure 4.16 Air pressure transients for Borehole 76 air-injection tests. 
The sensitivity of the Borehole 76 inversions with respect to porosity are negligible, making them incapable of providing reliable porosity estimates. In contrast, the Borehole 75 tests have reasonable sensitivity towards porosity. Figure 4.17 and 4.18 show the iTOUGH2 inversions of the data to best fit the Borehole 75 pressure transients. The assumed outer boundary radius for the Borehole $75-2$ test was $22 \pm 5$ meters; and for the Borehole $75-4$ test it was $14 \pm 2$ meters. Figure 4.19 shows the measured and modeled best-fit pressure transients for the Borehole 75 simulations. The best-fit porosity based upon the above simulations is 0.0015 for the $75-2$ air-injection test and 0.014 for the $75-4$ air-injection test.

Overall, the air-injection test analysis results in permeability estimates which range from $1.6 \times 10^{-15}$ to $9.7 \times 10^{-13}$. The porosity estimates range from 0.001 to 0.014 . This value is significantly greater than the value of 0.00027 that was arrived at by others applying hydraulic aperture analysis. Many uncertainties in the applied flow model point to gaps in available data, and lead to reduced confidence in the porosity parameter estimates. In the next section porosity estimates will be obtained by analyzing crosshole gas tracer tests conducted in the same locations as the Borehole 75 and Borehole 76, Zone 2 and Zone 4 air-injection tests. As will be shown, the tracer testing derived estimates compare favorably with the air-injection test estimates, indicating that the hydraulic aperture estimates are too low. 


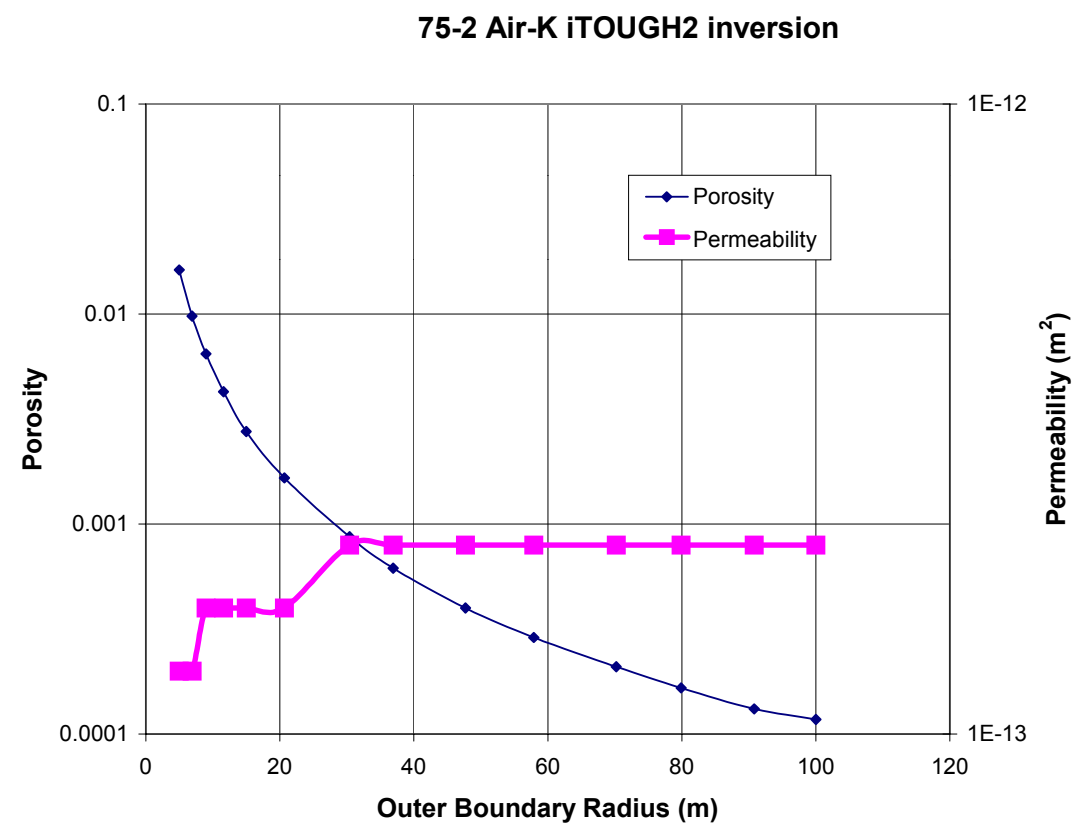

Figure 4.17 Best fit porosity and permeability as a function of distance to an outer boundary radius for Borehole 75-2 air-injection test.

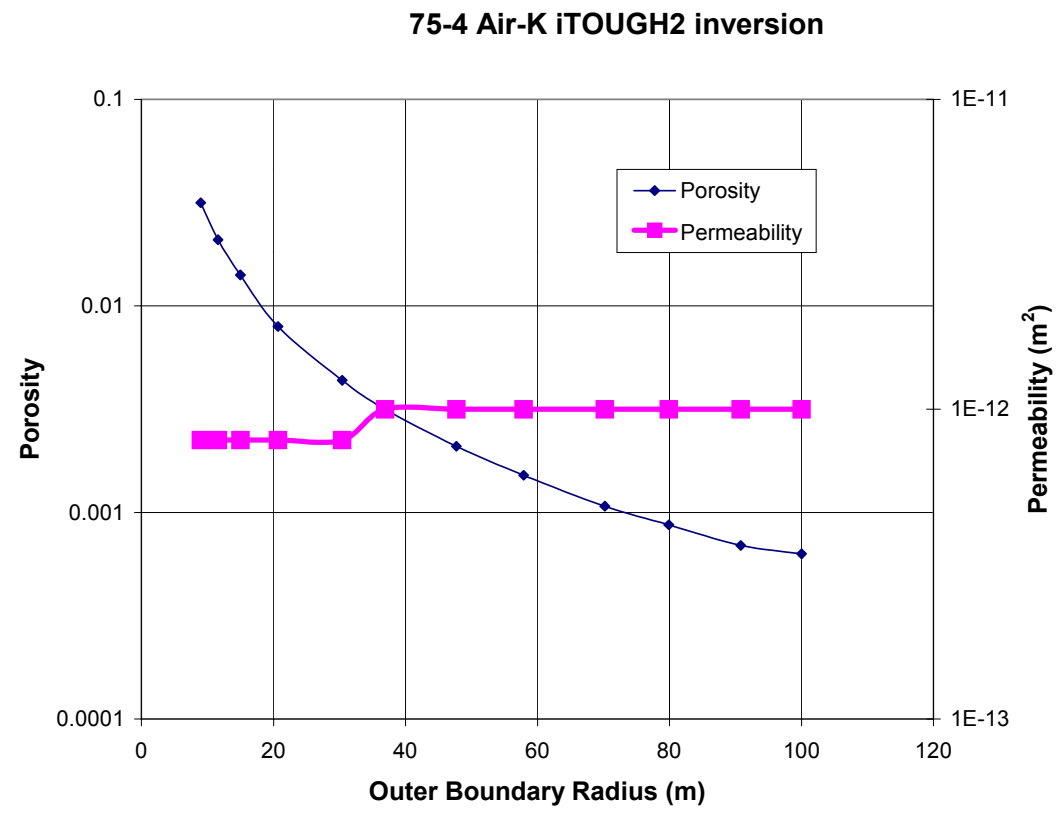

Figure 4.18 Best fit porosity and permeability as a function of distance to an outer boundary radius for Borehole 75-4 air-injection test. 

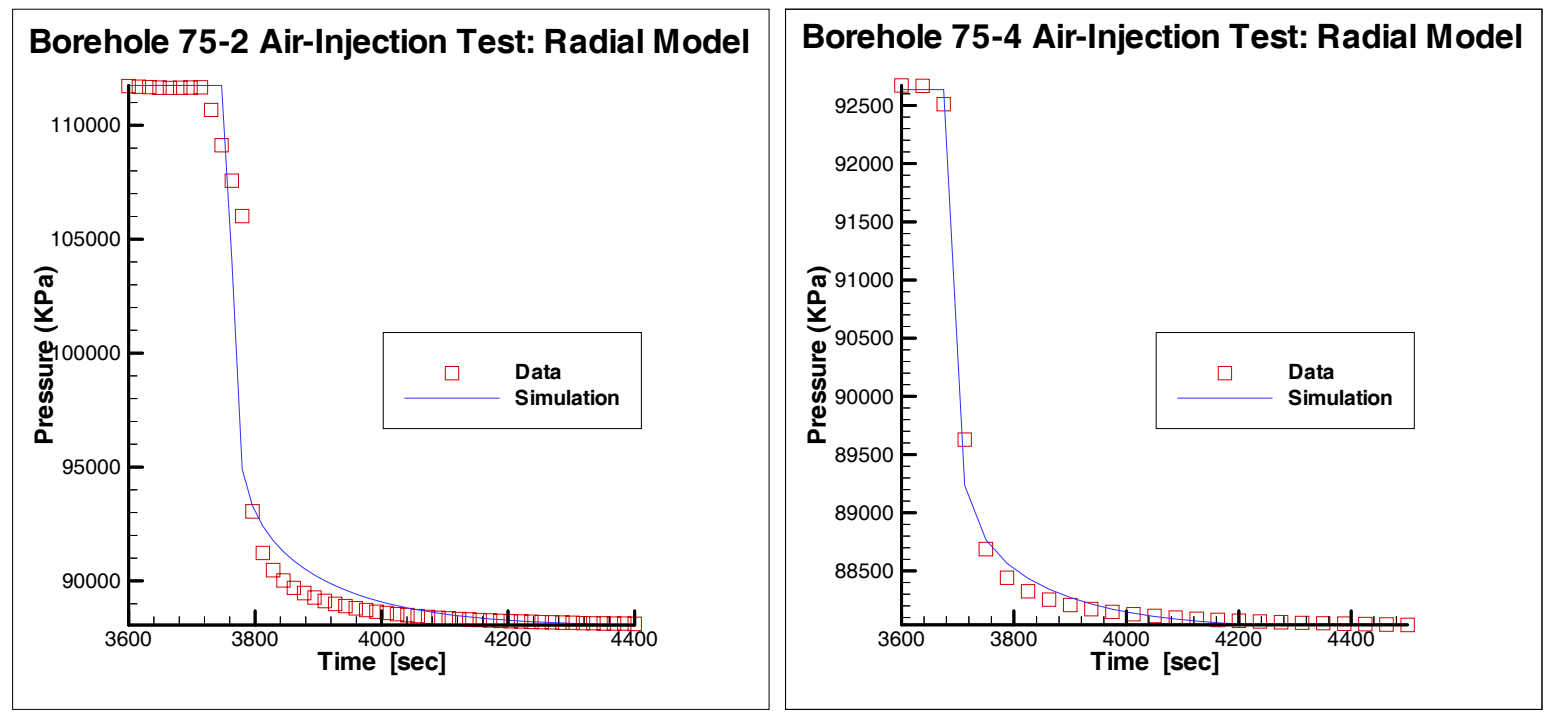

Figure 4.19 Radial model simulation of Borehole 75-2 and Borehole 75-4 air-injection test. 


\section{Tracer Test Results and Analysis}

\subsection{Introduction}

Very little prior work has been performed on the use of gas tracer testing to determine the porosity of fractured rock in the unsaturated zone. To date, gas tracer testing has primarily been used to investigate zone-of-influence/capture testing for producing natural gas reservoirs or characterization of gas transport to assist in designing soil vapor extraction remediation systems. Olschewski et al. [1995] performed $\mathrm{SF}_{6}$ gas tracer tests to aid in characterization of soil transport parameters for improving soil venting operations. The use of a gas tracer to test the structural integrity of an engineered subsurface contaminant barrier system was discussed by Heiser [1994]. Vapor-phase chlorofluorocarbon tracers were used by Adams et al. [1991] to study liquid injections in depleted geothermal reservoirs. The U.S. Army Corps of Engineers [1997] briefly mention the use of tracer gas injection to delineate the zone of influence for assisting in designing air-sparging systems. In a laboratory study, using a $20 \times 92 \times 21 \mathrm{~cm}$ block of tuff containing a single fracture, Rasmussen [1995] used gas tracer techniques to determine fracture volume and compared the results with gas pycnometer test results.

In contrast, tracer testing has been extensively used to determine saturated zone transport parameters and aquifer characteristics. Davis et al. [1980] review many studies conducted in the 1960s and 1970s that used conservative and nonconservative tracers. Dilution point tests were conducted by Drost et al. [1968] and Grisak et al. [1977] to determine 
groundwater flow velocity. Tracer investigations in karst flow systems were carried out by Arandjelovic [1977], Bauer and Zötl [1972], and Gardner and Gray [1976] in an effort to understand the nature of conduit flow. Fluorocarbon groundwater tracer tests were conducted by Thompson [1977] to determine the groundwater velocity and effective porosity in a shale underlying landfills at Oak Ridge National Laboratory. More recent groundwater studies that have led to further development in tracer test analysis include the natural gradient tracer tests conducted at the Borden Site in Ontario, Canada [Sudicky 1986; Bellin et al. 1996] and the Cape Cod Tracer test conducted in Falmouth, Massachusetts [LeBlanc et al.1991; Garabedian et al.1991; Ezzedine and Rubin, 1997; Woodbury and Rubin, 2000]. Both of these studies were conducted in sand and gravel aquifers, and analysis focused on the spatial variability of aquifer parameters and plume spatial and temporal moments.

Dipole tracer testing has also been carried out in the past for groundwater transport characterization. At the Finnsjön research area in Sweden, dipole tracer tests were conducted through several hundred meters of crystalline rock by Kimura and Munakata, [1992]. They used a numerical model to compute the effective fracture porosity. They noted that the effective flow porosity computed using a variable aperture model, $0.012 \mathrm{~m}$, is much greater than the aperture calculated from hydraulic interference tests, 0.00051 to $0.0012 \mathrm{~m}$. Another series of dipole tests were conducted in crystalline rock at the Grimsel Test Site, Switzerland by Herzog, [1991] and Hoehn et al. [1998]. They analyzed the results using a streamtube model, which incorporated longitudinal dispersion as well as matrix diffusion. Dipole tracer tests were also conducted at the Raymond Field Site, 
Raymond, CA [Karasaki et al., 2000] to investigate formation anisotropy and scale dependence using a suite of tracers.

In the present study, the analysis of gas tracer test data from Yucca Mountain was performed first by a simple analytic method assuming cylindrical plug flow (Section 5.2). Since this model does not take into effect diffusive and dispersive processes, and assumes a single-straight-line flow path, the porosity estimate generated by applying the plug-flow model will overpredict the actual fracture porosity. Hence, to take into account molecular diffusion and macrodispersive processes a random-walk particle-tracking model was also used to analyze the tracer test results (Section 5.4).

\subsection{Cylindrical Plug Flow Analysis}

First-order analysis of the collected crosshole gas tracer data can be performed assuming that the gas advectively flows along a one-dimensional streamline from the injection location to the extraction location. The injection flow rate is not incorporated in computing a streamline velocity from the injection to the withdrawal borehole. Figure 5.1 shows a schematic of the cylindrical flow model. The equation describing the average travel time, $\mathrm{t}_{50}$, along a cylindrical flow path is

$$
t_{50}=\int_{r} \frac{d r}{v(r)}
$$

where $\mathrm{r}$ represents the radial distance to the withdrawal borehole and $v(r)$ is the cylindrical flow velocity. The cylindrical flow velocity, assuming a borehole length, $l$, is 


$$
v(r)=\frac{Q}{2 \pi r l \phi}
$$

The "average" tracer arrival time, $t_{50}$, needs some further elaboration. An average tracer arrival time can be computed using the equation:

$$
t_{50}=\frac{\int_{t=0}^{\infty} t c(t) d t}{\int_{t=0}^{\infty} c(t) d t}
$$

This equation accounts for the fact that tracer recovery is frequently less than $100 \%$ by normalizing the time weighted cumulative mass recovery by the actual mass recovery. It should be noted that the mass breakthrough curves (see Figures 2.14-2.16) have long tails which cannot be reconciled using the simple plug flow assumed in Equation (5.1) and (5.2). This tailing is known to be caused by both diffusive and dispersive processes, neglected by the simple plug-flow model. Therefore, a more sophisticated analysis which considers both diffusion and dispersion is discussed next. The expression for fracture porosity can then be written using Equation (5.1) and (5.2) as

$$
\phi=\frac{Q t_{50}}{\pi r^{2} l}
$$

Fracture porosity values computed using Equation (5.4) for the three crosshole tests are shown in Table 5.1. These results should be taken as upper bounds on fracture porosity, since the diffusive and dispersive processes will act to retard the arrival of tracer along the straight-line cylindrical path assumed here. Any retardation of the arrival by a process other than the plug-flow advection or delay caused by deviation from the assumed straight-line flow path will increase the estimated fracture porosity computed using Equation 5.4. 
Table 5.1. Plug-Flow Tracer Analysis of Crosshole Tracer Data

\begin{tabular}{|l|l|l|l|}
\hline Tracer Test & Zone length $(\mathbf{m})$ & $\mathbf{t}_{\mathbf{5 0}}(\mathbf{m i n})$ & $\phi_{\text {fracture }}$ \\
\hline $76-2-75-210: 1$ & 7.93 & 67 & .010 \\
\hline $76-2-75-230: 1$ & 7.93 & 56 & .006 \\
\hline $76-4-75-410: 1$ & 9.12 & 294 & .009 \\
\hline
\end{tabular}

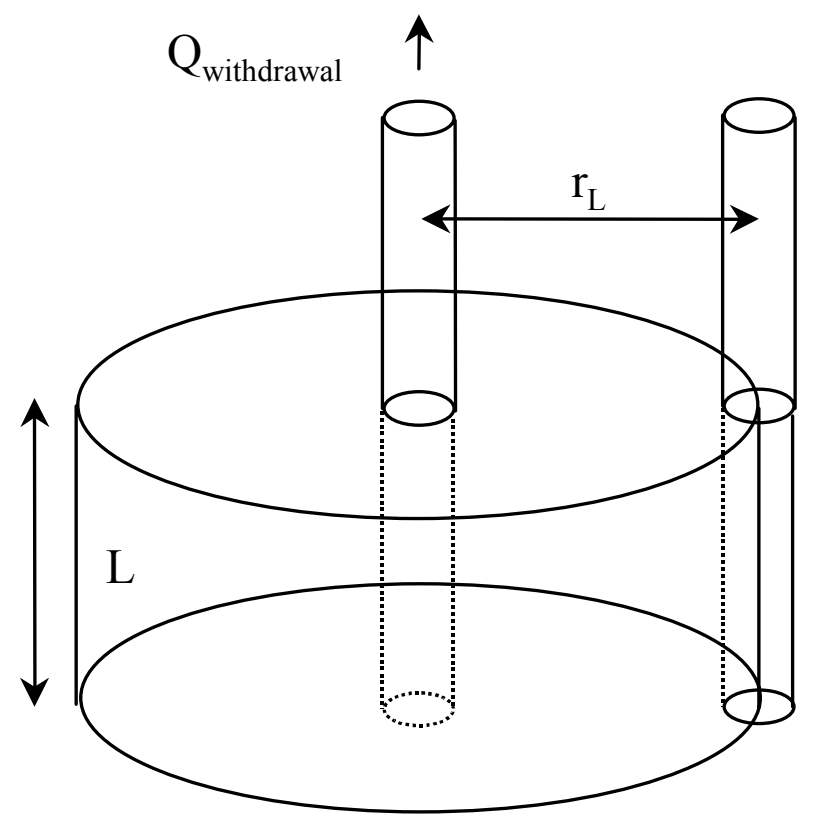

Figure 5.1 Plug flow advective model used to estimate fracture porosity.

\subsection{Transport Model Considerations}

The limitations of the cylindrical plug flow model used above are numerous. While it is expected that advection will be the dominant process in gas tracer tests conducted under large pressure gradients, the effects of diffusive and dispersive processes are clearly seen by the spreading and long tail in the tracer breakthrough curves. Also, the flow paths created by the dipole-flow field are not well represented by the single straight-line flow path assumed by the plug flow model. 


\subsubsection{Matrix Influence on Tracer Testing}

The effects of gas transport into the low-permeability matrix, which was shown to significantly influence the porosity estimates provided by analysis of the air-injection data, is not shared by the tracer tests. In the crosshole gas tracer tests, the dipole pressure field was brought to a steady state prior to the introduction of any trace gas. Since the matrix was given time to come into pressure equilibrium with the fracture network, no advective driving force exists between the fractures and the matrix. The huff-puff test has a pressure gradient from the fractures into the matrix during the injection period of testing, but this gradient is reversed during the subsequent gas withdrawal. Theoretically, the advective component of transport from the fractures into and out of the matrix is canceled for the huff-puff tuff.

Diffusion into and out of the matrix still does occur and influences the results of the gas tracer tests. Matrix diffusion will spread the tracer plume by creating stagnant regions, increasing the formations apparent dispersivity. In this study, the process of diffusion into the matrix is lumped into the dispersion coefficient and treated as a Fickian process. In recent years, there has been a significant effort to move beyond the Fickian description of transport using both stochastic and deterministic methods. These methods and their relationship to this work is discussed in the next section. In general, the ability to perform field measurements to estimate the parameters necessary to apply these more complicated models greatly lags the development of these models. It is because of this lack of more detailed transport process information that a Fickian description of diffusive 
and dispersive transport has been incorporated into the analysis of the tracer tests reported herein.

\subsubsection{Prior Work on Fractured Rock Tracer Transport}

Neretnieks [1983] discussed transport processes occurring in fractured media that lead to dispersion. These include molecular diffusion, velocity variations within a single fracture, velocity variations between various fractures, and chemical and physical reactions with the surrounding rock mass. Tsang and Tsang [1987] introduced a channel model that uses a stochastic approach to identify fracture aperture distribution and spatial correlation length to describe the "channels" through which flow occurs. A later paper by Tsang et al. [1988] further investigated the volume of these flow channels and relates the fracture aperture density distribution to a calculation of dispersion using the tracer massbreakthrough curve data.

Laboratory studies have been conducted on single fissures in granitic rocks by Neretnieks et al. [1982] and by Moreno et al. [1985]. Another interesting study on flow geometry and dispersive mechanisms was conducted by Keller et al. [1999]. Their study of transport used computed tomography x-ray scanning to analyze aperture variation on a $160 \mathrm{~mm}$ long granite core to predict tracer dispersion. The quantity and quality of information on fracture aperture variation and channel geometry obtained by Keller et al. [1999], while impressive, is simply impossible to obtain at the field scale. Even if that type of detailed information was available for a few discrete fractures, the ability to apply 
the same model to larger and larger hierarchically scaled features that intersect in threedimensional space does not exist.

While these laboratory studies provide great insight into dispersive processes and fracture volume, they provide little understanding of larger-scale behavior. Perhaps the most relevant insight into the gas tracer tests presented due to similarities in rock properties is the transport studies conducted by Haldeman et al. [1991] in a porous block of tuff with a single fracture. However, their study showed how three different tracer tests within the same fracture produced widely varying estimates for the fracture dispersivity, $\alpha(0.02 \mathrm{~m}$. to $8.01 \mathrm{~m}$ ). This study points out the complexity of understanding transport in a single fracture under laboratory conditions, and highlights some of the problems faced by trying to perform measurements at the field scale.

Field studies in saturated fractured rocks have been conducted on the scale of a few meters to several hundreds of meters. Experiments such as at the Stripa migration experiment in Sweden [Dverstorp et al., 1992] in granitic rocks have been analyzed using discrete fracture models. Double porosity flow models have been used to analyze tracer tests in the Cuelubra dolomite [Ostensen, 1998] at the Waste Isolation Pilot Plant in New Mexico.

Despite the prior work on fracture transport at the laboratory and field scale, there is no generally accepted theory on obtaining a field-scale fracture porosity estimate using readily measurable input parameters (such as permeability or fracture frequency). The 
areas where measurements have been made and models have proven to be tractable are at the laboratory scale, working on single fractures. This dissertation provides the framework for conducting tracer tests that can be reduced to provide a simple porosity estimate at the field scale.

\subsubsection{Fickian Transport}

The physical basis behind Fickian diffusive transport is relatively well understood at the molecular level. For binary gas pairs not at highly elevated pressures, diffusive transport follows kinetic gas theory fairly well [Bird et al., 1960]. The application of Fickian diffusive transport theory to describe macrodispersive processes is less accepted, although widely used. Gelhar et al. [1992] presented the analysis of transport at 59 different field sites that were all described with the Fickian macroscopic dispersion coefficient, $D$. Berkowitz and Scher [1995] investigated the adequacy of spatial averaging, inherent in Fickian transport, to describe observations of "anomalous" dispersive transport processess. They determined that formation connectedness, or a tracer's "encounter" with a representative range and size of fractures will justify the use of "representative elementary volume" (REV) representations of the formation and the applicability of a constant dispersion value.

Margolin and Berkowitz [2000] and Kosakowski et al. [2001] have applied a continuous time random walk (CTRW) model [Scher and Lax, 1973] to analyze tracer data. Using CTRW depends on knowledge of the mean size of local heterogeneities. The "dispersivity-like" parameter, $\beta$, used in the CTRW has been presented as a physically 
plausible model to account for observations of non-Fickian transport. Berkowitz and Scher [1995] use a general probabilistic function $\psi(s, t)$, where $\psi(s, t)$ is the probability that in a unit time, a particle will be transported a distance $s$, with arrival time $t$. The form of $\psi(s, t)$ used by Kosakowski et al. [2001] is $\psi(s, t) \rightarrow t^{-1-\beta}$ for large $t$, with Fickian transport occurring when $\beta>2$. The CTRW model is a general transport model that includes Fickian diffusion as a special case. For $\beta<1$, such as resulting from fitting transport tests conducted in fractured till [Kosakowski et al., 2001], the mean travel time for tracer transport was found to be infinite. This result, described as accounting for regions of stagnant flow, is nonphysical and uncharacteristic of the gas tracer tests conducted as part of this study. Therefore, in this study, it is assumed that the macrodispersive spreading can be accounted for by a Fickian model.

\subsection{Random-Walk Particle Method}

An attempt was made to analyze the gas tracer test data by applying the TOUGH2 numerical simulator, which incorporates Fickian transport modeling capabilities. However, because of the high Peclet number associated with the rapid advective gastracer transport numerical dispersion was significant. The application of a finite difference model, without the addition of front-tracking-type correction schemes, is not possible. It was therefore decided that a random-walk particle method (RWPM), incorporating Fickian transport, would be a reasonable approach to model the Topopah Spring tuff gas tracer data. The RWPM has long been used to analyze both conservative and reactive transport within porous media [Ahlstrom et al., 1977; Prickett et al., 1981; LaBolle et al., 1996]. 
In the standard continuum model description of porous media, dispersivity, $\alpha$, is lumped together with molecular diffusion to give a bulk dispersion coefficient,

$$
D^{*}=D_{m o l}+\alpha v
$$

where $D_{m o l}$ is the molecular diffusive component and $v$ is the average advective velocity. To account for both gaseous diffusion and dispersion that occur as a result of the varying channels through fractures that the tracer can take, the RWPM that was implemented incorporated the velocity dependent dispersion coefficient shown in Equation (5.7). Because of all the uncertainties in modeling flow within a fractured system, the implementation of a 3-D simulation to account for the end effects of the finite-length injection and withdrawal boreholes would only add minor variations to the results, which are insignificant given the overall uncertainty. The RWPM implemented tracked particles "injected" and "withdrawn" in a 2-D Cartesian system.

Mathematically, the center of the injection borehole was taken as the origin of a Cartesian flow system and the extraction borehole was placed at the coordinate $(r, 0)$ where $r$ represents the average separation between the injection and withdrawal borehole. Because the injection and withdrawal wells were inclined from each other for the crosshole tracer tests, a geometric trick was used to simulate this varying distance. The particle track was started along a circle centered around the origin with the radius, $\mathrm{r}_{0}$, equal to one-half the difference between the distances at the ends of the injection and withdrawal boreholes. An angle, $\beta$, selected using a random-number generator 
determines the exact position on the circle. The resulting starting coordinate is then $\left(r_{0} \cos \beta, r_{0} \sin \beta\right)$. The advective velocity in the steady-state flow field was computed as the sum of the vectors of two superimposed radial flow fields, yielding

$$
\begin{aligned}
& v_{x}=v_{x, i n j}+v_{x, \text { with }} \\
& v_{y}=v_{y, i n j}+v_{y, \text { with }}
\end{aligned}
$$

where the velocity field contribution caused by injection was written as

$$
\left(v_{x, i n j}, v_{y, i n j}\right)=\left(\frac{Q_{i n j}}{2 \pi l \phi} \frac{x}{x^{2}+y^{2}}, \frac{Q_{i n j}}{2 \pi l \phi} \frac{y}{x^{2}+y^{2}}\right)
$$

and the velocity field contribution caused by withdrawal was written as

$$
\left(v_{x, \text { with }}, v_{y, \text { with }}\right)=\left(\frac{Q_{\text {with }}}{2 \pi l \phi} \frac{x-x_{o}}{\left(x-x_{0}\right)^{2}+y^{2}}, \frac{Q_{\text {with }}}{2 \pi l \phi} \frac{y}{x^{2}+y^{2}}\right)
$$

where $x_{0}$ represents the average radial separation between the injection and withdrawal borehole. Superimposed over this flow field was an added motion to the particle resulting from the velocity-dependent dispersivity, $D^{*}$ as shown in Equation (5.7). The added "walk" of the particle from dispersivity was calculated using a random-number generator that returns numbers, $X$ and $Y$, with a mean of zero and a standard deviation of one. The actual displacement calculated for each particle displacement, for a time increment of $\Delta t$, was

$$
\begin{aligned}
& x=x+\left(v_{x} \Delta t+X \sqrt{2\left(D_{m o l}+\alpha v\right) \Delta t}\right) \\
& y=y+\left(v_{y} \Delta t+Y \sqrt{2\left(D_{m o l}+\alpha v\right) \Delta t}\right)
\end{aligned}
$$


This includes both the advective component as calculated by Equation (5.10) and the random-walk macrodispersivity. A total of 5,000 particles were tracked for each tracer transport simulation.

\subsection{Inversion of RWPM Results}

\subsubsection{Crosshole Tests}

History matching of the RWPM simulations and the field-test data was carried out in the $(\phi, \alpha)$ parameter space. A least-squares minimum objective function, $S$, fitting the RWPM simulation with the field data was found for each of the three crosshole tests and the huff-puff tracer test. A minimum for $S$ was determined for each test. The best fit model for each crosshole tracer data set is shown in Figures 5.2, 5.3, and 5.4. Figure 5.5 shows $S$ contoured throughout $(\phi, \alpha)$ space for each tracer test. An uncertainty investigation of $S$ in the $(\phi, \alpha)$ parameter space is performed in the next section.

For the three weak-dipole tracer tests, the best-fit porosities range from 0.002 to 0.004 . Best fit $\alpha$ values range between $0.6 \mathrm{~m}$ to $1.6 \mathrm{~m}$. The objective function $S$ determined for the 30:1 dipole test in Borehole 76-2 and the 10:1 dipole test in Borehole 76-4 are qualitatively very similar. The effective gas diffusivity is a function of advective velocity as shown in Equation 5.7. Average advective velocity for each RWPM simulation was calculated by summing the total displacements caused by the advective flow field and dividing by the total travel time taken for all the particles introduced into the system. 
Table 5.2 shows the best-fit porosity and dispersivity for each test, along with the average advective velocity. It is evident that tracer spreads considerably due to dispersive processes (because of different advective paths through the tortuous fracture network). It is clear from Figures 5.2, 5.3, and 5.4 that the Fickian model applied captures the long tailing observed for the cross-hole tracer tests. Saturated formation groundwater tracer studies performed in granitic rocks at the Grimsel Test Site, Switzerland [Frick et al. 1992] and at the Raymond Field Site, California [Karasaki et al., 2000] reveal similar long tails and large dispersivities.

A normalized best fit for all tests was calculated using $S_{\min }$ as the normalization factor to equally weight each cross-hole tracer test and then summing the normalized objective functions. The summed normalized best-fit porosity was found to be 0.003 , with a dispersivity of 0.8 meters.

Table 5.2. RWPM Tracer-Test Best-Fit Results

\begin{tabular}{|l|l|l|l|}
\hline $\begin{array}{l}\text { Tracer } \\
\text { Test }\end{array}$ & Porosity & $\begin{array}{l}\text { Alpha } \\
\text { (m) }\end{array}$ & $\begin{array}{l}\text { Average } \\
\text { Advective } \\
\text { Velocity vadv } \\
\text { (m/s) }\end{array}$ \\
\hline $76-210: 1$ & .002 & 1.4 & $1.62 \times 10^{-3}$ \\
\hline $76-230: 1$ & .004 & 0.6 & $1.40 \times 10^{-3}$ \\
\hline $76-410: 1$ & .003 & 0.8 & $5.43 \times 10^{-4}$ \\
\hline Huff-puff & $*$ & 0.0 & $*$ \\
\hline
\end{tabular}

* No porosity is given because the simulation is only weakly dependent on the porosity value. 
Borehole 76-2 10:1 Tracer Test

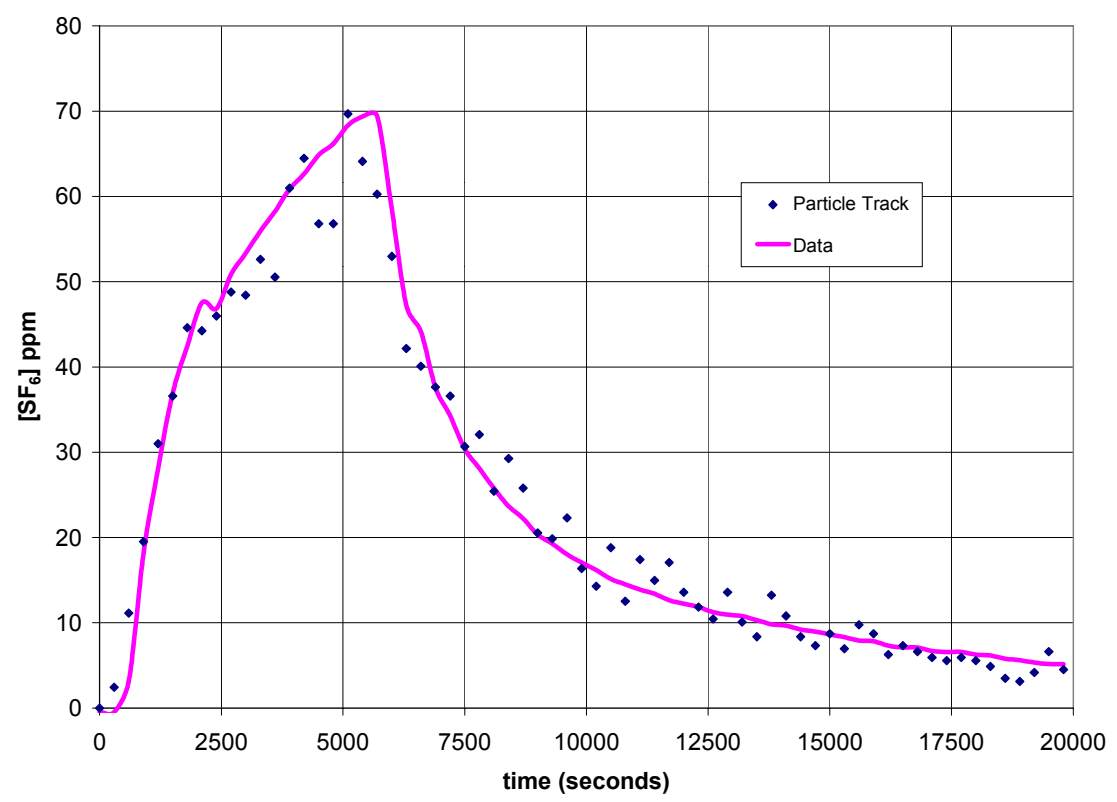

Figure 5.2 Borehole 76-2 10:1 dipole tracer test RWPM least-squares best fit.

Borehole 76-2 30:1 Tracer Test

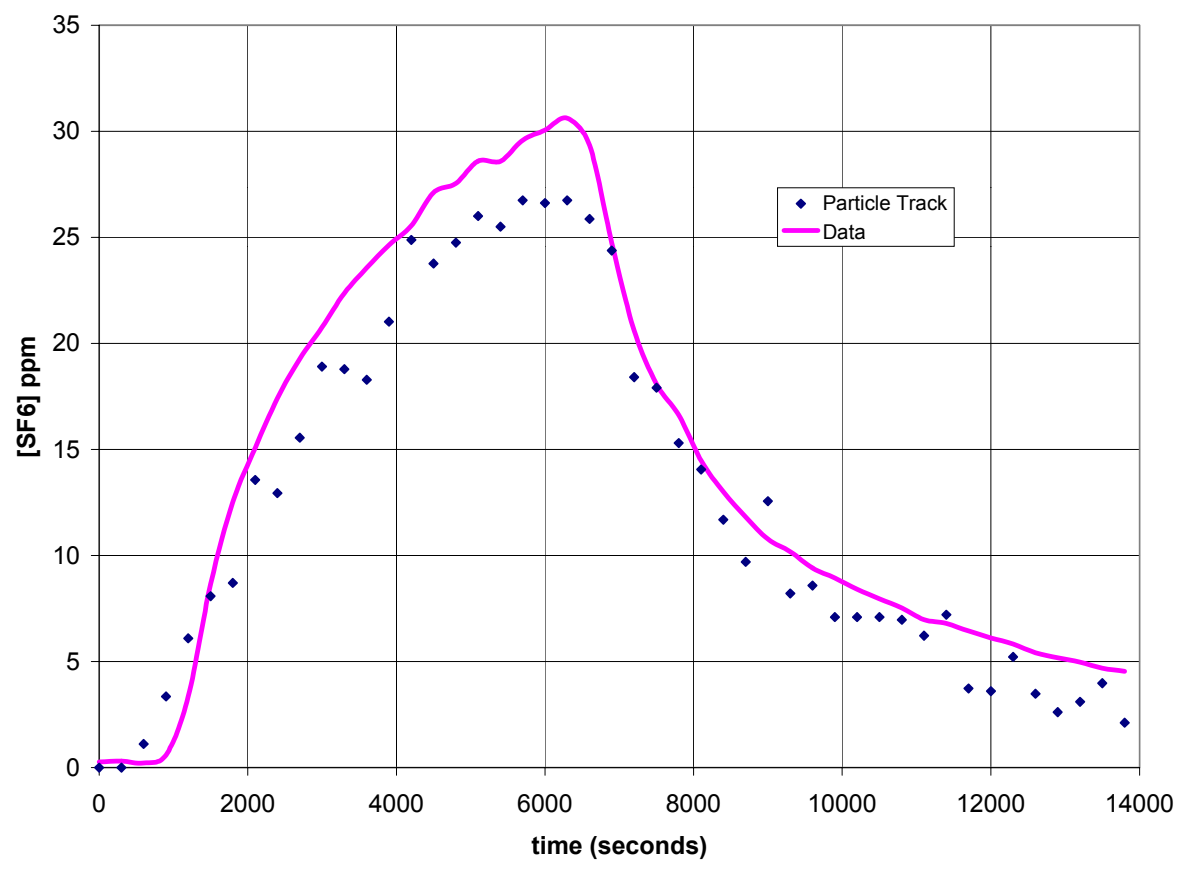

Figure 5.3 Borehole 76-2 30:1 dipole tracer test RWPM least-squares best fit. 
Borehole 76-4 Tracer Test

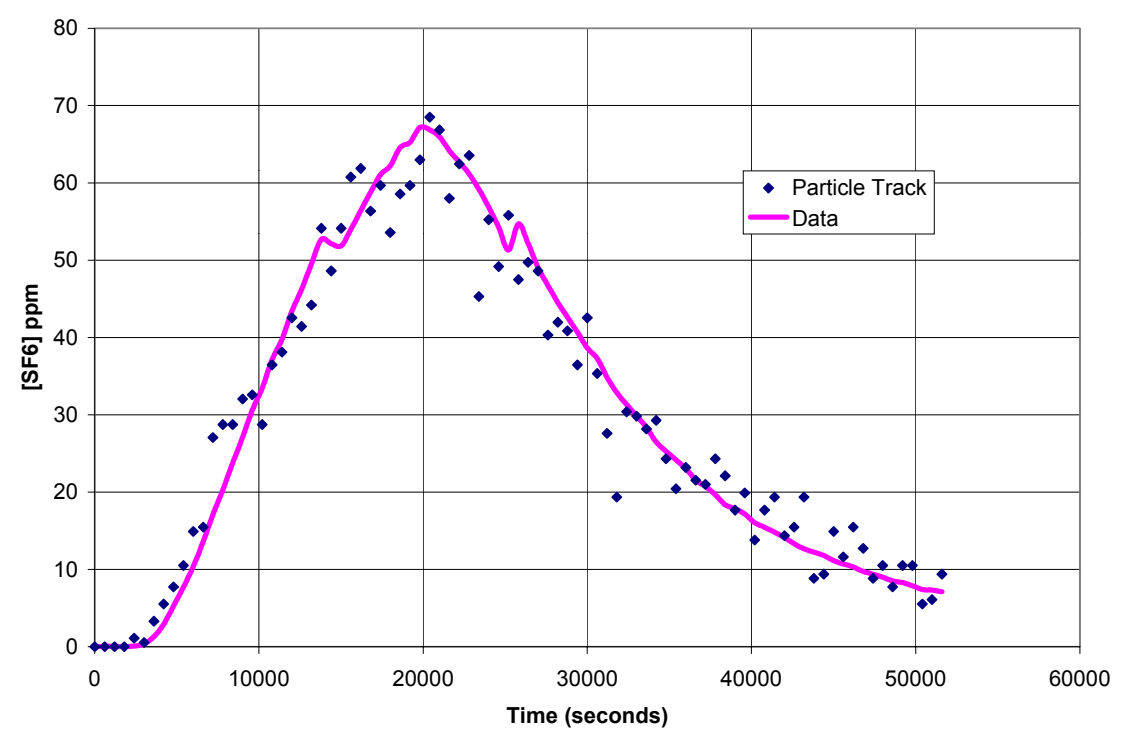

Figure 5.4 Borehole 76-4 10:1 dipole tracer test RWPM least-squares best fit. 

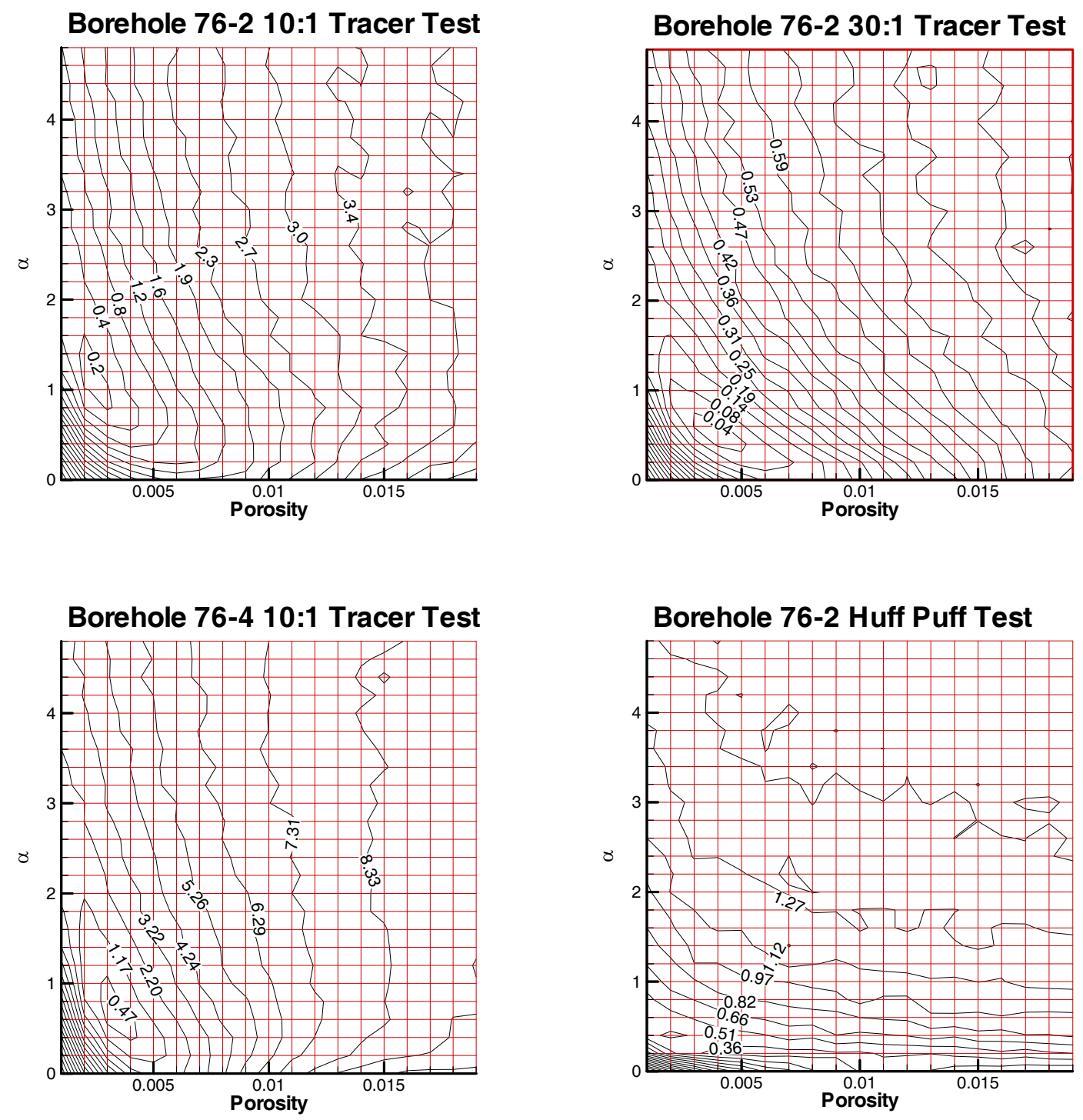

Figure 5.5 Least-square fitting of RWPM simulation to gas tracer data.

\subsubsection{Parameter Uncertainty}

The determination of parameter uncertainty follows the estimation-identification problem studies performed by Finsterle and Pruess [1995]. If the RWPM model follows linearity and normality assumptions, then we can determine an elliptical confidence region for our estimated parameter vector, $\mathbf{p}$, consisting of the unknown parameters $\alpha$, and $\phi$. The 
assumption of normality implies that the estimated error variance is a random value, in which the sample of random values tends towards normal as the sample size becomes sufficiently large. Linearity assumes that within the region covered by the confidence region, the model behaves linearly. The determination of the $100\left(1-\alpha_{S}\right) \%$ confidence region is defined by the region in which the difference between the objective function, $\mathrm{S}$, determined at $\mathbf{p}$, and $\mathrm{S}$ at $\hat{\boldsymbol{p}}$, where $\hat{\boldsymbol{p}}$ is the optimum parameter set, meets the criterion [Donaldson and Schnabel, 1987]

$$
S(p)-S(\hat{p}) \leq s_{0}^{2} n F_{n, m-n, 1-\alpha_{s}}
$$

where $s_{0}^{2}$ is the a posteriori estimated error variance and $F_{n, m-n, 1-\alpha_{s}}$ is a quantile of the $F$ distribution. The probability that a parameter set is accepted while false is given the symbol $\alpha_{\mathrm{S}}$, with the subscript $\mathrm{S}$ used to differentiate it from the dispersivity $\alpha$. The $a$ posteriori estimated error variance $s_{0}^{2}$ can be computed for each tracer test as

$$
s_{0}^{2}=\frac{S_{\min }}{m-n}
$$

where $m$ is the number of concentration observations (model observations) and $n$ is the dimension of the vector p. For the crosshole tracer tests conducted in Borehole 76-2, 10:1 dipole and 30:1 dipole, and the Borehole 76-4 10:1 dipole, the number of observations used to compute $S$ is 42,47 , and 87 respectively. The value of $F_{n, m-n, 1-\alpha_{s}}$ for the $95 \%$ confidence interval, $\alpha_{S}=0.05$, is approximately 3 for all three crosshole tracer tests. The region of confidence is defined as the region within the S contour defined by

$$
S \leq S_{\min }+s_{0}^{2} n F_{n, m-n, 1-\alpha_{s}}
$$


Approximating the $S$ contour as a ellipse, which encircles the region defined by Equation (5.13) provides a simple graphical determination of marginal and conditional standard deviations for each parameter in p. Figure 5.6 shows graphically the determination of both the marginal, $\sigma_{\mathbf{p}, \mathbf{i}}$, and conditional, $\sigma_{\mathbf{p}, \mathrm{i}}{ }^{\prime}$, standard deviations for parameters in $\mathbf{p}$, as defined by an elliptical confidence region for the Borehole 76-4 tracer test. The conditional standard deviation is smaller than the marginal standard deviation, since the conditional standard deviation for a parameter assumes that all other parameters are known exactly. Similar confidence regions were determined for the Borehole 76-2 10:1 and 30:1 tracer tests and are shown in Figure 5.7 and Figure 5.8 respectively. The determination of transport parameter confidence regions by the criteria of Donaldson and Schnabel [1987] is validated by the smooth, well-behaved isolines of $S$, which closely mimic the theoretical ellipses applied. Relevant variables calculated for the parameter uncertainty analysis for the three crosshole tracer tests are shown in Table 5.3. The results show that the estimates provided for $\mathbf{p}$ have very high confidence based on the model applied, as indicated by the very small confidence regions.

Table 5.3. Parameter Uncertainty Analysis Based on A Posteriori Error Variance

\begin{tabular}{|l|l|l|l|l|l|l|l|}
\hline Tracer Test & $S_{\min }$ & $m$ & $s_{0}^{2}$ & $\sigma_{\alpha}$ & $\sigma_{\phi}$ & $\sigma_{\alpha}{ }^{\prime}$ & $\sigma_{\phi}{ }^{\prime}$ \\
\hline $76-210: 1$ & 0.074 & 42 & 0.011 & 0.15 & 0.0002 & 0.15 & 0.0002 \\
\hline $76-230: 1$ & 0.031 & 47 & 0.0038 & 0.17 & 0.0008 & 0.12 & 0.0004 \\
\hline $76-4$ & 0.669 & 87 & 0.047 & 0.55 & 0.0012 & 0.35 & 0.0006 \\
\hline
\end{tabular}




\section{Borehole 76-4 10:1 Tracer Test}

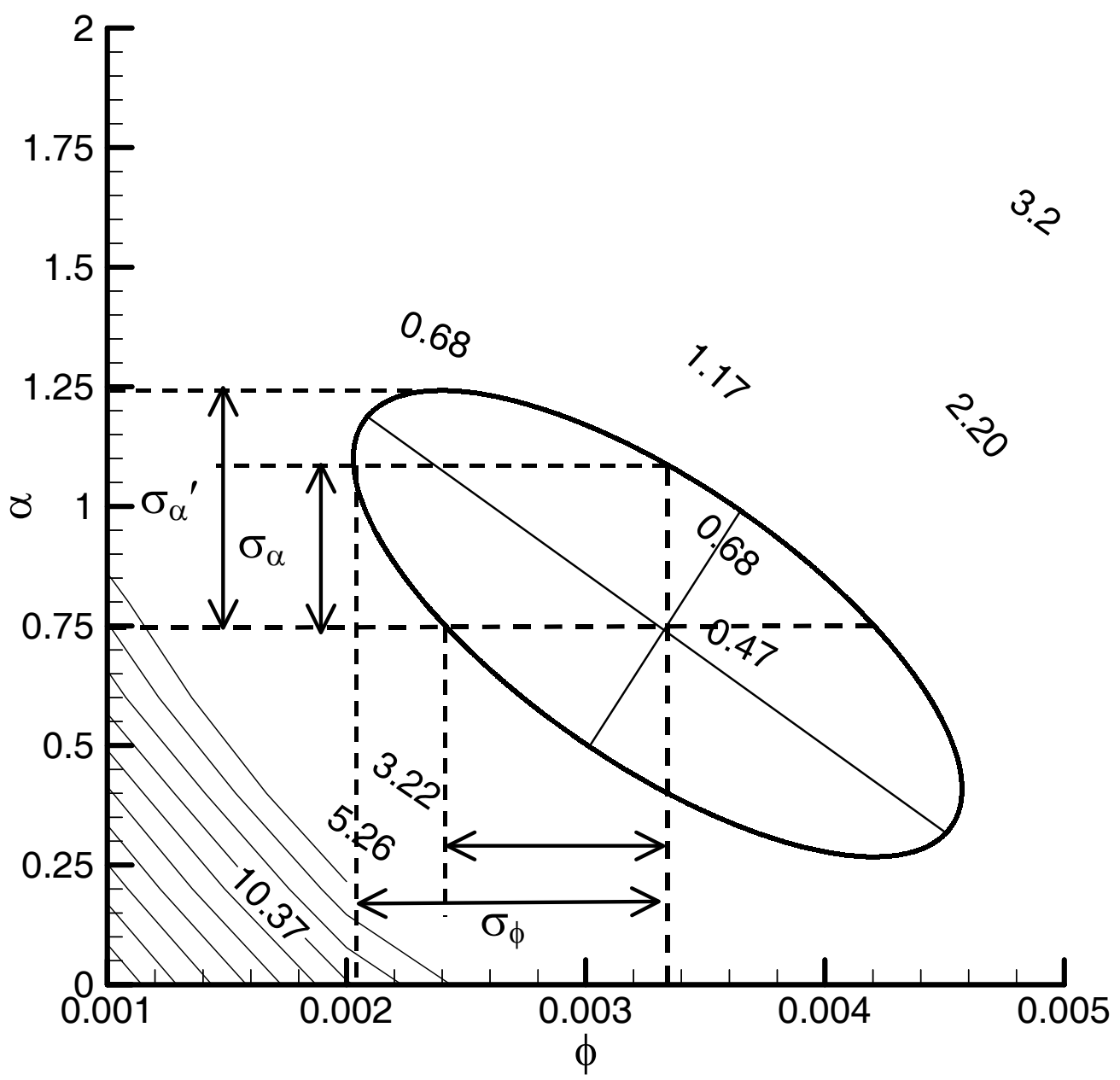

Figure 5.6 Graphical representation of the estimation covariance matrix shown as an elliptical confidence region for the Borehole 76-4 gas tracer test. The prime indicates conditional standard deviation. 


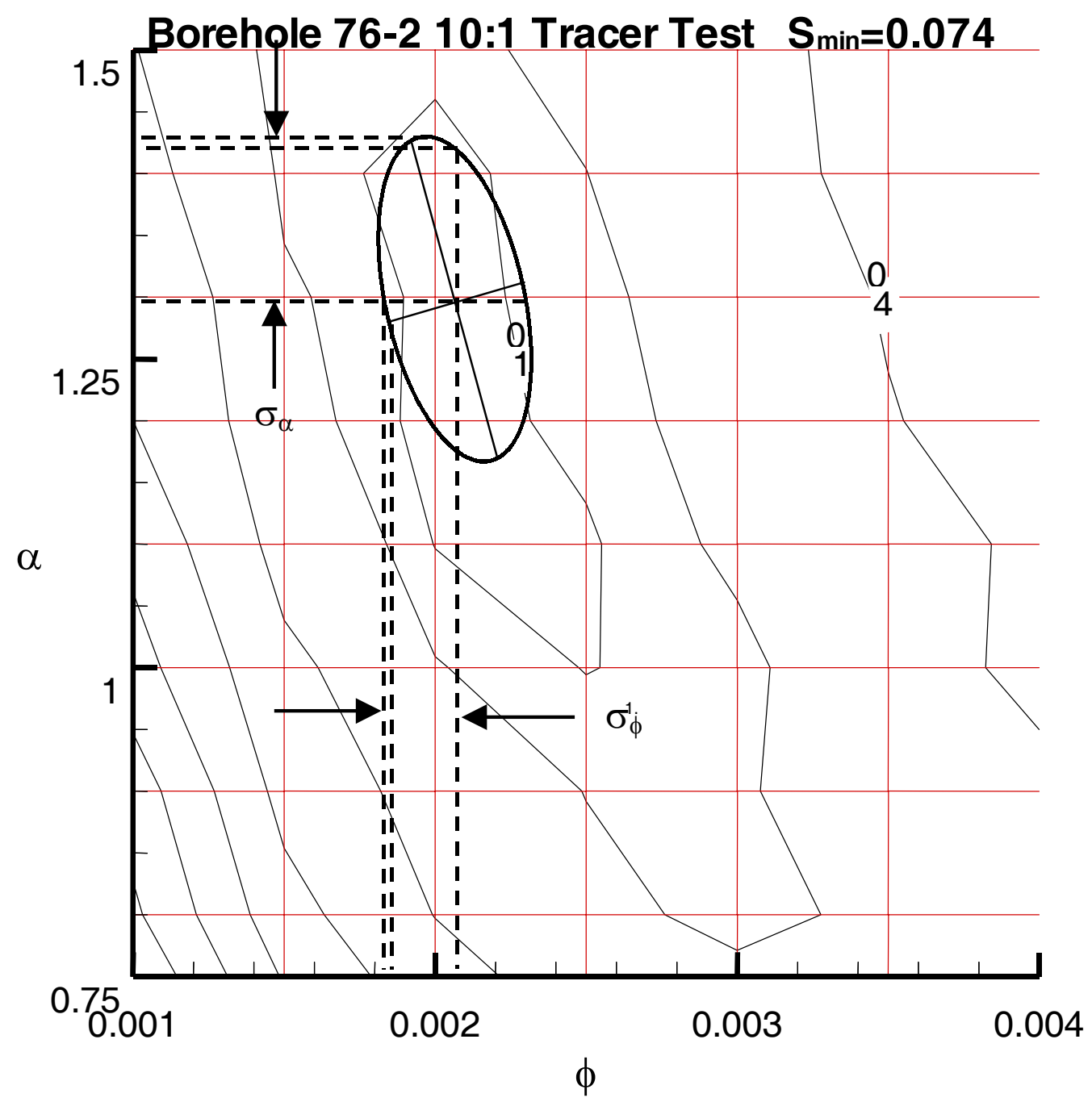

Figure 5.7 Graphical representation of the estimation covariance matrix shown as an elliptical confidence region for the Borehole 76-2 10:1 gas tracer test. The marginal and conditional standard deviations are approximately the same. 


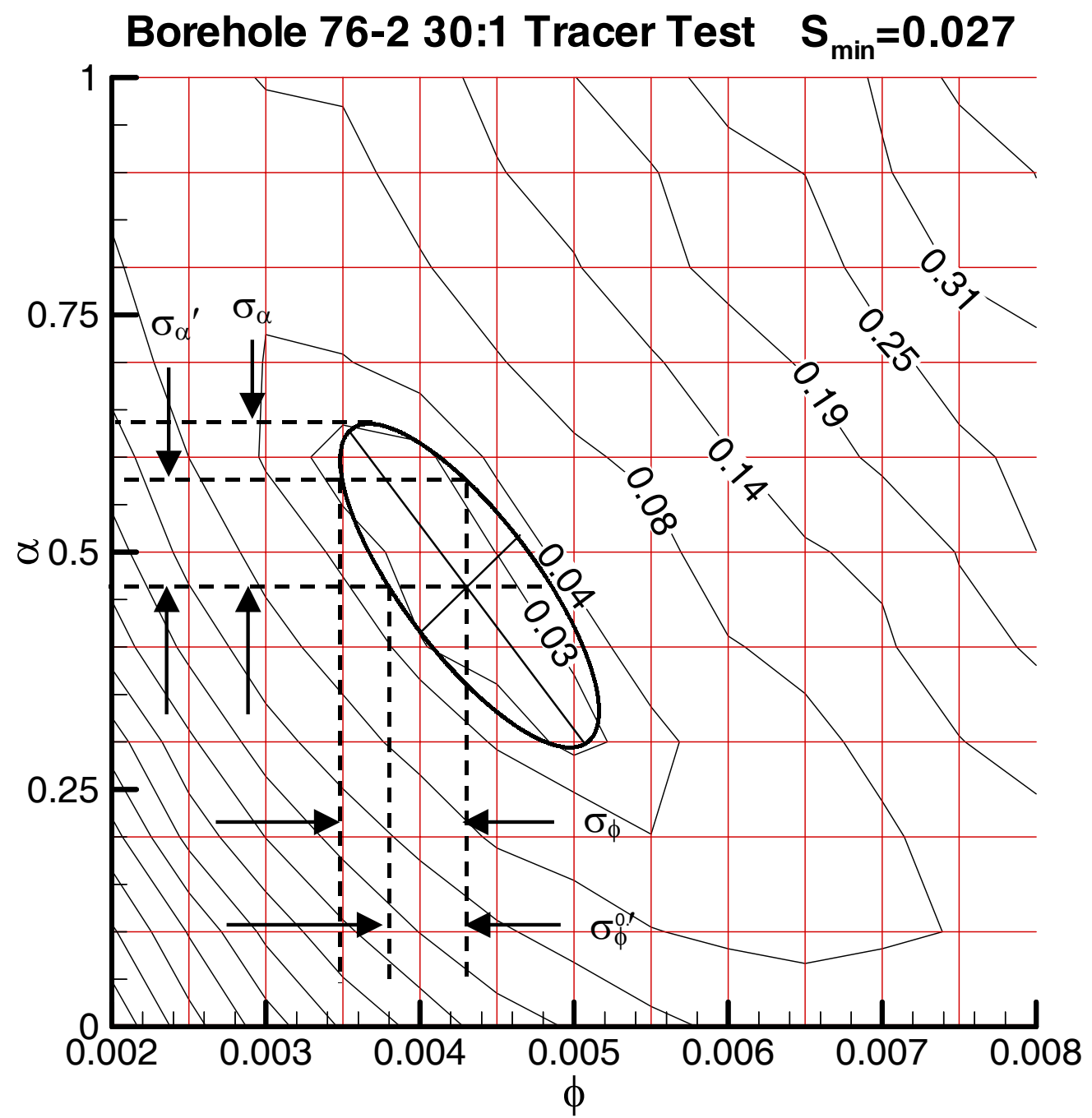

Figure 5.8 Graphical representation of the estimation covariance matrix shown as an elliptical confidence region for the Borehole 76-2 30:1 gas tracer test. The prime indicates conditional standard deviation.

\subsubsection{Huff-Puff Test}

The huff-puff test objective function displays a very different structure compared to the crosshole tests. The major qualitative difference in flow between the huff-puff test and the crosshole tracer tests is that the huff-puff test will not be influenced by flow 
channeling, which leads to macrodispersive spreading of the tracer plume. The distance over which gas is advectively transported in a flow channel during tracer injection is equal in magnitude and opposite the distance the gas travels during the withdrawal portion of the huff-puff test. Ideally, we can conceptualize that a pulse input of tracer will spread out through different channels at different velocities, but when the flow direction is reversed, they will all arrive back at the withdrawal point at the same time. Matrix diffusion (which is attributable to molecular diffusion from the fractures into the matrix) will retard tracer transport and molecular diffusion within the fracture network will spread tracer in both the huff-puff test and the crosshole tests.

The huff-puff test separates macrodispersive processes attributable to flow channeling from molecular diffusive processes. Only gas diffusive processes will "spread" the plume during a huff-puff test. The best-fit huff-puff inversion is shown in Figure 5.9. Figure 5.5 shows the structure of the least-squared-fit objective function in $(\phi, \alpha)$ space with the optimal value for $\alpha$ near 0 . This result is expected, because the macrodispersive flow channels that $\alpha$ accounts for should not be apparent in a huff-puff test.

A more detailed investigation of the best-fit parameters in $\left(\phi, D_{\text {mol }}\right)$ space with $\alpha=0$, shows that some sensitivity to porosity and also to the assumed value for molecular diffusivity exists (Figure 5.10). The estimated molecular diffusivity ranges between $1 \times$ $10^{-4} \mathrm{~m}^{2} / \mathrm{s}$ to $4 \times 10^{-4} \mathrm{~m}^{2} / \mathrm{s}$, as porosity is reduced from 0.004 to 0.001 . This is greater than the molecular diffusive value assumed for the tracer in air, which is roughly $2.3 \times 10^{-5}$ 
$\mathrm{m}^{2} / \mathrm{s}$. The molecular diffusion value determined using the RWPM model partially reflects the mixing process tracer gas undergoes within the borehole, prior to its entering the formation. Since the 7.81-meter-long injection zone in Borehole 76-2 holds 32 liters of air when installed equipment is accounted for, the injected tracer gas will mix with the gas within the wellbore prior to entering the formation. This mixing will make the withdrawal gas stream more dilute than if the gas were injected directly into the formation.

The expected dilution from wellbore mixing can be computed by looking at the volume injected in comparison to the wellbore volume, with the assumption of a batch mixing process. In the 20 minute injection, 200 liters were mixed with 32 liters of air in the wellbore. This would account for a reduction of injection gas concentration from 100 PPM to 86 PPM. The actual peak withdrawal concentration for the huff-puff test was 58 PPM. Both matrix diffusion and borehole mixing are therefore contributing to the gas diffusivity appearing greater than the molecular diffusive value. 


\section{Huff-Puff Test}

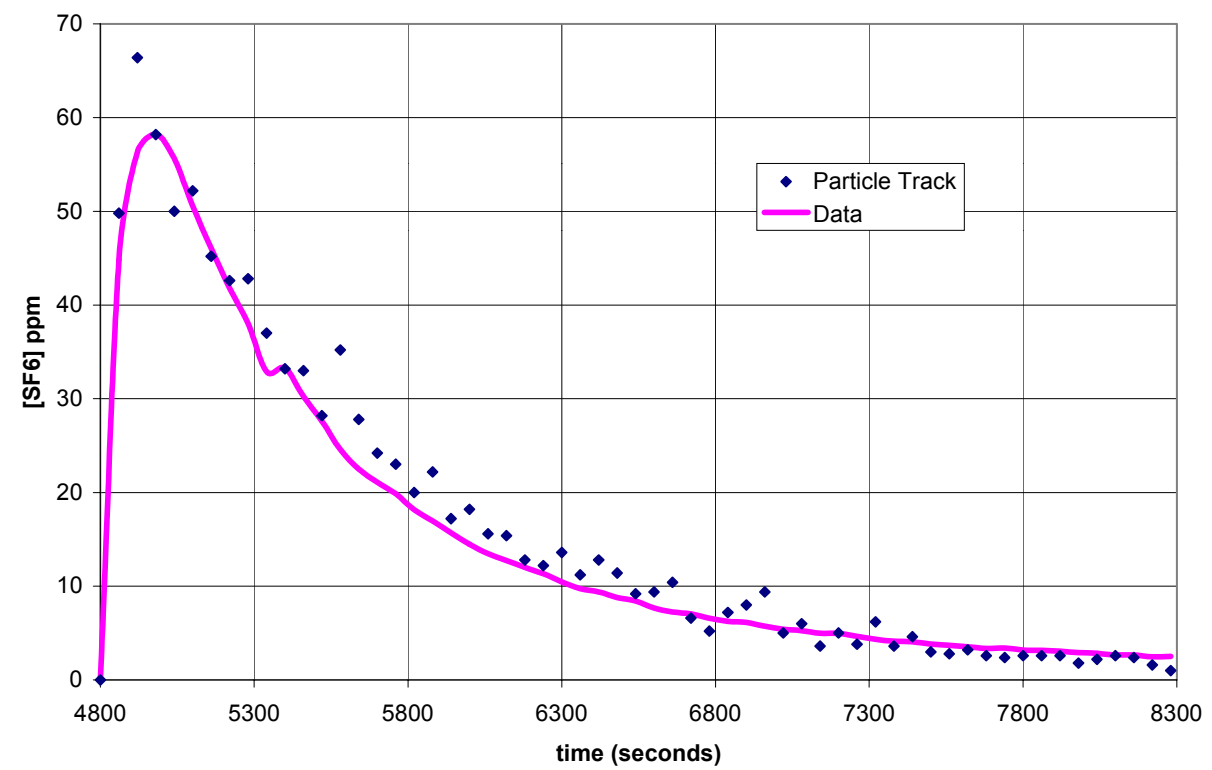

Figure 5.9 Huff-puff tracer test RWPM least-squares best fit.

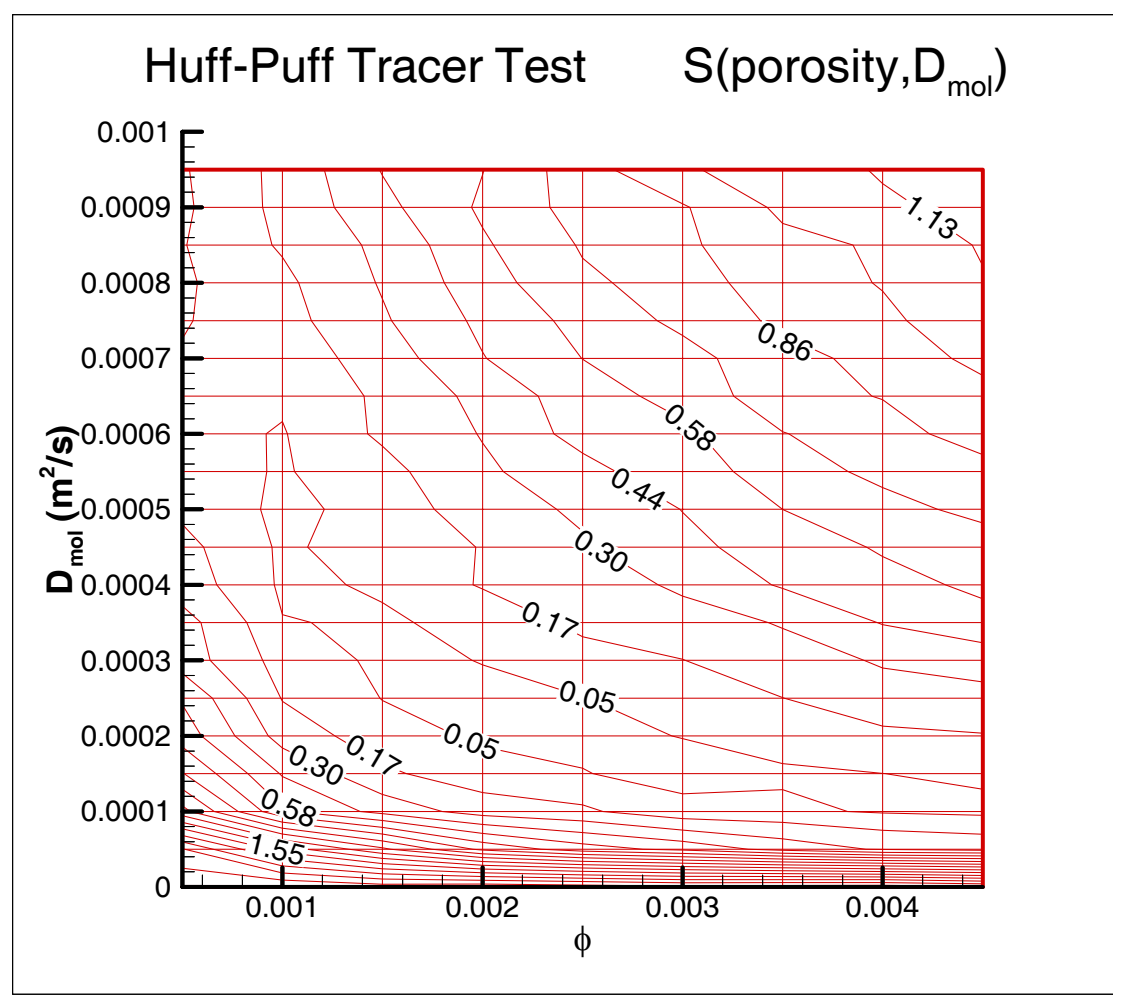

Figure 5.10 Objective function for huff-puff tracer test inverted in $\left(\phi, \mathrm{D}_{\mathrm{mol}}\right)$ space. 


\section{Discussion and Conclusions}

\subsection{Comparison between Air-Injection and Tracer Results}

A comparison between the air-permeability and gas tracer-testing results lead to different fracture porosity estimates; however, they are of similar magnitudes (see Table 6.1). Based on the uncertainty analysis for the gas tracer tests, a high degree of confidence is placed on the parameter estimate for fracture porosity in the gas tracer-test model. The air-permeability porosity estimate is considered more uncertain than the tracer estimate because of the sensitivity to the assumed flow model and the string of conditional arguments presented to account for matrix gas permeability.

In this work, fracture porosity estimates rely on either a measurement of the gas storage volume of the fractures (as interpreted by observing gas pressure transients in airinjection tests) or the time required for transport of a solute from one location to another. Assuming both air-injection and gas tracer testing models are valid representations of the physical processes, then we can compare the disparate physical processes in both models to assess the expected outcome of performing the two tests on the same region of the formation.

Air-injection tests will measure the pore space in all connected fractures, including deadend fractures that do not participate in advective transport. Gas tracer tests, alternatively, measure only fractures that are kinematically connected between the region of tracer 
injection and the region of tracer withdrawal. Because of this difference, the air-injection tests are expected to provide estimates of fracture porosities that are equal to or somewhat larger than the gas tracer tests. Note that this argument is different from the arguments presented in the literature concerning comparisons between hydraulic and tracer aperture estimates [Silliman, 1989; Tsang, 1992], which are predicated on fracture aperture variation's effect on steady-state flow. The air-injection test analysis performed here is based on transient flow analysis and measures a different process.

Based on the limited number of data points contained in Table 6.1, the air-injection and gas tracer test results do not follow the conjecture that gas-tracer-test porosity estimates will be smaller than air-permeability transient analysis estimates. The differences between the gas tracer and the air-permeability porosity estimates may derive from the fact that even conducted near the same borehole locations, these tests have different regions of influence. Gas-tracer-test flow paths are confined to a volume extending between the injection and withdrawal boreholes, while the air-permeability tests have been shown to have a zone of influence that extend out radially 10 meters or more.

Table 6.1. Porosity Estimates Using Both Air-Permeability and Gas Tracer Testing Analysis

\begin{tabular}{|l|l|l|}
\hline Location & $\begin{array}{l}\text { Air-Permeability Estimate } \\
\text { (Radial Model) }\end{array}$ & Gas Tracer Estimate \\
\hline $76-2-75-2^{*}$ & 0.0015 & $0.002-0.004$ \\
\hline $76-4-75-4^{*}$ & 0.014 & 0.003 \\
\hline $58-3$ & 0.01 & $\#$ \\
\hline $74-2$ & 0.001 & $\#$ \\
\hline
\end{tabular}

* Tracer test conducted between zones. Air-injection performed in Borehole 75. \# No tracer test performed at this location 
The air-permeability estimated fracture porosities included in Table 6.1, which vary from 0.001 to 0.014 , are considered to be reasonable based on what is known about the spatial variations in fracture densities. Figure 6.1 shows the relationship between airpermeability and fracture porosity based on the air-injection test analysis. A general trend of increasing permeability with increasing porosity is clearly evident. This result suggests that to model transport in Topopah Spring tuff, a heterogeneous permeability field should also be correlated with a heterogeneous porosity field, as suggested by Hassan et al. [1998].

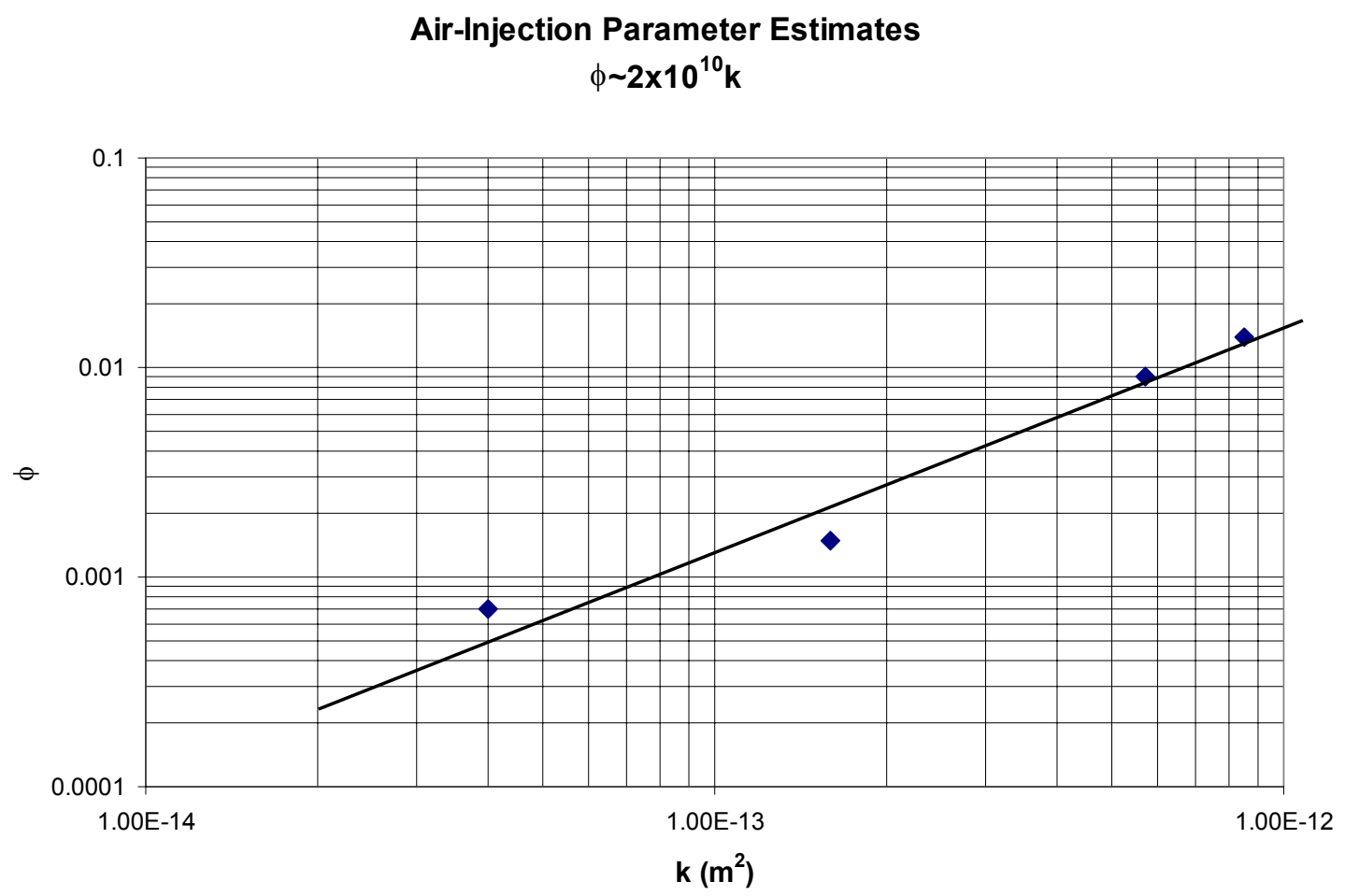

Figure 6.1 Relationship established between permeability and porosity for Topopah Spring tuff using air-injection test transient analysis. 


\subsection{Field Testing Lessons Learned}

The four tracer tests conducted required a far greater expenditure of effort and cost than performing an entire sequence of air-injection tests in all 46 isolated DST intervals.

Assuming the pneumatic packers and injection flow controllers for both the gas tracer and air-permeability tests are the same, the gas tracer test also requires calibration and field implementation of a gas analyzer, as well as maintaining a withdrawal gas stream at a constant flow rate. This simple summary of the difference between equipment required for both tests belies the real complexity of conducting the gas tracer tests.

Each of the four tracer tests required only one day to execute, but a few days were spent prior to each test preparing gas standards, setting up the flow equipment, and calibrating the mass spectrometer. A person was required to be in the field to oversee the gas tracer tests and to calibrate the mass spectrometer on a periodic basis. Two attempts to conduct gas tracer tests prior to the collection of the data sets presented here resulted in unusable data. The first attempt failed to provide acceptable mass balances because of calibration errors associated with learning the tuning behavior of the Balzer mass spectrometer, and the second attempt failed because of the inability to maintain the gas withdrawal stream at a steady flowrate. In each case, mobilization, demobilization, and correcting the associated problems required additional time and effort.

For the gas tracer tests, the withdrawal gas stream proved to be problematic to maintain at a constant flow rate, since the formation air is often saturated with water vapor. Water vapor, although not a problem for the mass spectrometer, (which was fitted with a heated 
inlet capillary) interferes with some measurement techniques, (such as infrared photoacoustic emission monitoring) and needs to be removed from the gas stream. If the formation is a few degrees warmer than the atmospheric air, as is often the case, then large volumes of water can condense to completely fill gas extraction tubes and foul flow controllers if they are not equipped with a method to purge accumulated condensate. This was the reason that the refrigeration chiller was added to the gas withdrawal equipment upstream of the flow controlling unit.

For the air-injection measurements, the test in each zone consisted of one hour of gas injection followed by one hour of recovery monitoring. For many tests, this could have been shortened considerably, but was kept longer for consistency and to ensure that steady-state conditions were always obtained. To perform all 46 air-injection tests required 92 hours of continuous operation. The air-permeability testing procedure had been completely automated, and intelligent algorithms programmed into the data acquisition and control system obviated the need for human oversight. The initial effort to fully automate the testing process made trivial what would have been a time-consuming testing task. As heating of the DST continues, fully automated air-injection tests continue to be executed on a quarterly basis.

\subsection{Conclusions}

A new methodology has been developed for conducting gas tracer tests to investigate the kinematic porosity of a fractured welded tuff. The cumulative mass balances are shown to be almost $100 \%$ for the four tests conducted, and tracer concentration measurements 
performed in real-time in the field provide extremely high-quality data. A random walk particle-tracking method (RWPM) has been applied to provide estimates for fracture porosity and formation dispersivity. An uncertainty analysis of the RWPM parameter estimates reveals that the uncertainty associated with the fracture porosity estimate is small. The estimates generated are considered to be far more accurate than those from prior work, which used the cubic power law to generate fracture aperture estimates. Based on the RWPM results, a realistic kinematic fracture porosity value to use in process models for the tested region of Topopah Spring tuff investigated is 0.003 .

The air-injection test analysis has revealed a positive correlation between permeability and porosity estimates. Based on the test results plotted in Figure 6.1, a correlation between permeability and porosity has been established suggesting that the porosity can be expressed as

$$
\phi \approx 2 \times 10^{10} k
$$

where permeability is in units of $\mathrm{m}^{2}$ and porosity is $\mathrm{m}^{3} / \mathrm{m}^{3}$. Since the measurements that have provided this relationship were made on the scale of the air-injection test zones ( 5 to 20 meters), this fundamental relationship is applicable for continuum modeling at this scale.

Finally, the process of conducting a transport experiment, rather than just performing hydraulic testing, has been shown to be invaluable. This is particularly true in a fractured rock system, where permeability and the kinematic fracture porosity may span several orders of magnitude. Tracer transport tests provide robust estimates for fracture porosity 
on the field scale at which they are conducted on. The ability to conduct more airpermeability tests on different spatial scales is an attractive approach for understanding the variability of porosity and its relationship to the permeability structure of the formation. However, gas tracer tests and air-injection tests measure fundamentally different processes. The porosity estimates will be similar when the fracture network is dense, leading to the bulk of the fractures being kinematically connected. Furthermore, air-injection test analyses cannot replace the understanding of macrodispersive processes provided by conducting actual transport studies.

\subsection{Recommendations for Future Work}

From an experimental standpoint, a logical extension to the gas tracer testing methodology developed would be to fully automate the gas tracer testing process in a manner that would facilitate acquisition of a large set of test data. The high level of automation required to keep a complex chemical analyzer fully calibrated for long periods of time under field conditions has been demonstrated at a TCE plume at Fort Ord, California, using sample streams from different wells fed into an automated gas chromatograph [Daley, 2001]. For gas tracer testing, only a two-point calibration would be required, based on the observed linearity of the Balzer Omnistar Mass Spectrometer. The acquisition of a large set of gas tracer transport data, conducted in the same locations as air-permeability tests, would enhance the development of a fundamental relationship between porosity and permeability and could provide better information on the expected parameter variations. 
The air-injection data can potentially be analyzed by simultaneous inversions of multiple pressure transients. Parameter estimates using simultaneous inversions of multiple pressure transients were attempted using a radial homogeneous model and a composite radial model (two different concentric regions with different permeabilities and porosities), but model inversions provided very poor, unreliable results. This was somewhat expected, in light of the known heterogeneity of the formation. Future work could incorporate an empirically determined relationship between permeability and porosity into flow models. A set of heterogeneous realizations of the formation can be used to simultaneously invert multiple sets of acquired pressure transient data and provide a more robust estimate of transport parameters using an inversion process such as the simulated annealing technique used by Mauldon et al. [1993] to develop discrete fracture networks. 


\section{References}

Adams, M.C., J.J. Beall, S. L. Enedy, P. Hirtz, 1991, The application of halogenated alkanes as vapor-phase tracers: a field test in the Southeast Geysers, Geothermal Resources Council, Transactions 15, 457-463.

Adams, M.C., 1995, Vapour, liquid, and two-phase tracers for geothermal systems, Proc. World Geothermal Congress, Proc., Pisa, Italy, 1875-1880.

Ahlstrom, S.W., H.P. Foote, R.C. Arnett, C.R. Cole, and R.J. Serne, 1977, Multicomponent mass transport model: theory and numerical implementation, Rep. BNWL2127, Batelle Pacific Northwest Lab., Richland, Washington.

Arandjelovic, D., 1977, Determining groundwater flow in karst using "Geobomb." In Karst Hydrology, edited by J.S. Tolson, and F. L. Doyle. Memoirs of the $12^{\text {th }}$ Congress of the Int. Assoc. Hydrogeologists, University of Alabama Press, Huntsville, 399-400.

Baehr, A.L. and M.F. Hult, 1991 Evaluation of unsaturated zone air permeability through pneumatic tests, Water Resour. Res. 27 (10), 2605-2617.

Bauer, F. and J. Zötl, 1972, Karst of Austria. In Karst, Important Karst Regions of the Northern Hemisphere. Edited by M. Herak and V. T. Stringfield, Amsterdam, Elsevier Publ. Co., 225-265.

Bear, J., 1972, Dynamics of Fluids in Porous Media, American Elsevier Publishing Company, Inc., New York.

Bellin, A., G. Dagan, and Y. Rubin, 1996, The impact of head gradient transients on transport in heterogeneous formations: Application to the Borden Site, Water Resourc. Res. 32 (9), 2705-2713

Berkowitz, B., H. Scher, 1995, On characterization of anomolous dispersion in porous and fracture media, Water Resour. Res. 31 (6), 1461-1466.

Bird, R.B., W.E. Stewart, and E.N. Lightfoot, 1960, Transport Phenomena, John Wiley \& Sons, Inc, New York.

Bodvarsson G. S., W. Boyle, R. Patterson, D. Williams, 1999, Overview of scientific investigations at Yucca Mountain, the potential repository for high-level nuclear waste, J. Contam. Hydrol. 38, 3-24.

Brooks, R.J. and A.T. Corey, 1964, Hydraulic properties of porous media, Hydrol. Pap. 3, Colorado State University, Fort Collins, Colorado. 
Buesch, D. C., and R. W. Spengler, 1998, Character of the middle nonlithophysal zone of the Topopah Spring tuff at Yucca Mountain, Proceedings of the $8^{\text {th }}$ International Conference, High-Level Radioactive Waste Management, American Nuclear Society, $16-23$.

Daley, P., 2001, personal communication.

Dana, E., and F. Skoczylas, 1999, Gas relative permeability and pore structure of sandstones, Int. J. Rock Mechanics 36, 612-625.

Davis, S.N., G.M. Thompson, H.W. Bentley, and G. Stiles, 1980, Ground-water tracers a short review, Groundwater 18 (1), 12-28.

Donaldson, J. R. , and R. B. Schnabel, 1987, Computational experience with confidence regions and confidence intervals for nonlinear least squares, Technometrics 29 (1), $67-82$.

Drost, W., D. Klotz, A. Koch, H. Moser, F. Neumaier, and W. Ravert, 1968, Point dilution methods of investigating ground-water flow by means of radioisotope, Water Resour. Res. 4 (1), 125-146.

Dverstorp, B.J., J. Andersson, and W. Nordqvist, 1992, Discrete fracture network interprestation of field tracer migration in sparsely fracture rock, Water Resourc. Res. 28 (9), 2327-2343.

Edwards, K.B., and L.C. Jones, 1994, Air permeability from pneumatic tests in oxidized till, J. of Env. Eng. 120 (2), 329-347.

Ezzedine, S. and Y. Rubin, Analysis of the Cape Cod tracer data, Water Resourc. Res. 33 (1), 1-11.

Fabryka-Martin, J. A.V. Wolfsberg, P.R. Dixon, S. Levy, J. Musgrave, and H.J. Turin, 1996, Summary report of chlorine-36 studies: sampling, analysis and simulation of chlorine-36 in the exploratory studies facility, Level 3 Milestone Report, 3783M, Los Alamos National Laboratory, Los Alamos, New Mexico.

Finsterle, S., 1997a ITOUGH2 command reference, Rep. LBNL 40041, Lawrence Berkeley National Lab., Berkeley, California.

Finsterle, S., 1997b ITOUGH2 sample problems, Rep. LBNL 40042, Lawrence Berkeley National Lab., Berkeley, California.

Finseterle, S., 1997c, Application of inverse modeling to geothermal reservoir simulation, Proceedings of the Twenty-Second Workshop on Geothermal Reservoir Engineering, Stamford, California. 
Finsterle, S. and K. Pruess, 1995, Solving the estimation-identification problem in twophase flow modeling, Water Resour. Res. 31 (4), 913-924

Flint, L. E., 1996, Matrix properties of hydrogeologic units at Yucca Mountain, Nevada, U.S. Geological Survey Water-Resources Investigations Report 96-XX.

Flint, L. E., 1997, Physical properties, water content and water potential on samples from boreholes ESF-NAD-GTB\#1 and ESF-NAD-GTB\#1A from Alcove \#6 in the ESF, Data Tracking Number GS970208312231.003, U. S. Geological Survey.

Fredlund, D.G., A. Xing, and S. Huang, 1994, Predicting the permeability function for unsaturated soils using the soil-water characteristic curve, Can. Geotech. J. 31, 533-546.

Frick, U., W.R. Alexander, B. Baeyens, P. Bossart, M.H. Bradbury, Ch. Bühler, J. Eikenberg, Th. Fierz, W. Heer, E. Hoehn, I.G. McKinley and P.A. Smith, 1992, The radionuclide migration experiment - overview of investigations 1985-1990, National Cooperative for the Disposal of Radioactive Waste, Technical Report 91-04, Switzerland.

Gardner, G. D., and R. E. Gray, 1976 Tracing subsurface flow in karst regions using artificially colored spores. Assoc Eng. Geologists Bull. (13), 177-197.

Gelhar, L.W., C. Welty, K.R. Rehfeldt, 1992, A critical review of field-scale dispersion in aquifers, Water Resour. Res. (28) 7, 1955-1974.

Glover, R.B. and J.P. Kim, 1993, SF6 - a new nonradioactive geothermal tracer, Proceedings NZ Geothermal Workshop, $15^{\text {th }}, 25-132$.

Grisak, G.E., W.F. Merritt, and D.W. Williams, A fluoride borehole dilution apparatus for groundwater velocity measurements, Can. Geotech. J. (14), 554-561.

Haldeman, W.R., Y. Chuang, T.S. Rasmussen, and D.D. Evans, 1991, Laboratory analysis of fluid flow and solute transport through a fracture embedded in porous tuff, Water Resour. Res. 27 (1), 53-65.

Hanks, T.C., I.J. Winograd, R.E. Anderson, T.E. Reilly, and E.P. Weeks, 1999, Yucca Mountain as a radioactive-waste repository, U.S. Geological Survey circular 1184, Denver, $\mathrm{CO}$.

Hassan, A. E., J. H. Cushman, J. W. Delleur, 1998, Significance of porosity variability to transport in heterogeneous porous media, Water Resour. Res. 34 (9) 2249-2259.

Heiser, J.H. , 1994, Subsurface barrier verification technologies, BNL-61127, Brookhaven National Laboratory. 
Herzog, F., 1991, A simple transport model for the Grimsel migration experiments, National Cooperative for the Disposal of Radioactive Waste, Technical Report 91-31, Switzerland

Hoehn, E., J. Eikenberg, T. Fierz, W. Drost, E. Reichlmayr, 1998, The Grimsel migration field experiment: field injection-withdrawal experiments in fractured rock with sorbing tracers, J. of Contam. Hydrol. 34, 85-106.

Horslev, M. J., 1951, Time lag and soil permeability in ground-water observations: U. S. Army Corps of Engineers, Waterways Experimental Station, Vicksberg, Miss., Bulletin no. $36,47 \mathrm{p}$.

Karasaki, K., B. Freifeld, A. Cohen, K. Grossenbacher, P. Cook, and D. Vasco, 2000 A multidisciplinary fracture rock characterization study at Raymond field site, Raymond, CA, J. of Hydrol. 236, 17-34.

Kearl, P.M., R. J. Zinkl, J.J. Dexter, and T. Cronk, 1990, Air permeability measurements of the unsaturated Bandalier tuff near Los Alamos,. New Mexico, J. of Hydrol. 117(1990), $225-240$.

Keller, A.A., P.V. Roberts, and M.J. Blunt, 1999 Effect of fracture aperture variations on the dispersion of contaminants, Water. Resour. Res. 35(1), 55-63.

Kimura, H. and M. Munakata, 1992, Validation studies of tracer tests in a fracture zone at the Finnsjön research area, Advances in Water Resources 15, 63-74.

Klinkenberg, L. J., 1941, The permeability of porous media to liquids and gases, in: API Drilling and Production Practice, 200-213.

Kosakowski, G., B. Berkowitz, and H. Scher, 2001, Analysis of field observations of tracer transport in a fracture till, J. Contam. Hydrol. 47, 29-51.

LaBolle, E. M., G.E. Fogg, and A. F. B. Tompson, 1996, Random-walk simulation in heterogeneous porous media: local mass-conservation problem and implementation methods, Water Resour. Res. 32 (3), 583-593.

LeCain, G.D., 1995, Pneumatic testing in 45-degree-inclined boreholes in ash-flow tuff near superior, Arizona, U.S. Geological Survey Water-Resource Investigations Report 95-4073.

LeCain, G.D., 1997, Air-injection testing in vertical norejholes in welded and nonwelded tuff, Yucca Mountain, Nevada, U.S. Geological Survey Water-Resource Investigations Report 96-4262. 
LeCain, G.D., L.O. Anna, and M.F. Fahy, 2000, Results from geothermal logging, air and core-water chemistry sampling, air-injection testing, and tracer testing in the Northern Ghost Dance Fault, Yucca Mountain, Nevada, November 1996 to August 1998, U.S. Geological Survey Water-Resource Investigations Report 99-4210.

Margolin, G. and B. Berkowitz, 2000, Application of continuous time random walks to transport in porous media, J. Phys. Che,. B 104, 3942-3947.

Marsily, G. de, 1986, Quantitative Hydrogeology, Groundwater Hydrology for Engineers, Academic Press, New York.

Massmann, J. W., and M. Madden, 1994, Estimating air conductivity and porosity from vadose-zone pumping tests, J. of Env. Eng. 120 (2), 313-328.

Mauldon A.D.; K. Karasaki, S.J. Martel; J.C.S. Long, M. Landsfeld; A. Moench, and S. Vomvoris, 1993, An inverse technique for developing models for fluid flow in fracture systems using simulated annealing, Water Resourc. Res. 29 (11), 3775-3789.

Moench, A.F., 1995, Convergent radial dispersion in a double-porosity aquifer with fracture skin - Analytical solution and application to a field experiment in fracture chalk. Water Resourc. Res. 31 (8), 1823-1835

Morel-Seytoux, H., P.D. Meyer, M. Nachabe, J. Touma, M.T. van Genuchten, and R.J. Lenhard, 1996, Parameter equivalence for the Brooks-Corey and van Genuchten soil characteristics: preserving the effective capillary drive, Water Resourc. Res. 32 (5), 1251-1258.

Moreno, L., I. Neretnieks, and T. Erikson, 1985, Analysis of some laboratory tracer runs in natural fissures, Water Resourc. Res. 21 (7), 951-958

Moreno, L. and C.F. Tsang, 1991, Multiple-peak response to tracer injection tests in single fractures: a numerical study, Water Resourc. Res. 27 (8) 2143-2150

Mroczek, E. K., 1997, Henry's Law constants and distribution coefficients of sulfur hexafluoride in water from 25C to 230C, J. Chem. Eng. Data 42, 116-119.

Neretnieks, I., 1980, Diffusion in the rock matrix: an important factor in radionuclide retardation, J. of Geophys. Res. 85 (B8), 4379-4397.

Neretnieks, I., 1983, A note on fracture flow dispersion mechanisms in the ground, Water Resour. Res. 19 (2), 364-370. 
Neretnieks, I., T. Eriksen, and P. Tähtinen, Tracer movement in a single fissure in granitic rock: Some experimental results and their interpretation, Water Resour. Res. 18 (4), 849-858.

Olschewski, A., Fischer, U., Hofer, M. and Schulin, R. (1995) Sulfur hexafluoride as a gas tracer in soil venting operations. Environmental Science and Technology 29, 264-266.

Ostensen, R.W., 1998, Tracer tests and contaminant transport rates in dual-porosity formations with application to the WIPP, J. of Hydrol. 204, 197-216.

Prickett, T.A., T.G. Naymik, and C.G. Longquist, 1981, A random walk solute transport model for selected groundwater quality evaluations, Bull. Ill. State Water Survey. 65.

Pruess, K. and T. N. Narasimhan., 1982, On fluid reserves and the production of superheated steam from fractured, vapor dominated geothermal reservoirs, J. Geophys. Res. 87 (B11), 9329-9339.

Pruess, K. and T.N. Narasimhan., 1985 A practical method for modeling fluid and heat flow in fractured porous media, Soc. Pet. Eng. J. 25 (1), 14-26.

Pruess, K., C. Oldenburg, and G. Moridis, 1999, TOUGH2 User's Guide Version 2, Lawrence Berkeley National Laboratory, LBNL-43134, Berkeley, California.

Ramey, H. J., 1970, Approximate solutions for unsteady liquid flow in composite reservoirs, J. of Can. Pet. Tech., 32-37.

Rasmussen, T. C., D. D. Evans, P. J. Sheets, J. H. Blanford, 1990, Unsaturated fractured rock characterization methods and data sets at the Apache Leap Tuff Site, Rep NUREG/CR-5596, 125 pp., Nucl. Reg. Comm., Washington, D. C.

Rasmussen, T. C., 1995, Laboratory characterization of fluid flow parameters in a porous rock containing a discrete fracture, Geophysical Research Letters, 22 (11), 1401-1404.

Rousseau, J.P., E.M. Kwicklis, D.C. Gillies, 1999, Hydrogeology of the unsaturated zone, north ramp area of the exploratory studies facility, Yucca Mountain, Nevada, Water-Resources Investigations Report 98-4050, U.S. Geological Survey, Denver, Colorado.

Scher, H., and M. Lax, 1973, Stochastic transport in a disordered solid: I. theory, Phys. Rev. B 7 (10), 4491-4502

Shan, C., R.W. Falta, and I. Javendel, 1992, Analytical solutions for steady state gas flow to a soil vapor extraction well, Water Resour. Res. 28 (4), 1105-1120. 
Silliman, S.E., 1989, An interpretation of the difference between aperture estimates derived from hydraulic and tracer tests in a single fracture, Water Resour. Res. 25 (10), $227-2283$.

Snow, D.T., 1965, A parallel plate model of fractured permeable media, Ph.D. dissertation, University of California, Berkeley, California.

Sonnenthal, E.L., C.F. Ahlers and G.S. Bodvarssom, 1997, Fracture and fault properties for the UZ site-scale flow model, chapter 7 in "The Site-Scale Unsaturated Zone Model of Yucca Mountain, Nevada, for the Viability Assessment," Report LBNL-40376, Lawrence Berkeley National Laboratory, Berkeley, California.

Sonnenthal, E.L., N. Spycher, and J. Apps, 1998, Interpretive analysis of the thermohydrologicl-chemical processes of the drift-scale test, chapter 3 in Drift Scale Test Progress Report, Milestone report SP2930M4, Lawrence Berkeley National Laboratory, Berkeley, California.

Sudicky, E.A., 1996, A natural gradient experiment on solute transport in a sand aquifer: Spatial variability of hydraulic conductivity and its role in the dispersion process, Water Resourc. Res., 22 (13), 2069-2082.

Thompson, G., 1977, Fluorocarbon tracing test at Burial Ground 6, Oak Ridge National Laboratory, Oak Ridge, Tennessee, subcontract 7224.

Tsang, Y. W., J. Apps, J. T. Birkholzer, B. Freifeld, M. Q. Hu, J. Peterson, E. Sonnenthal, and N. Spycher, 1999, Yucca Mountain Single Heater Test final report, LBNL-42537, Berkeley, California.

Tsang, Y. W., 1992, Usage of "equivalent apertures" for rock fractures as derived from hydraulic and tracer tests, Water Resour. Res. 28 (5), 1451-1455.

Tsang, Y. W., 1995, Study of alternative tracer tests in characterizing transport in fracture rocks, Geophysical Research Letters 22 (11), 1421-1424.

Tsang, Y. W. and C. F. Tsang, 1987, Channel model of flow through fractured media, Water Resour. Res. 23 (3), 467-479.

Tsang, Y.W., C.F. Tsang, I. Neretnieks, and L. Moreno, 1988, Flow and tracer transport in fractured media: a variable aperture channel model and its properties, Water Resour. Res. 24 (12), 2049-2060.

U. S. Army Corps of Engineers, 1997, In situ air sparging, engineer manual, 1110-1-4005 U. S. Army Corps of Engineers, Washington DC, 4-2. 
U.S. DOE, 2000, Yucca Mountain site description, TDR-CRW-GS-000001, U. S. Department of Energy, Las Vegas, Nevada.

Van Genuchten, M. T., 1980 A closed-form equation for predicting the hydraulic conductivity of unsaturated soils, Soil Sci. Soc. Am. J. 44 (1980), 892-898.

Wang, J.S.Y., and R. Suarez-Rivera, 1997, Laboratory results of hydrological properties from dry drilled cores in the drift scale test area and in the single heater test area of the thermal test facility, Lawrence Berkeley National Laboratory, Level 4 Milestone SP5130M4, Berkeley, California.

Warren, J. E., and P. J. Root, 1963, The behavior on naturally fractured reservoirs, Soc. of Petrol. Eng. J. 3 (1), 245-255.

Wilson, R.D. and D.M. Mackay, 1993, The use of sulfur hexafluoride as a conservative tracer in saturated sandy media, Ground Water 21, 719-724.

Woodbury, A. D. and Y. Rubin, 2000, A full-Bayesian approach to parameter inference from tracer tracel time moments and investigation of scale effects at the Cape Cod experimental site, Water Resourc. Res. 36 (1), 159-171

Zimmerman, R. W., S. Kumar, and G. S. Bodvarsson, 1991, Lubrication theory analysis of the permeability of rough-walled fractures, Int. J. Rock Mech. 28, 325-333 
Appendix A: Air-injection Test Data 
DP 57-1 (11-7-97)

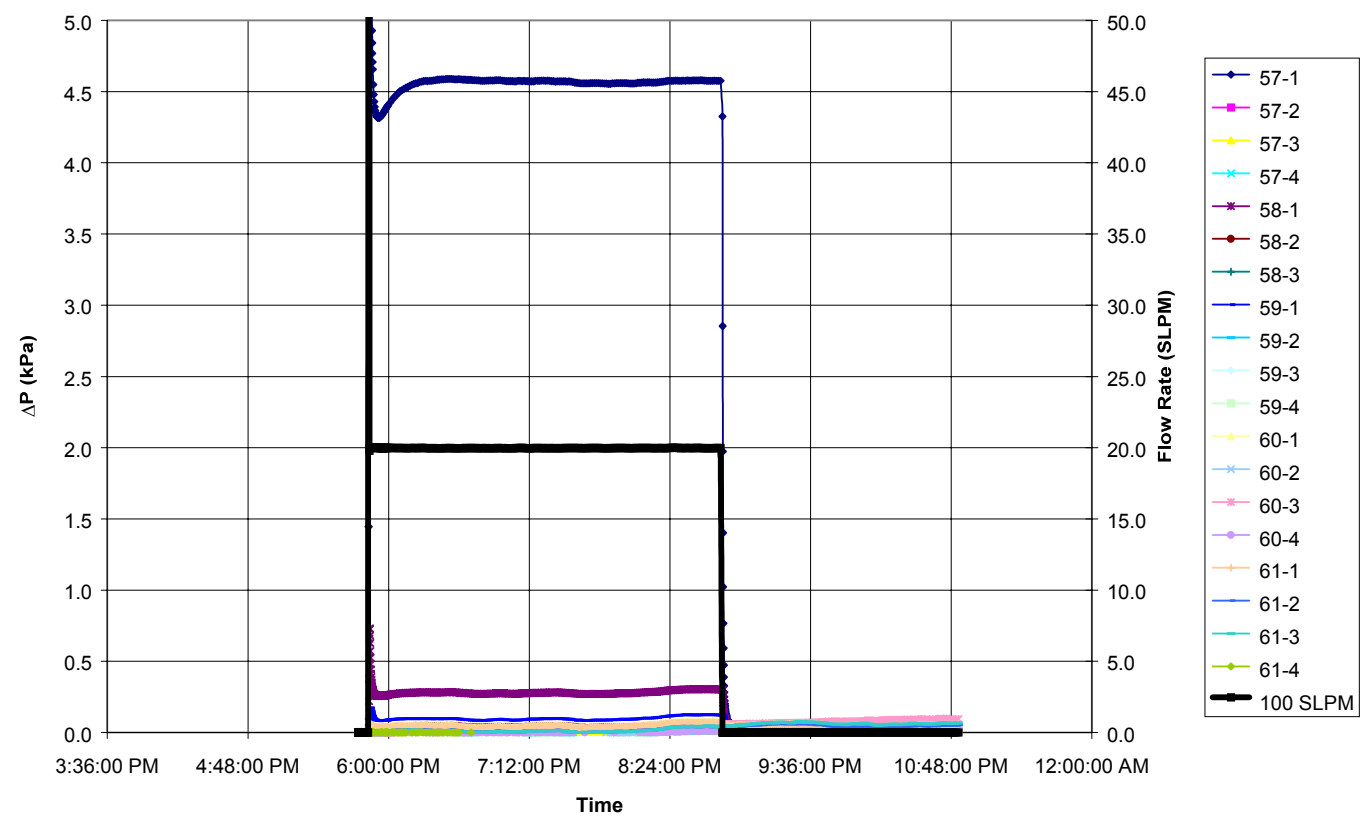

DP 57-2 (11-8-97)

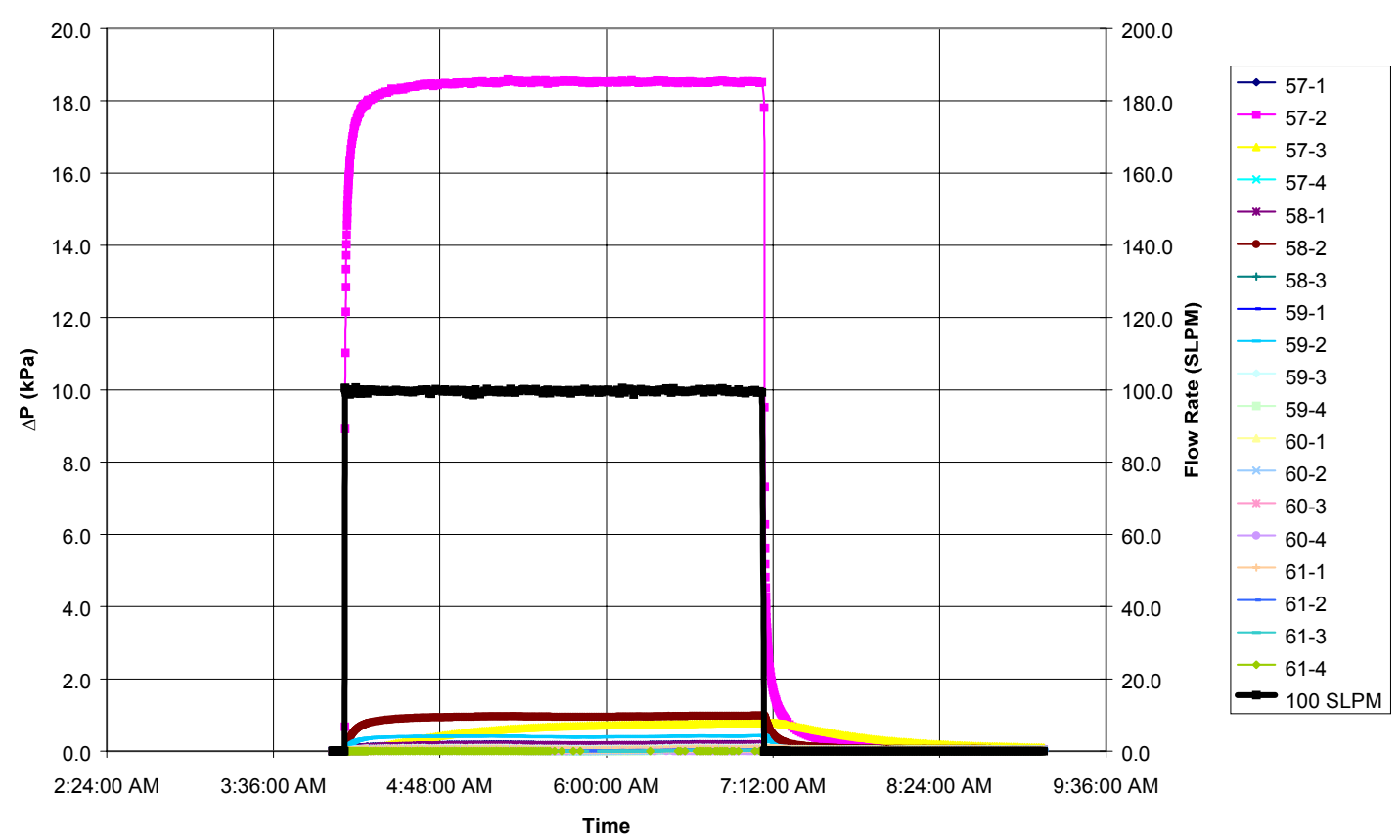


DP 57-3 (11-8-97)

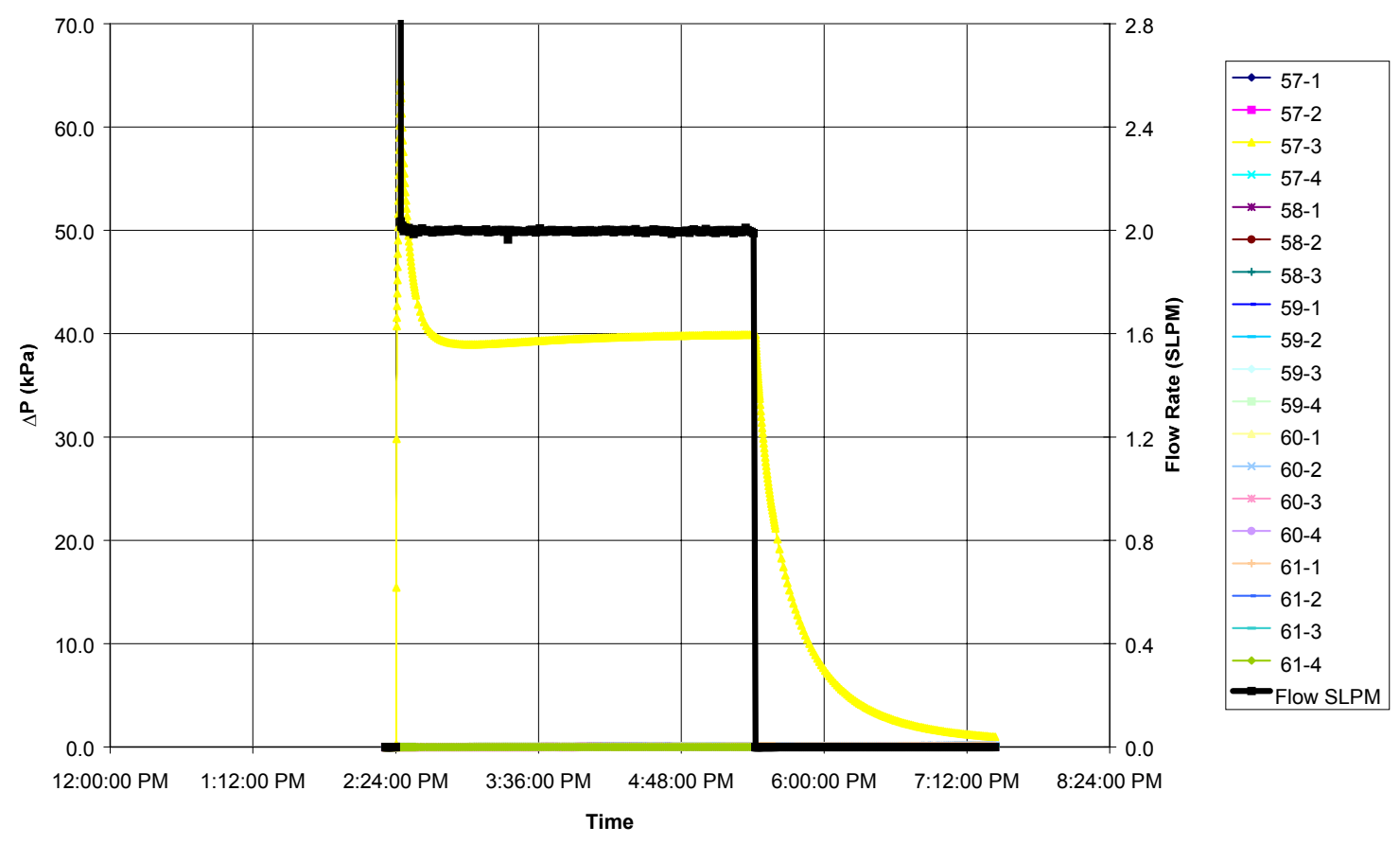

DP 57-4 (11-9-97)

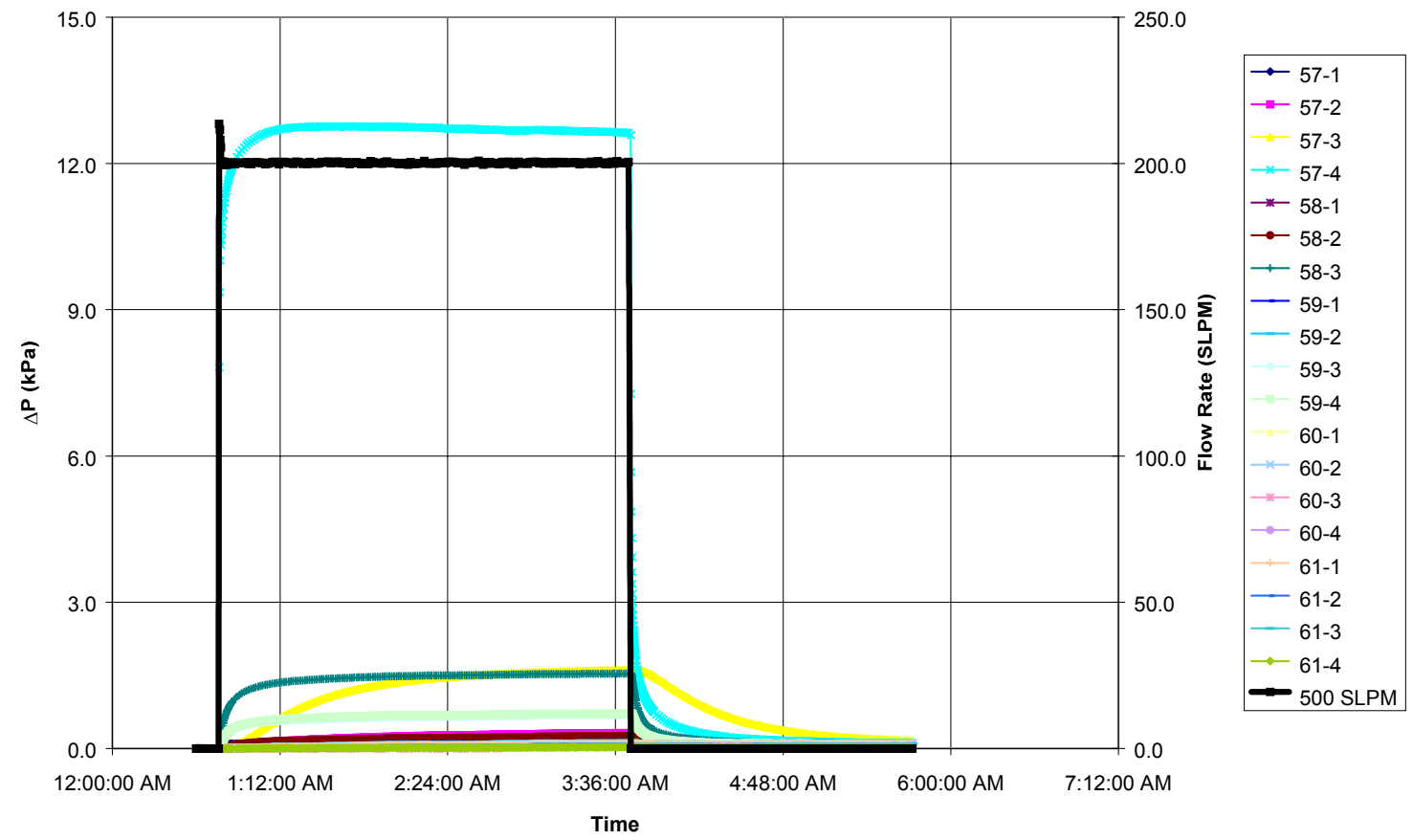


DP 58-1 (11-16-97)

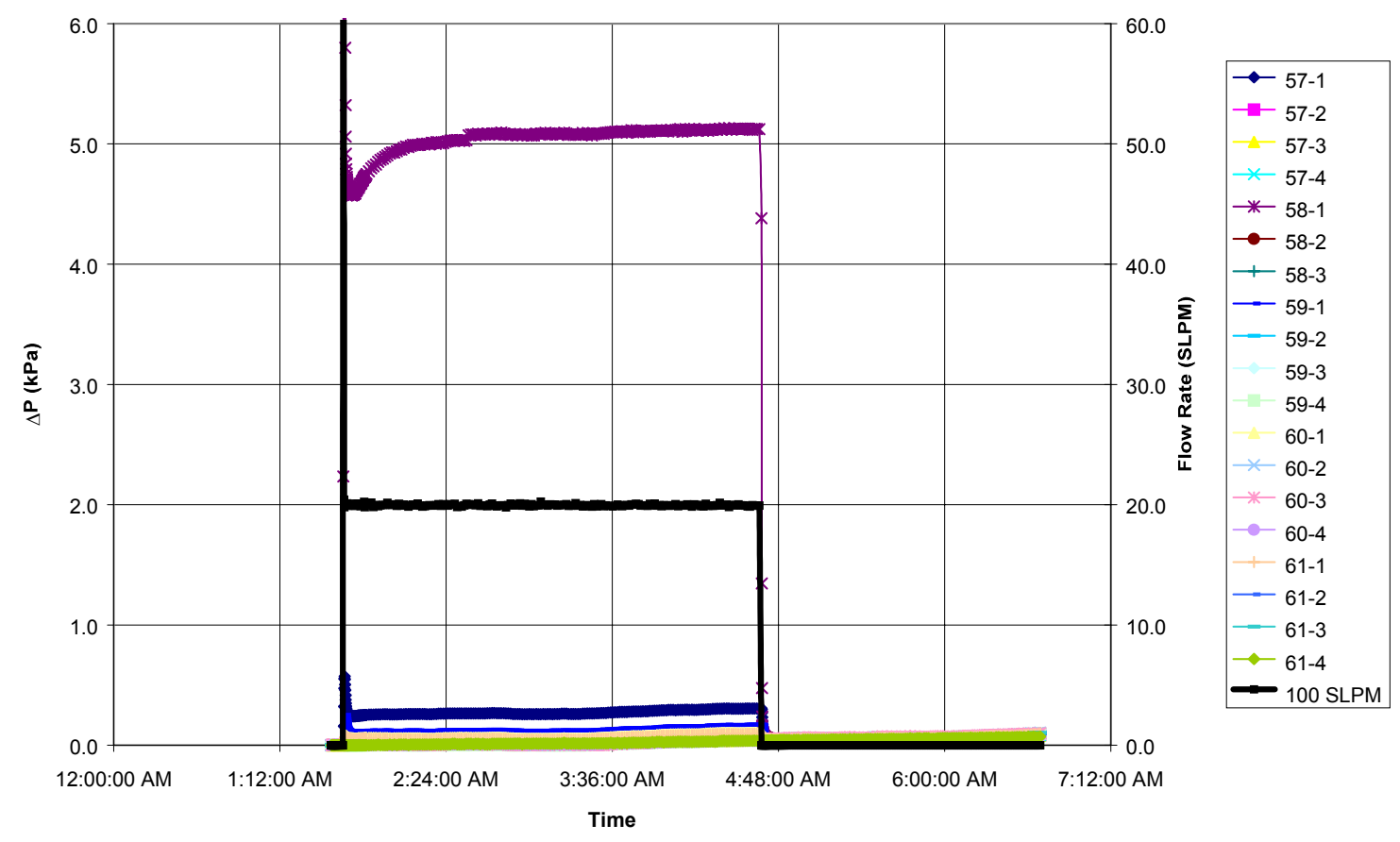

DP 58-2 (11-16-97)

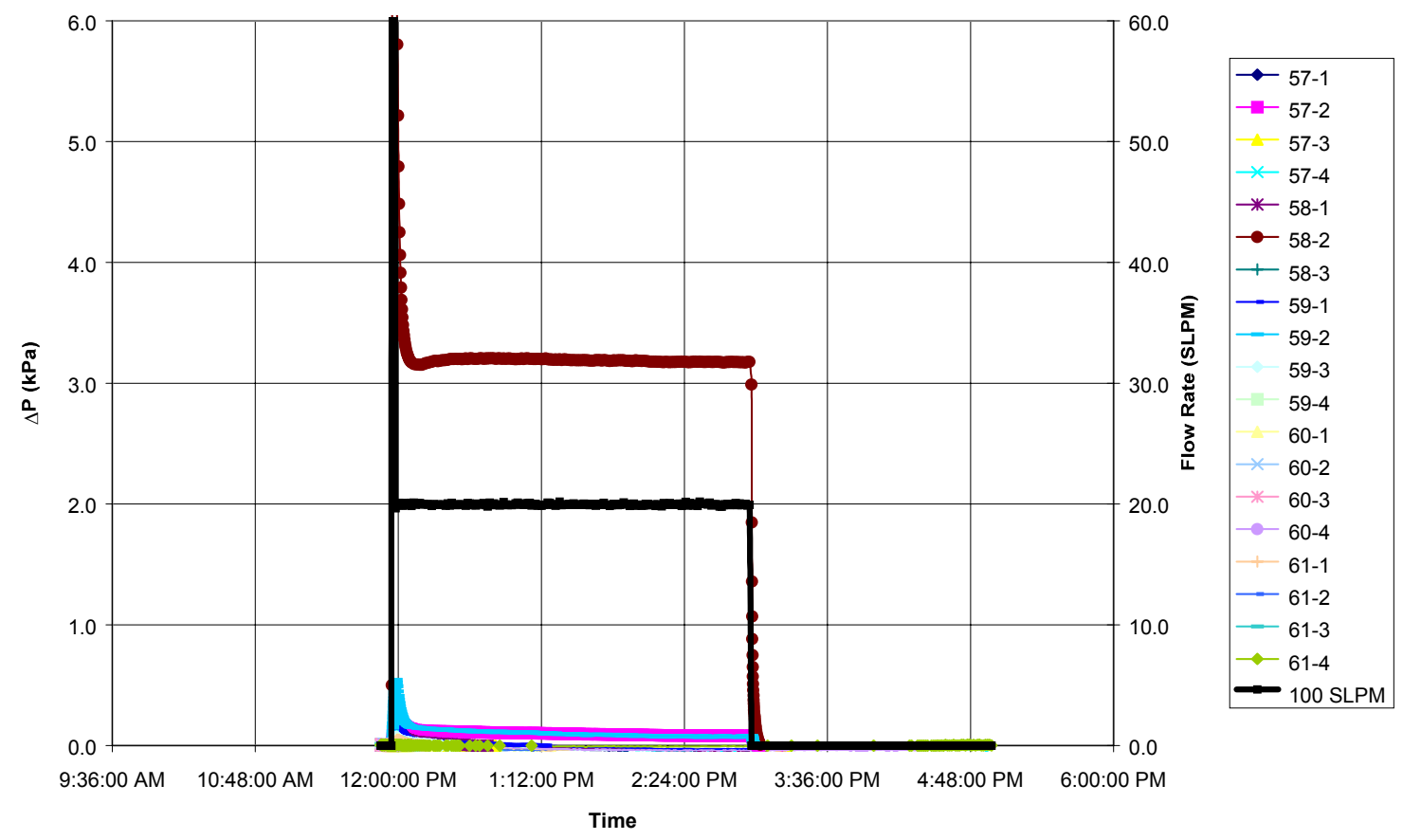


$\Delta \mathrm{P}$ 58-3 (11-16-97)

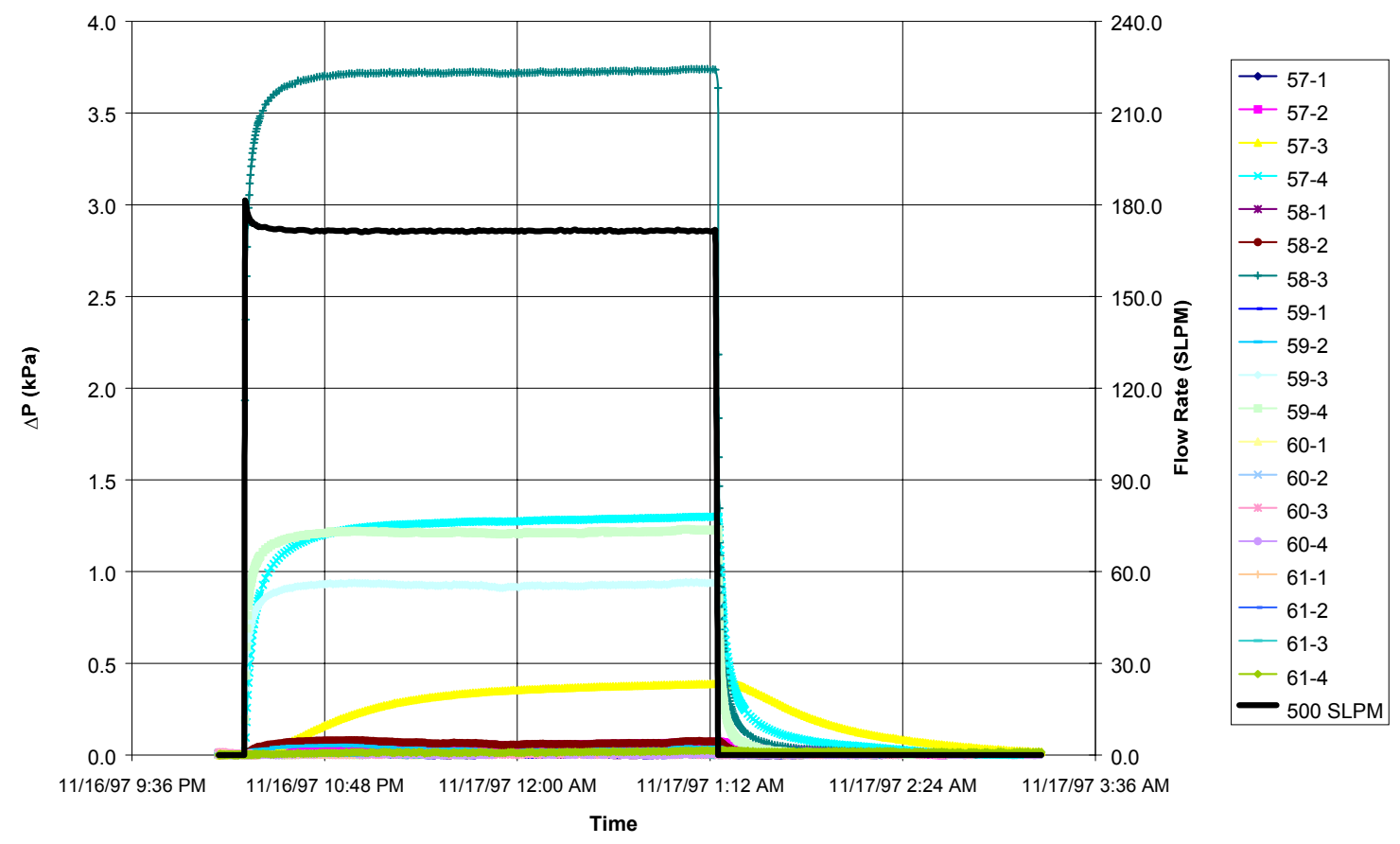

DP 59-1 (11-10-97)

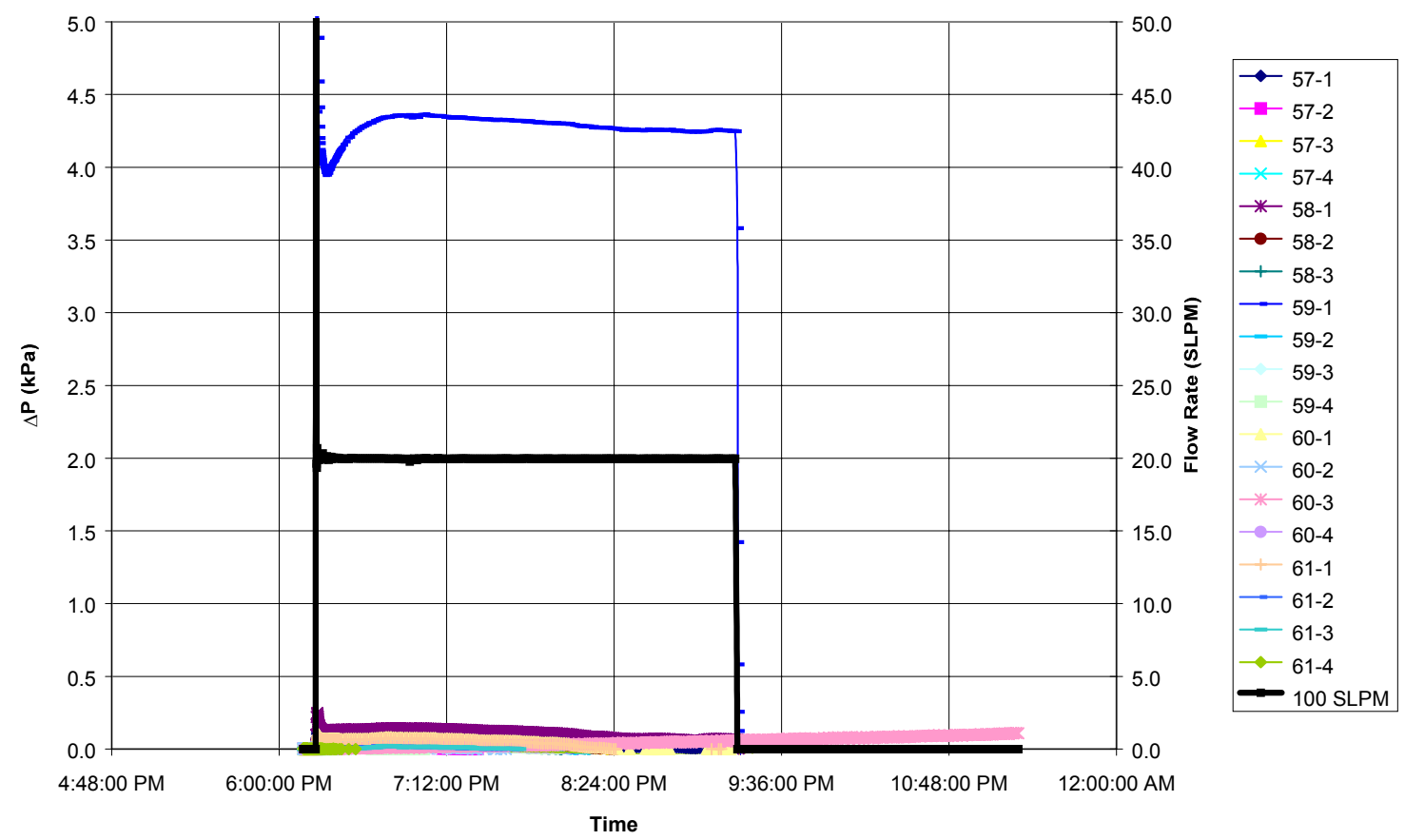


DP 59-3 (11-11-97)

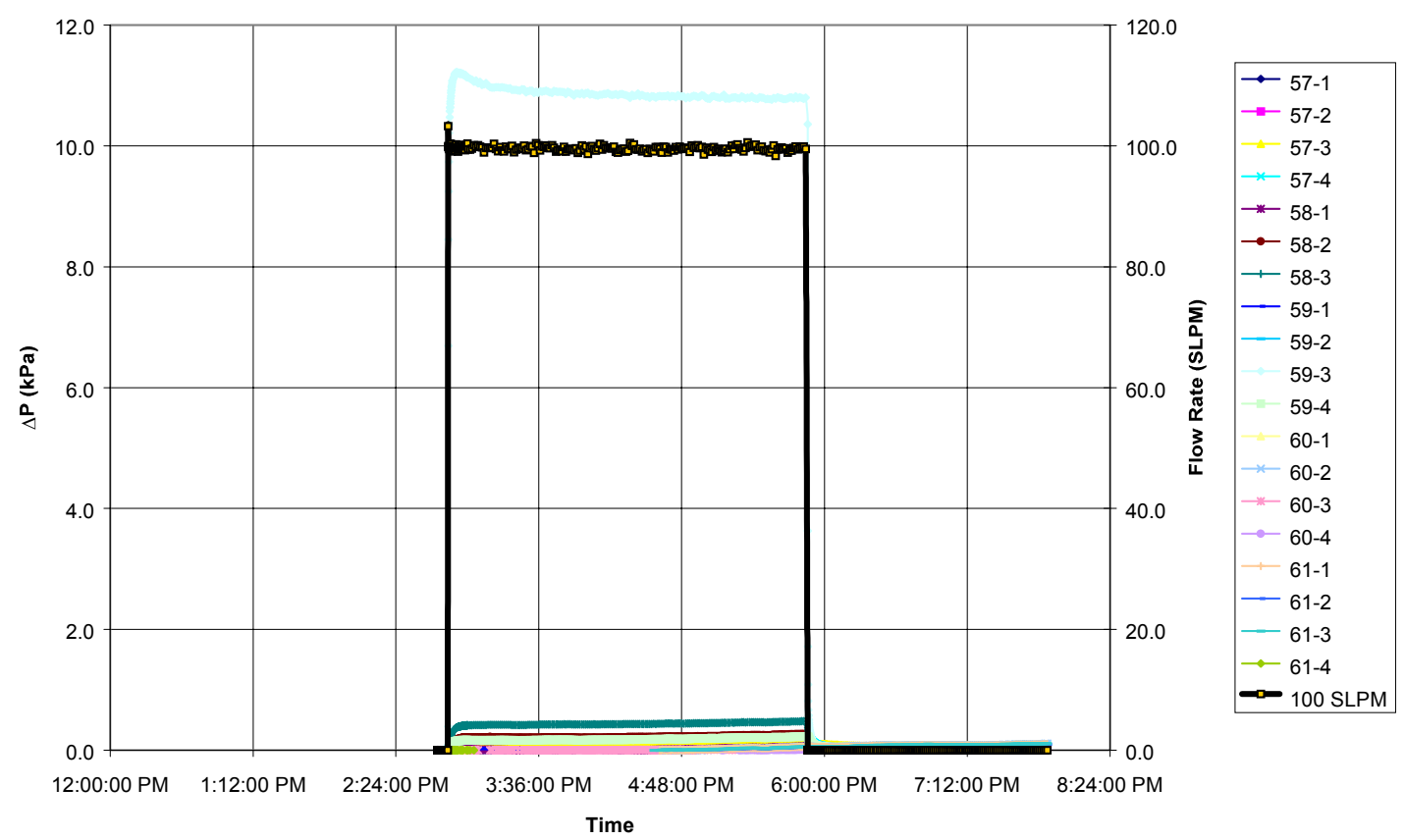

$\Delta P$ 59-4 (11-12-97)

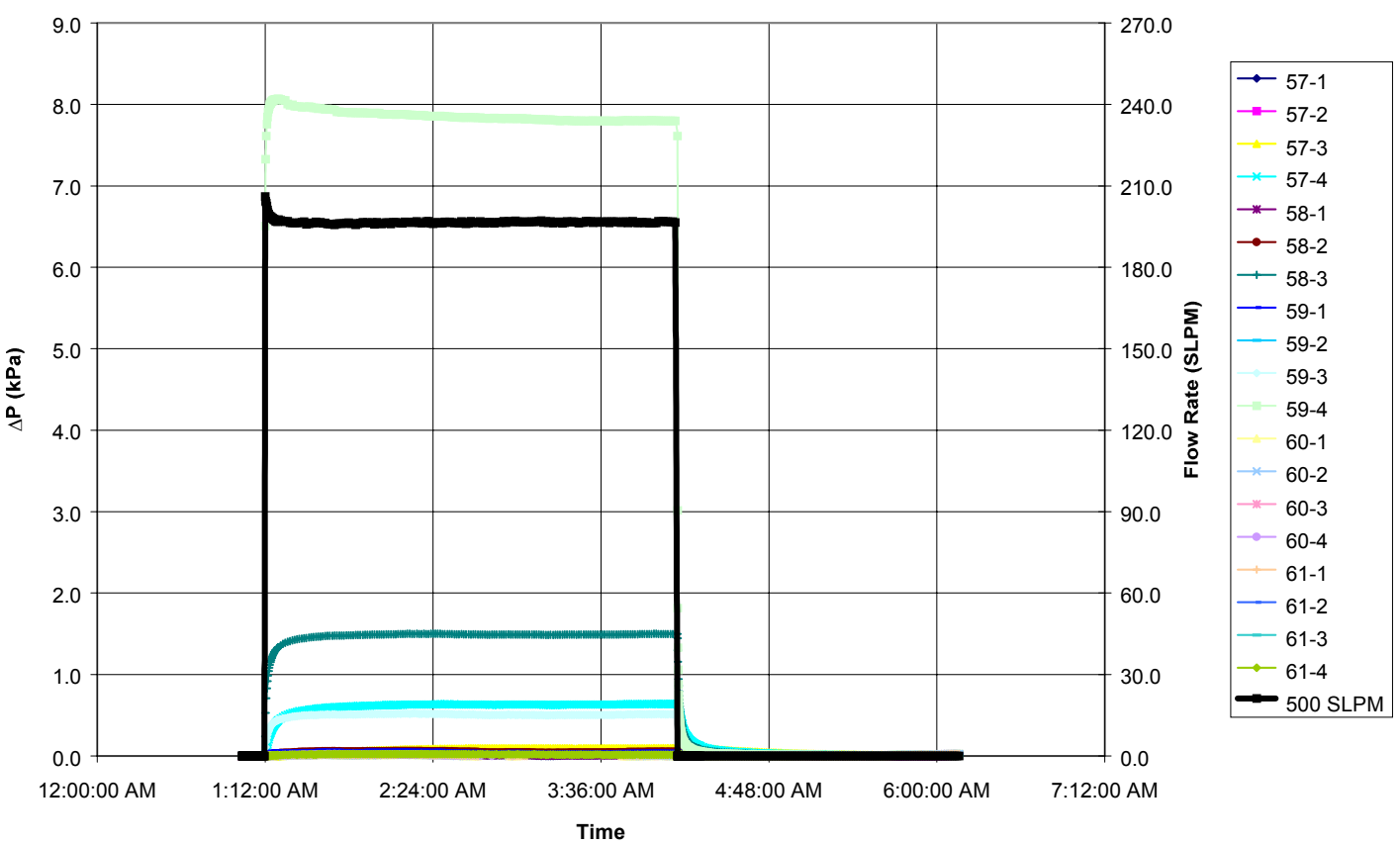


DP 60-1 (11-10-97)

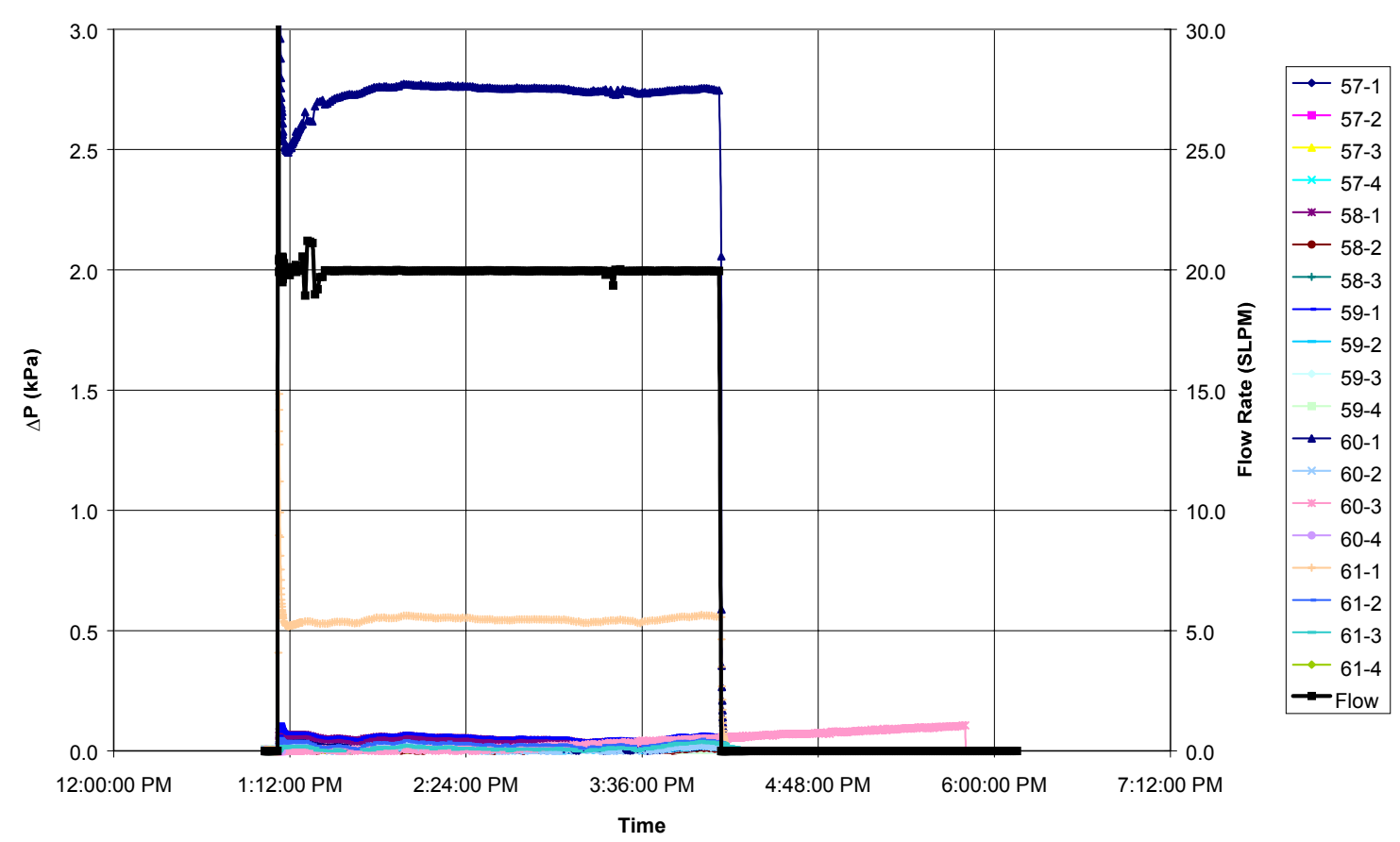

DP 60-2 (11-10-97)

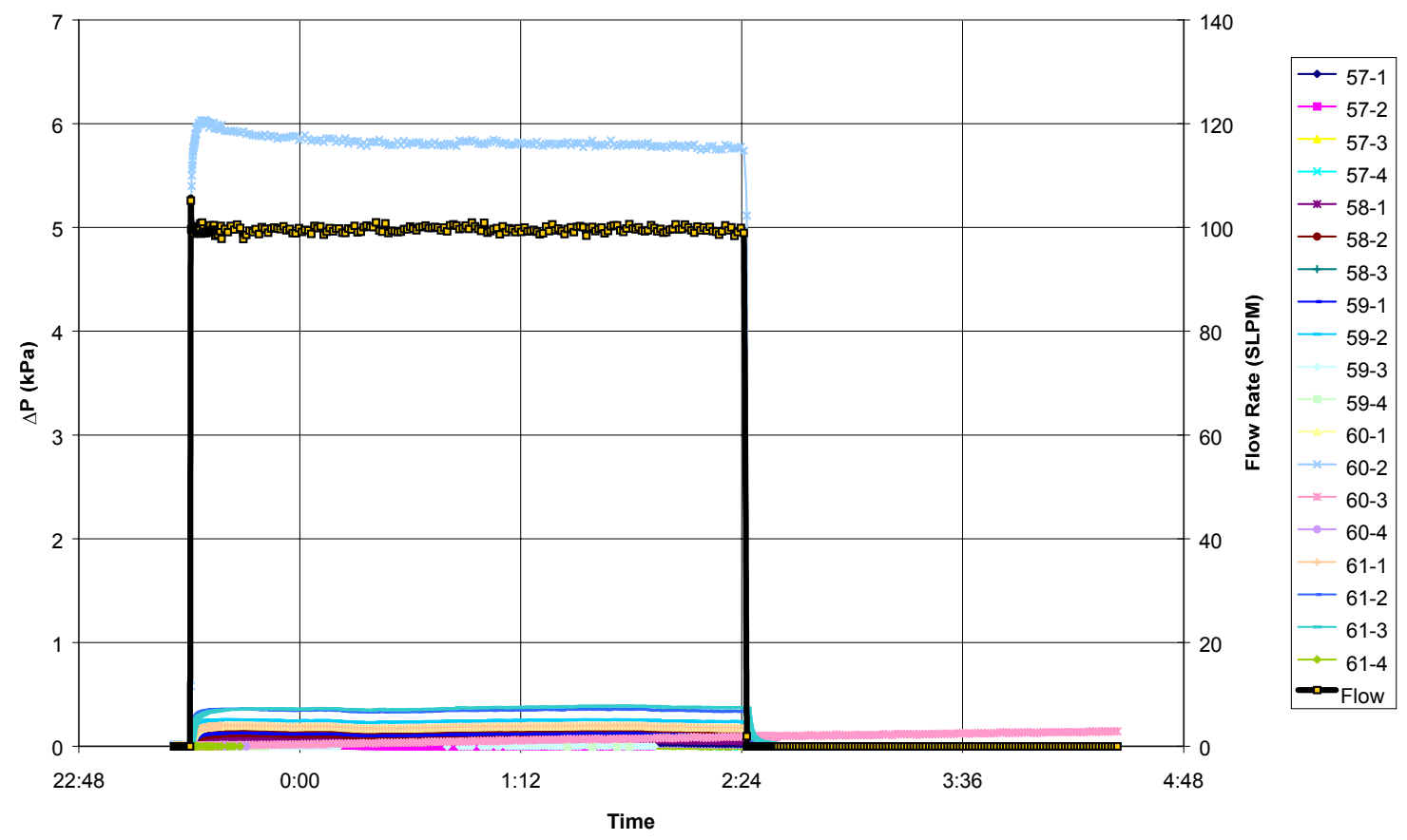


DP 60-3 (11-11-97)

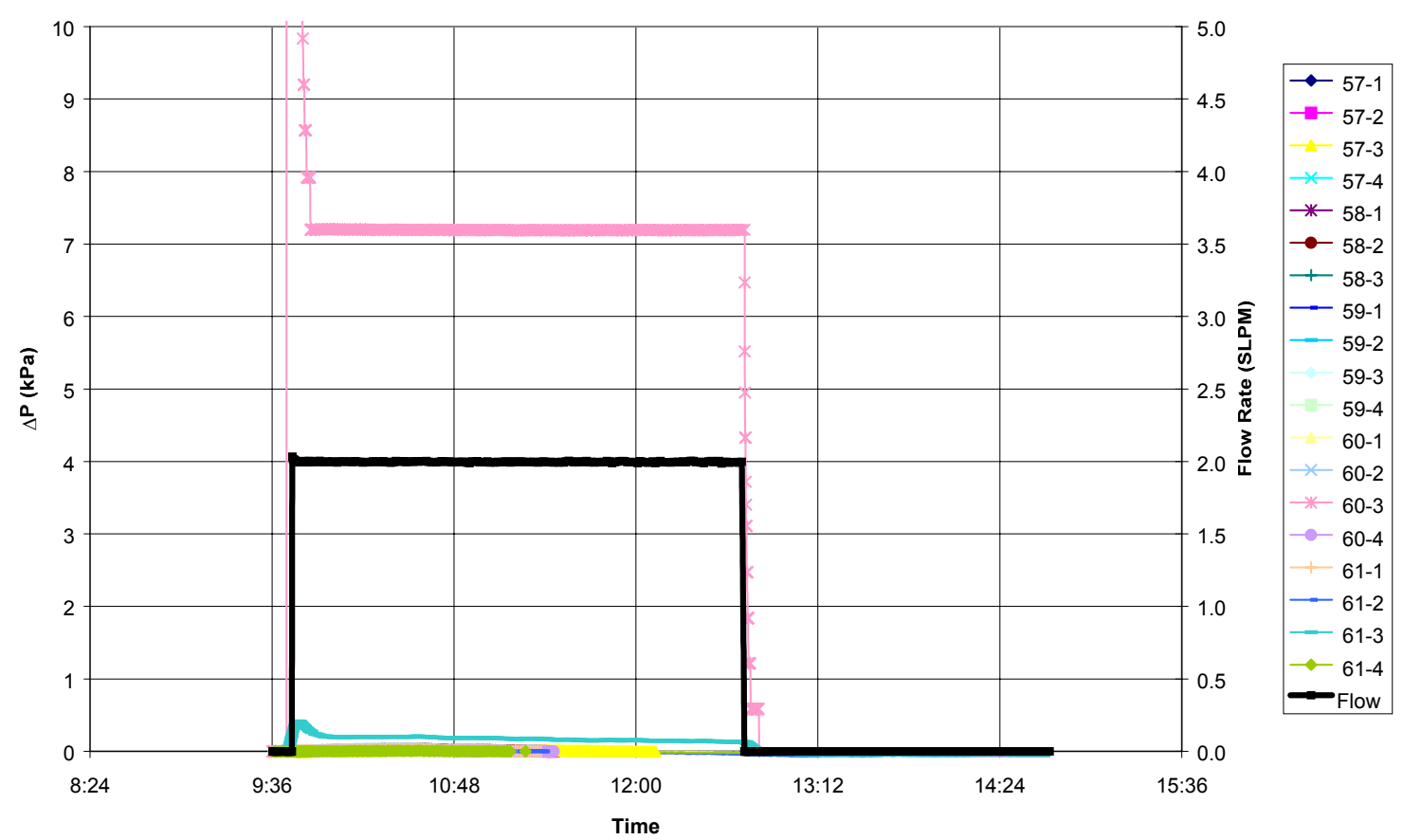

DP 60-4 (11-11-97)

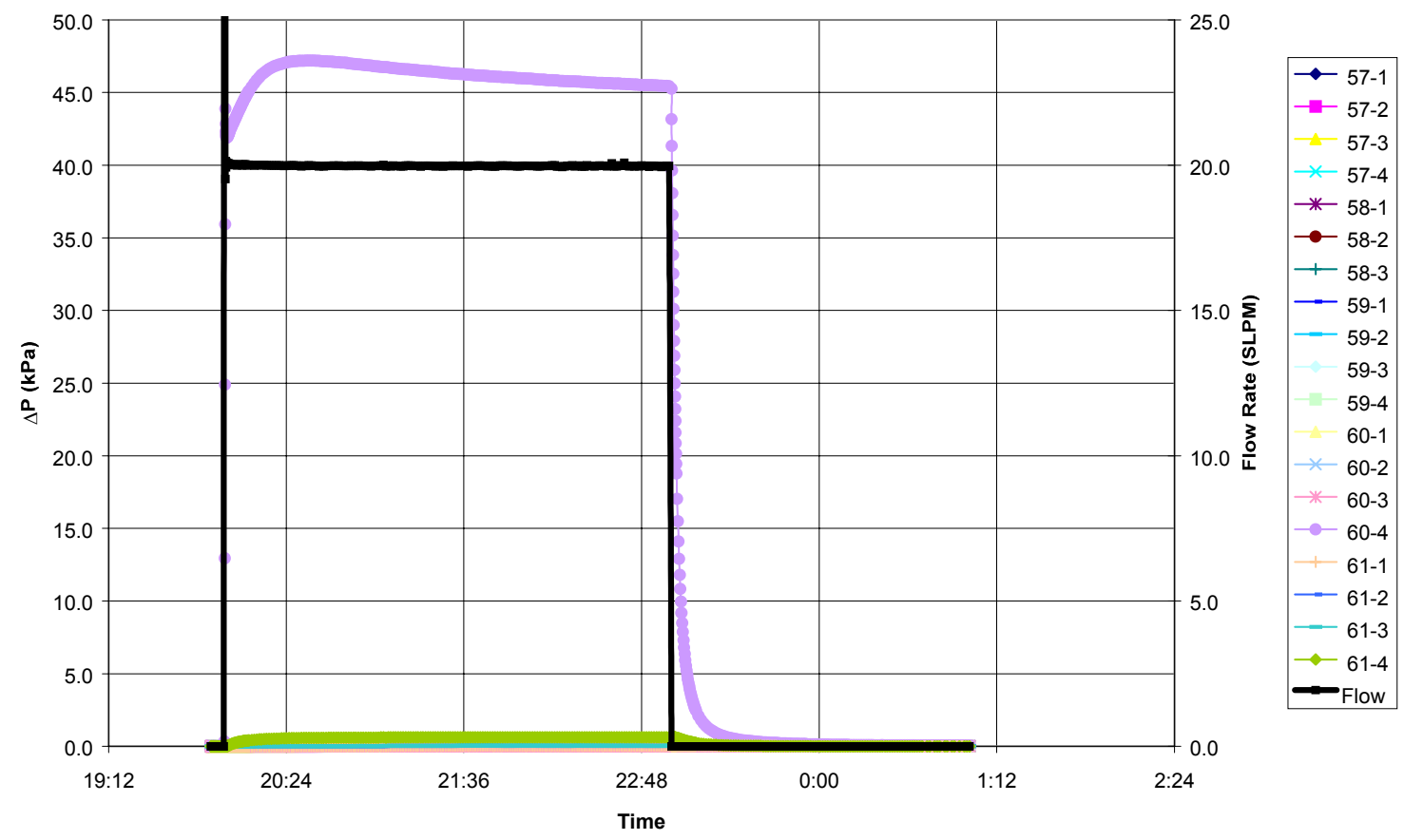




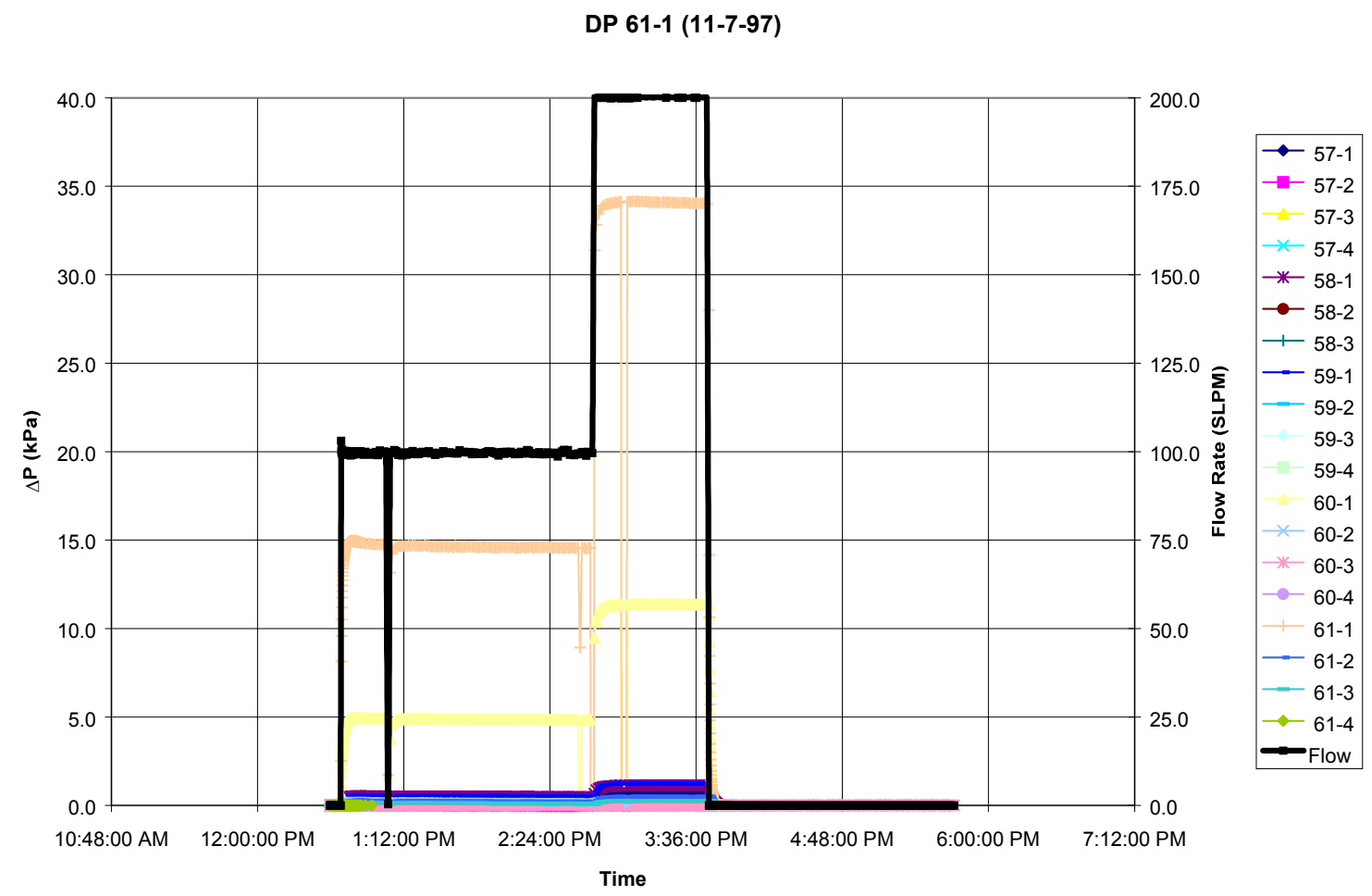


DP 61-2 (11-7-97)

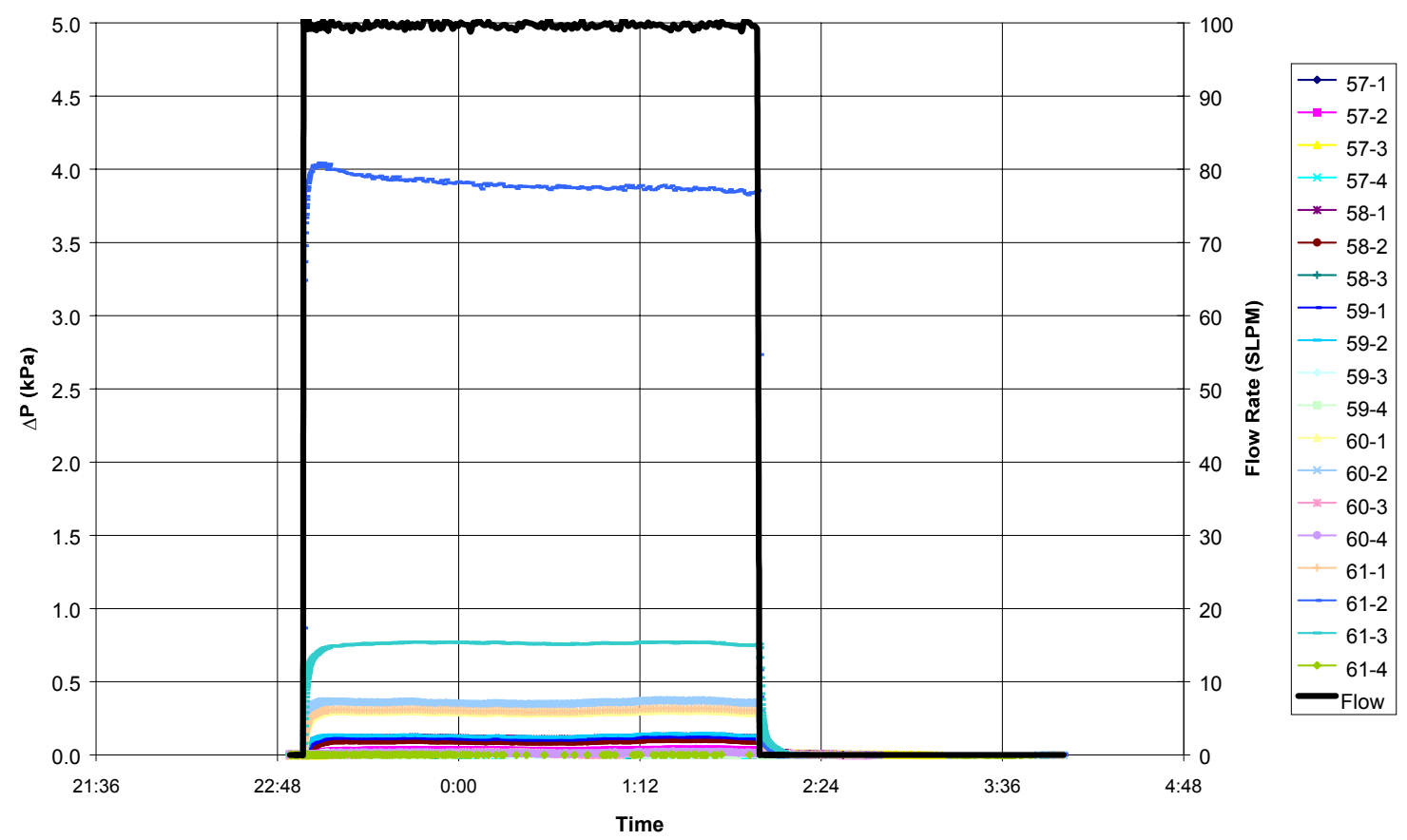

DP $61-3$ (11-8-97)

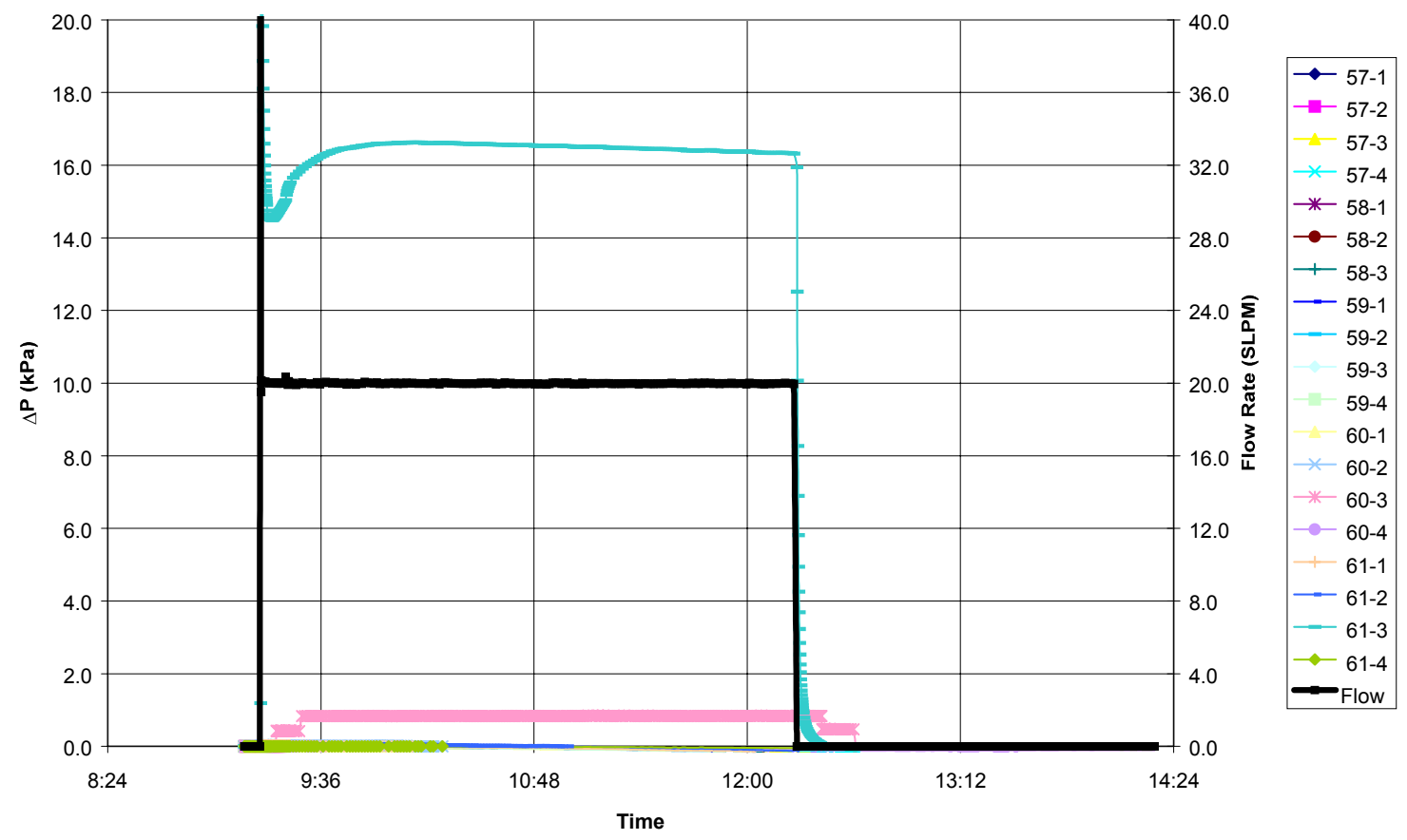


DP $61-4$ (11-08-97)

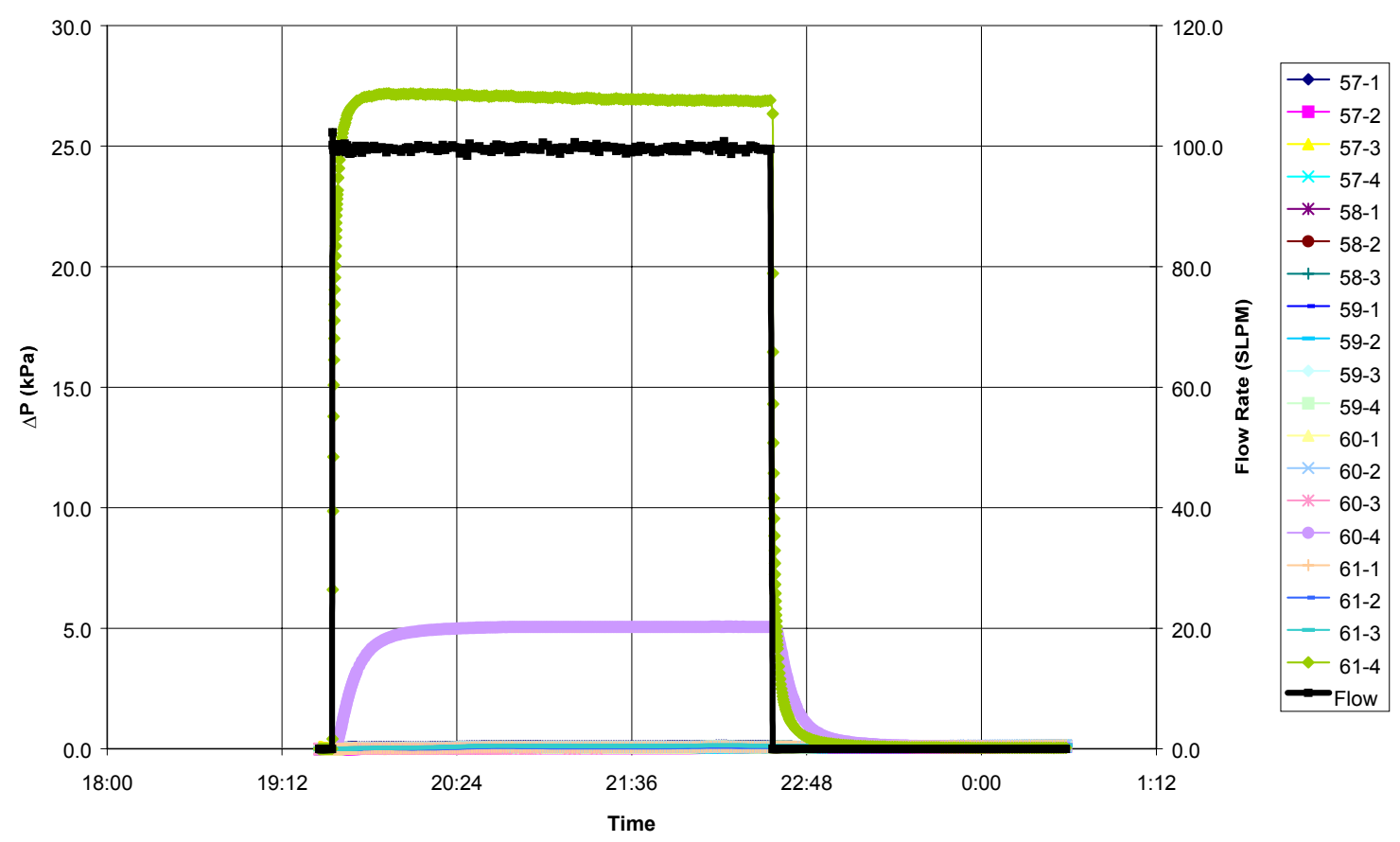

DP 74-1 (11-04-97)

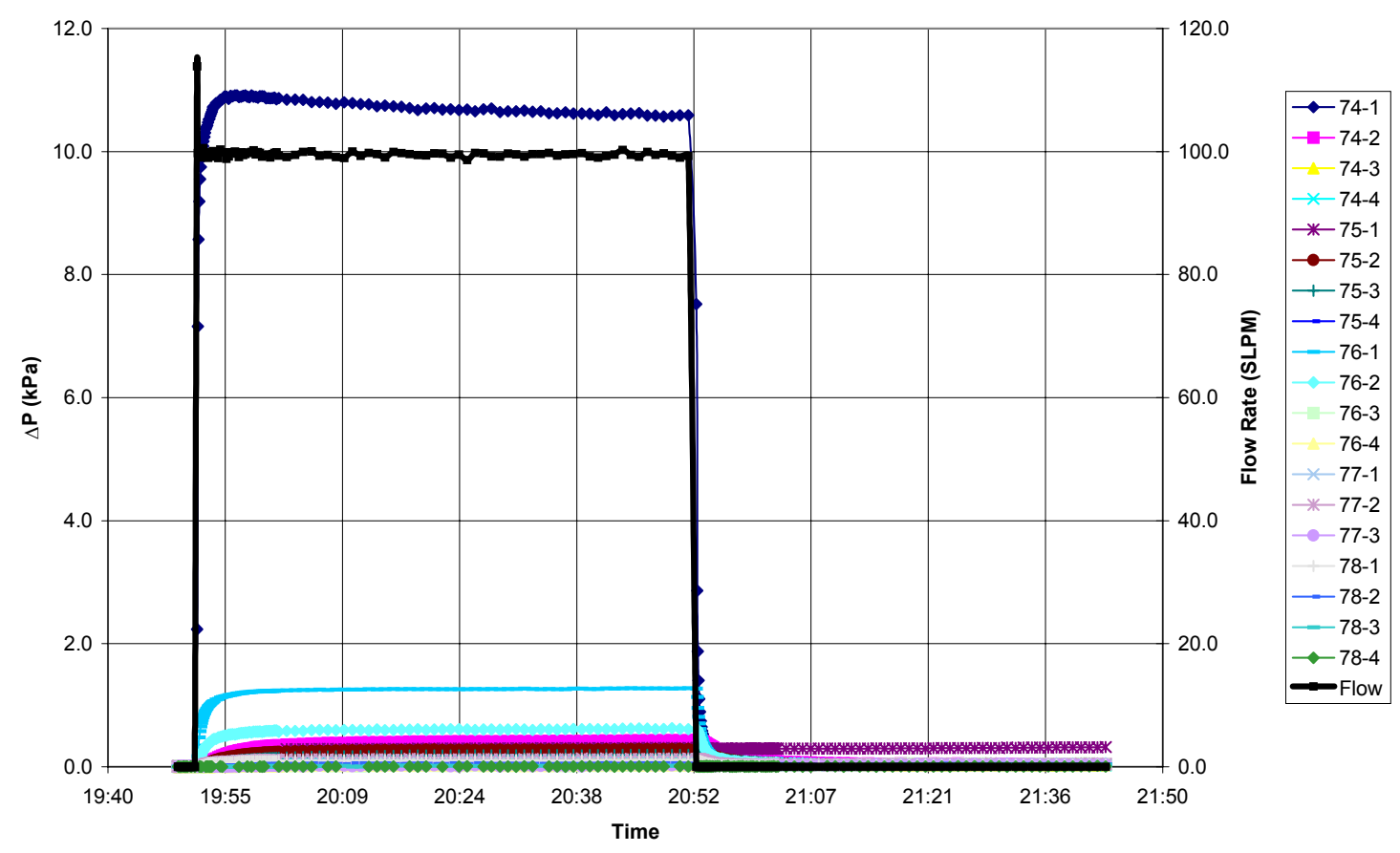




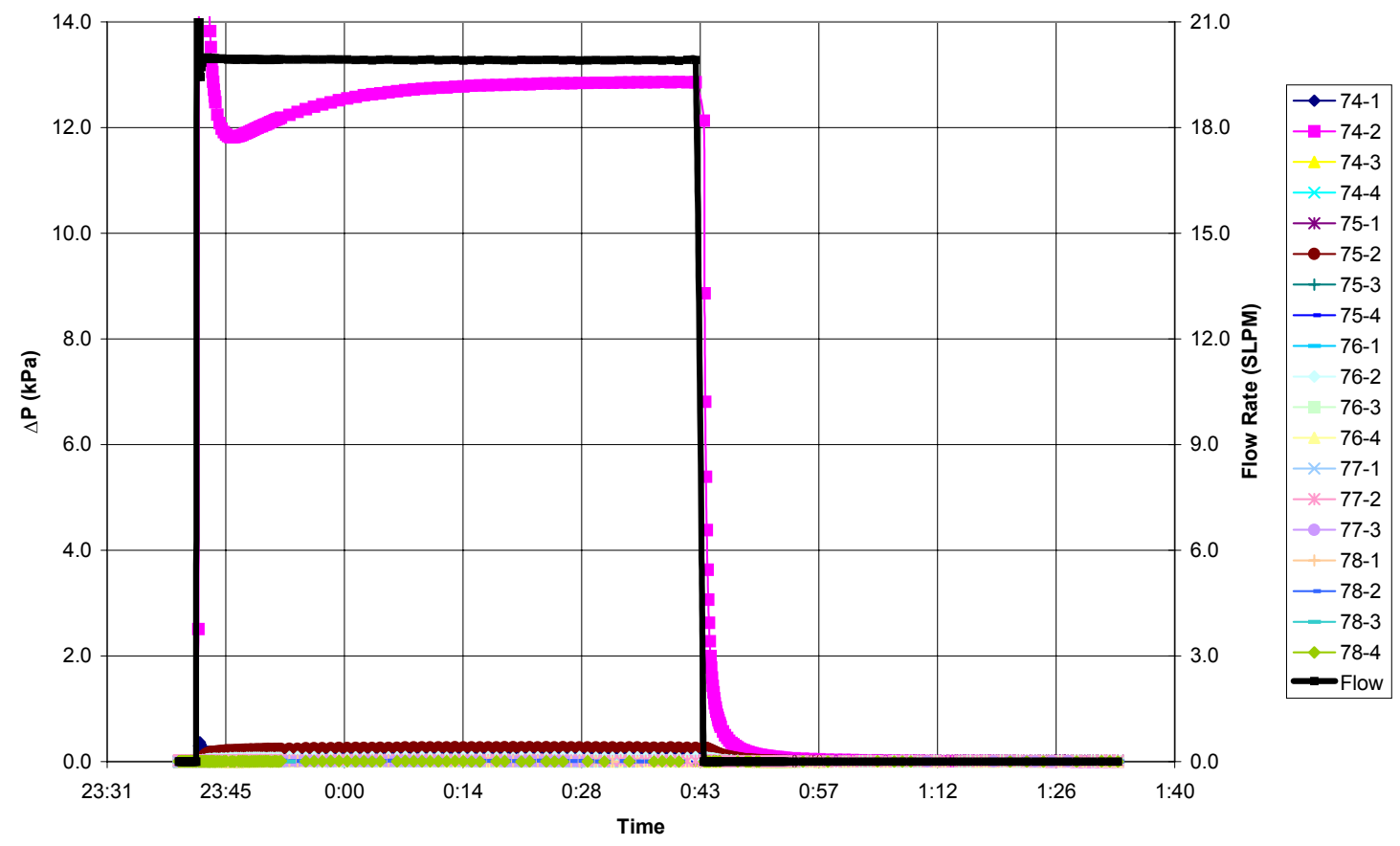

DP 74-3 (11-05-97)

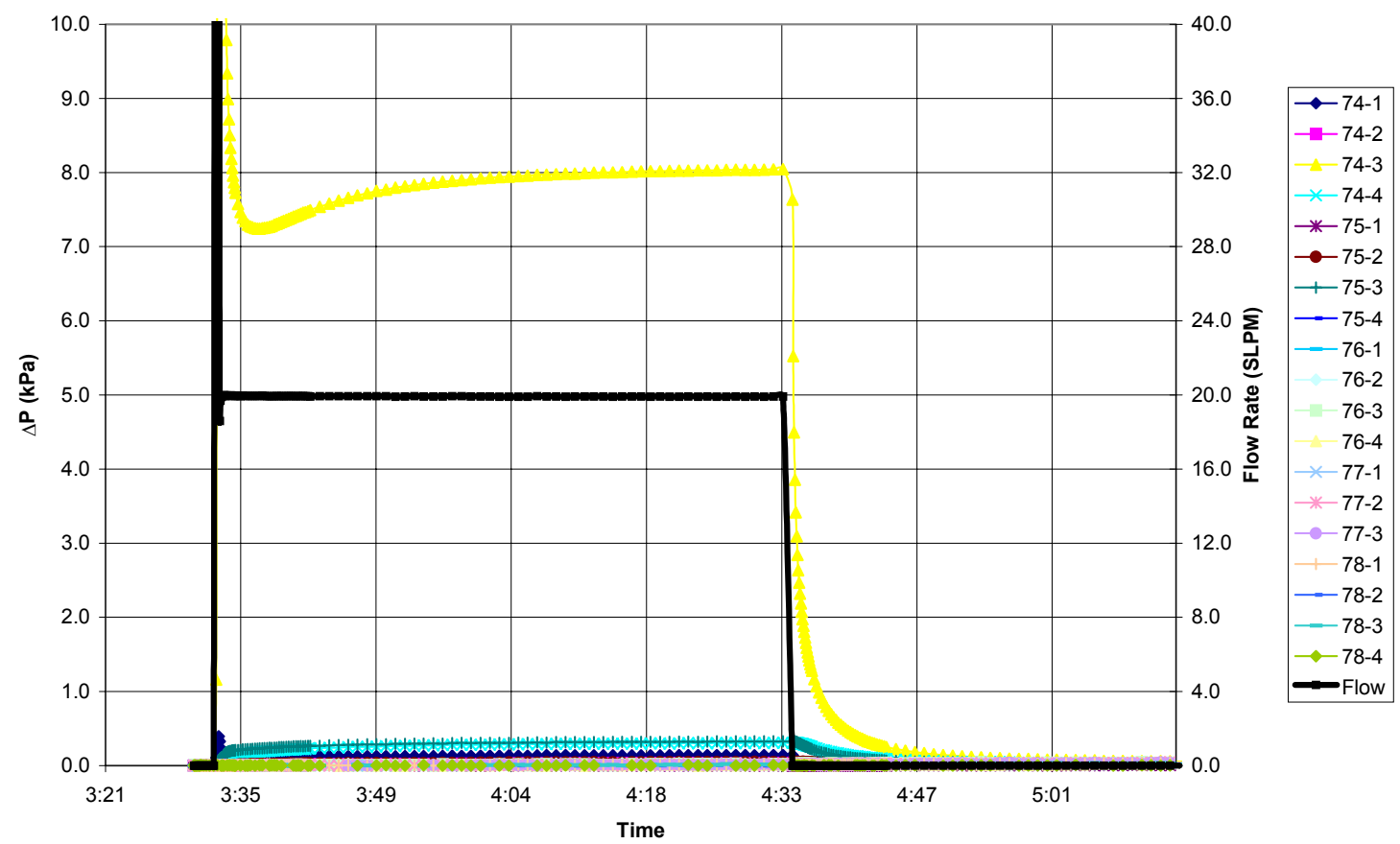


DP 74-4 (11-17-97)

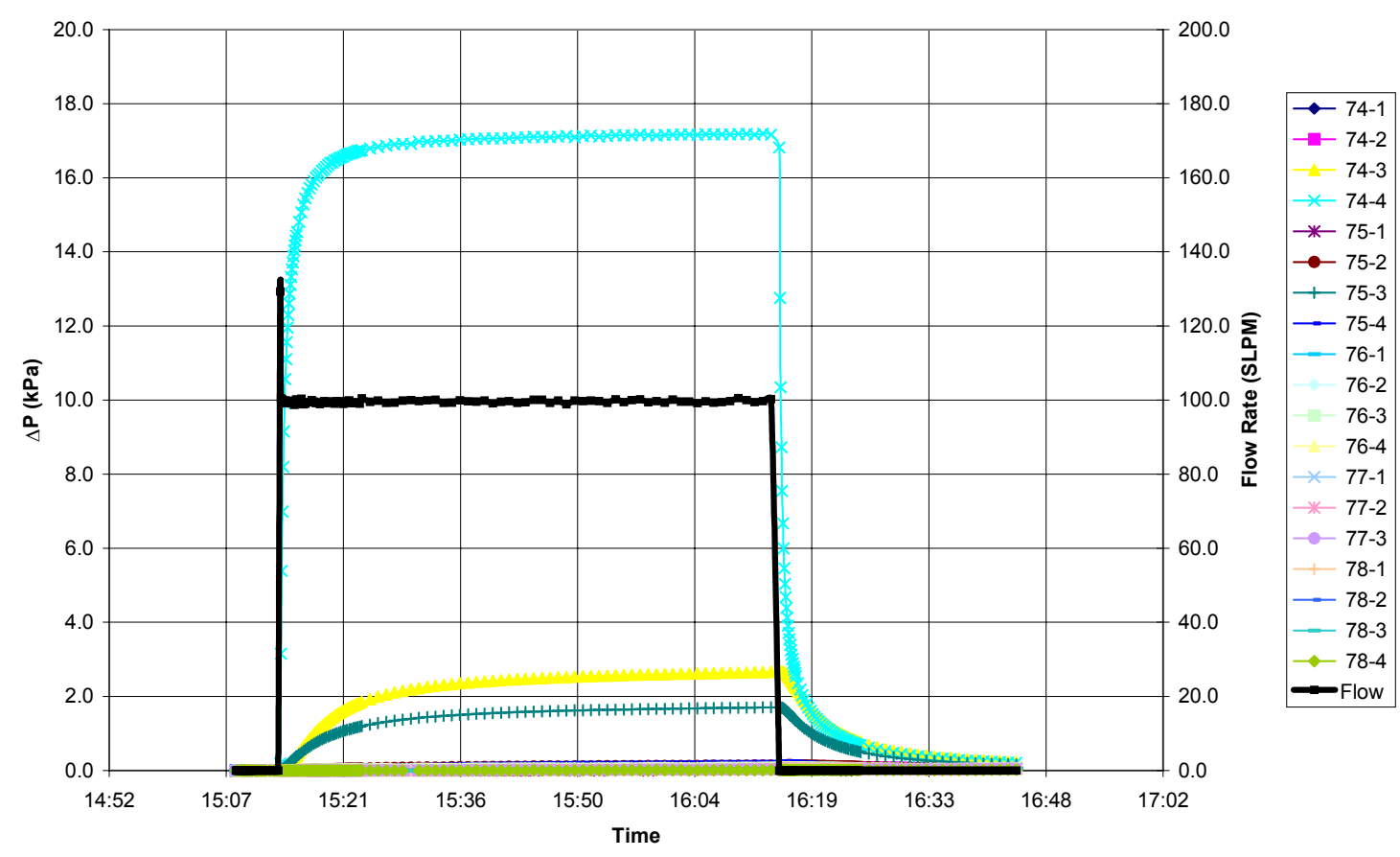


DP 75-1 (11-5-97)

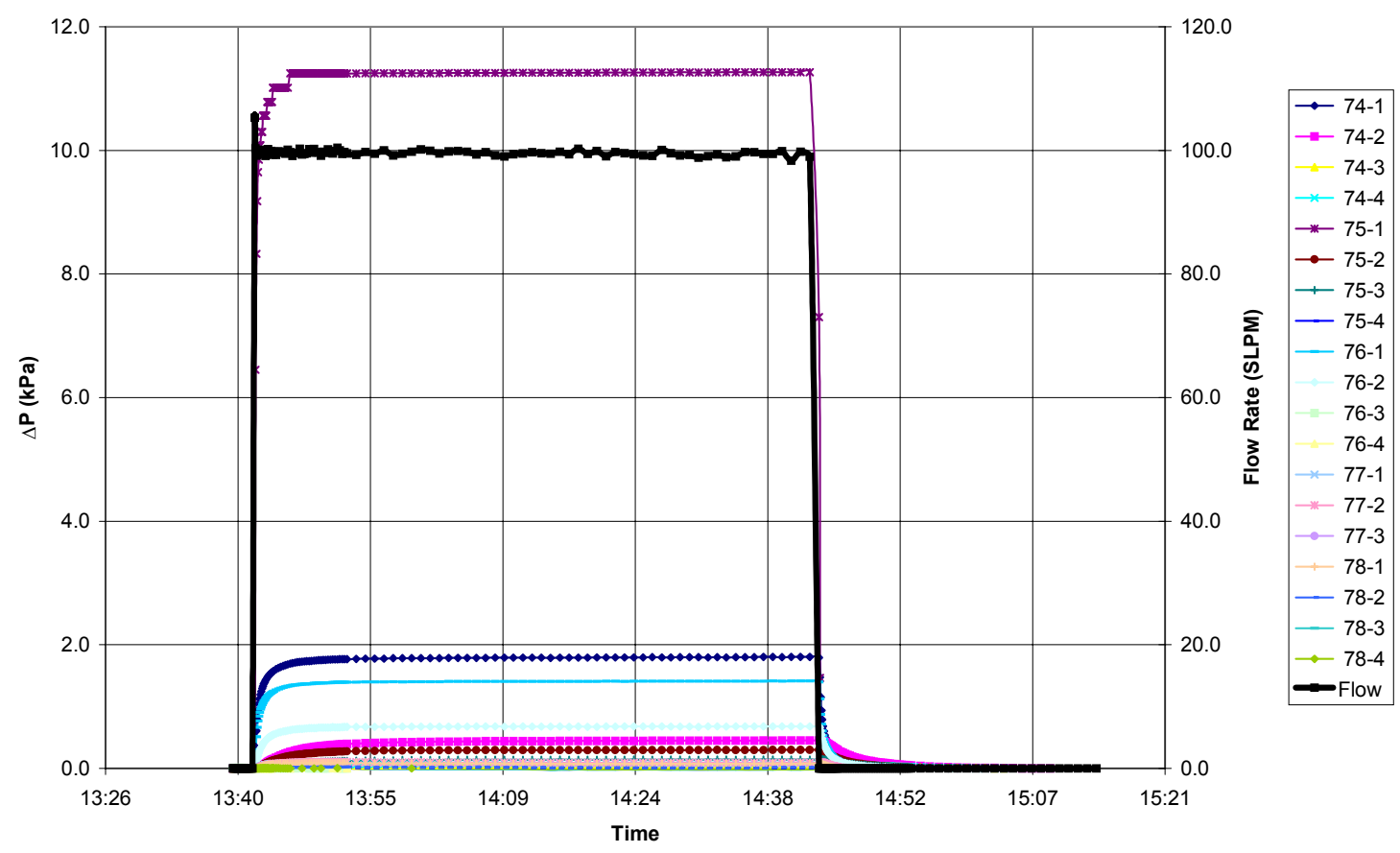

DP 75-2 (11-5-97)

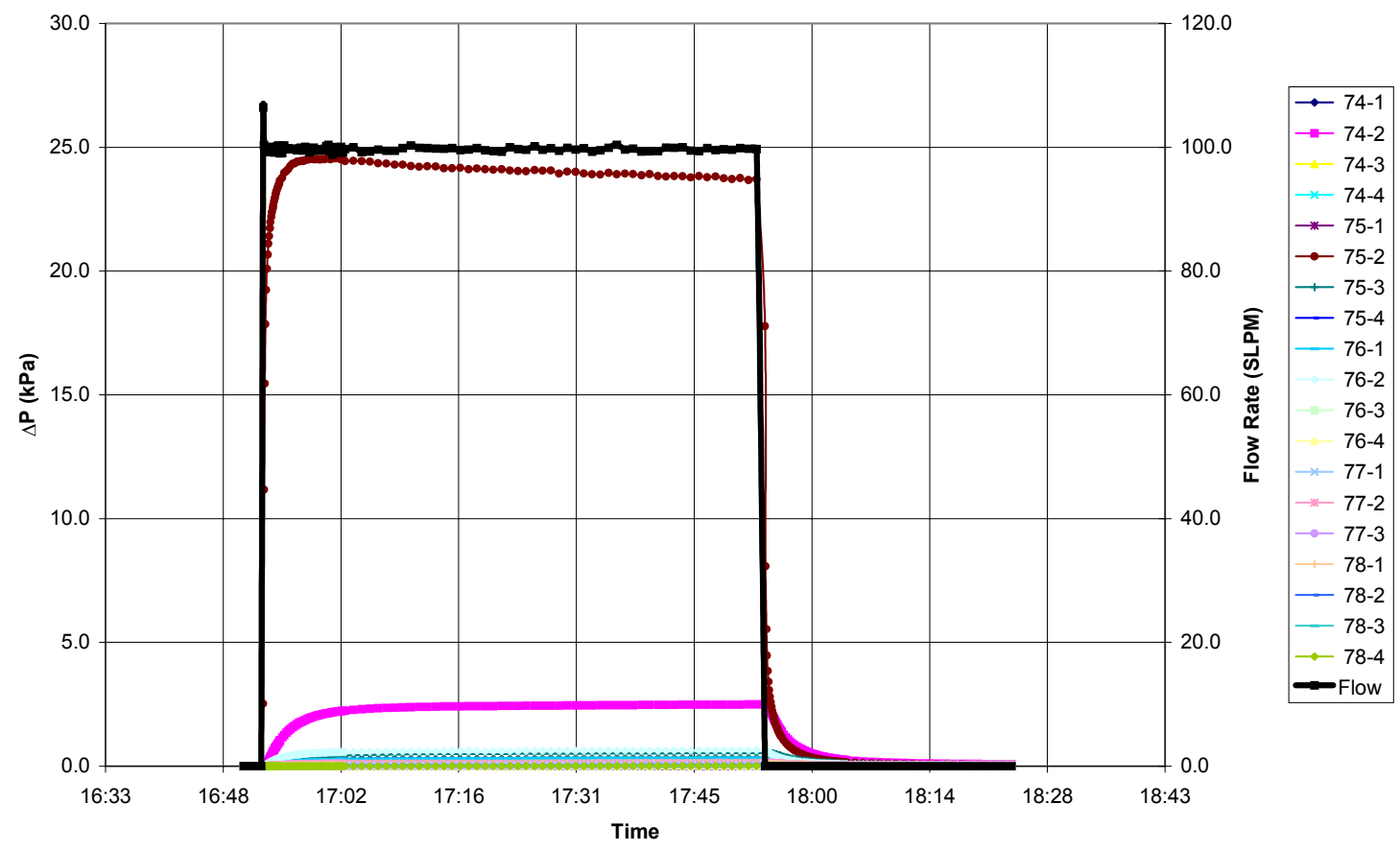


DP 76-2 (11-6-97)

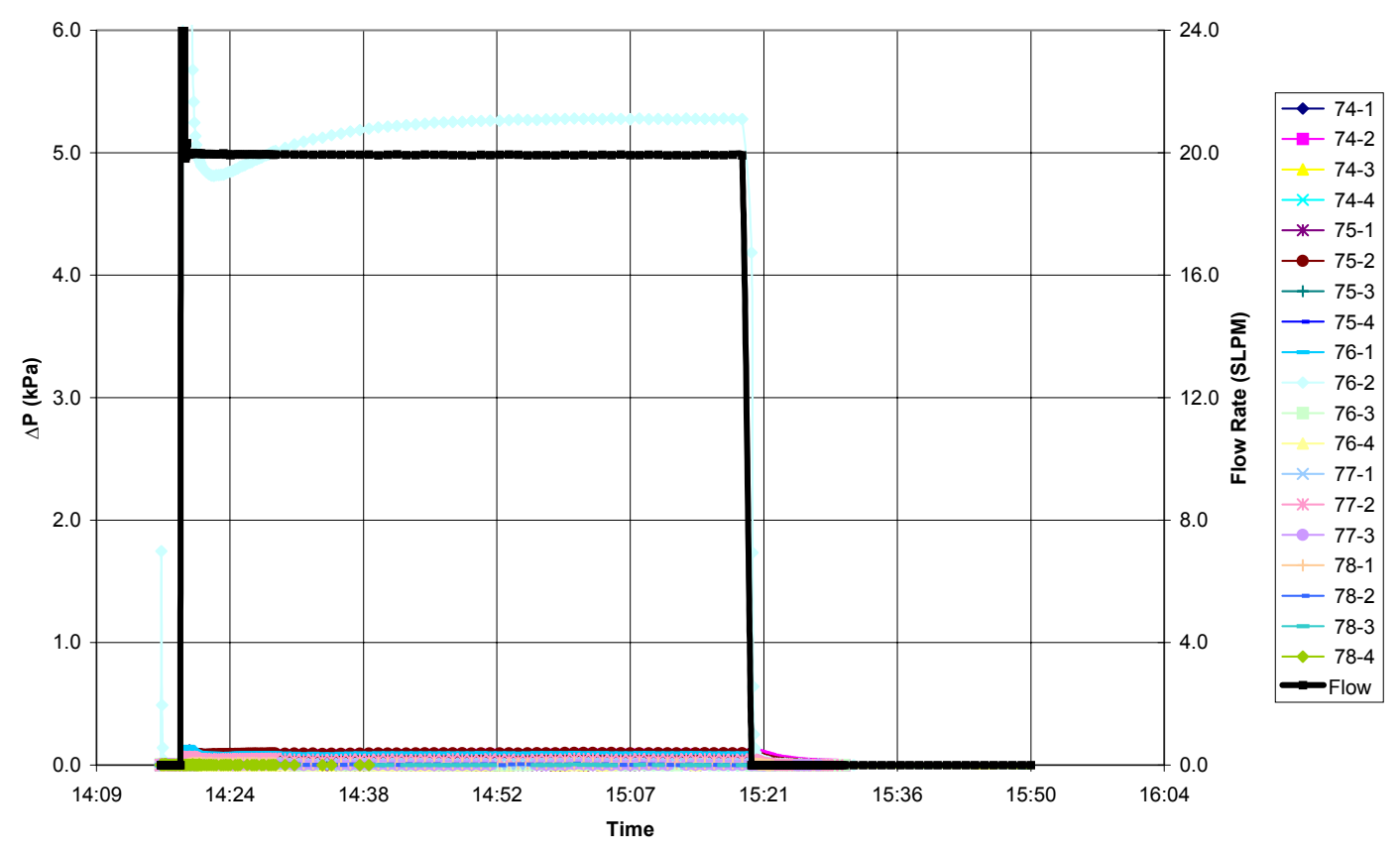

DP 75-3 (11-5-97)

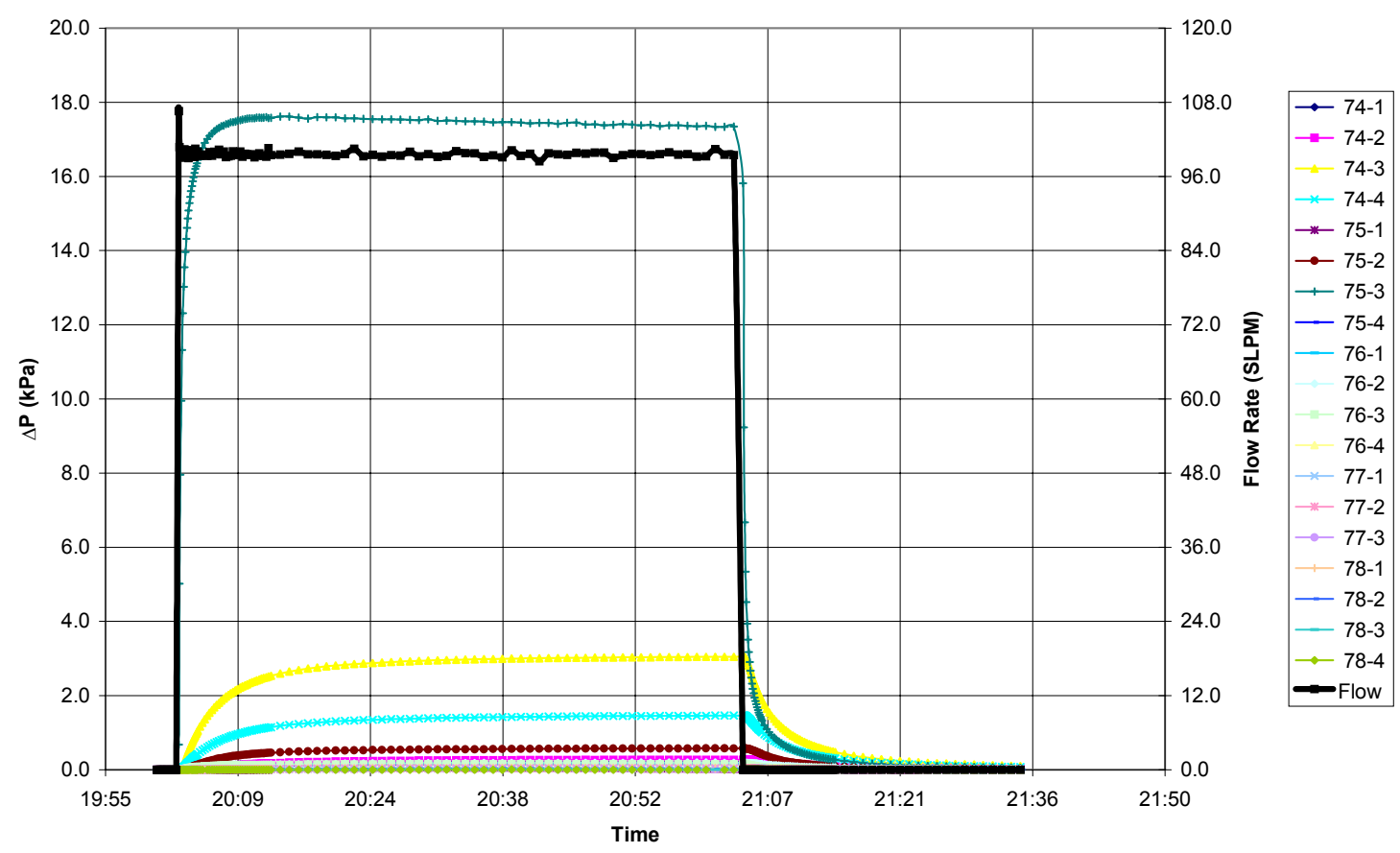




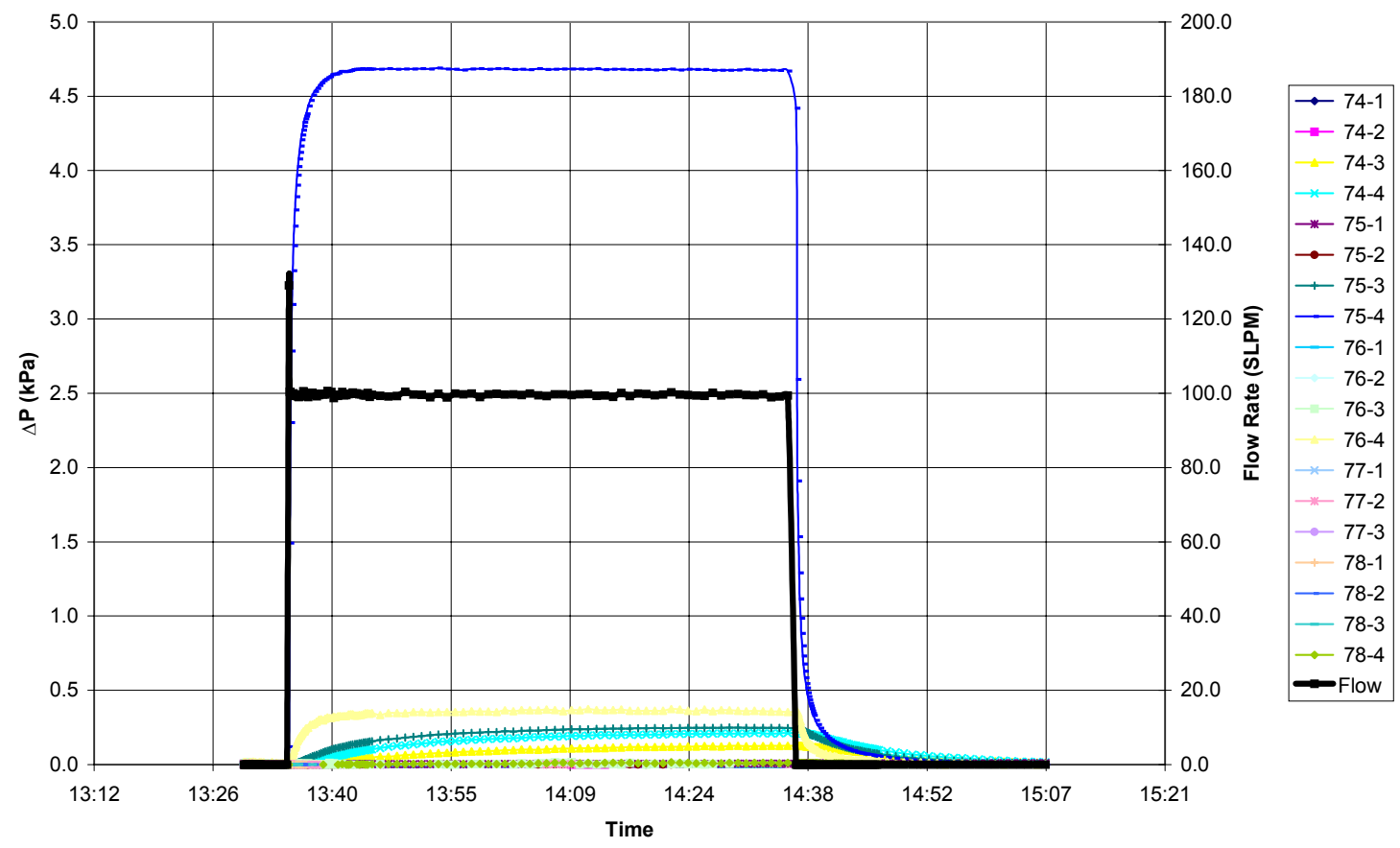

DP 76-1 (11-6-97)

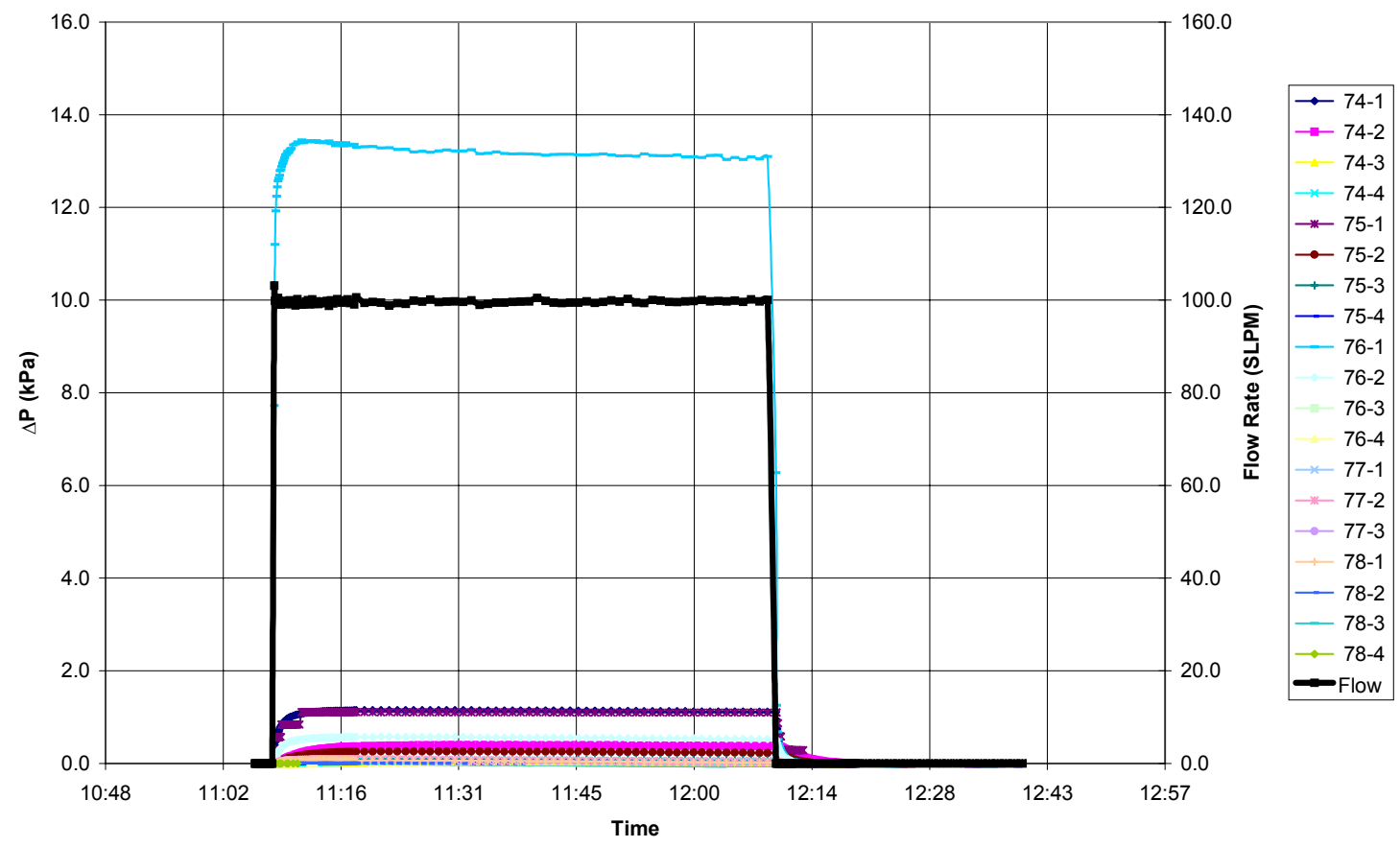


DP 76-2 (11-6-97)

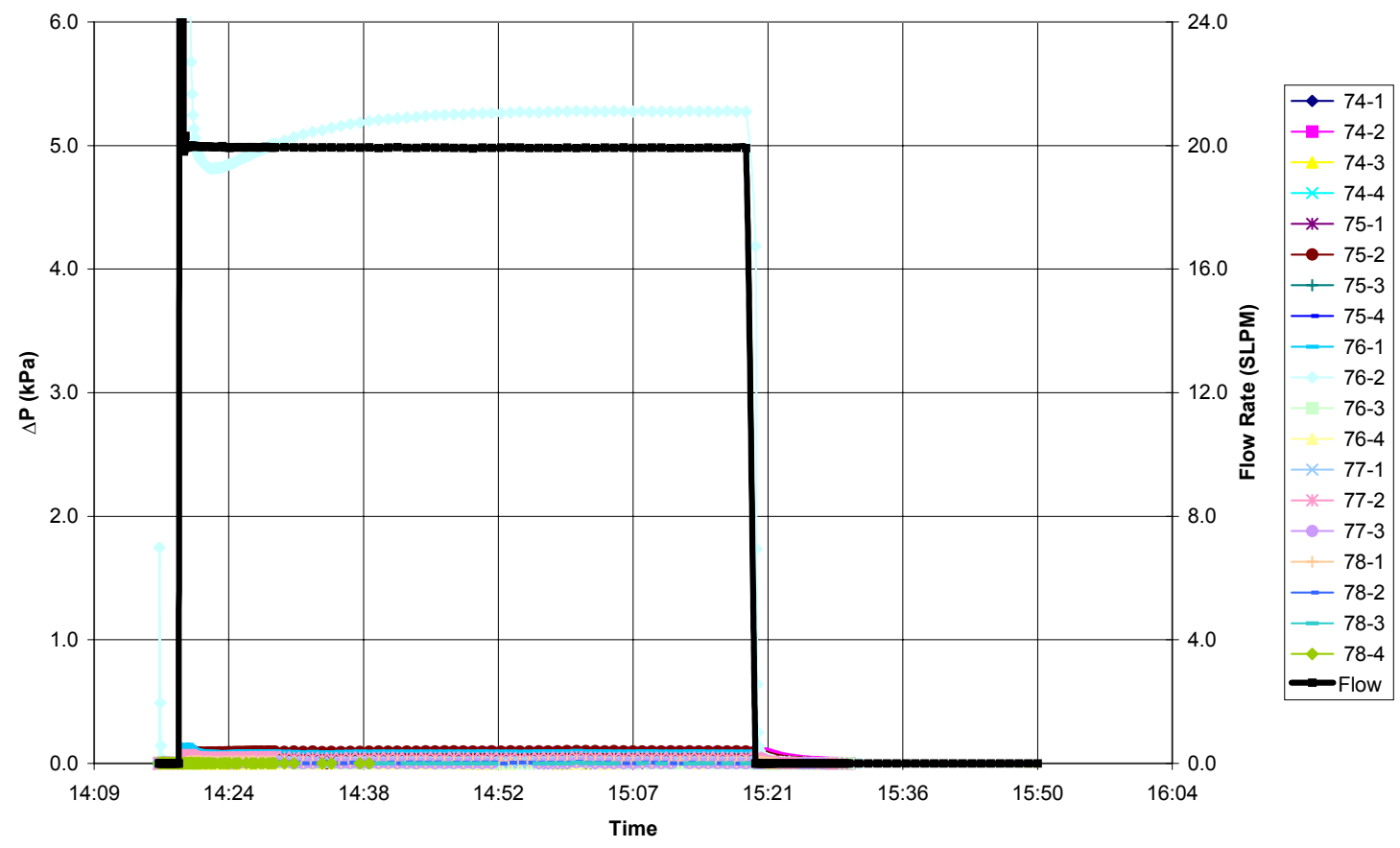

DP 76-3 (11-6-97)

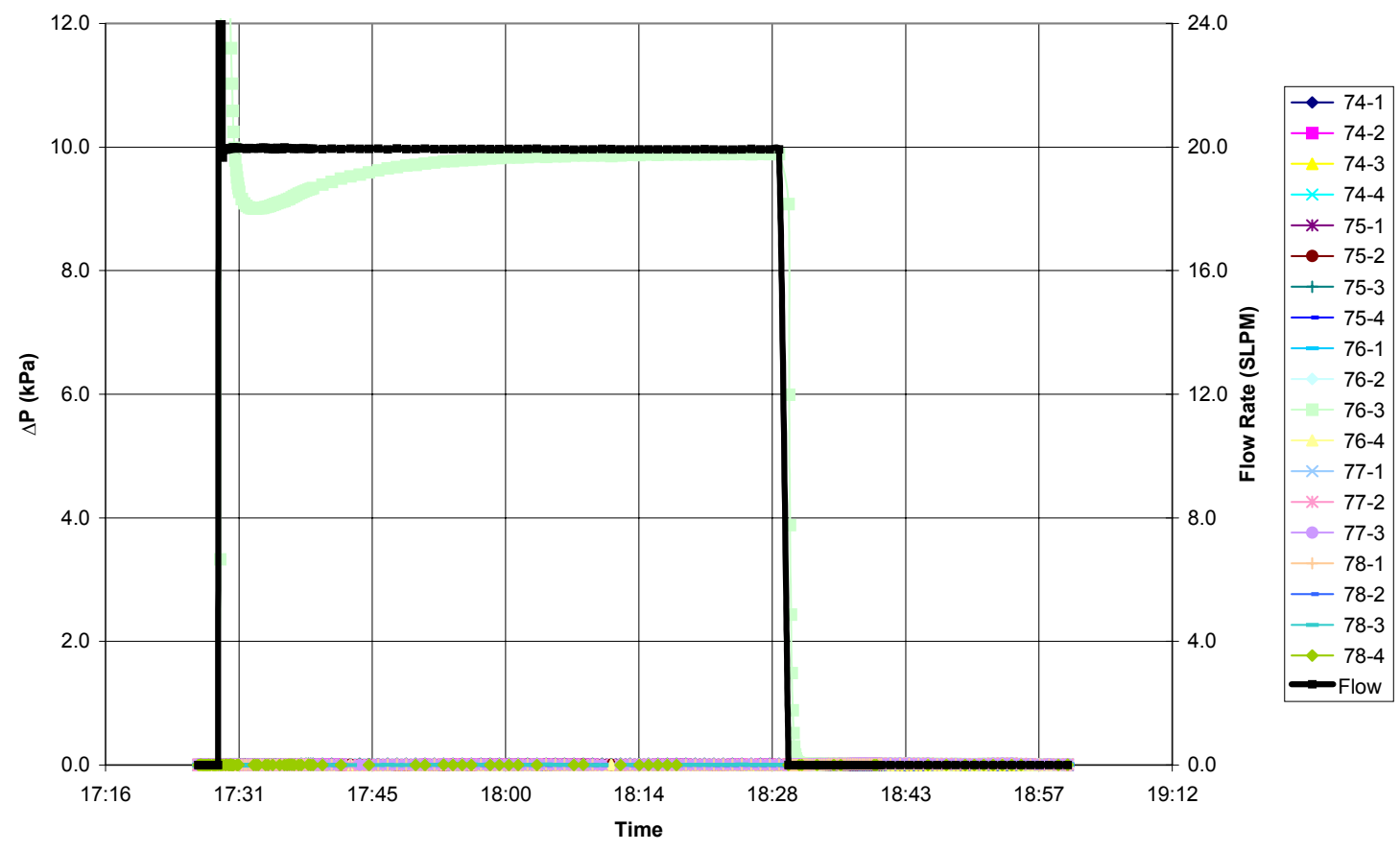




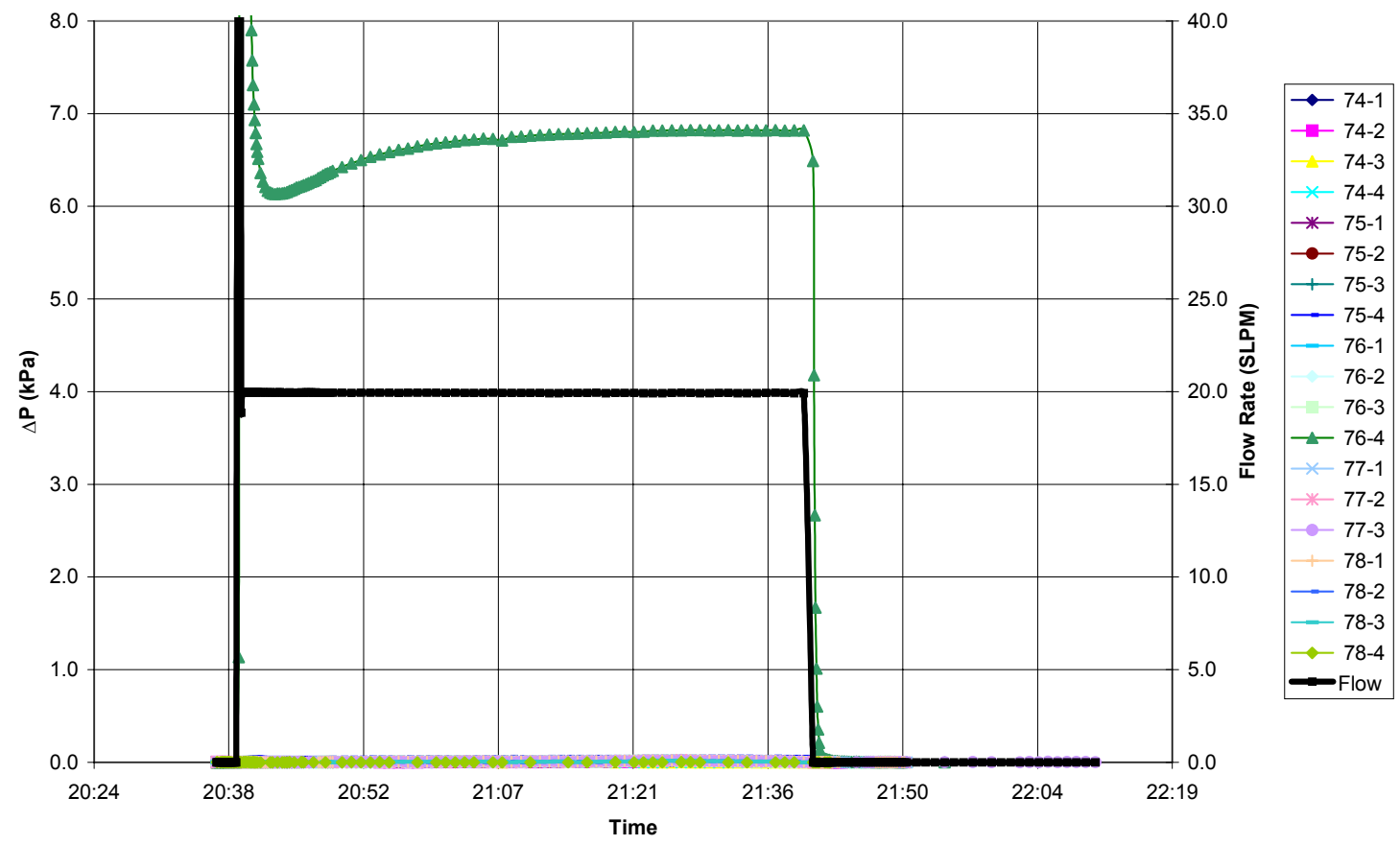

DP 77-1 (11-15-97)

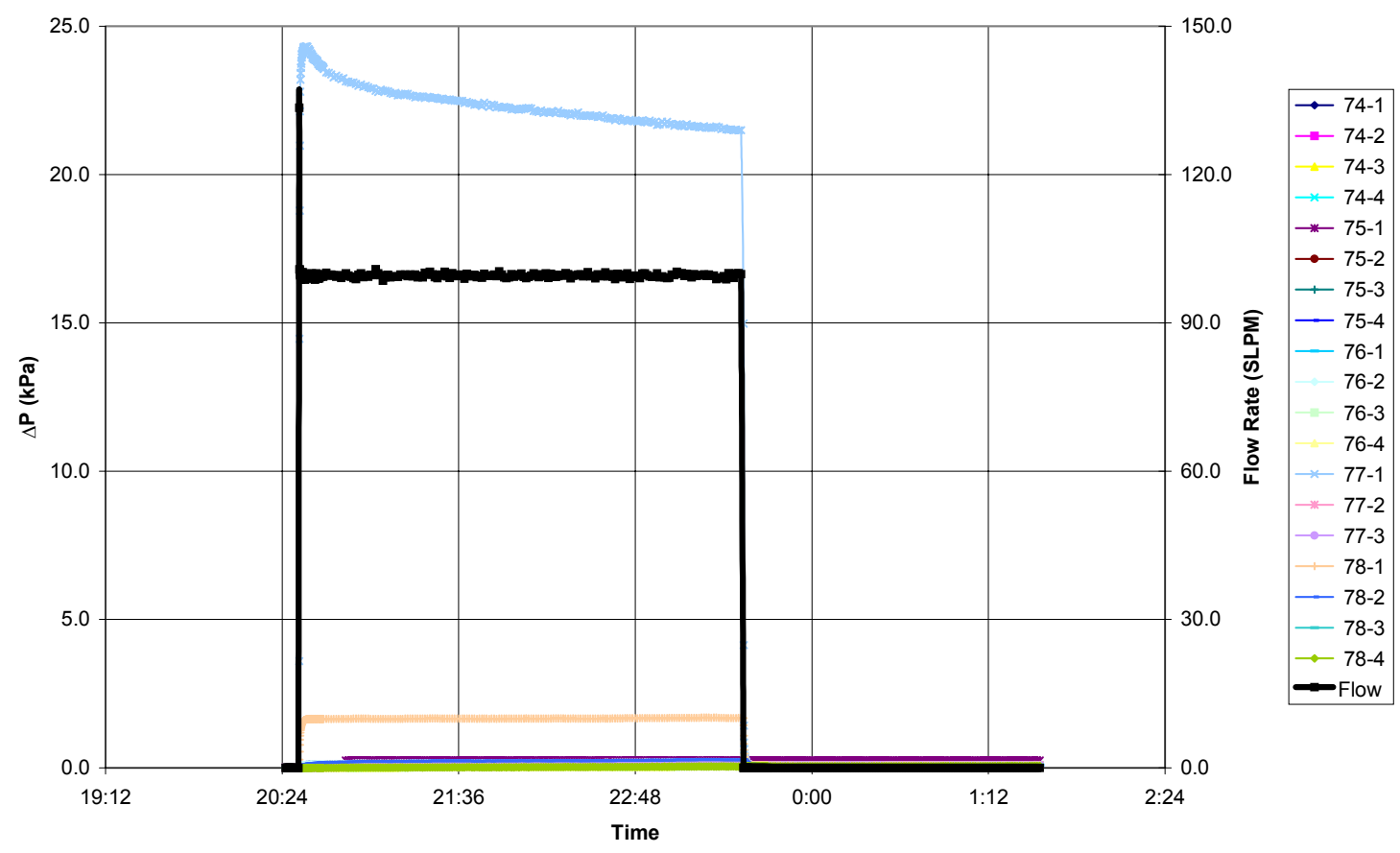


DP 77-2 (11-13-97)

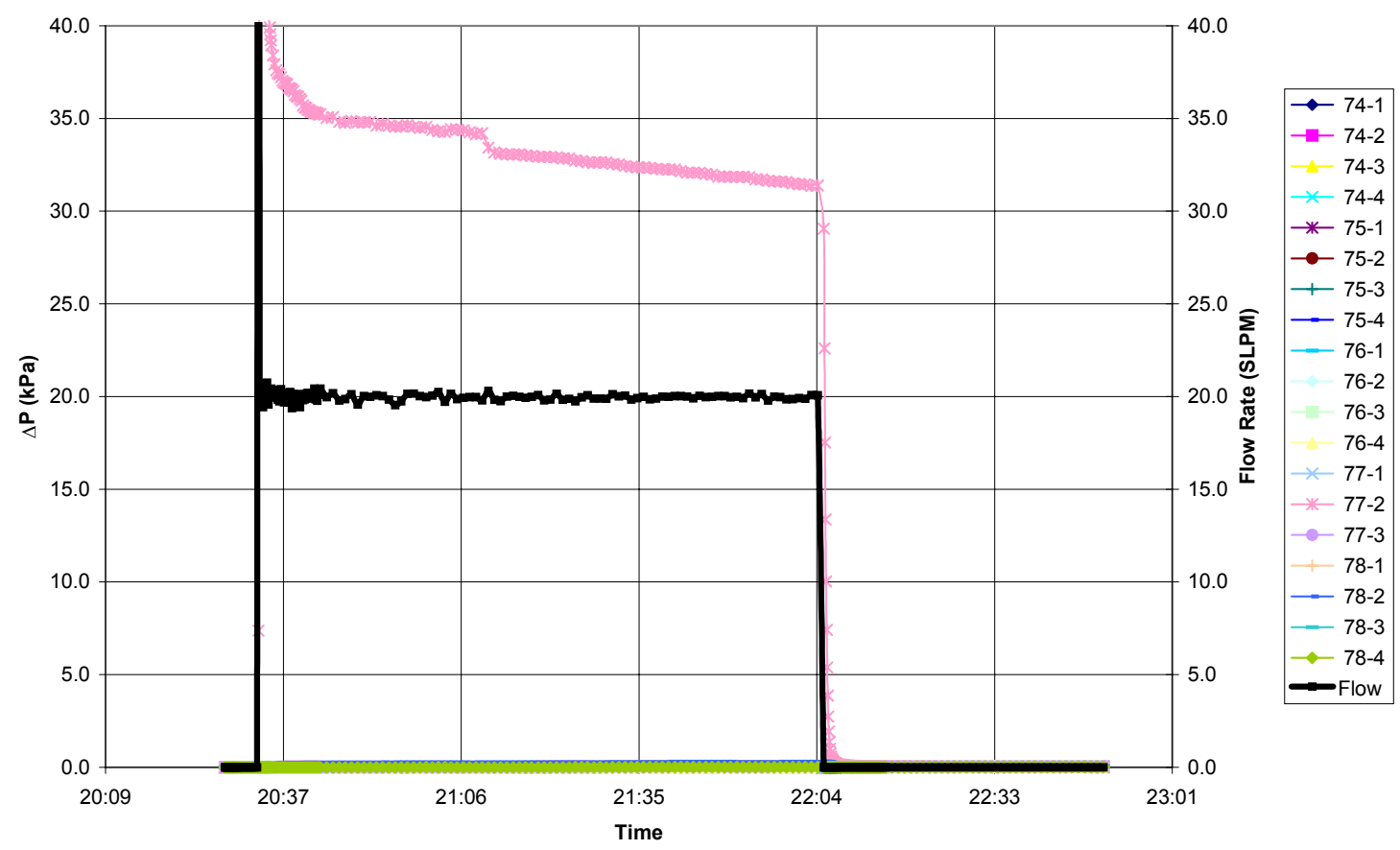

DP 77-3 (11-16-97)

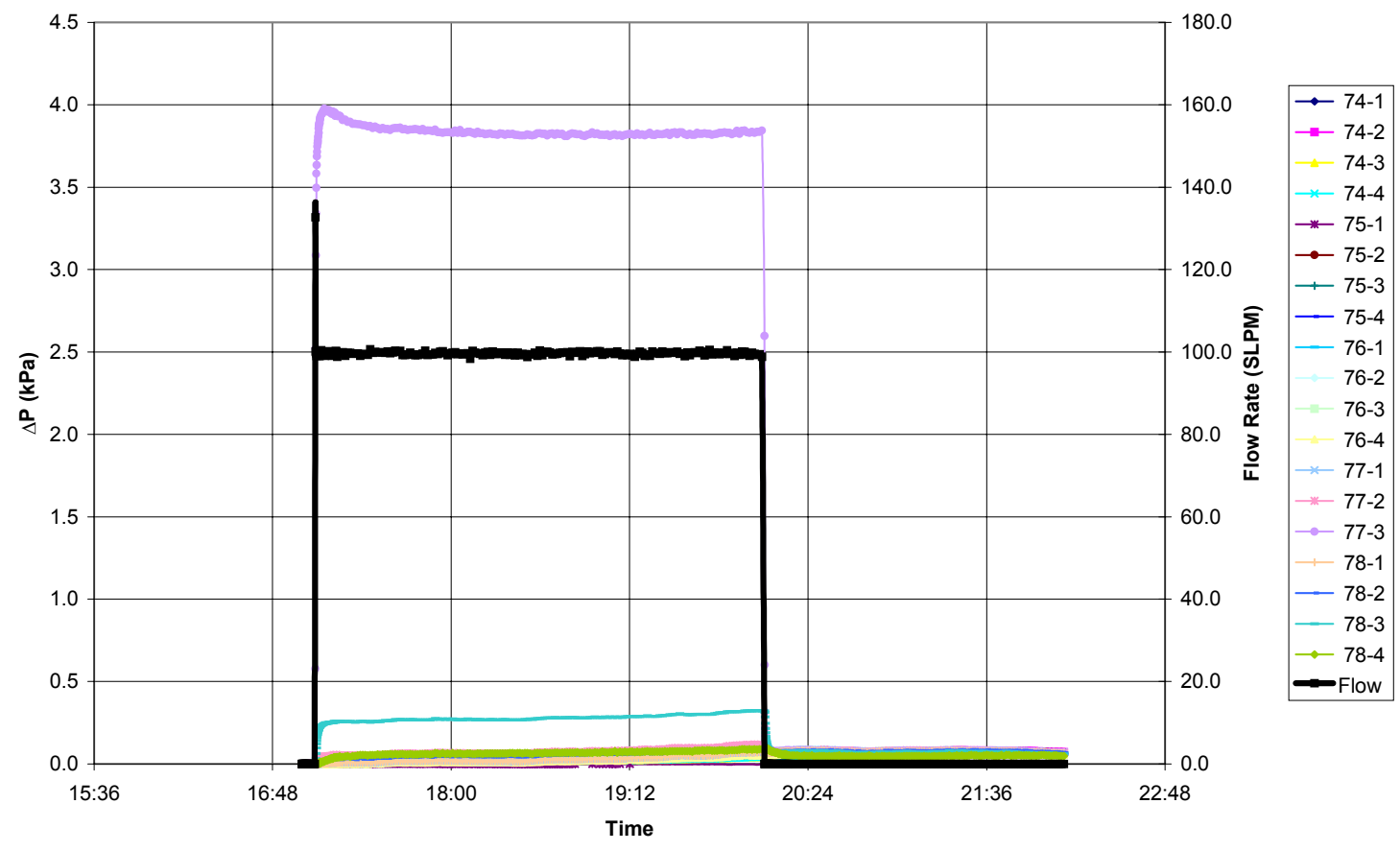


DP 78-1 (11-17-97)

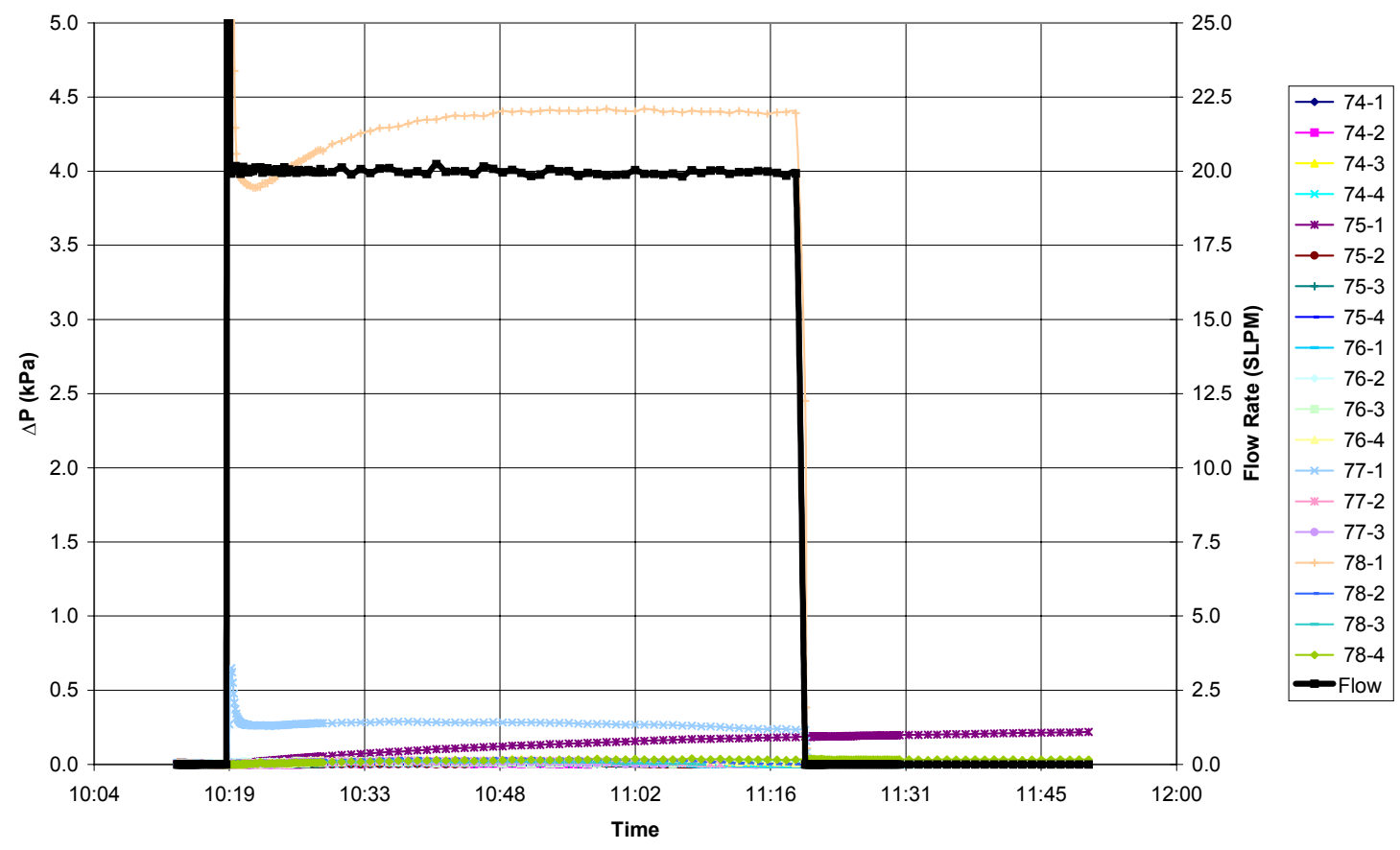

DP 78-2 (11-7-97)

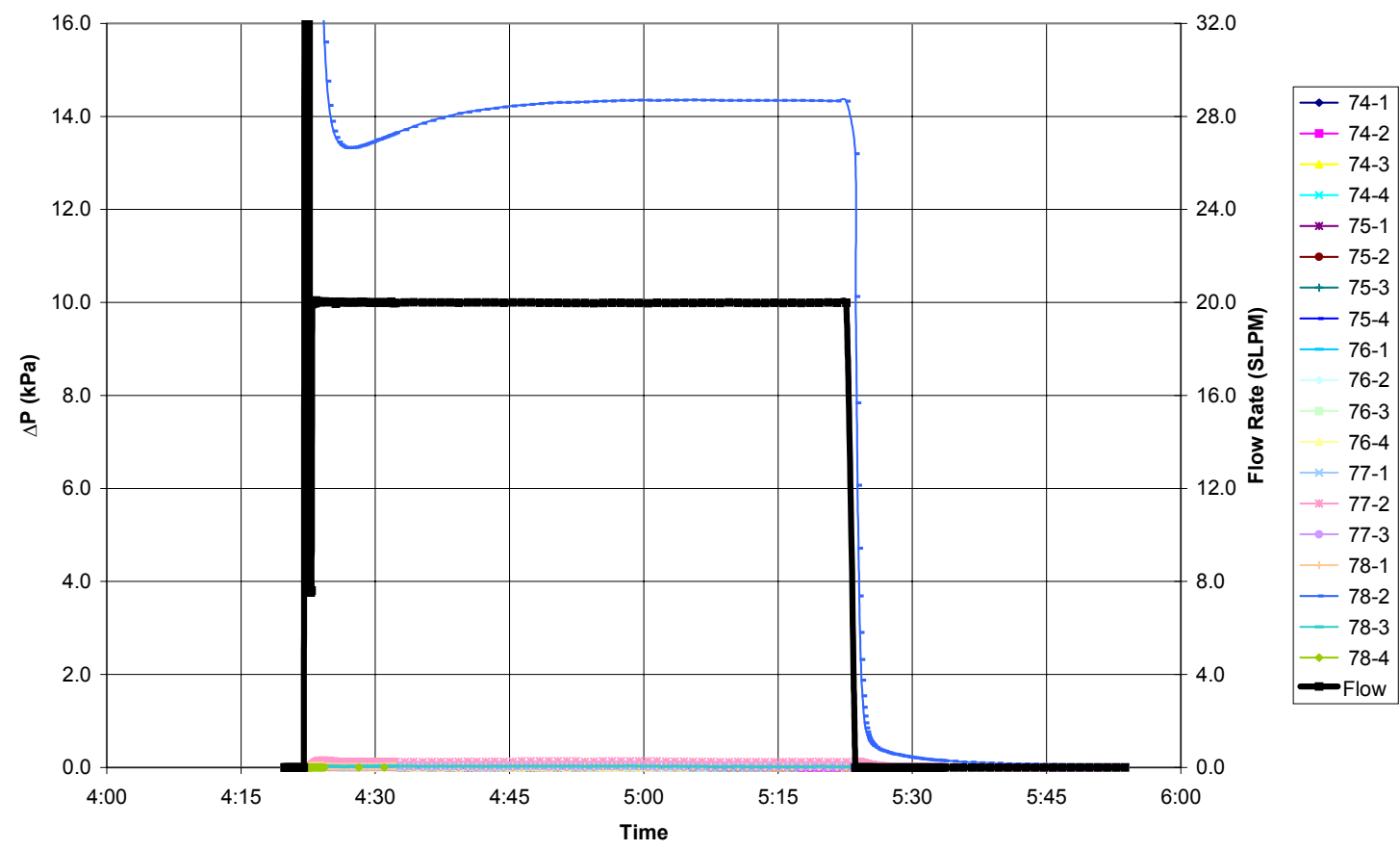


DP 78-3 (11-7-97)

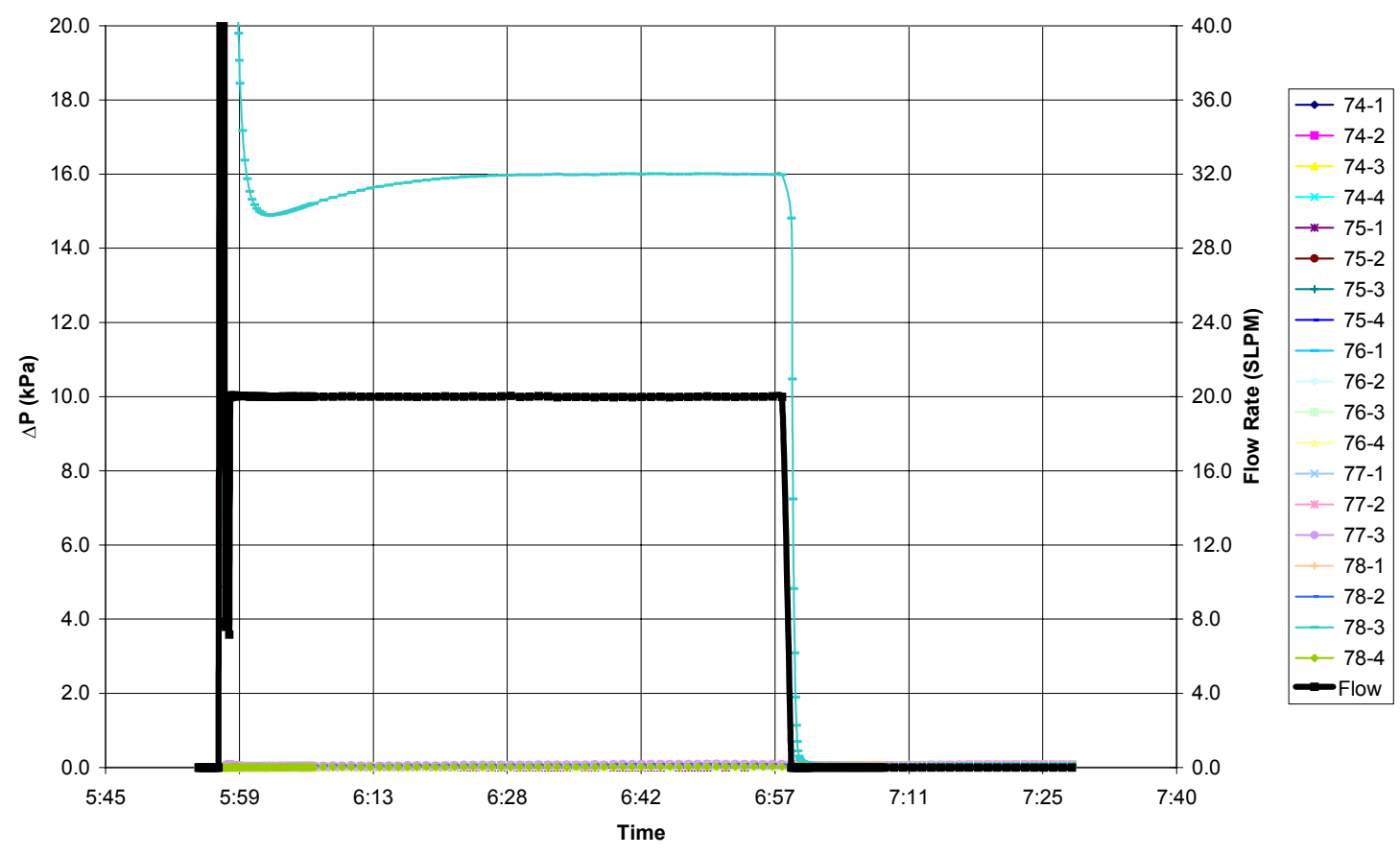

DP 78-4 (11-15-97)

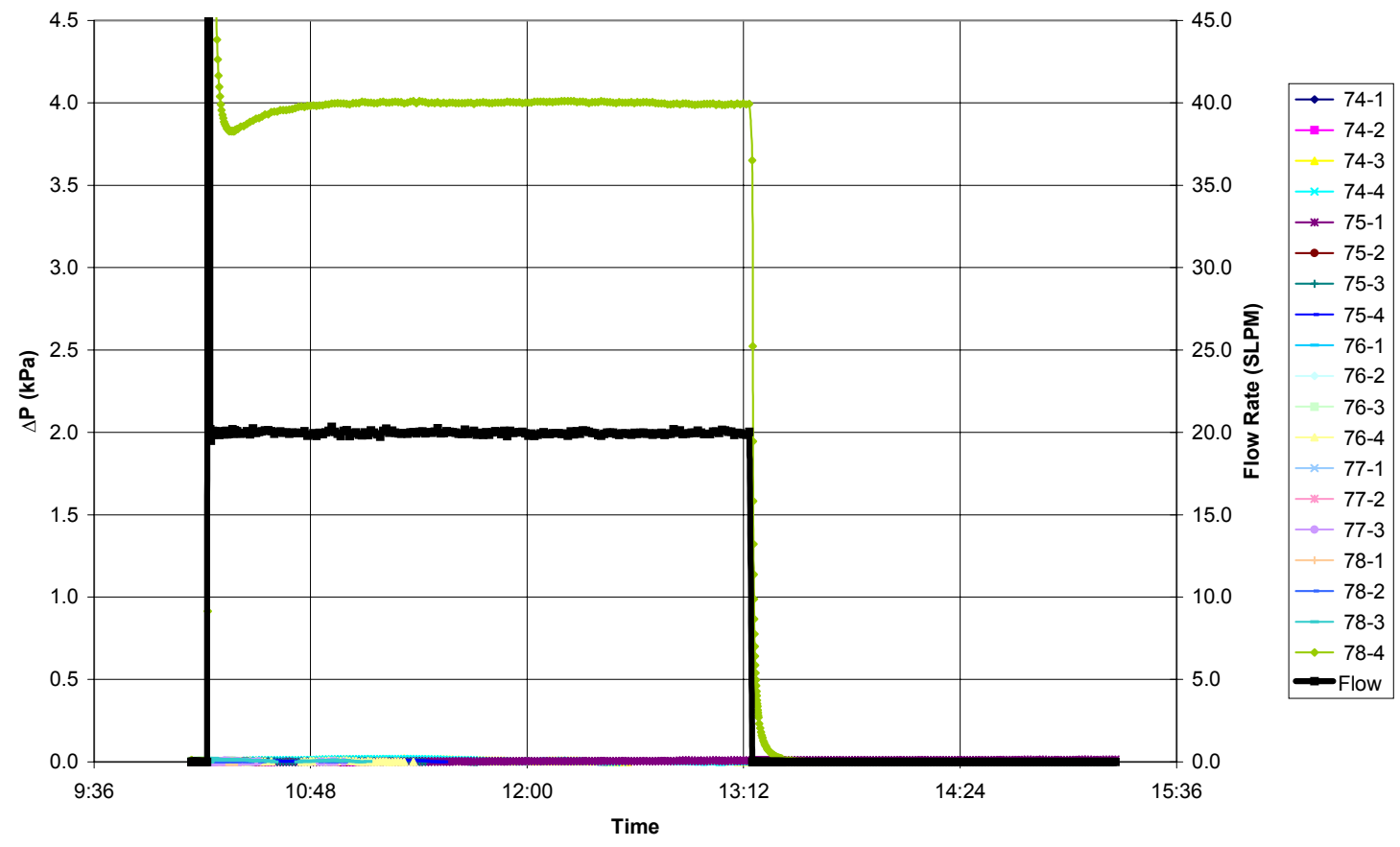


DP 185-1 (11-5-97)

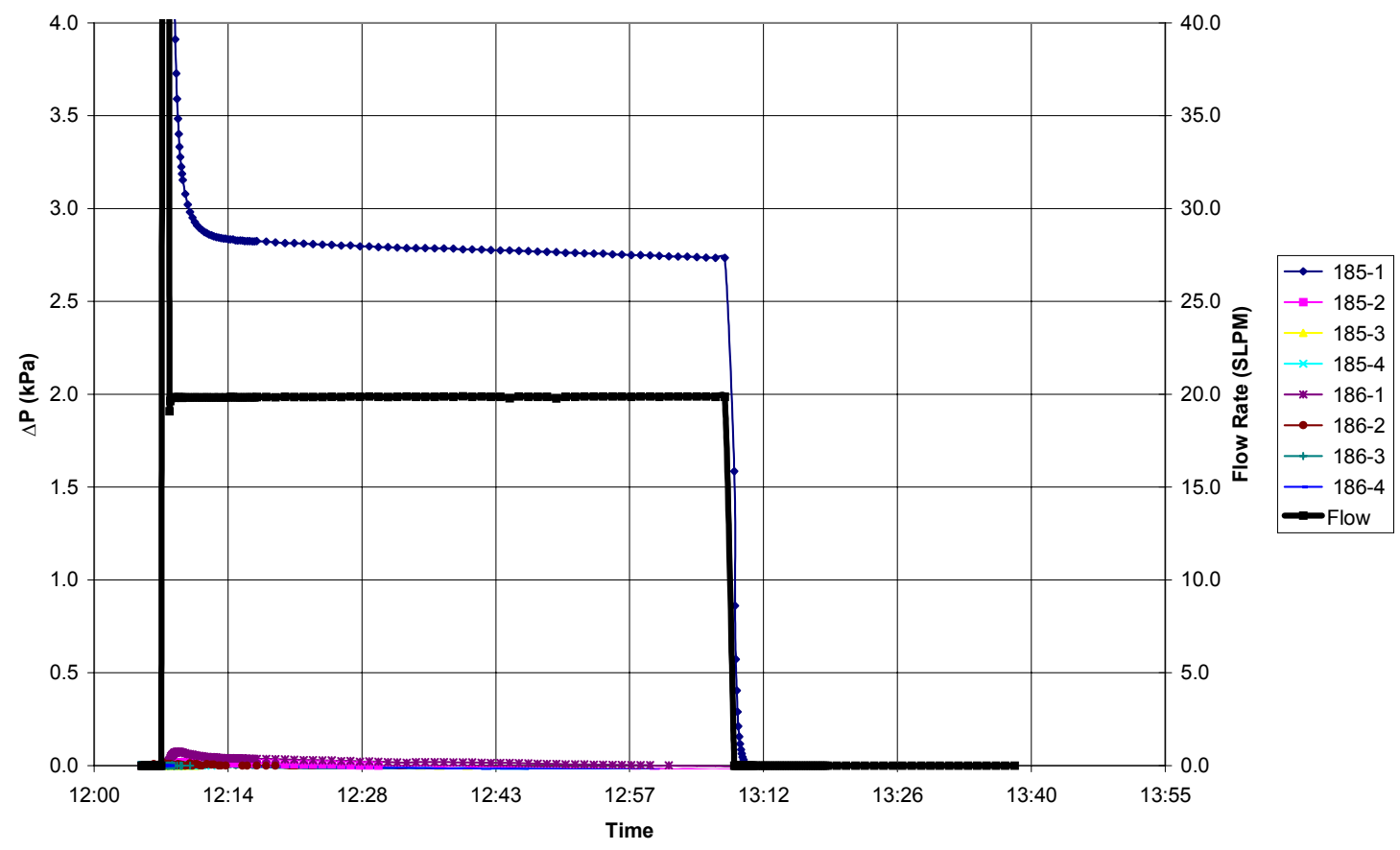

DP 185-2 (11-05-97)

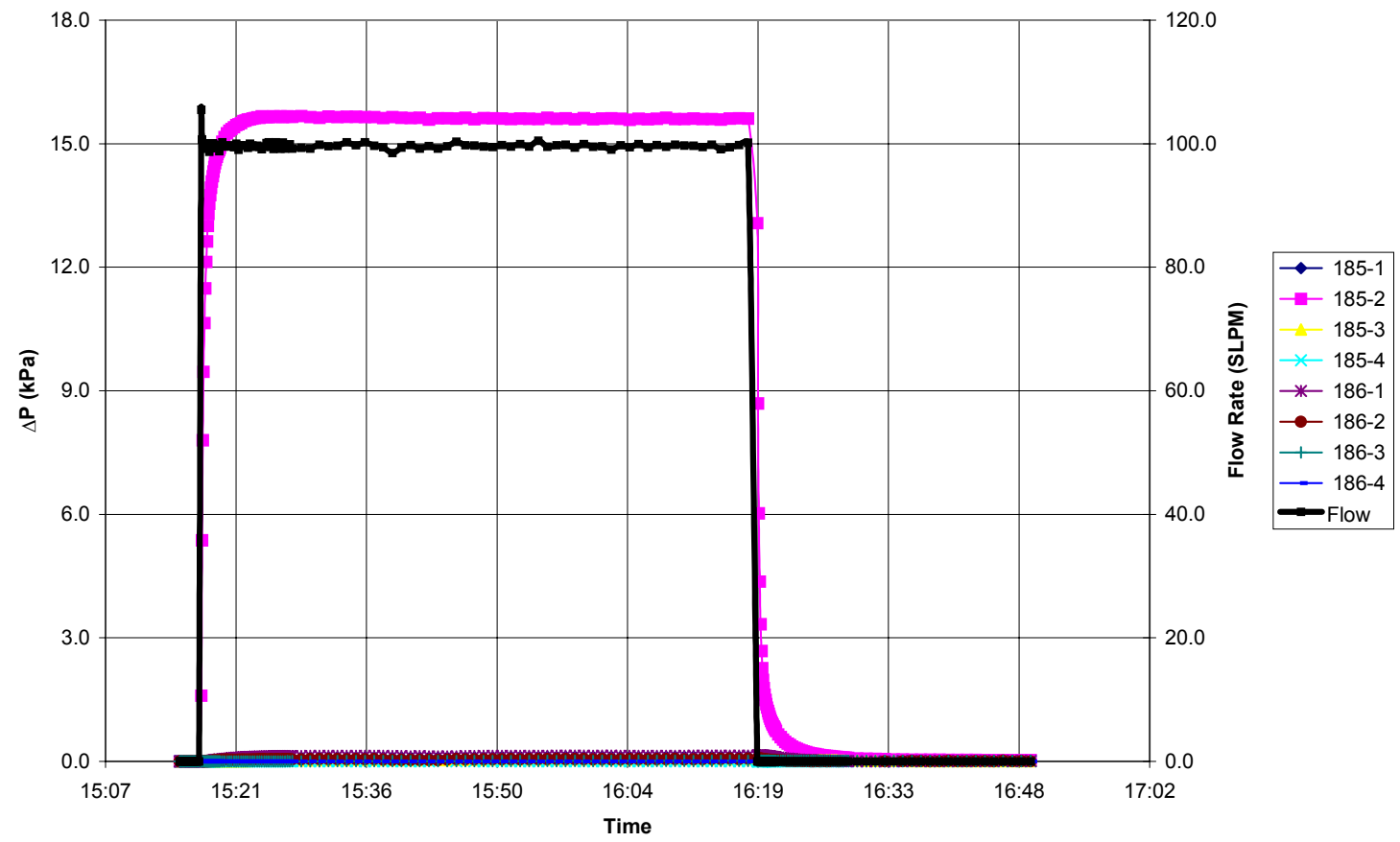


DP 185-3 (11-05-97)

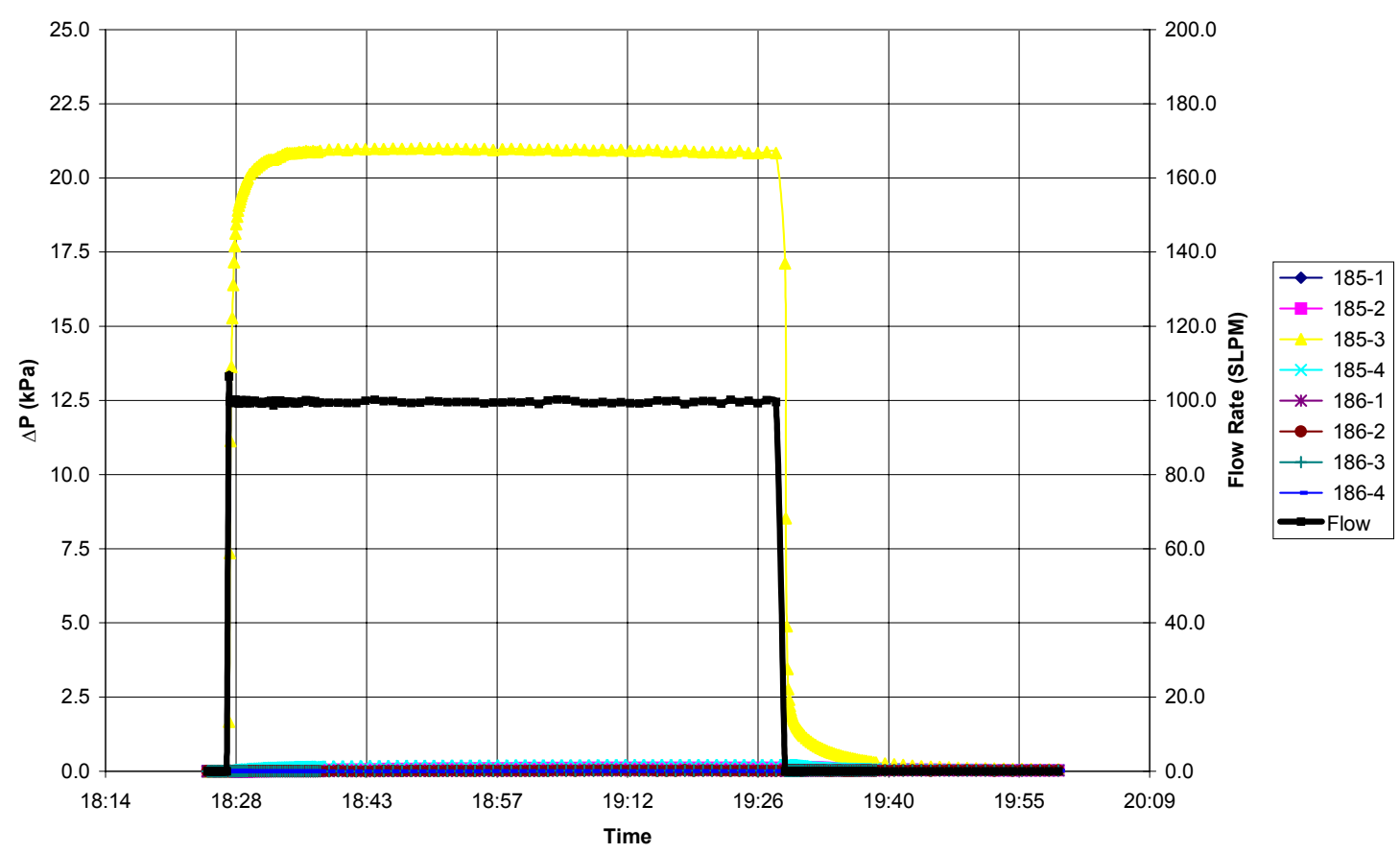

DP 185-4 (11-05-97)

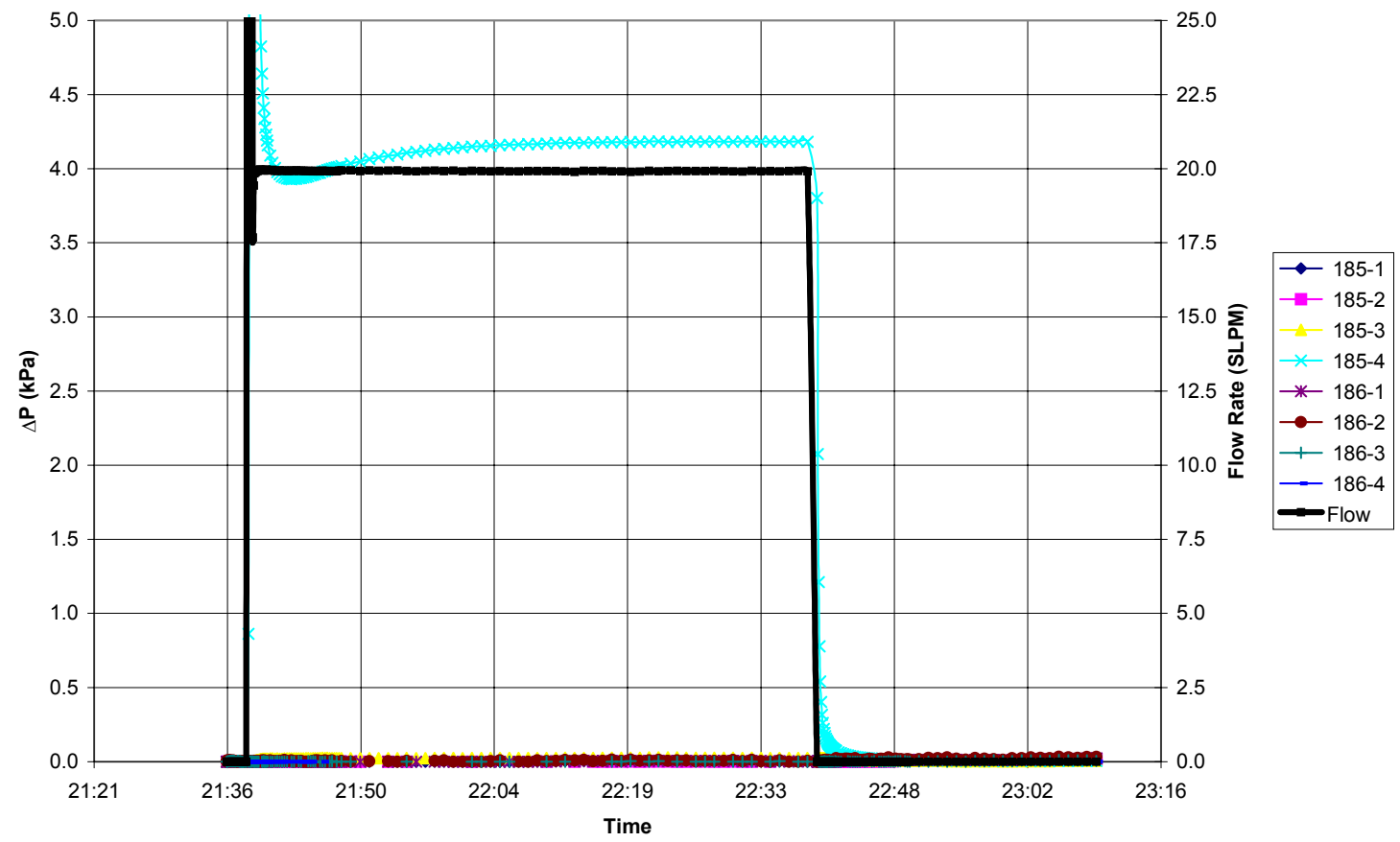


DP 186-1 (11-4-97)

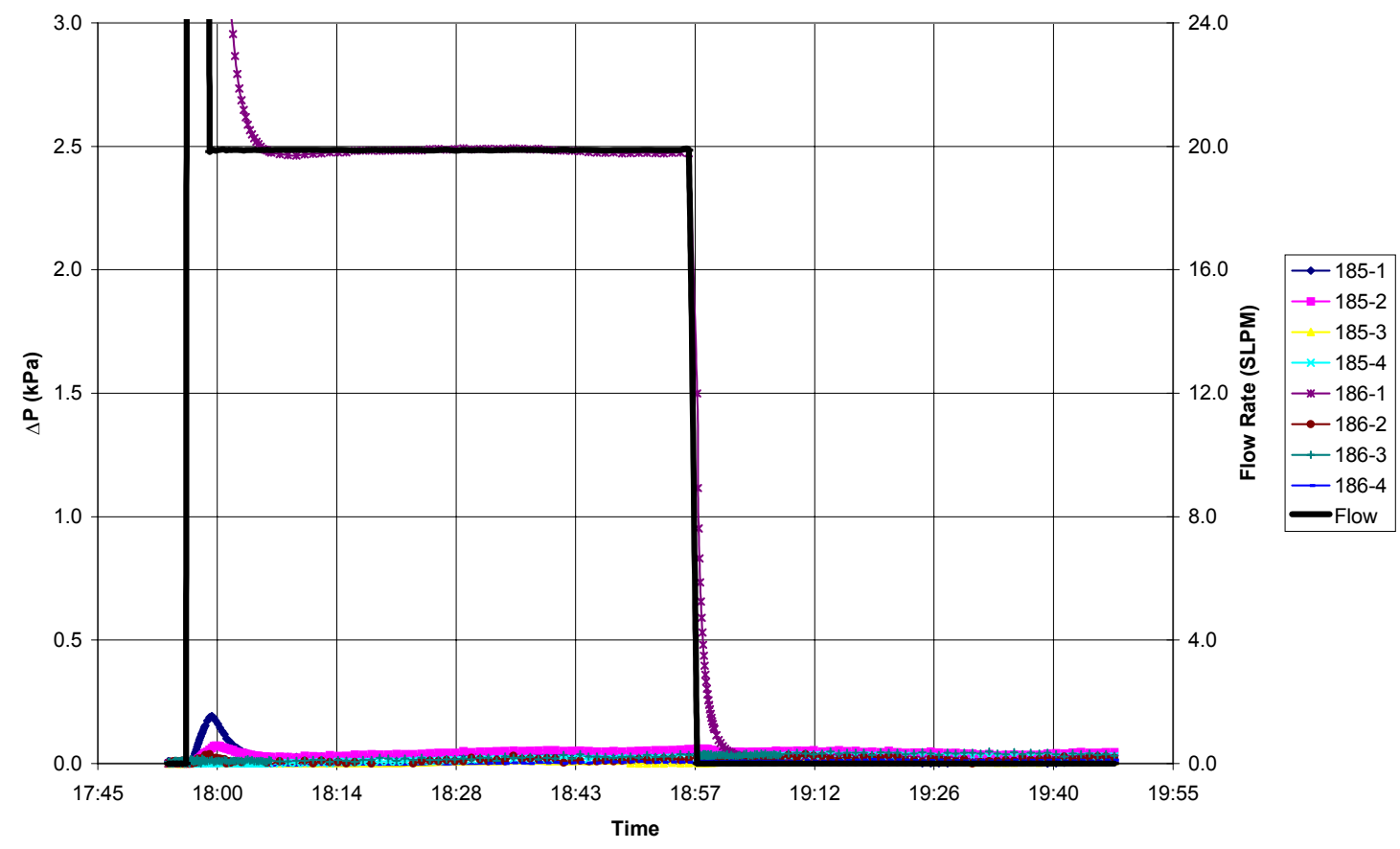

DP 186-2 (11-04-97)

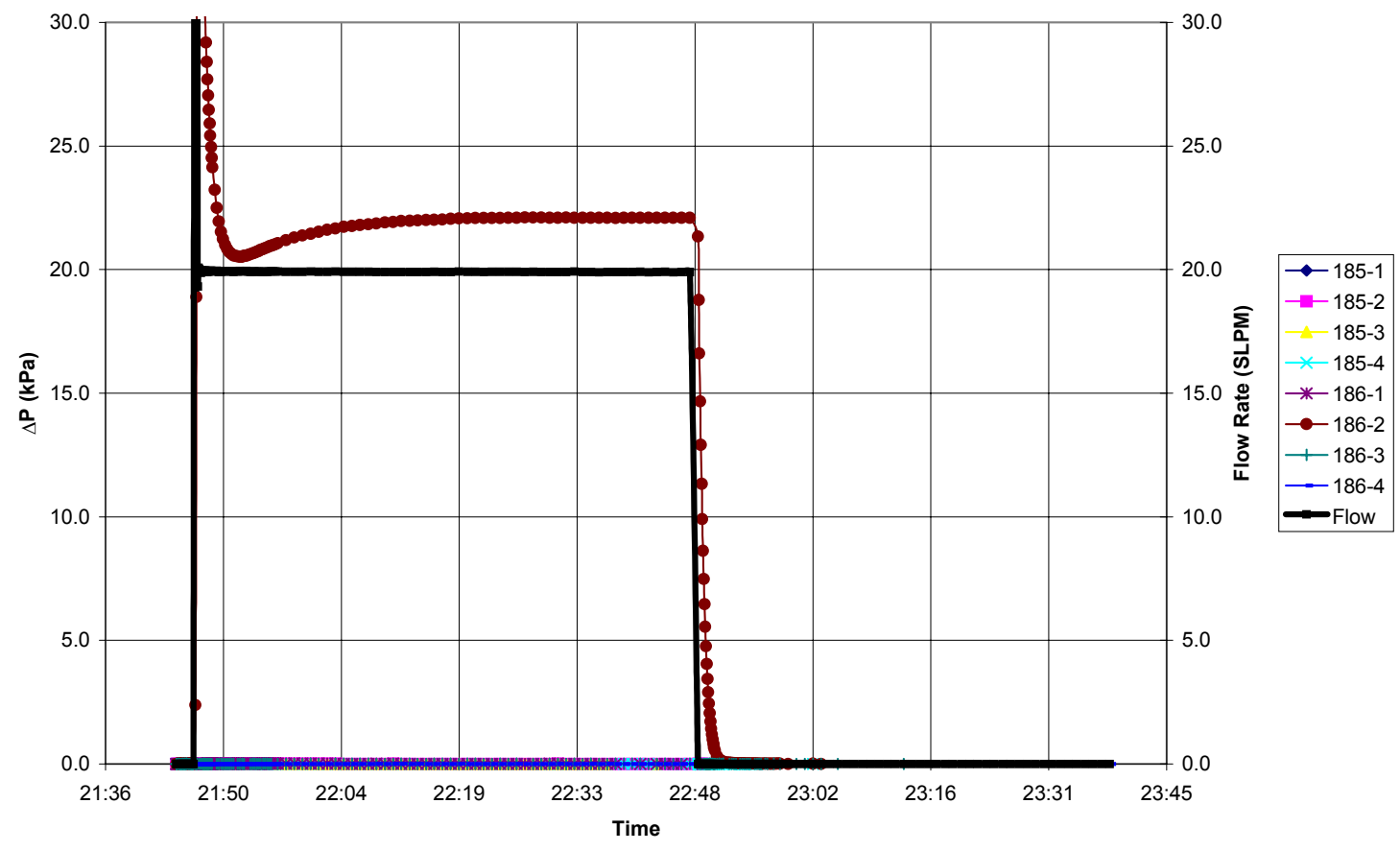


DP $186-3$ (11-05-97)

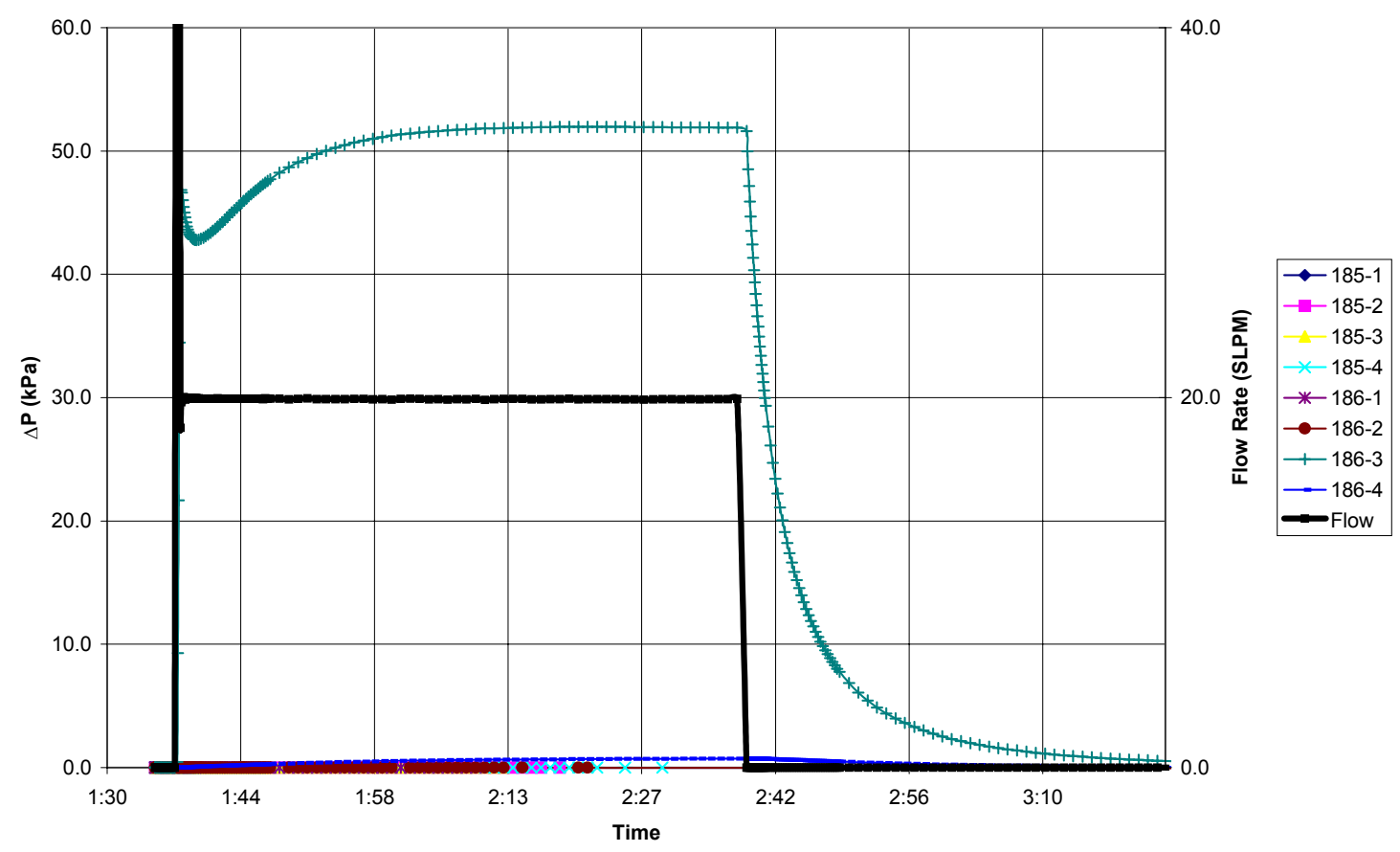

DP 186-4 (11-17-97)

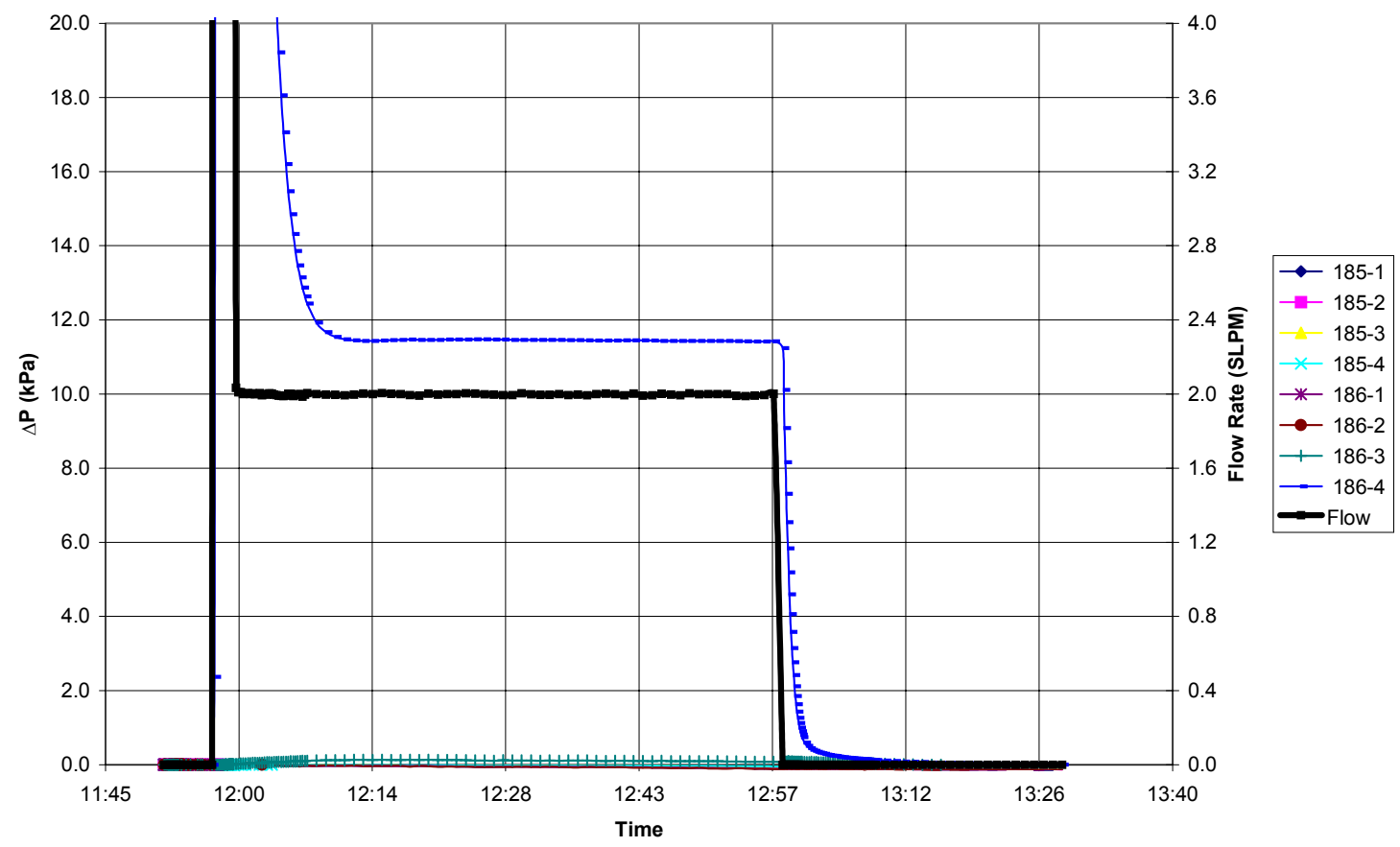


Appendix B: Standard Operating Procedure for Conducting Air-Permeability Tests 


\section{PURPOSE}

This Standard Operating Procedure (SOP) describes the methods of airpermeability testing in the Drift Scale Test (DST) for the Yucca Mountain Site Characterization Project (YMP) at Ernest Orlando Lawrence Berkeley National Laboratory (LBNL).

The objective of air-permeability testing in the DST area is to monitor changes in permeability over time as thermal testing is being conducted. To assure the accuracy, validity, and applicability of the method used to collect routine constant mass flux air-permeability test data in the area, this procedure provides directions for LBNL personnel and contractors performing the described activity.

This procedure describes the components of the work. It also describes the methods to be used for calibration, operation, and performance verification of any equipment, if needed. In addition, it defines the requirements for data acceptance, documentation, and control.

\section{SCOPE}

This procedure applies to all LBNL personnel or contractor personnel following LBNL procedures who conduct constant flux air-permeability testing in the DST Hydrology Boreholes. The hydrology boreholes consist of twelve boreholes in the DST area commonly referred to as Boreholes 57 to 61,74 to 78 , and 185 and 186. Each borehole has zones that are isolated using pneumatic packers. Zone 1 is closest to the collar of the borehole, with the zone number ascending toward the bottom of the boreholes.

For all technical activities, data collected from using this procedure and any equipment calibrations or recalibrations that may be required shall be in accordance with this technical procedure and all test and measuring equipment shall be in calibration with traceability to NIST standards.

\section{PROCEDURE}

\subsection{System Components}

The air-permeability testing uses a Gas Control System and a Data 
Acquisition System. The gas control system consists of all pneumatic plumbing, solenoid valves, mass flow controllers, etc. that are used to regulate and control the injection of air. The data acquisition system consists of all sensors, acquisition hardware, software, and wiring that interfaces to the gas control system.

\subsubsection{Data Acquisition System}

The data acquisition system is composed of two Keithley 20017 $1 / 2$ digit multimeters, a Keithley 7002 scanner system, a Windows NT Personal Computer with monitor, and two Hewlett-Packard E3631A programmable power supplies. There is a GPIB IEEE488.2 compliant interface card installed in the personal computer, which interfaces the computer to the aforementioned electronics. The personal computer is running Labview data collection software, and uses three executable codes, referred to as virtual instruments, vi, for data collection. They are called automated_DST.vi, automated2_DST.vi, and automated3_DST.vi.

\subsubsection{Flow control system}

Air supplied through the tunnel compressed air system is first filtered, dehumidified using a regenerative twin-tower desiccator, and filtered again before being sent through mass flow controllers. Attachment 1 is a piping diagram for the injection gas control system. Four Sierra Instruments mass flow controllers (MFCs), with full flow ranges of 1 Standard Liter Per Minute (SLPM), 10 SLPM, 100 SLPM, and 500 SLPM, which are connected in parallel, are selectively used to control the precise amount of gas being introduced into a borehole interval. The outlet of each mass flow controller has a pneumatically controlled valve to ensure positive shut off when the mass flow controller is not in use. Downstream of the mass flow controller manifold is an array selection manifold. The array selection manifold directs the gas flow to one of the three arrays of hydrology boreholes, Boreholes 57 to 61, Boreholes 74 to 78, and Boreholes 185 and 186. Located near the collars of each borehole is another manifold, which directs the gas flow to the isolated zones within the borehole. A tracer gas injection system, as shown in Attachment 1 is connected to the flow control system, but is not used during 
air-permeability testing. Verify before conducting airpermeability tests, that tracer gas cylinders are closed at the compressed gas cylinder.

\subsubsection{Software}

A. The program named automated_DST.vi is used for collecting data in the Boreholes 185 and 186. Automated2_DST.vi is used for collecting data in Boreholes 74 to 78, and automated3_DST.vi is used for collecting data in Boreholes 57 to 61 . They will be referred to as automated*_DST.vi hereafter, with the wildcard indicating that any one of the three routines is being referred to. The subroutines utilized by the three main routines, automated*_DST.vi, are identical. The graphical code for automated_DST.vi is included in Attachment 2. The only differences between automated_DST.vi and automated2 (3)_DST.vi are the string array which is used to specify which solenoids are opened during testing and the number of zones in the borehole cluster. The Labview vis shall come under the control and documentation requirement of YMPLBNL-QIP-SI.0, Computer Software Qualification and YMPLBNL-QIP-SI.1, Software Configuration Management.

B. The main routine first initializes the Keithley scanner by opening all switches, thereby closing all solenoid actuated valves. This ensures that each packed-off interval is closed and that no gas is flowing in the system. It then calls a subroutine, Data File, which is responsible for opening and assigning names to data files based upon the date and time the test was started. The suffix on the data file name indicates whether the file contains raw unprocessed data or whether it has been converted to engineering units, and whether it is temperature data or pressure data. The suffixes are .pres or .pres_cal for pressure data files and .rtd or .rtd_cal for temperature data files. The files with suffixes that have _cal in them are engineered units while the files that do not have _cal are in unprocessed format.

C. Subroutines PRESSUREDATA and RTD are called upon next to start logging pressure and temperature data, respectively. After logging one set of values from all 
sensors, the main routine, automated*_DST.vi, commences background data collection. This usually consists of a few minutes of data used to establish baseline pressures for each test. Next automated*_DST.vi enters an injection phase, and finally a recovery phase of testing. In each of the three phases, background, injection, and recovery, the subroutine Loop Delay is used to set the frequency of data collection. Loop Delay has been set to record a set of data every 5 seconds for the first two minutes of each test phase, then every fifteen seconds for the next eight minutes, and then finally every minute. These predetermined data sampling rates are used to meet the goals of creating data files of workable size while fully capturing the transient behavior that occurs during the initial injection and recovery periods.

D. During injection, the Adjust Flow routine monitors the maximum change in pressure during air injection and adjusts the flow rate accordingly. This is done to keep the change in pressure between 1 and $50 \mathrm{kPa}$. It is felt that at these pressures, the ratio between pressure and flow will be constant, and the nonlinear response associated with air compressibility will be minimized. The algorithm, which controls the flow rate, is based upon both the elapsed time of injection and the pressure change in the injection interval. The injection test is automatically started at a default flow rate, nominally 100 SLPM. If the elapsed injection time is less than 2 minutes and the change in pressure in the injection zone is greater than $25 \mathrm{kPa}$, the flow rate is reduced to $20 \mathrm{SLPM}$. If the elapsed time is greater than two minutes and the pressure has gone over $50 \mathrm{kPa}$, then the flow rate is reduced to 2 SLPM. If the pressure has not increased to at least $6 \mathrm{kPa}$ after four minutes of injection than the flow rate is increased to 200 SLPM. These breakpoints in time and pressure were established by trial and error during baseline measurements, and were found to provide good test results for the entire range of permeabilities encountered within the DST area. Even though the computer may adjust the flow rate during testing, the injections are still referred to as constant mass flux injections, since the flow rate is only adjusted to maintain a controlled injection pressure and the test is carried out predominantly at one fixed flow rate. 
E. After the injection phase of the test has been completed, the gas flow is halted and the solenoid valves that were opened to start testing are closed. The recovery phase of the test then commences for a predetermined length of time. To start the next injection test, the main routine opens new data files and begins repeating the sequence of background data logging, gas injection, and finally recovery data logging.

3.2 Test Preparation Staff member preparing for air-permeability testing shall perform the actions described below.

\subsubsection{Electronics}

A. Before turning on the electronics for testing, turn on the air conditioner on the Electronic Rack and verify that it is properly cooling the rack. The air conditioner should maintain the rack at a temperature, which will fluctuate between $70^{\circ} \mathrm{F}$ and $95^{\circ} \mathrm{F}$.

B. Turn on the Keithley electronics, the Hewlett-Packard power supplies, and the $\pm 15 \mathrm{~V}$ power supply used for the MFCs, which are all located in the electronic enclosure. Then proceed to turn on the computer monitor and finally the computer.

C. The power supply to the Setra transducers, which is located in the Acoustic Emission Electronic Enclosure in the main data acquisition office, shall be verified as being turned on and set to 24 volts.

\subsubsection{Flow Control System}

A. Check all manually operated valves located on the injection lines visually to verify that they are in the open position.

B. Turn on the twin-tower desiccant dryer, open the mine air supply valve and set the regulator on the output of the desiccant dryer to 60 PSIG.

C. Verify that the two manually operated $1 / 8^{\prime \prime}$ supply air line valves, located near the pressure regulator are open. 
D. The inlet and outlet filters on the twin-tower dryer have visual gauges, which indicate the status of the filters. If at any time the indicator appears red, replace the filters at the next convenient time. It is not necessary to interrupt ongoing tests to change a filter. This is anticipated to be a once a year or less frequent maintenance item.

\subsection{Calibration Requirements}

\subsubsection{Calibration Interval}

The Mass Flow Controllers and Digital Multimeters are on a yearly calibration cycle. Verify that their calibration is still valid before collecting data. If they are not within current calibration or the data they are generating is suspect, they shall be removed from service and replaced with calibrated units. The units requiring calibration shall be treated as per the requirements of YMP-LBNL-QIP-12.0.

\subsubsection{System Component Accuracy}

The accuracy of the MFC in the field is typically less than the published manufacturer's specifications. Although Sierra Instruments MFCs are calibrated to their manufactured specification of $\pm 1 \%$ of full scale, their required performance in the field for compliance with this SOP is $\pm 10 \%$. The Setra pressure transducers have a calibrated accuracy of $\pm 0.1 \%$, but under this SOP they are expected to provide data with an accuracy of $\pm 0.25 \%$.

\subsection{Data Collection}

3.4.1 Executing automated_DST.vi, automated2_DST.vi, and automated3_DST.vi performs a complete cycle of data collection in all 12 hydrology boreholes. Data file names are automatically selected, and include the date and time of testing to make them unique and distinguishable. They are saved onto the E: \drive of the data acquisition PC. The only parameters that are user selectable are the starting flow rate, duration of background data collection, injection duration and duration of recovery, which are all located on the front panel of 
automated*_DST.vi. Testing has shown that a background data collection time of 2 minutes, with an injection time of 60 minutes and a recovery time of 60 minutes is satisfactory for obtaining a good data set, with most pressure transients reaching the desired pseudo-steady state. Pseudo-steady state is defined as when the pressure response curve shows only a very gradual change over time, which may be due to secondary influences such as barometric drift or redistribution of moisture. The starting flow rate default of 100 SLPM also was found to be acceptable. These parameters may need to be changed by the user during the course of the DST due to the changing thermal-hydrologic conditions. It shall also be noted that due to the two-phase and non-isothermal conditions within the DST area, it is not possible or practical to conduct each test until it reaches true steady state conditions.

\subsubsection{Notebook Records}

Staff members shall record the following information in their scientific notebook used for testing and include:
A.Personnel present
B. Time when each vi was started.
C. Any unusual occurrences, equipment malfunction or testing interferences from activities in other boreholes.
D. Results of data review as conducted under section 4.1.
E. Reference to this SOP by number, revision and Mod.

\section{RECORDS}

\subsection{Lifetime}

The data generated from air-permeability testing are stored on the hard disk of the data acquisition system PC. The data shall be backed up after data collection has concluded and the backup shall be verified by comparing the sizes of the original and duplicate data files and by opening and visually spot checking a few copied data points. The data generated by following this procedure and the references to scientific notebooks used in test preparation and 
describing processing and analysis of the data shall be submitted to the YMP Technical Database.

The data shall be reviewed before submittal to verify that the flow rates during testing were constant and that the pressure transients have been properly recorded. Any variation outside of expected equipment accuracy and repeatability shall be investigated and the data shall be evaluated as to whether they are to be considered acceptable and qualified. The impact of any unusual occurrences, equipment malfunctions or testing interferences as noted under section 3.4.2.C and 3.4.2.D shall be evaluated before submittal of data to the Technical Database.

\section{ACRONYMS}

DST Drift Scale Test

ESF Exploratory Studies Facility

Kpa Kilopascal

LBNL Lawrence Berkeley National Laboratory

MFC Mass Flow Controller

PC Personal Computer

PSIG Pounds Per Square Inch, gage

SLPM Standard Liter Per Minute

\section{ATTACHMENTS}

Attachment $1 \quad$ Figure 1. Flow Control System

Attachment 2 Labview Software 
Attachment 1: Gas Flow Control System
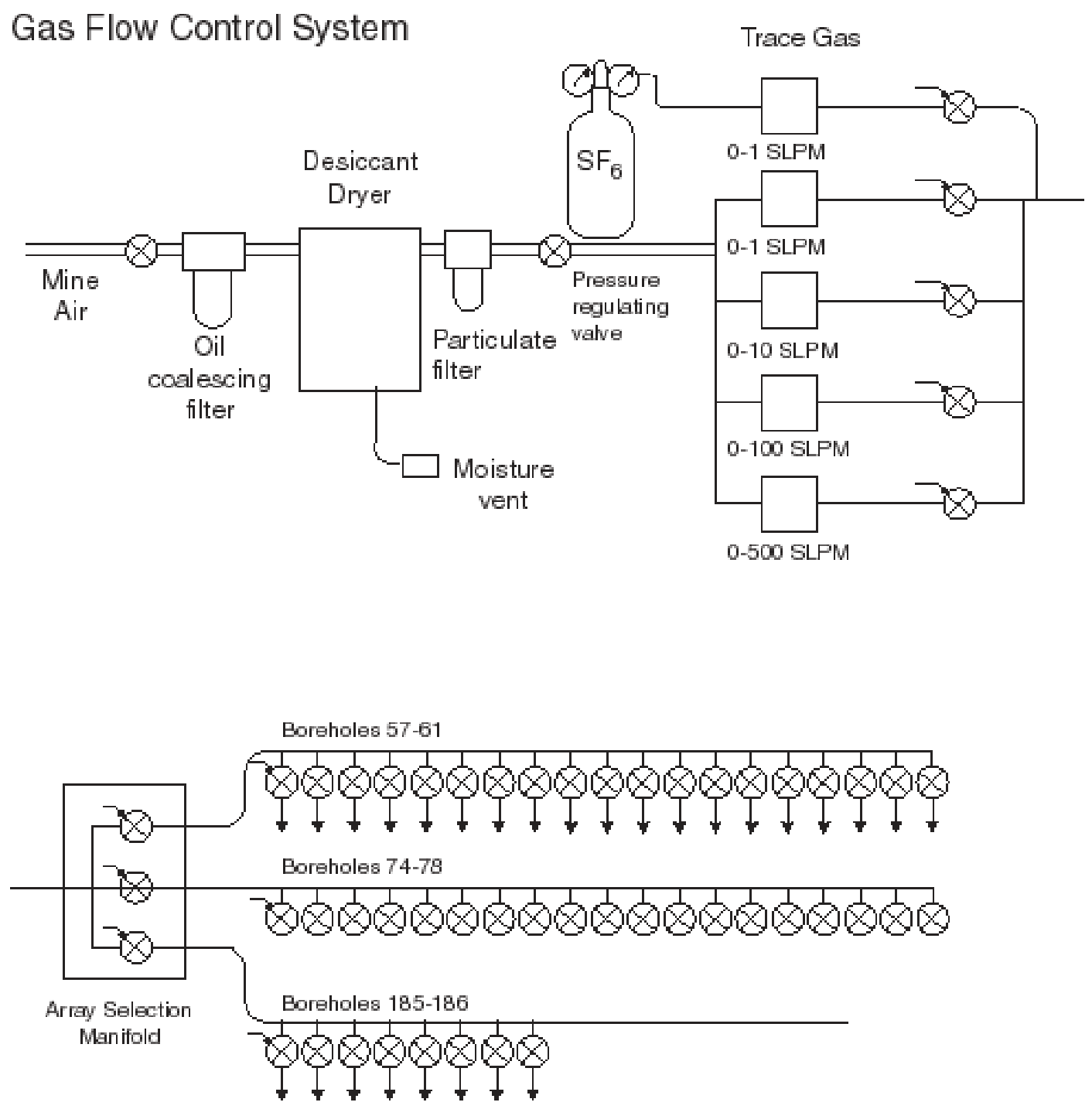

Injection Zone Selection Manifolds 
Attachment 2: Labview Software Routines

1. Program Hierarchy

2. Automated DST.vi

3. LoopDelay.vi

4. NewFile.vi

5. RTD.vi

6. AdjFlow.vi

7. pressuredata.vi

8. Flowrate.vi

9. Keithleyinit.vi

10. Plotdata.vi 
Program Hierarchy

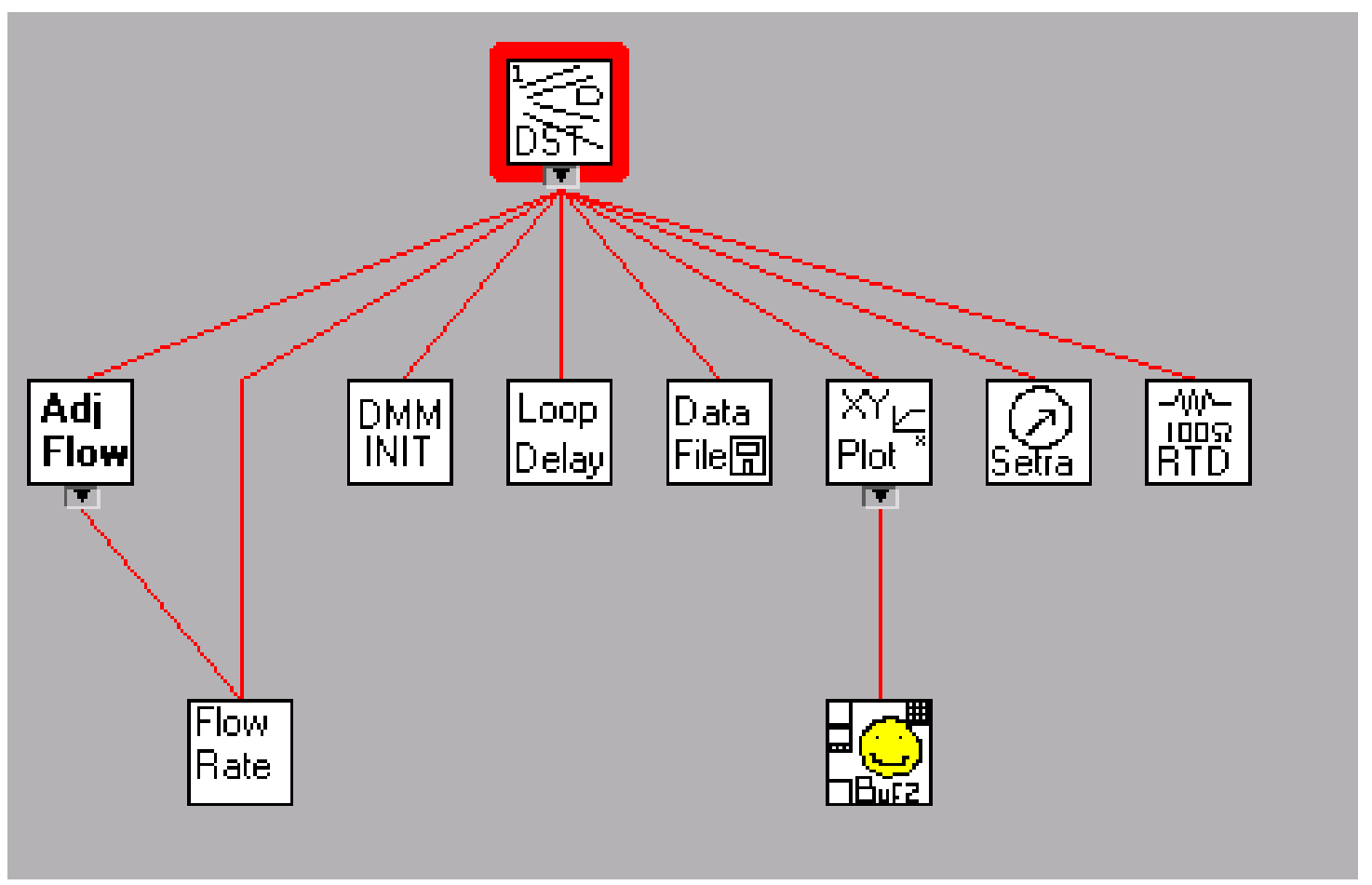


AutomatedDST.vi

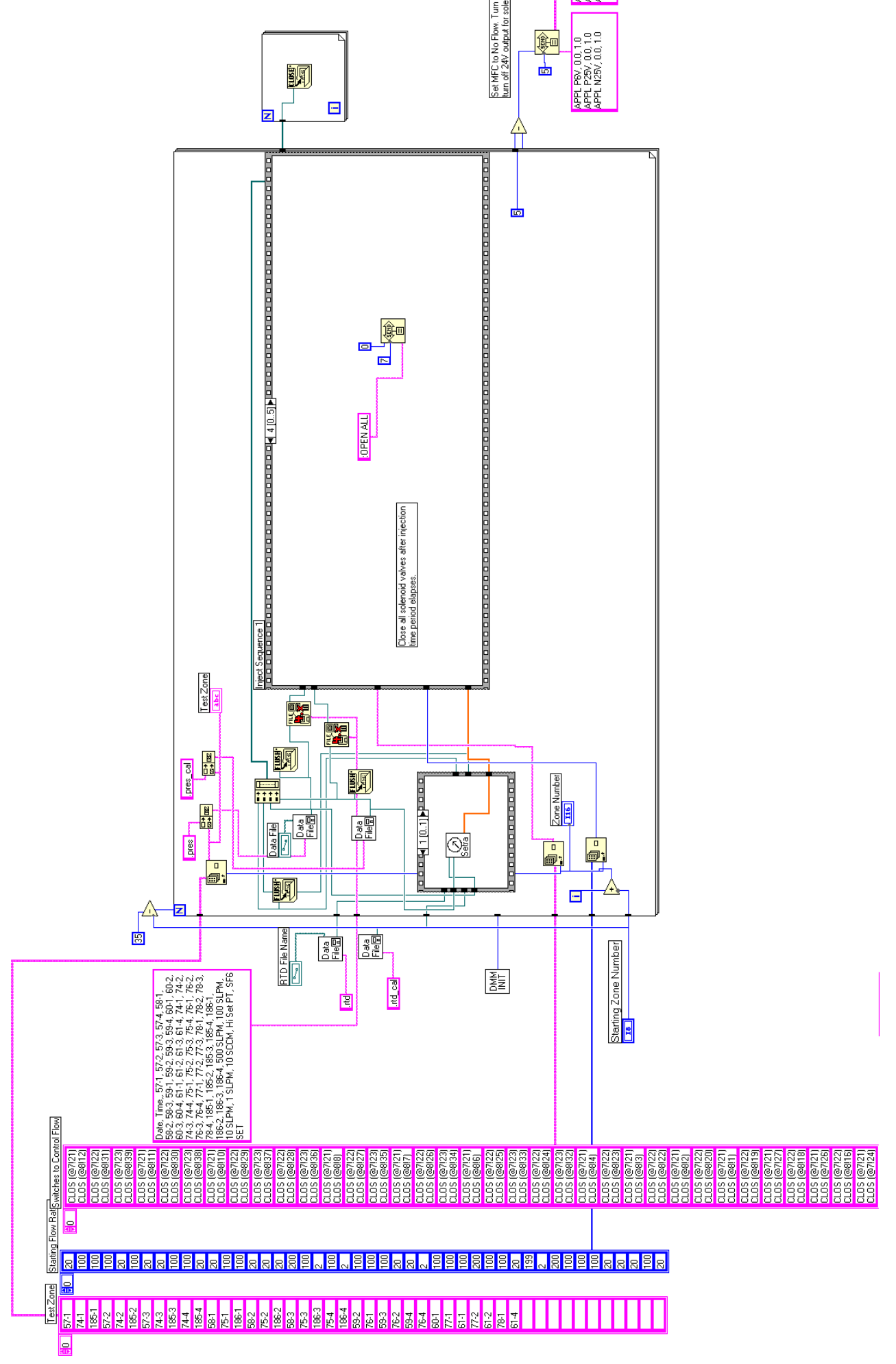



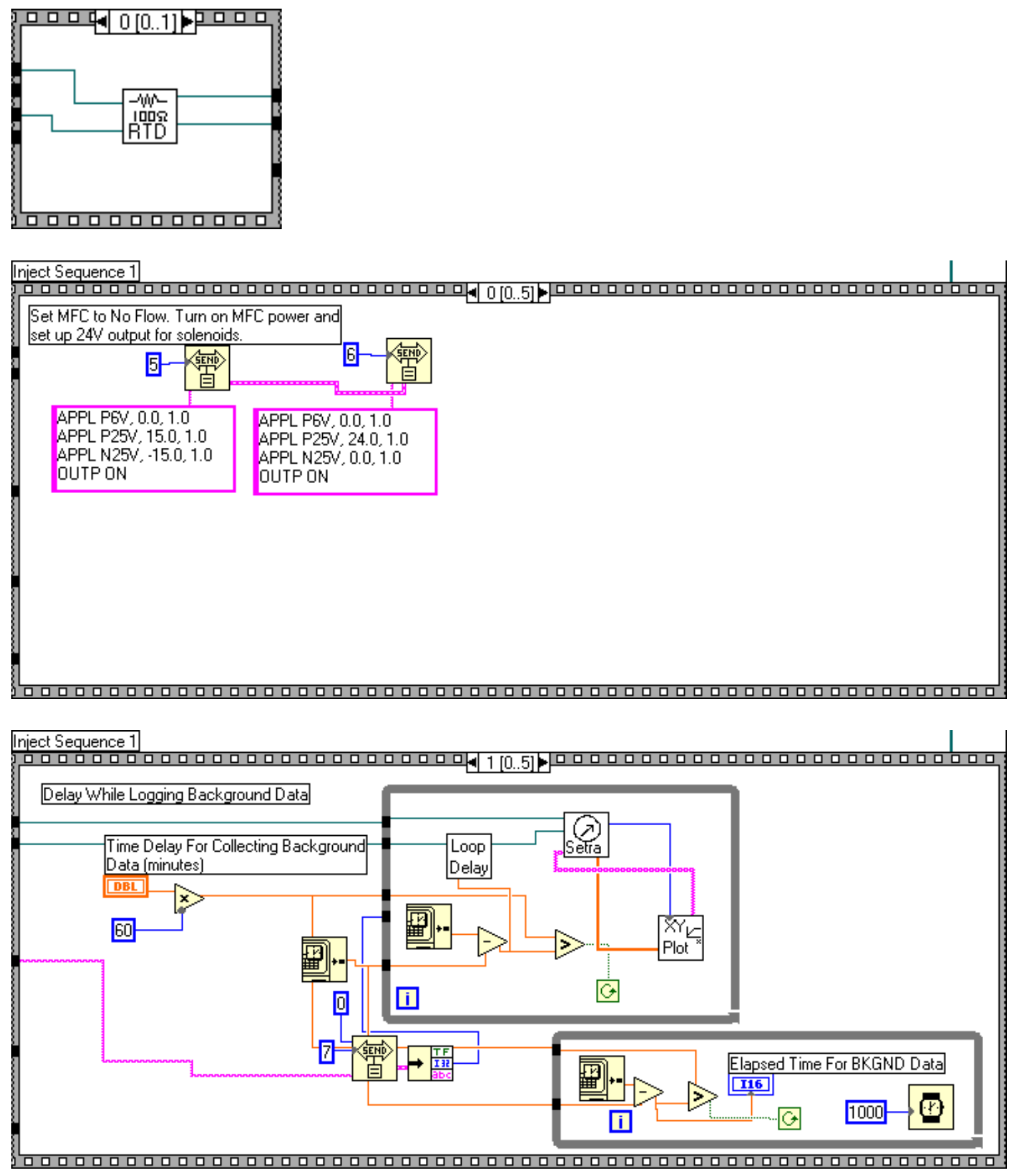
Inject Sequence 1

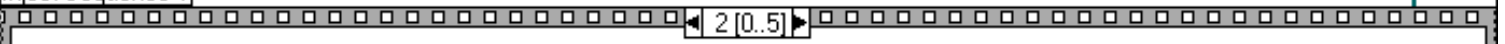

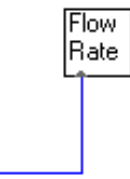

Set Power Supply Voltage for Flow Rate and Dpen Solenoids

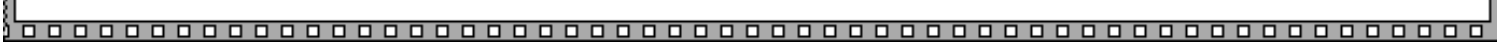

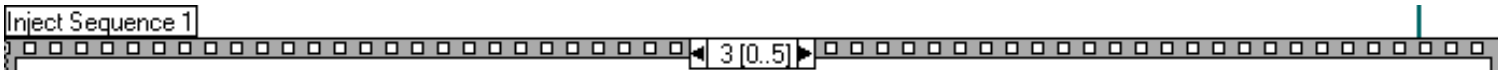
Log Data while Injecting

Injection Time Period [minutes) DBD
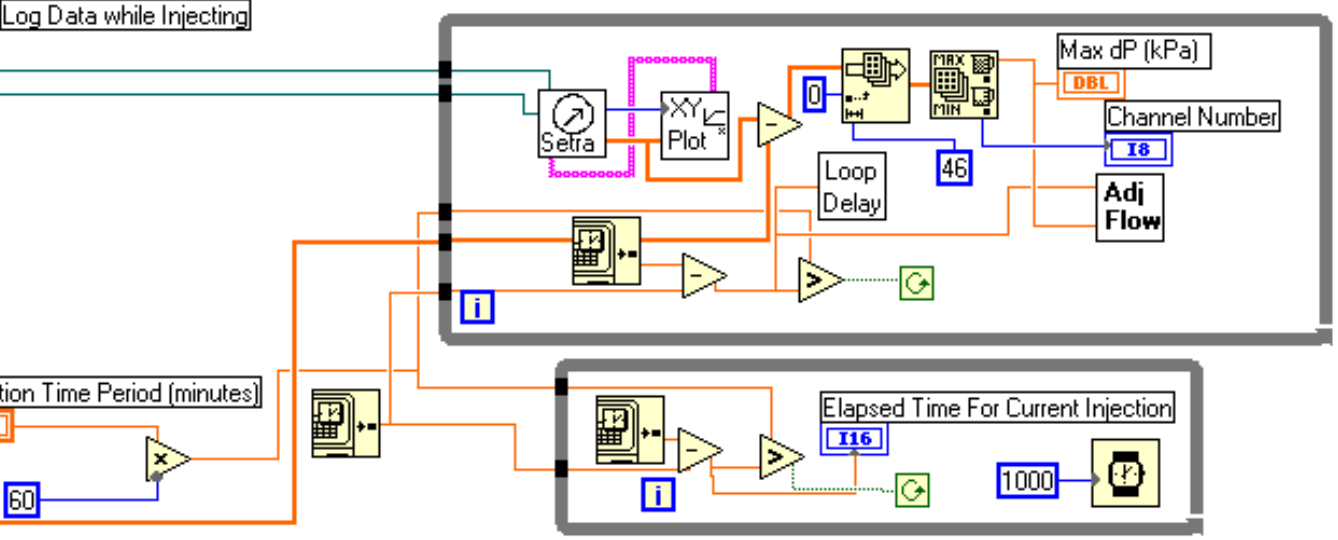

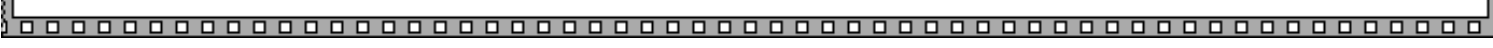

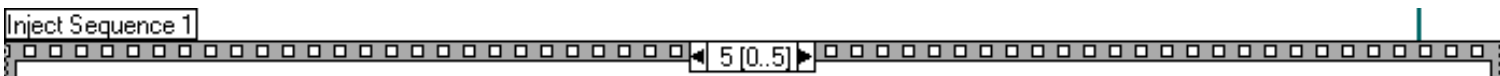

Log Data While Recovering

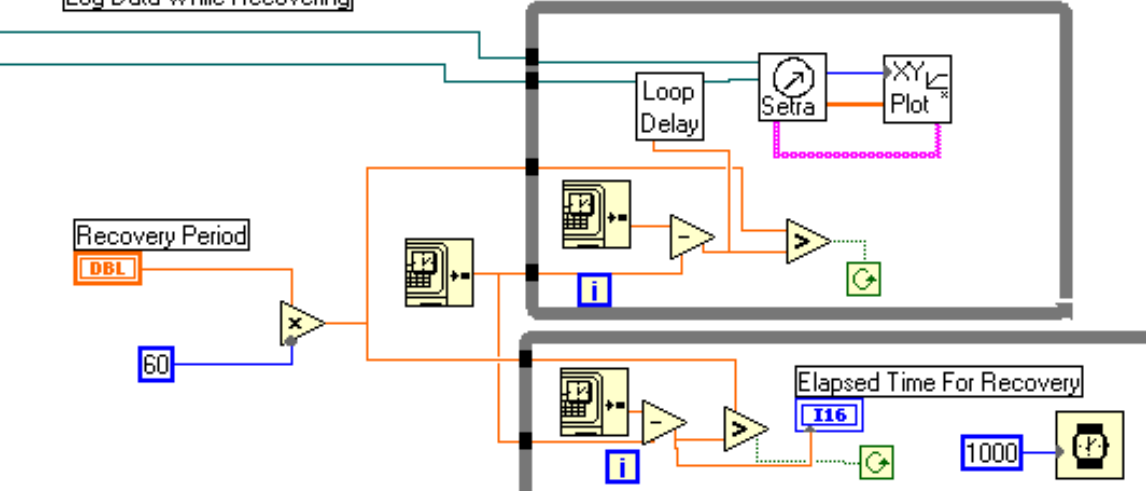

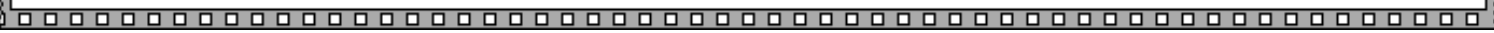




\section{LoopDelay.vi}

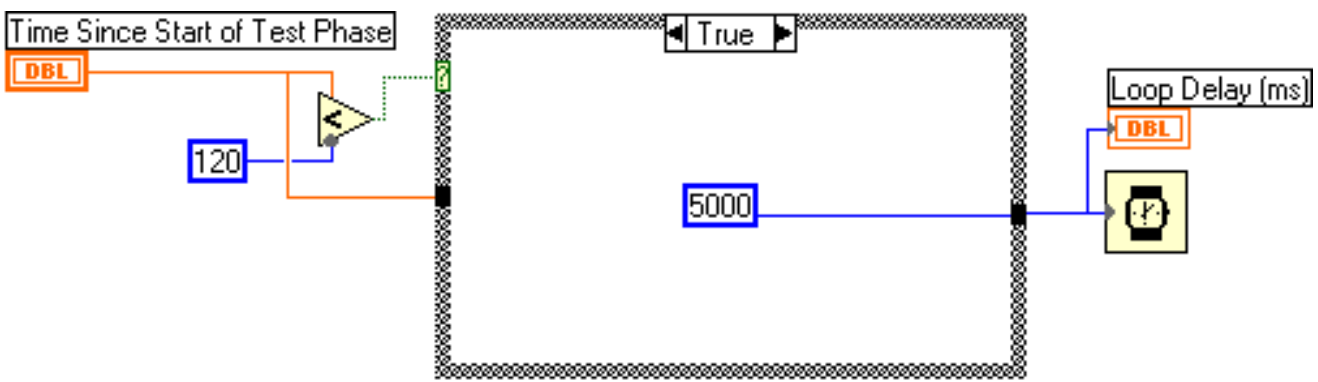

This routine determines the time delay between measurements based on a predetermined set of time values
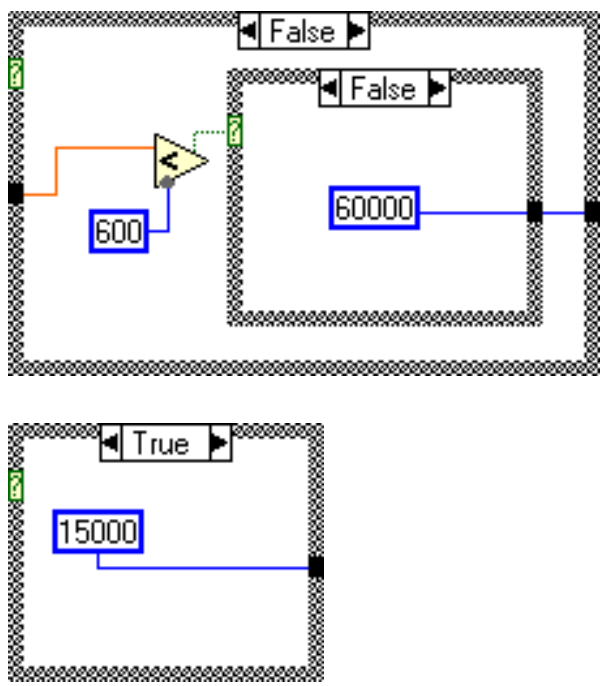

NewFile.vi

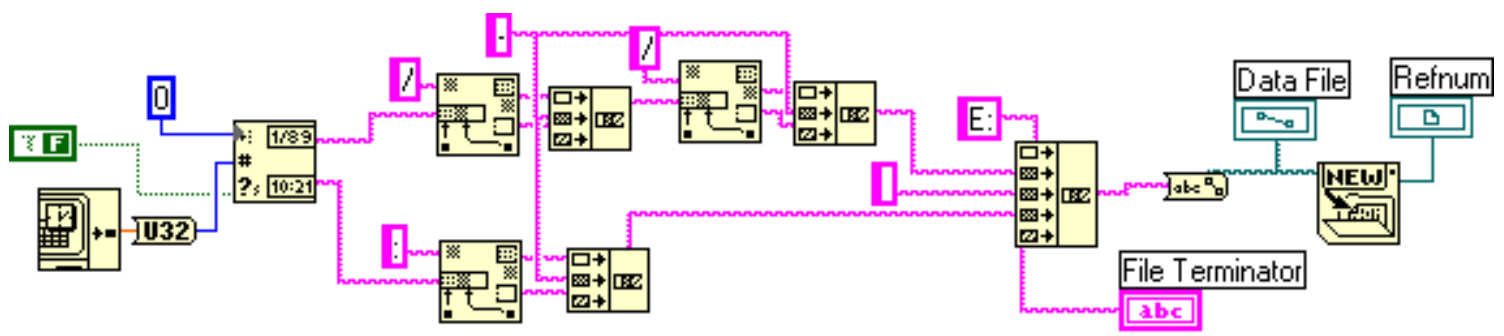

Opens a new file based on the current date and time and appends a file terminator to the end. The output consists of a Data File name in PATH format and a Refnum being passed to the calling VI. 


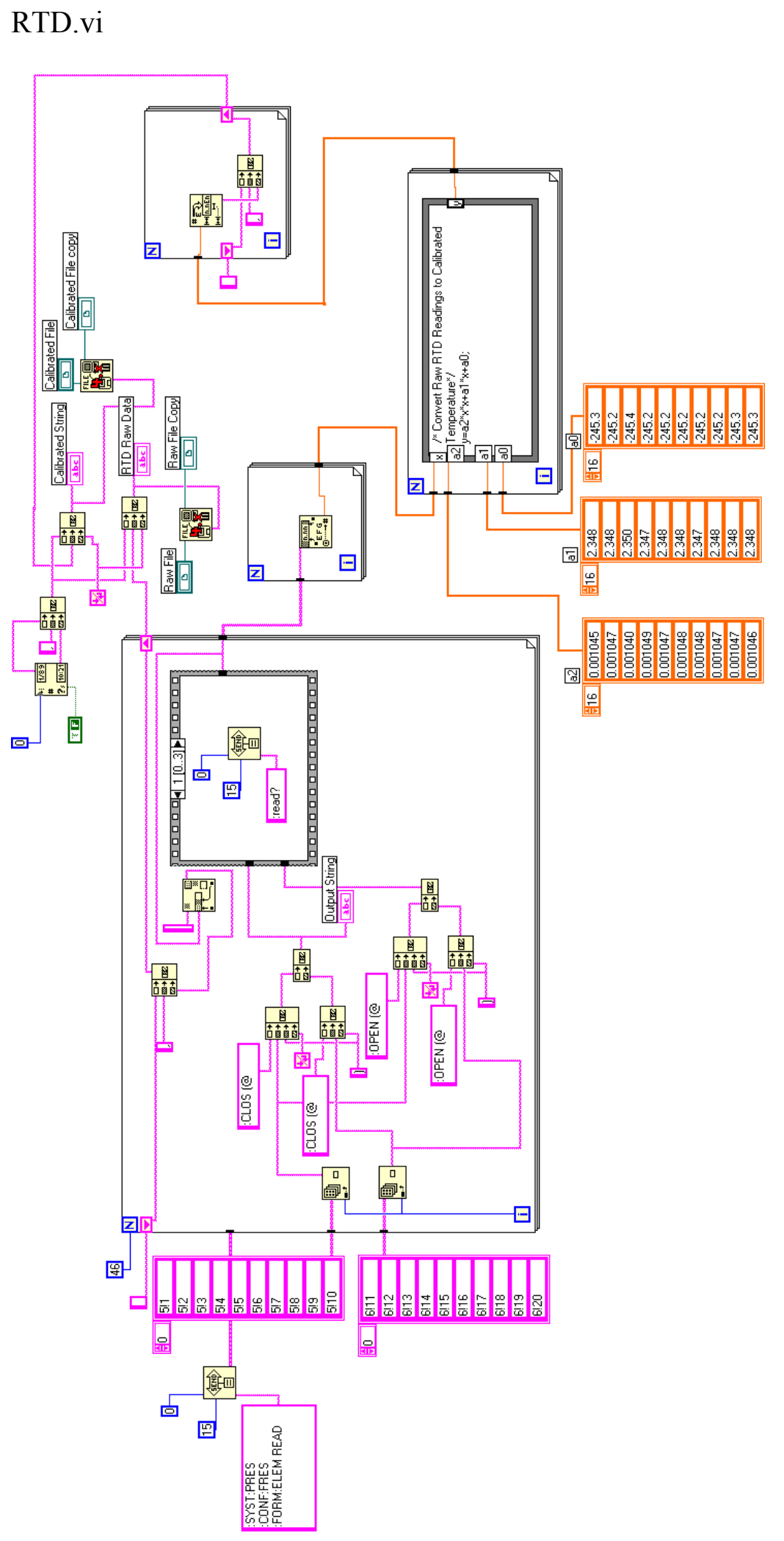


AdjFlow.vi

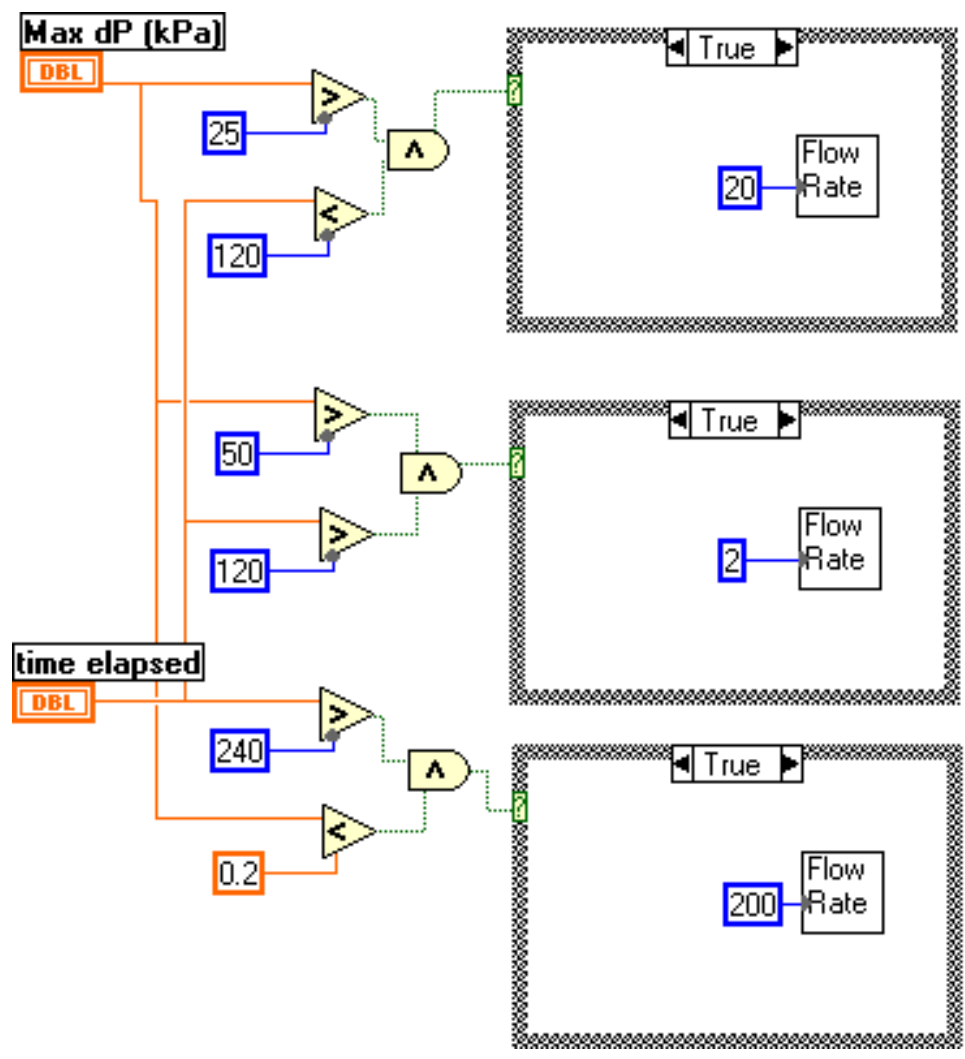

Sets flow rate to 20 SLPM if pressure is between 25 $50 \mathrm{kPa}$.

Sets flow rate to 2 SLPM if pressure is greater than 50 SLPM

If after $\mathbf{4}$ minutes pressure is less than $6 \mathrm{kPa}$ will boost flow rate to $200 \mathrm{SLPH}$. 


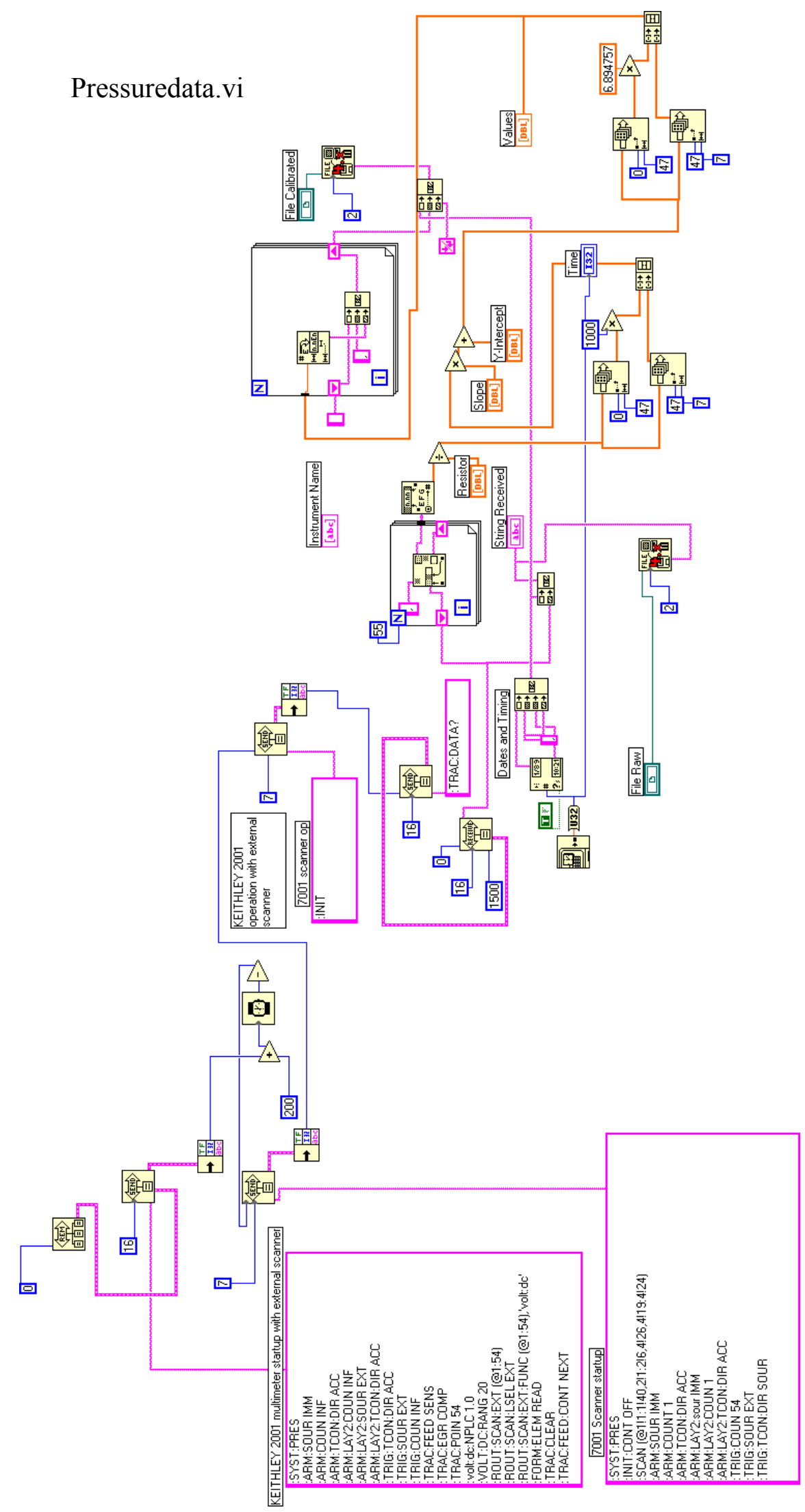


Flowrate.vi
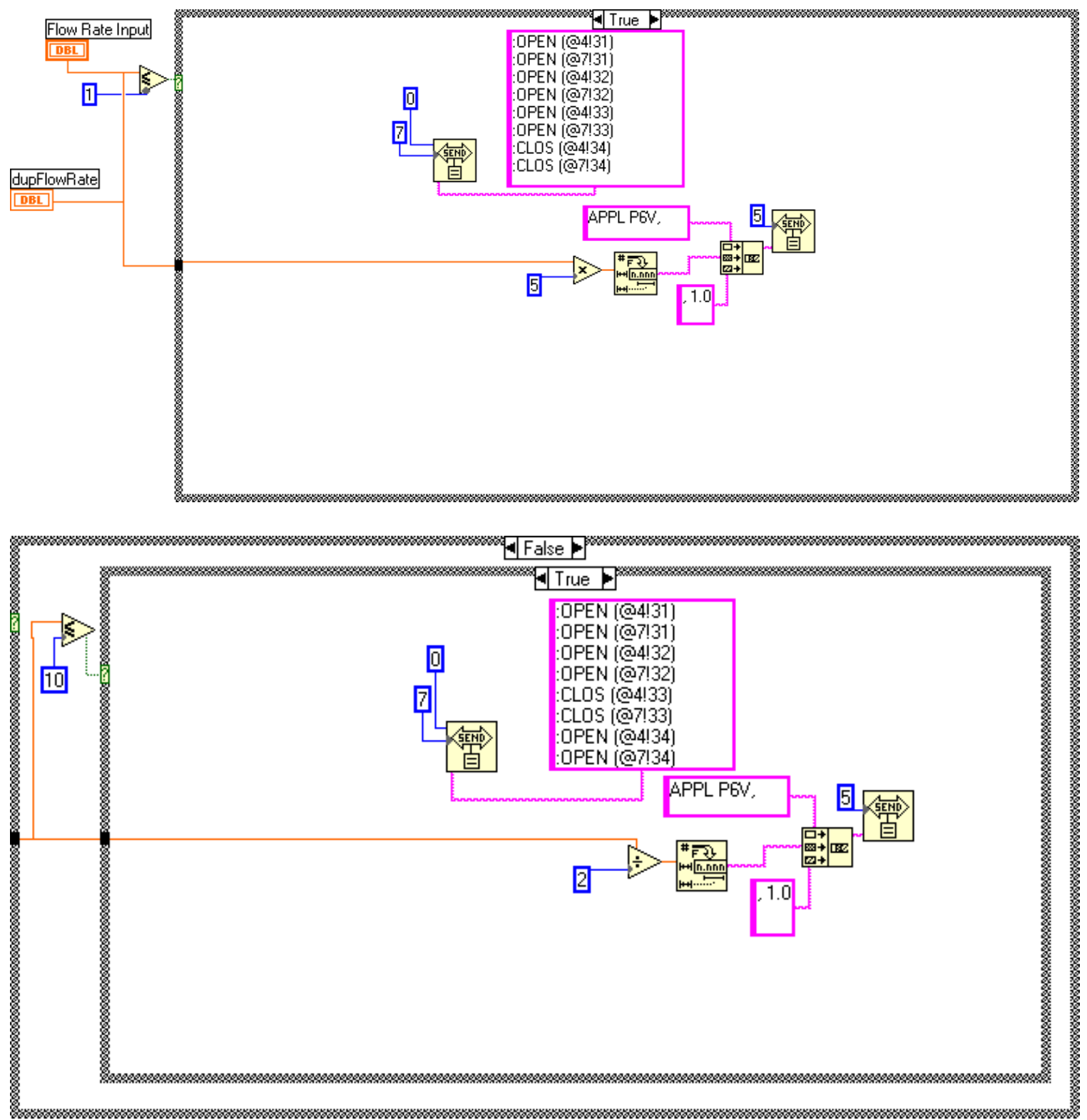

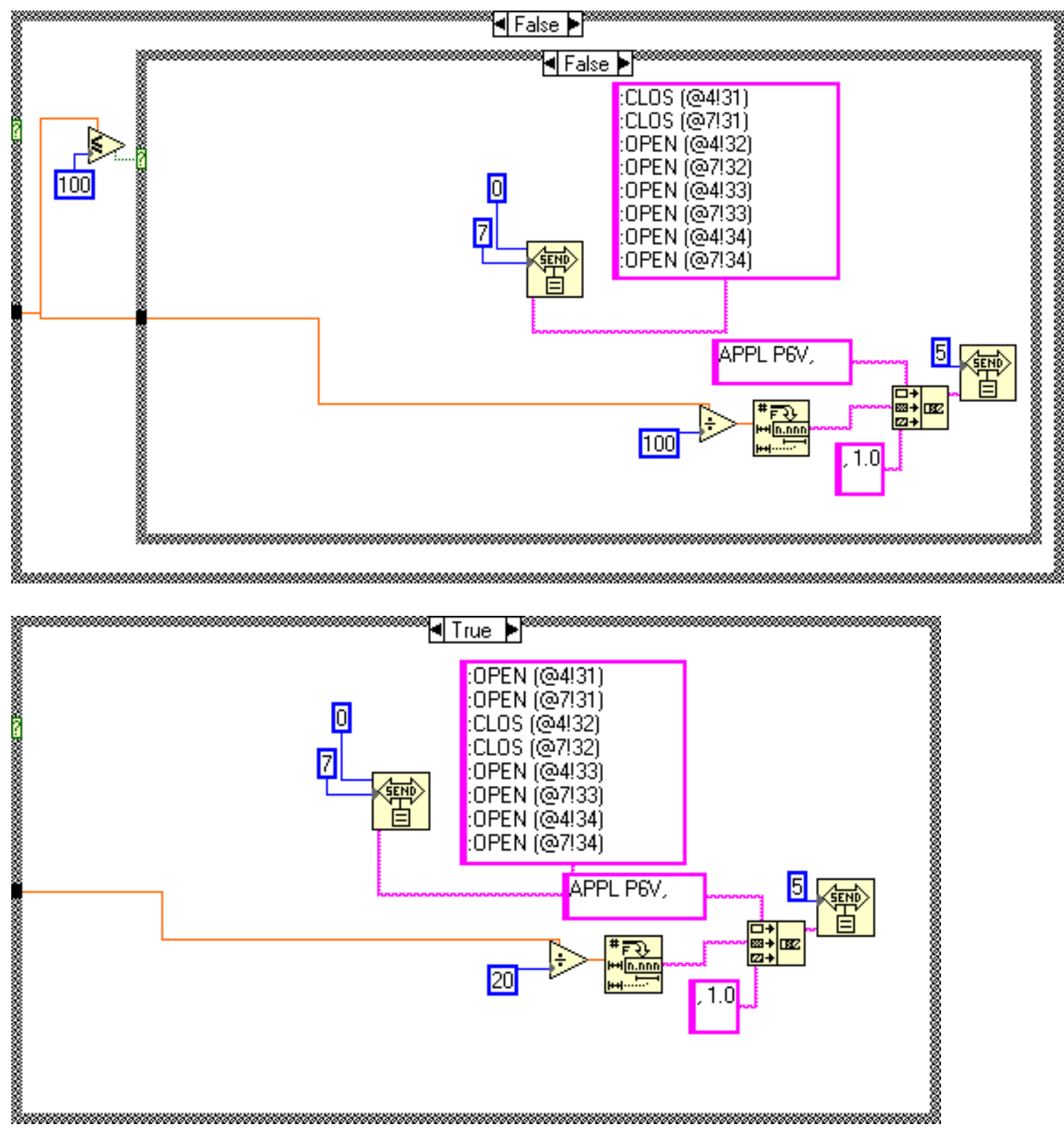


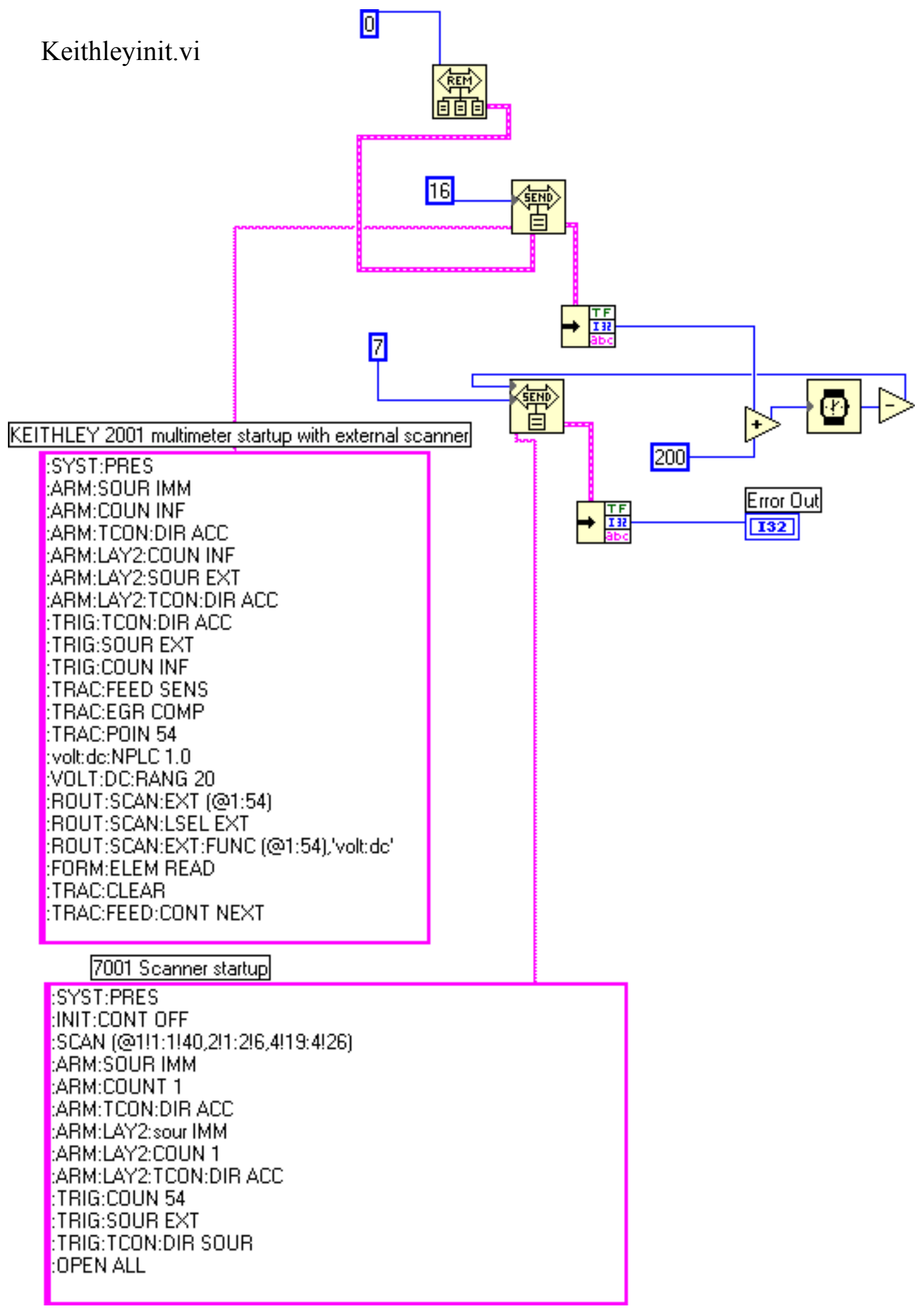


Plotdata.vi

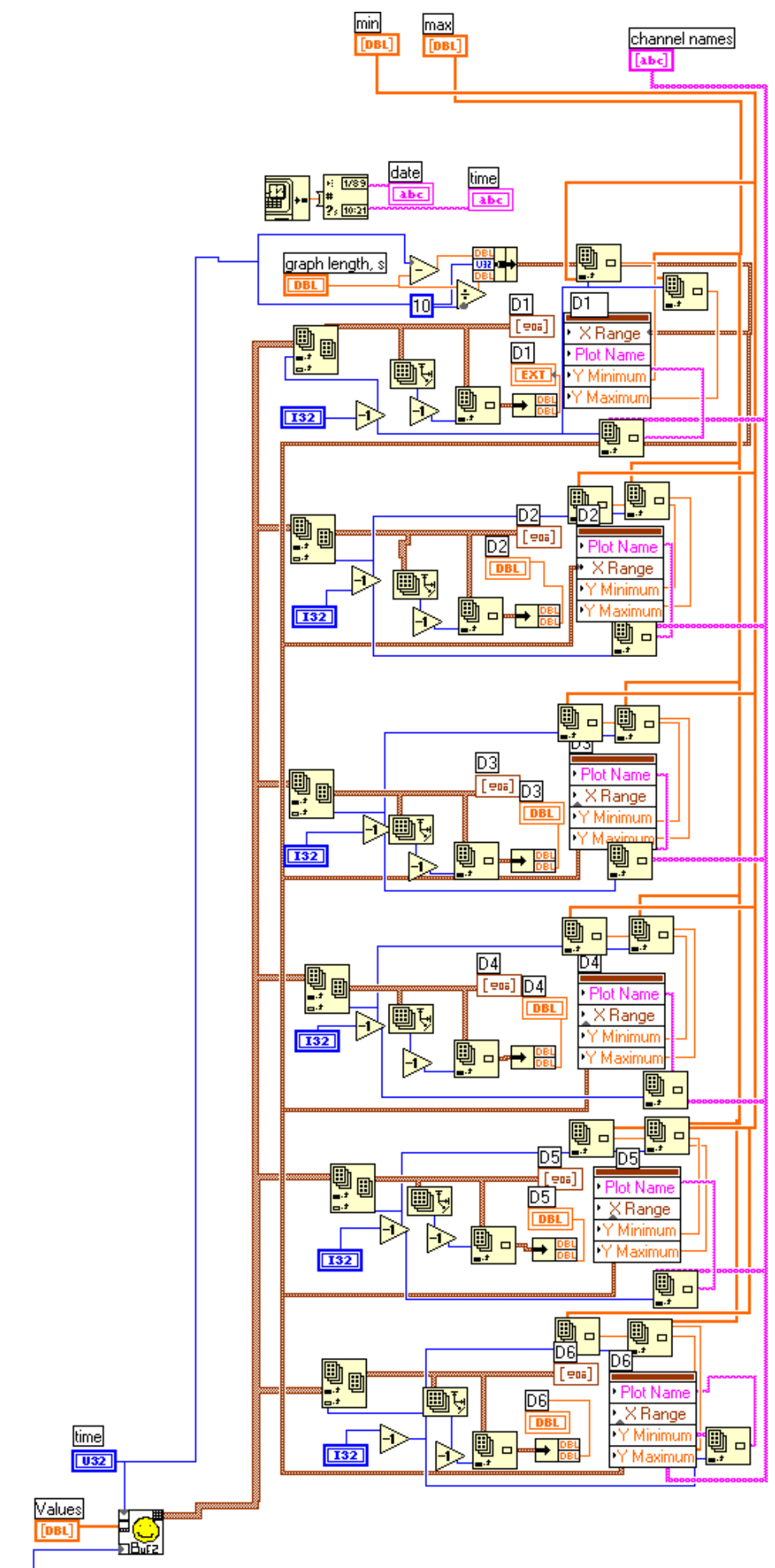

Plot Buffer Size

18 
Appendix C: Standard Operating Procedure for Conducting Gas Tracer Tests 


\section{PURPOSE}

This Standard Operating Procedure (SOP) describes the methods of airpermeability testing in the Drift Scale Test (DST) for the Yucca Mountain Site Characterization Project (YMP) at Ernest Orlando Lawrence Berkeley National Laboratory (LBNL).

The objective of air-permeability testing in the DST area is to monitor changes in permeability over time as thermal testing is being conducted. To assure the accuracy, validity, and applicability of the method used to collect routine constant mass flux air-permeability test data in the area, this procedure provides directions for LBNL personnel and contractors performing the described activity.

This procedure describes the components of the work. It also describes the methods to be used for calibration, operation, and performance verification of any equipment, if needed. In addition, it defines the requirements for data acceptance, documentation, and control.

\section{SCOPE}

This procedure applies to all LBNL personnel or contractor personnel following LBNL procedures who conduct constant flux air-permeability testing in the DST Hydrology Boreholes. The hydrology boreholes consist of twelve boreholes in the DST area commonly referred to as Boreholes 57 to 61,74 to 78, and 185 and 186. Each borehole has zones that are isolated using pneumatic packers. Zone 1 is closest to the collar of the borehole, with the zone number ascending toward the bottom of the boreholes.

For all technical activities, data collected from using this procedure and any equipment calibrations or recalibrations that may be required shall be in accordance with this technical procedure and all test and measuring equipment shall be in calibration with traceability to NIST standards.

\section{PROCEDURE}

\subsection{System Components}


The air-permeability testing uses a Gas Control System and a Data Acquisition System. The gas control system consists of all pneumatic plumbing, solenoid valves, mass flow controllers, etc. that are used to regulate and control the injection of air. The data acquisition system consists of all sensors, acquisition hardware, software, and wiring that interfaces to the gas control system.

\subsubsection{Data Acquisition System}

The data acquisition system is composed of two Keithley 20017 $1 / 2$ digit multimeters, a Keithley 7002 scanner system, a Windows NT Personal Computer with monitor, and two Hewlett-Packard E3631A programmable power supplies. There is a GPIB IEEE488.2 compliant interface card installed in the personal computer, which interfaces the computer to the aforementioned electronics. The personal computer is running Labview data collection software, and uses three executable codes, referred to as virtual instruments, vi, for data collection. They are called automated_DST.vi, automated2_DST.vi, and automated3_DST.vi.

\subsubsection{Flow control system}

Air supplied through the tunnel compressed air system is first filtered, dehumidified using a regenerative twin-tower desiccator, and filtered again before being sent through mass flow controllers. Attachment 1 is a piping diagram for the injection gas control system. Four Sierra Instruments mass flow controllers (MFCs), with full flow ranges of 1 Standard Liter Per Minute (SLPM), 10 SLPM, 100 SLPM, and 500 SLPM, which are connected in parallel, are selectively used to control the precise amount of gas being introduced into a borehole interval. The outlet of each mass flow controller has a pneumatically controlled valve to ensure positive shut off when the mass flow controller is not in use. Downstream of the mass flow controller manifold is an array selection manifold. The array selection manifold directs the gas flow to one of the three arrays of hydrology boreholes, Boreholes 57 to 61, Boreholes 74 to 78, and Boreholes 185 and 186. Located near the collars of each borehole is another manifold, which directs the gas flow to the isolated zones within the borehole. A tracer gas injection system, as shown in Attachment 1 is 
connected to the flow control system, but is not used during air-permeability testing. Verify before conducting airpermeability tests, that tracer gas cylinders are closed at the compressed gas cylinder.

\subsubsection{Software}

A. The program named automated_DST.vi is used for collecting data in the Boreholes 185 and 186. Automated2_DST.vi is used for collecting data in Boreholes 74 to 78 , and automated3_DST.vi is used for collecting data in Boreholes 57 to 61 . They will be referred to as automated*_DST.vi hereafter, with the wildcard indicating that any one of the three routines is being referred to. The subroutines utilized by the three main routines, automated*_DST.vi, are identical. The graphical code for automated_DST.vi is included in Attachment 2. The only differences between automated_DST.vi and automated2 (3)_DST.vi are the string array which is used to specify which solenoids are opened during testing and the number of zones in the borehole cluster.

D. The main routine first initializes the Keithley scanner by opening all switches, thereby closing all solenoid actuated valves. This ensures that each packed-off interval is closed and that no gas is flowing in the system. It then calls a subroutine, Data File, which is responsible for opening and assigning names to data files based upon the date and time the test was started. The suffix on the data file name indicates whether the file contains raw unprocessed data or whether it has been converted to engineering units, and whether it is temperature data or pressure data. The suffixes are .pres or .pres_cal for pressure data files and .rtd or .rtd_cal for temperature data files. The files with suffixes that have _cal in them are engineered units while the files that do not have _cal are in unprocessed format.

C. Subroutines PRESSUREDATA and RTD are called upon next to start logging pressure and temperature data, respectively. After logging one set of values from all sensors, the main routine, automated*_DST.vi, commences background data collection. This usually consists of a few 
minutes of data used to establish baseline pressures for each test. Next automated*_DST.vi enters an injection phase, and finally a recovery phase of testing. In each of the three phases, background, injection, and recovery, the subroutine Loop Delay is used to set the frequency of data collection. Loop Delay has been set to record a set of data every 5 seconds for the first two minutes of each test phase, then every fifteen seconds for the next eight minutes, and then finally every minute. These predetermined data sampling rates are used to meet the goals of creating data files of workable size while fully capturing the transient behavior that occurs during the initial injection and recovery periods.

D. During injection, the Adjust Flow routine monitors the maximum change in pressure during air injection and adjusts the flow rate accordingly. This is done to keep the change in pressure between 1 and $50 \mathrm{kPa}$. It is felt that at these pressures, the ratio between pressure and flow will be constant, and the nonlinear response associated with air compressibility will be minimized. The algorithm, which controls the flow rate, is based upon both the elapsed time of injection and the pressure change in the injection interval. The injection test is automatically started at a default flow rate, nominally 100 SLPM. If the elapsed injection time is less than 2 minutes and the change in pressure in the injection zone is greater than $25 \mathrm{kPa}$, the flow rate is reduced to 20 SLPM. If the elapsed time is greater than two minutes and the pressure has gone over $50 \mathrm{kPa}$, then the flow rate is reduced to 2 SLPM. If the pressure has not increased to at least $6 \mathrm{kPa}$ after four minutes of injection than the flow rate is increased to 200 SLPM. These breakpoints in time and pressure were established by trial and error during baseline measurements, and were found to provide good test results for the entire range of permeabilities encountered within the DST area. Even though the computer may adjust the flow rate during testing, the injections are still referred to as constant mass flux injections, since the flow rate is only adjusted to maintain a controlled injection pressure and the test is carried out predominantly at one fixed flow rate.

E. After the injection phase of the test has been completed, the 
gas flow is halted and the solenoid valves that were opened to start testing are closed. The recovery phase of the test then commences for a predetermined length of time. To start the next injection test, the main routine opens new data files and begins repeating the sequence of background data logging, gas injection, and finally recovery data logging.

3.2 Test Preparation Staff member preparing for air-permeability testing shall perform the actions described below.

\subsubsection{Electronics}

A. Before turning on the electronics for testing, turn on the air conditioner on the Electronic Rack and verify that it is properly cooling the rack. The air conditioner should maintain the rack at a temperature, which will fluctuate between $70^{\circ} \mathrm{F}$ and $95^{\circ} \mathrm{F}$.

B. Turn on the Keithley electronics, the Hewlett-Packard power supplies, and the $\pm 15 \mathrm{~V}$ power supply used for the MFCs, which are all located in the electronic enclosure. Then proceed to turn on the computer monitor and finally the computer.

C. The power supply to the Setra transducers, which is located in the Acoustic Emission Electronic Enclosure in the main data acquisition office, shall be verified as being turned on and set to 24 volts.

\subsubsection{Flow Control System}

A. Check all manually operated valves located on the injection lines visually to verify that they are in the open position.

B. Turn on the twin-tower desiccant dryer, open the mine air supply valve and set the regulator on the output of the desiccant dryer to 60 PSIG.

E. Verify that the two manually operated $1 / 8^{\prime \prime}$ supply air line valves, located near the pressure regulator are open.

D. The inlet and outlet filters on the twin-tower dryer have 
visual gauges, which indicate the status of the filters. If at any time the indicator appears red, replace the filters at the next convenient time. It is not necessary to interrupt ongoing tests to change a filter. This is anticipated to be a once a year or less frequent maintenance item.

\subsection{Calibration Requirements}

\subsubsection{Calibration Interval}

The Mass Flow Controllers and Digital Multimeters are on a yearly calibration cycle. Verify that their calibration is still valid before collecting data. If they are not within current calibration or the data they are generating is suspect, they shall be removed from service and replaced with calibrated units.

\subsubsection{System Component Accuracy}

The accuracy of the MFC in the field is typically less than the published manufacturer's specifications. Although Sierra Instruments MFCs are calibrated to their manufactured specification of $\pm 1 \%$ of full scale, their required performance in the field for compliance with this SOP is $\pm 10 \%$. The Setra pressure transducers have a calibrated accuracy of $\pm 0.1 \%$, but under this SOP they are expected to provide data with an accuracy of $\pm 0.25 \%$.

\subsection{Data Collection}

3.4.1 Executing automated_DST.vi, automated2_DST.vi, and automated3_DST.vi performs a complete cycle of data collection in all 12 hydrology boreholes. Data file names are automatically selected, and include the date and time of testing to make them unique and distinguishable. They are saved onto the E: $\backslash$ drive of the data acquisition PC. The only parameters that are user selectable are the starting flow rate, duration of background data collection, injection duration and duration of recovery, which are all located on the front panel of automated*_DST.vi. Testing has shown that a background data collection time of 2 minutes, with an injection time of 60 minutes and a recovery time of 60 minutes is satisfactory for 
obtaining a good data set, with most pressure transients reaching the desired pseudo-steady state. Pseudo-steady state is defined as when the pressure response curve shows only a very gradual change over time, which may be due to secondary influences such as barometric drift or redistribution of moisture. The starting flow rate default of 100 SLPM also was found to be acceptable. These parameters may need to be changed by the user during the course of the DST due to the changing thermal-hydrologic conditions. It shall also be noted that due to the two-phase and non-isothermal conditions within the DST area, it is not possible or practical to conduct each test until it reaches true steady state conditions.

\subsubsection{Notebook Records}

Staff members shall record the following information in their scientific notebook used for testing. At a minimum notebook entries shall include:

\section{A.Personnel present}

F. Time when each vi was started.

G. Any unusual occurrences, equipment malfunction or testing interferences from activities in other boreholes.

H. Results of data review as conducted under section 4.1.

\section{Reference to this SOP}

\section{RECORDS}

\subsection{Lifetime}

The data generated from air-permeability testing are stored on the hard disk of the data acquisition system PC. The data shall be backed up after data collection has concluded and the backup shall be verified by comparing the sizes of the original and duplicate data files and by opening and visually spot checking a few copied data points. The data generated by following this procedure and the references to scientific notebooks used in test preparation and describing processing and analysis of the data shall be submitted to the YMP Technical Database. 
The data shall be reviewed before submittal to verify that the flow rates during testing were constant and that the pressure transients have been properly recorded. Any variation outside of expected equipment accuracy and repeatability shall be investigated and the data shall be evaluated as to whether they are to be considered acceptable and qualified. The impact of any unusual occurrences, equipment malfunctions or testing interferences as noted under section 3.4.2.C and 3.4.2.D shall be evaluated before submittal of data to the Technical Database.

\title{
6. ACRONYMS
}

\author{
DST Drift Scale Test \\ ESF Exploratory Studies Facility \\ Kpa Kilopascal \\ LBNL Lawrence Berkeley National Laboratory \\ MFC Mass Flow Controller \\ PC Personal Computer \\ PSIG Pounds Per Square Inch, gage \\ SLPM Standard Liter Per Minute
}

\section{ATTACHMENTS}

Attachment $1 \quad$ Figure 1. Flow Control System

Attachment 2 Labview Software 
Appendix D: Standard Operating Procedure for Calibrating a Mass Spectrometer Using Standard Reference Tedlar Bags 


\section{PURPOSE}

This Standard Operating Procedure (SOP) establishes the methods to ensure that consistent and repeatable analysis of tracer gas concentrations is accomplished by generating qualified reference gas standards, and using those standards to calibrate the Balzer's Omnistar Mass Spectrometer (MS) for the Yucca Mountain Site Characterization Project (YMP) at Ernest Orlando Lawrence Berkeley National Laboratory (LBNL).

\section{SCOPE}

This procedure applies to all LBNL personnel or contractor personnel following the LBNL procedures who conduct gas concentration tests using the Balzer's Omnistar MS. For all technical activities, data collected using this procedure, and any equipment calibrations or recalibrations that may be required, shall be in accordance with this technical procedure. All test and measuring equipment shall be certified as being in calibration with traceability to NIST standards.

This procedure is designed to provide detailed methodology to assure consistent calibrations of the Omnistar MS.

3. PROCEDURE The following procedures shall be followed to prepare gas reference standards and to calibrate the MS. Section 3.2 discusses the preparation of reference gas storage bags. Section 3.3 is followed to fill a reference bag directly from a cylinder while section 3.4 is used to prepare dilutions from a cylinder.

\subsection{Specialized Equipment Requirements}

\subsubsection{Reference Gas Cylinders}

Q cylinders are obtained through vendors that are on the Qualified Supplier List. If $Q$ cylinders are not available, a calibration may still be performed which can provide concentration relative to the initial cylinder gas concentration. This calibration will not give absolute concentration, but only a relative concentration, which is acceptable for many types of 
gas tracer tests. Data from calibrations using non-Q gas cylinder shall be reported in units of $\mathrm{C} / \mathrm{C}_{0}$. Calibrations using $\mathrm{Q}$ gas cylinders may be reported in absolute units. The cylinder type and its Q-status shall be referenced in the scientific notebook.

\subsubsection{Gas Storage Bags}

5 liter gas storage bags are used for holding reference gas samples. A recommended manufacturer is Calibrated Instruments Inc. Fill the 5 liter bags with no more than approximately 1.2 liters of gas to prevent damage to the bag in transit.

\subsubsection{Stec sgd-710c Gas Divider}

A Stec sgd-710c gas divider is used for producing dilutions of tracer gas. Since this unit is not directly traceable to the National Institute of Standards and Technology, the gas divider must be calibrated using calibrated Mass Flow Controllers (MFCs). See appendix A for calibration of the Stec sgd-710c.

\subsubsection{Calibrated Mass Flow Controllers (MFCs)}

MFCs in the ranges from 0-100 standard cubic centimeters per minute (SCCM) to 0-10 standard liters per minute (SLPM) shall be used to verify the calibration of the Stec sgd-710c gas divider. They can also be used to produce dilutions of gas. The serial number and calibration due date shall be entered in the scientific notebook for each MFC utilized.

\subsection{Preparing Bags to be Filled}

A. Verify by visual inspection that the integrity of the bag is not compromised. Reject any damaged bags.

B. Evacuate the bag using a Mityvac Model ld109 hand pump or equivalent, which is attached to the reference bag using a Leur fitting. Pump the bag until the vacuum gage reads greater than 
$20.0 \mathrm{~cm} \mathrm{Hg}$. (Note: this is a non-quality affecting measurement, which shall use the visual gage that is connected to the Mityvac hand pump. The gage should be checked so that there is no visible zero shift and periodically its performance should be verified by pulling a hard vacuum to ensure that its indicator will go through its full scale range.) The bag should be able to maintain this vacuum for 1 minute. Bags that cannot maintain a vacuum for 1 minute shall be rejected.

C. Mark each bag with a permanent marker to identify tracer type and concentration as well as date of filling.

D. Record the bag number, tracer type, concentration, source cylinder(s), dilution, fill date and time, fill volume, and personnel present into a scientific notebook.

\subsection{Filling from a Cylinder with no Dilution.}

A. Identify the cylinder to be used and install the dedicated pressure regulator for that compound.

B. Connect a length of $1 / 4$ " poly-flo or other similar plastic tubing to the regulator with a compression fitting.

C. Close the regulator's outlet valve and open the cylinder's valve, leak check all connections with a snoop or a soap solution.

D. Connect a 0-1 SLPM MFC to the poly-flo tubing and set the MFC to 300 SCCM.

E. Adjust the regulator on the gas cylinder to deliver gas flow to the MFC.

F. Let the system purge itself for 5 minutes.

G. Connect a prepared bag to the outlet of the MFC using a polyflo to Leur adapter.

H. Connect a prepared bag to the Leur adapter outlet for 4 minutes, for a total fill volume of 1.2 Standard Liters. 
I. Record all fill data in a scientific notebook.

J. Close cylinder valve.

\subsection{Making Gas Dilutions with the Stec sgd-710 Gas Divider}

A. Check the Calibration on the Stec sgd-710 using calibrated MFCs as outlined in Attachment 1. Record the flow rates for the Balance and Component gas streams in a scientific notebook for all dilutions that will be used at the Component and Balance pressures that will be used during the generation of the gas reference bags.

B. Identify the cylinder to be diluted and install the dedicated pressure regulator for that compound.

C. Identify the zero air cylinder and install the dedicated pressure regulator.

D. Connect the cylinder to be diluted to a $1 / 4$ " compression fitting at the rear of the gas divider marked COMP (component gas) using poly-flo tubing.

E. Connect the zero air cylinder to the $1 / 4$ " compression fitting at the rear of the gas divider marked Balance. Use 1/4" poly-flo tubing.

F. Connect a short length of $1 / 4$ " poly-flo tubing to the gas divider fitting marked OUTLET. Install a barb to Leur adapter on the other end.

G. Turn selection valve to the " 0 " position and open the component cylinder valve and set the regulator to about 18 PSIG. Note: no gas should flow from the cylinder at this time. If gas does flow then dirt contamination of the gas divider should be suspected and the instrument should be should be treated as an out of calibration instrument as directed by YMP-LBNLQIP-12.0. 
H. Open the zero air cylinder valve and set the regulator to about 10 PSI. Note: exact pressures are not critical but the zero air pressure must be kept below the component gas pressure.

I. Leak check all connections with a snoop or a soap solution at this time.

J. Set the selection valve to the desired dilution, wait twenty seconds for the flow to stabilize and read the flow rate from the visual indicator at the front of the gas divider. (Note: this is a non-Q measurement.)

K. Based on the flow rate observed, fill the bag for the amount of time required to fill the bag to a volume of 1.2 liters.

L. Record all fill data in a scientific notebook.

M. Repeat steps 3.4.J to 3.4.L for each different dilution required.

N. At the end of use, set selection valve to "90" and turn off the component gas cylinder valve. Allow the pressure in the component gas regulator to reach 0 PSI. Turn zero air cylinder valve off and allow its regulator to reach 0 psig. Disconnect cylinders from the gas divider and store the divider in a clean place.

O. Make sure cylinders are closed and not leaking.

\subsection{Tuning the Mass Spectrometer}

Two aspects of the Omnistar MS must be tuned, the ion source, and the mass scale. Pull down menus, associated with the software that is used to operate the MS are often referred to. An underscore will be used to indicate reference to a pull down menu.

The MS must be turned on and pumped down, and the SEM \& Emission must be turned on for at least 1 hour before proceeding to the next step.

3.5.1 Tune Ion Source (filament) 
Use the software Tuneup.exe that is provided with the QS421 software package. From the Tune Menu choose IonSource. The Tune Ion Source QMA200 window opens. Presently there are three ranges which are enabled, \#0 (mass range 8090), \#1 (mass range 120-135), and \#2 (mass range 24-32). To view the output from a channel click on Display, then select MeasureData. Ion source parameters may be changed and the effect on the output may be viewed in real time. Follow the discussion of "Optimizing Ion Source Parameter" in the Omnistar manual, section 2, page 21.

\subsubsection{Tune Mass Scale}

The mass scale is tuned in several steps. First the overall scale must be adjusted (Tune Mass Scale), then each compound must be fine tuned (Calibrate Mass Scale)

\section{A. Tune Mass Scale}

With the MS pumped down and warmed up, start the Tuneup.exe program. Choose Tune then choose QMS 200 Tune Mass Scale. The mass scale is tuned with a high concentration (10PPM or greater) of the compound of interest. Connect the gas to be tuned to the inlet of the MS and using the mouse pointing to the graph click to obtain a vertical line. Using the arrows move the peak until it is as close as possible to the correct peak location. The peak can be made sharper by adjusting the Resolution parameter.

B. When the mass scale has been adjusted then each of the compounds of interest must be fine tuned. Leave the compound of interest connected to the inlet of the MS, close the tuneup.exe window and execute measure.exe. Choose calibration. Then for mass scale choose the compound connected (e.g. $\mathrm{SF}_{6} \cdot \mathrm{msp}$ ). Choose Coarse, then OK. Now the MS will adjust the peaks. Repeat this again using the Fine adjustment. If the program returns the indicator "calibration failed," rerun the mass scale calibration, several times if necessary. If still unsuccessful choose parameter, and under mass reduce the Resolution. 


\section{For each compound of interest, repeat the Mass Scale Calibration but do not retune the mass scale.}

\subsection{Calibrating the Mass Spectrometer using Standard Bags-}

A. Use the measure.exe program to record the data to the laptop computer. Make sure that Save Cycle Data has been chosen before starting the calibration. Record in a scientific notebook the name of the personnel, data file name, and the time data collection has started.

B. Using the Calibrated Standards Bags created in sections 3.3 and 3.4, sequentially attach the bags to the MS. Start with a zero air reference bag and allow the ion current to reach a steady state for the compound of interest. If the MS has been exposed to high concentrations of the calibration compound, it may take up to an hour to reach steady state.

C. Sequentially replace the bags, going from lower to higher concentration. It will take between 5 to 15 minutes to reach a steady state ion current for each concentration. Record the time, cycle number, and concentration in the scientific notebook when each gas standard bag is attached to the MS.

\subsection{Scientific Notebook Requirements}

A scientific notebook record log for calibrating the mass spectrometer shall include at a minimum:

A. Calibrating personnel.

B. MFC and Stec-sgd-710c serial numbers and calibration due date.

C. Flow rates and pressures used for filling gas sample bags.

D. Tracer bag concentrations and identifiers for all reference bags used or filled. 
E. Time, cycle number, and sample bag identifier for each sample bag attached to the MS.

F. When checking calibration of the Stec-sgd-710c according to attachment 1 , include selection valve position and flow rates of the mass flow controllers.

\section{4. $\quad$ Records}

The data generated from calibrating and tuning the MS is stored on the hard disk of the computer attached to the MS. The data shall be backed up at least daily. The data generated by following this procedure and the scientific notebook used in MS calibration is used for converting tracer test data from ion current format, to qualified absolute concentration or relative concentration units. The calibration data collected under this SOP shall be submitted along with gas analysis test data, which is processed using the calibrations generated by this SOP.

\section{ACRONYMS AND DEFINITIONS}

\subsection{Acronyms}

DST Drift Scale Test

ESF exploratory studies facility

Kpa kilopascal

LBNL Lawrence Berkeley National Laboratory

MFC mass flow controller

MS Mass Spectrometer

PC personal computer

PSIG pounds per square inch, gage

SCCM standard cubic centimeters per minute

SLPM standard liter per minute

SOP Standard Operating Procedure

YMP Yucca Mountain Site Characterization Project

\section{REFERENCE}

Omnistar Users Manual 


\section{ATTACHMENTS Checking the calibration of the Stec sgd-710c}

1.0 Install the dedicated pressure regulator to the zero air cylinder and using $1 / 4^{\prime \prime}$ poly-flo tubing attach a 0 to 10 SLPM MFC. Attach the outlet of the MFC to the BALANCE compression fitting on the back of the Stec sgd-710c.

2.0 Install a pressure regulator to a component gas substitute, either nitrogen or air. Attach a 0 to 10 SLPM MFC to the pressure regulator using 1/4" poly-flo tubing, and connect the outlet of the MFC to the COMP (component) compression fitting on the back of the Stec sgd710c.

3.0 Adjust the supply voltage to the MFCs to their full scale output range (5V for Sierra Instruments model 840 MFCs) so that they will only act in sensor mode and not in control mode.

4.0 Adjust the pressure on the component gas to 18 PSIG. Adjust the pressure on the zero air regulator to 10 PSIG.

5.0 Leak check all connections with a soap solution.

6.0 Set the selection valve on the Stec sgd-710c to the desired position and allow the flow rate to stabilize for 20 seconds. Record the selection valve position and the flow rates on the two MFCs in a scientific notebook.

7.0 Repeat step 6.0 for all selection positions.

8.0 Switch the MFCs and repeat steps 3.0 through 7.0.

1. The flow rates should match the desired Component to Balance ratios. The Stec sgd-710c is an extremely stable device, which has an inherent accuracy greater than the $\pm 1 \%$ associated with MFCs under laboratory conditions. If there is a systematic error between the component and balance gas ratios that is not reversed by switching the flowmeters then malfunction of the Stec sgd$710 \mathrm{c}$, probably due to dirt contamination, should be suspected. The Stec sgd710c should be treated as an out of calibration instrument. 
